\title{
THE ROLE OF BETACYANINS IN PLANT SALT TOLERANCE
}

BY

\section{TANJA KARL}

\begin{abstract}
A thesis
submitted to the Victoria University of Wellington in fulfilment of the requirements for the degree of

Doctor of Philosophy
\end{abstract}

Victoria University of Wellington

(2020) 


\section{Abstract}

Soil salinity is a major threat to future food stability. Almost $20 \%$ of irrigated land is currently too saline to grow traditional crops. Moreover, rising sea levels, scarcity of fresh water, and more intense and prolonged periods of drought are exacerbating the problem. Saline soils severely reduce yields of most crop plants. By contrast, halophytes, which naturally thrive on saline substrates, have a variety of mechanisms to tolerate both the osmotic and cytotoxic components of salt stress. There has been concerted scientific effort worldwide to understand these mechanisms, and to introduce genes that may increase salinity tolerance in crop plants.

Many halophytes in the Caryophyllales are pigmented red owing to a tyrosine-derived alkaloid called betacyanin. Recent studies using Disphyma australe, a succulent halophyte common on coastal dunes and rocky outcrops throughout New Zealand, have indicated a role for betacyanins in salinity tolerance. This thesis focuses on how the mechanism through which betacyanins might affect salt tolerance mechanisms in $D$. australe and whether the putative benefits of betacyanins on salt tolerance might be transferred to naturally non-betacyanic plants.

Effects of betacyanin on $\mathrm{Na}^{+}$distribution in salt-stressed leaves of red and green morphs of $D$. australe were studied using fluorescence microscopy, cryo-scanning electron microscopy with energy dispersive X-ray analysis, and atomic absorption spectrometry (AAS). In betacyanic leaves $\mathrm{Na}^{+}$accumulated in the epidermis, while in green leaves $\mathrm{Na}^{+}$was distributed more evenly across the epidermis and mesophyll. Both leaf types had similar numbers of salt glands, but salt secretion rates were higher in red than in green leaves. Betacyanic leaves under salt stress were able to maintain relatively high $\mathrm{K}^{+} / \mathrm{Na}^{+}$ratios, essential for many metabolic processes, while the leaves of green plants were not. Leaf sections stained with fluorescein diacetate and propidium iodide showed that mesophyll viability decreased significantly in green leaves under salt stress, while there was almost no decrease in mesophyll viability in the presence of betacyanins. Thus, betacyanic leaves might protect the photosynthetically active mesophyll from cytotoxic effects of $\mathrm{Na}^{+}$by accumulating $\mathrm{Na}^{+}$in the epidermis instead of the mesophyll. This in turn leads to more efficient salt secretion and higher $\mathrm{K}^{+} / \mathrm{Na}^{+}$ratios in the mesophyll, resulting in increased mesophyll viability under salt stress.

Effects of high apoplastic sodium concentrations on ion flux kinetics in mesophyll tissue was studied using the non-invasive microelectrode ion flux estimation technique. Mesophyll cells of both betacyanic and green leaves showed a highly unusual $\mathrm{K}^{+}$flux response; most crop plants leak $\mathrm{K}^{+}$out of cells upon salt stress, but D. australe and the native Australian Disphyma 
crassifolium both showed $\mathrm{K}^{+}$influx upon salt stress. Actively taking up $\mathrm{K}^{+}$from the apoplast to maintain a high cytosolic $\mathrm{K}^{+} / \mathrm{Na}^{+}$ratio during salt stress might be an entirely new mechanism to combat the cytotoxic stress component of salinity stress in these halophytes. The salt induced $\mathrm{K}^{+}$uptake was dependent on the presence of $\mathrm{Cl}^{-}$and $\mathrm{Cl}^{-}$was also taken up into mesophyll cells upon salt stress. Taking up both cations and anions at the same time could avoid membrane depolarisation. Voltage-gated channels, which are involved in the salt induced $\mathrm{K}^{+}$efflux in glycophytes, would not be activated and this could be a new mechanism to avoid a $\mathrm{K}^{+}$leak during salt stress.

To test whether the beneficial effect of betacyanin production on salt tolerance could be transferred to naturally non-betacyanic plants, transgenic betacyanin-over-expression (BtOE) mutants of Nicotiana tabacum were generated by our colleagues at Plant \& Food Research Ltd. Betacyanins in leaf discs of $N$. tabacum were associated with decreased chlorophyll degradation upon high light and high salt stress. Additionally, the decline in maximum quantum efficiency of PSII after high light and salt treatment was significantly greater in green than in betacyanic leaves. Placing a polycarbonate filter with a similar absorption spectrum to betacyanin over green $N$. tabacum leaf discs had a similar effect to the presence of betacyanin. Thus, betacyanins probably have a photoprotective effect in N. tabacum, which is essential as both high light and salinity can impair photosynthesis. To assess if the salt tolerance enhancing effect of betacyanin production observed in the leaf discs also occurs in whole $N$. tabacum plants, the ability to recover from exposure to saturating light was assessed. Betacyanic plants were able to fully recover quicker after exposure to saturation light than green leaves.

This research shows that the presence of betacyanins during salt stress correlates with an altered $\mathrm{Na}^{+}$distribution in leaf tissues and a higher salt secretion rate, which contributed to higher mesophyll viability. Moreover, a completely new ion flux response to salt stress was observed in D. australe and D. crassifolium. The observed salt induced $\mathrm{K}^{+}$uptake into the mesophyll cells during salt stress might be an entirely new mechanism, to maintain a high $\mathrm{K}^{+} / \mathrm{Na}^{+}$ratio in the cytosol and avoid the cytotoxic effects of $\mathrm{Na}^{+}$in photosynthetically active tissue. The beneficial effects of betacyanins could also be transferred to non-betacyanic species, by introducing betacyanin production. These results strongly suggest that betacyanins play a role in salt tolerance in halophytes and might be a valuable resource in increasing the salt tolerance of naturally non-betacyanic crop plants. 


\section{Acknowledgements}

This thesis would not have been possible without the guidance and scientific advice from Kevin Gould, Ken Ryan, Kathy Schwinn, Kevin Davies, and Sergey Shabala. Kevin and Ken, I could not have wished for a better supervisor duo. You both always offered encouragement and sage advice when I needed it most. Kevin your passion for teaching was truly inspiring and contagious. I will be forever grateful for your support, generosity, and mentorship.

I wish to thank Sergey and Lana Shabala for welcoming me to their lab in Hobart and for teaching me how to MIFE. Thank you to the whole lab family and especially to Widad for making me feel at home in Hobart.

Many thanks to Yanfei Zhou, Kathy Schwinn, and Kevin Davies for their help during my time in Palmerston North and for generating these beautiful red tobacco plants.

Thanks to David Flynn for his assistance with the cryo-SEM and Sushila Pillai for her assistance with fluorescence microscopy. Many thanks to Lesley Milicich for providing lab and glasshouse equipment.

I also had fantastic help with my lab work from students. Thanks to Cameron Johnson, Josef Polec, and Chris Fink for their practical help with AAS and the cryo-SEM.

Many thanks to my office mates, Natascha, Laura and Ronja, for sharing equipment, chemicals, and many coffees (teas) with me. You made this journey a wonderful experience.

This research was funded by the Royal Society of New Zealand Marsden Grant and I also received funding from the Victoria University of Wellington for traveling to an international conference.

I would not be here without the unwavering support of my family. I would like to thank my parents, Hans and Angela, for always encouraging me to reach for the stars, and my brothers, Tobias and Fabian, for keeping my feet on the ground. Thank you, Elli, for being there for me on every step of this journey. Tobi, Tami, and Leon, thank you for always making me feel like part of your little family. Thank you, Christa and Eberhard, for your support and the care packages. Lastly, I would like to thank my husband, Johannes, for always believing in me. Your support and love mean the world to me. I could not have done this without you. 


\section{Co-authorship statement}

All experiments presented in this thesis were conceived, designed, executed, and analysed by myself with the exception of the sodium-gluconate experiment (Figure 3.4.6), which was conducted and analysed by Dr. Lana Shabala, and some of the data shown in Chapter 4 . All the genetic transformation was done by Dr. Yanfei Zhou with contributions from Dr. Kathy Schwinn and Dr. Kevin Davies. The pictures and data from genetic transformation and confirmation of the presence of betacyanin in the mutant line were added to better describe the plants that were used for salt tolerance experiments. I contributed the micrographs of cross sections through leaves of WT and BtOE N. tabacum shown in Figure 4.4.2. The main focus of Chapter 4 is comparing the salt tolerance of WT and BtOE $N$. tabacum. I conceived the ideas and developed the methods for testing salt tolerance with Dr. Yanfei Zhou. I conducted the leaf disc assay and the whole plant experiment with assistance from Dr. Yanfei Zhou at Plant and Food Research in Palmerston North. The chlorophyll analysis was performed by a staff member of Plant and Food Research and the data was analysed by Dr. Yanfei Zhou and Dr. Yanfei Zhou conducted the seedling assay. I collected, analysed, and interpreted the chlorophyll fluorescence data to assess salt tolerance in WT and BtOE N. tabacum. 


\section{Table of contents}

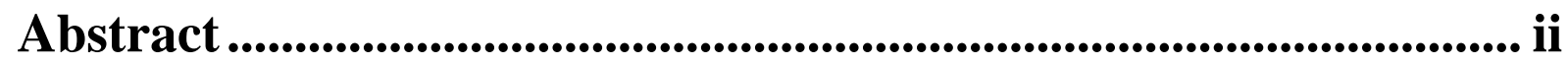

Acknowledgements.............................................................................................. iv

Co-authorship statement ......................................................................................v

Table of contents ................................................................................. vi

List of Figures ..............................................................................................................

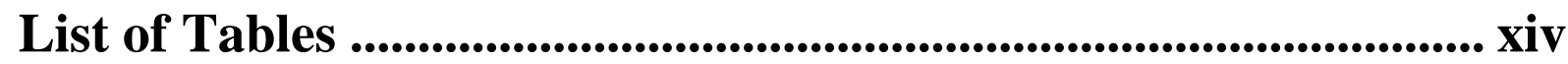

Chapter 1 Introduction.............................................................................1

$1.1 \quad$ Soil Salinity........................................................................................................... 1

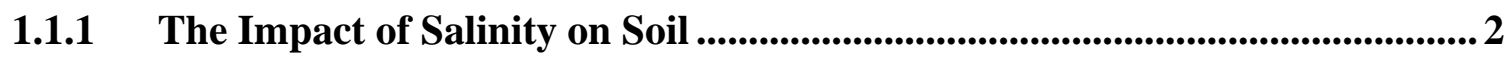

1.1.2 The Impact of Soil Salinity on Plants ...............................................................2

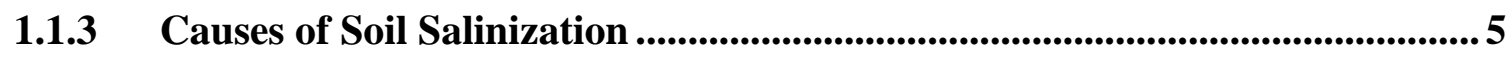

1.1.4 Possible Solutions to Soil Salinity .............................................................................6 6

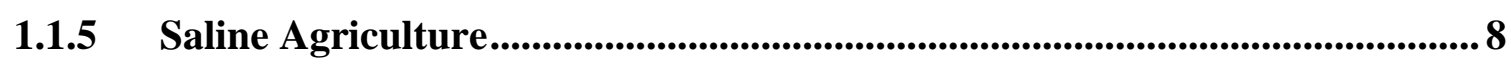

$1.2 \quad$ Plant Salt Stress ................................................................................................ 10

1.2.1 Osmotic Stress.............................................................................................................. 10

1.2.2 Cytotoxic Stress ......................................................................................................... 11

$1.3 \quad$ Salt Tolerance Mechanisms in Plants...................................................... 13

1.3.1 Salt glands and bladders ...................................................................................... 13

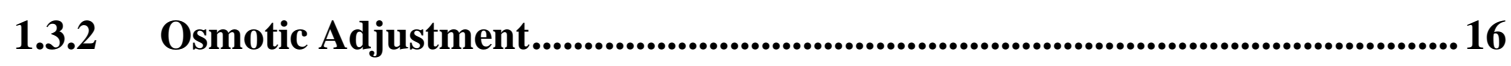

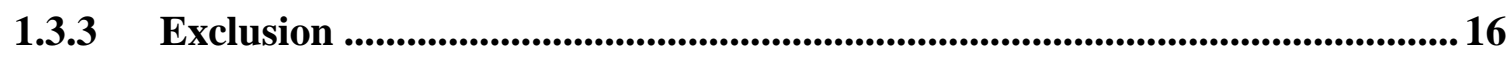

1.3.4 Compartmentalisation ................................................................................... 19

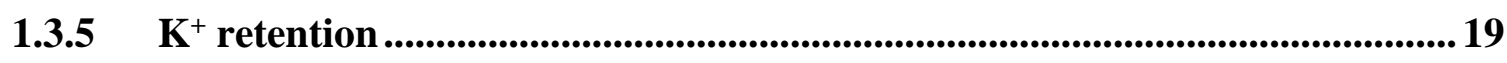


1.3.6 Transporters involved in Salt Tolerance 19

1.4 Betalains ............................................................................................................ 28

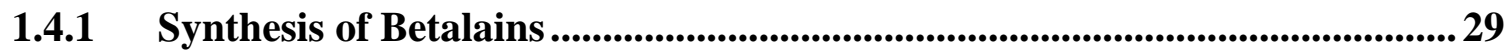

1.4.2 Functions of Betacyanins in Plant Defence Against Biotic and Abiotic Stress 32

1.4.3 The Role of Betacyanin in Response to Salt Stress........................................... 34

1.5 Disphyma australe ..................................................................... 34

1.5.1 Disphyma australe as a Model Organism to Study the Role of Betacyanins

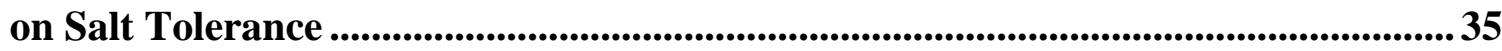

1.6 Aims and Objectives of this Thesis ................................................. 37

\section{Chapter 2 The Betacyanins in Epidermal Cells Protect Leaf}

Mesophyll from Effects of Salt Stress in Disphyma australe

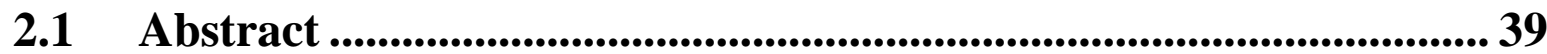

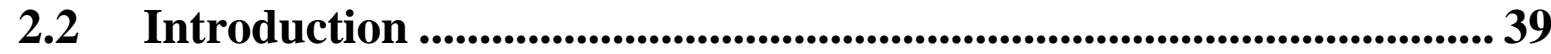

2.3 Materials and Methods ....................................................................41

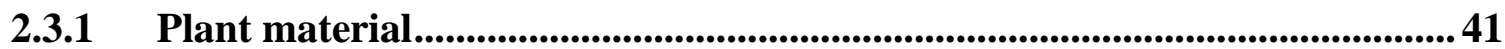

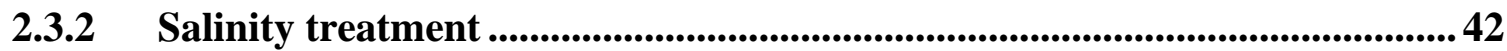

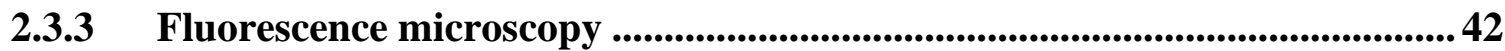

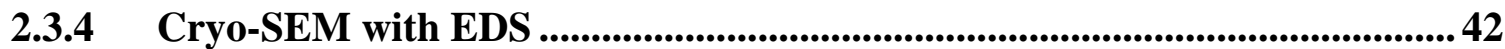

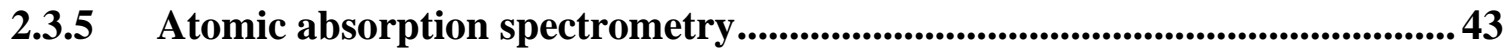

2.3.6 Conductivity measurements ....................................................................................... 43

2.3.7 Salt gland counts............................................................................................................... 44

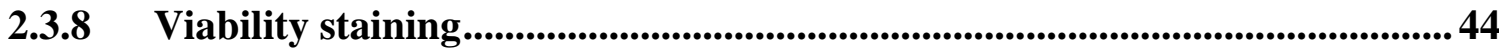

2.3.9 Statistics.............................................................................................................................. 44

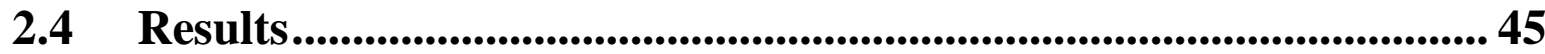

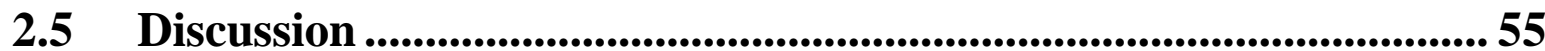




\section{Chapter 3 Salt Stress Induced $\mathrm{K}^{+}$Uptake into Leaf Mesophyll}

Cells of Disphyma australe and Disphyma crassifolium .....................58

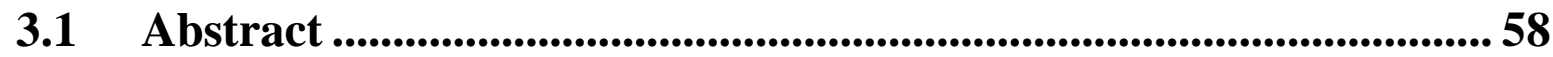

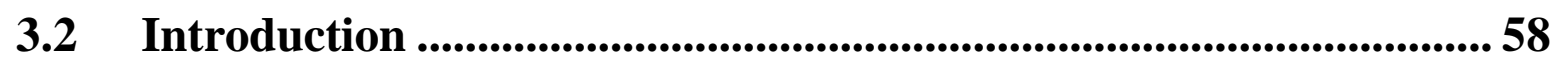

3.3 Materials and Methods .................................................................... 62

3.3.1 Plant Material .............................................................................................................. 62

3.3.2 The Non-Invasive MIFE Technique .................................................................... 63

3.3.3 Non-Invasive Ion Flux Measurements................................................................67

3.3.4 Viability Staining .......................................................................................................... 68

3.3.5 Chlorophyll Fluorescence ……………......................................................................... 68

3.3.6 Chlorophyll Content..................................................................................................... 68

3.3.7 Statistics........................................................................................................................ 69

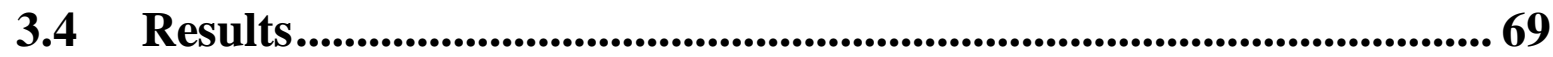

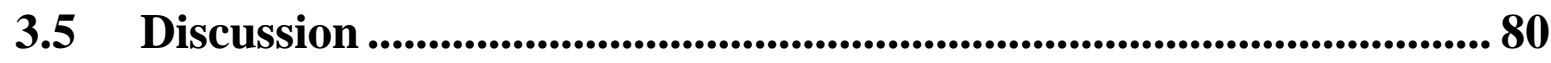

Chapter 4 Increased Salt Tolerance by Betacyanin Synthesis in

Transgenic Nicotiana tabacum ....................................................................85

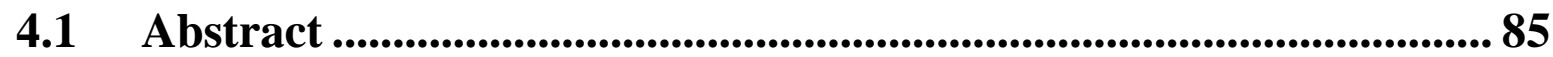

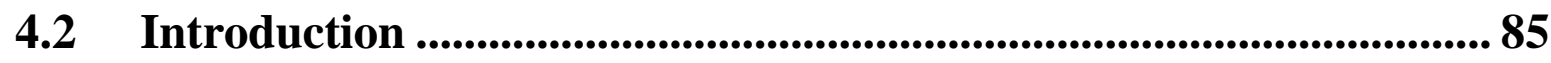

4.3 Materials and Methods ............................................................................ 87

4.3.1 Plant Material .......................................................................................................... 87

4.3.2 Binary Vector Construction ............................................................................... 87

4.3.3 Plant Transformation.................................................................................................. 88

4.3.4 Confirmation of Expression of Transgenes.......................................................... 88

4.3.5 Betalain analysis .......................................................................................................... 89

4.3.6 Chlorophyll and Carotenoid Quantification ........................................................90 


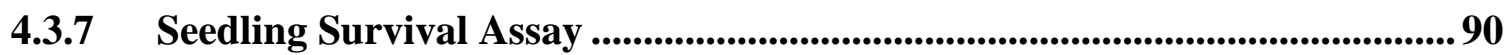

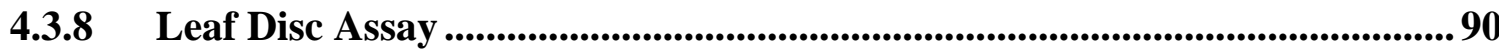

4.3.9 Photo Recovery Assay .........................................................................................................91

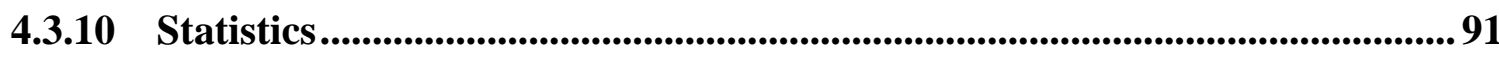

4.4 Results.......................................................................................... 91

4.4.1 Generation of betacyanin producing $N$. tabacum plants...............................91

4.4.2 Increased Survival of Betacyanic Seedlings under Severe Salt Stress.......... 96

4.4.3 Delayed Leaf Senescence under Salt Stress in Betacyanic N. tabacum ....... 98

4.4.4 Reduced Response to Salt Stress of Betacyanic N. tabacum ........................ 100

4.5 Discussion ........................................................................................ 104

Chapter 5 General Discussion............................................................. 108

References ..................................................................................................... 118

Appendix 1 ...................................................................................................... 144 


\section{List of Figures}

Figure 1.1.1 Diversity in the salt tolerance of various species. 3

Figure 1.1.2 Schematic illustration of the two-phase growth response to salinity for genotypes that differ in salt tolerance 4

Figure 1.3.1 Phylogenetic distribution of angiosperm clades reported to have salt glands and representative cellular organization of distinct salt gland structures found in angiosperms .... 15

Figure 1.3.2 Overview of salt tolerance mechanisms. 17

Figure 1.3.3 Schematic representation the two possible pathways for $\mathrm{Na}^{+}$and $\mathrm{Cl}^{-}$uptake at the roots

Figure 1.3.4 Overview of the cellular location of the two most common $\mathrm{H}^{+}$-pumps 20

Figure 1.3.5 Schematic overview of the SOS pathway 23

Figure 1.3.6 Schematic representation showing key plasma and tonoplast membrane transporters, channels, and pumps mediating $\mathrm{Na}^{+}$homeostasis in plants under salt stress ...... 26

Figure 1.3.7 Schematic overview showing key plasma and tonoplast membrane transporters of $\mathrm{K}^{+}$homeostasis under salt stress. 28

Figure 1.4.1 The betalain biosynthetic pathway 31

Figure 1.5.1 Both D. australe morphs growing side by side at Te Kopahou Reserve, Wellington 36

Figure 2.4.1 Light- and fluorescence micrographs of transverse sections through red and green D. australe leaves and internodes 46

Figure 2.4.2 Mean relative sodium content per cell in epidermis and mesophyll of leaves and stems treated with $200 \mathrm{mM} \mathrm{NaCl}$ or distilled water 47

Figure 2.4.3 Mean $\mathrm{Na}$ and $\mathrm{K}$ content of epidermis and mesophyll tissue of red and green $D$. australe leaves treated with 0,200 , or $400 \mathrm{mM} \mathrm{NaCl}$.... 
Figure 2.4.4 Ratio of mean $\mathrm{Na}$ and $\mathrm{K}$ content in epidermis to mesophyll tissue of leaves from red and green morphs treated with 0,200 , or $400 \mathrm{mM} \mathrm{NaCl}$

Figure 2.4.5 Ratio of mean $\mathrm{K}$ to $\mathrm{Na}$ content in epidermis and mesophyll tissue of leaves from red and green morphs treated with 0,200 , or $400 \mathrm{mM} \mathrm{NaCl}$

Figure 2.4.6 Mean conductivity of leaf washes from shoot cuttings treated with $800 \mathrm{mM} \mathrm{NaCl}$ or water. Micrographs showing salt glands of green and betacyanic D. australe leaves

Figure 2.4.7 Fluorescence micrographs of cross-sections of green and red $D$. australe leaves; co-stained with fluorescein diacetate and propidium iodide after $24 \mathrm{~h}$ in $\mathrm{BSM}$ or $400 \mathrm{mM} \mathrm{NaCl}$

Figure 3.3.1 Principle of the non-invasive MIFE technique 64

Figure 3.3.2 An assembled MIFE system 65

Figure 3.4.1 Photographs of $D$. crassifolium, and the green and red morph of $D$. australe shoot cuttings before and after treatment with $400 \mathrm{mM} \mathrm{NaCl}, 800 \mathrm{mM} \mathrm{NaCl}, 35 \%$ PEG, and water 70

Figure 3.4.2 Fv/Fm of $D$. crassifolium, the green, and red morph of $D$. australe leaves over 8 d under treatment with $35 \%$ PEG, 0, 400 , and $800 \mathrm{mM} \mathrm{NaCl}$ 71

Figure 3.4.3 Fluorescence micrographs of cross-sections of green and red D. crassifolium leaves; co-stained with fluorescein diacetate and propidium iodide after $24 \mathrm{~h}$ in BSM or 400 $\mathrm{mM} \mathrm{NaCl}$.....

Figure 3.4.4 Transient net $\mathrm{Na}^{+}, \mathrm{K}^{+}$, and $\mathrm{Cl}^{-}$flux kinetics measured from mesophyll of betacyanic and green leaves from $D$. australe and $D$. crassifolium in response to increasing $\mathrm{NaCl}$ concentration

Figure 3.4.5 Peak $\mathrm{Na}^{+}, \mathrm{K}^{+}$, and $\mathrm{Cl}^{-}$flux measured from mesophyll of betacyanic and green leaves from $D$. australe and D. crassifolium in response to treatment with $300 \mathrm{mM} \mathrm{NaCl} \ldots 75$

Figure 3.4.6 Transient net $\mathrm{Na}^{+}, \mathrm{K}^{+}$, and $\mathrm{Cl}^{-}$flux kinetics measured from mesophyll of betacyanic and green leaves from $D$. crassifolium in response to increasing $\mathrm{LiCl}, \mathrm{KCl}$, and $\mathrm{NaCl}$ concentration 
Figure 3.4.7 Peak $\mathrm{Na}^{+}, \mathrm{K}^{+}$, and $\mathrm{Cl}$ flux kinetics measured from mesophyll of betacyanic and green leaves from $D$. crassifolium in response to treatment with $300 \mathrm{mM} \mathrm{LiCl}, \mathrm{KCl}$, and $\mathrm{NaCl}$

Figure 3.4.8 Transient net $\mathrm{Na}^{+}, \mathrm{K}^{+}$flux kinetics measured from mesophyll of betacyanic and green leaves from $D$. australe in response to increasing sodium gluconate concentration...... 79

Figure 3.4.9 Transient net $\mathrm{Na}^{+}$fluxes and peak $\mathrm{Na}^{+}, \mathrm{K}^{+}$, and $\mathrm{Cl}^{-}$fluxes in mesophyll cells from greenand red $D$. crassifolium leaves, incubated with BSM, betacyanin (red beet root extract), or betaxanthin (golden beet root extract), in response to treatment with $300 \mathrm{mM} \mathrm{NaCl} \ldots \ldots . . .80$

Figure 4.3.1 Schematic overview of betalain overexpression vector ..... 88

Figure 4.4.1 Transformation with the betalain over-expressing vector resulted in formation of violet-red pigmented plants in N. tabacum. 93

Figure 4.4.2 Transverse sections through leaves of BtOE and WT N. tabacum 94

Figure 4.4.3 The location of betacyanin pigments in mesophyll cells and guard cells of BtOE N. tabacum leaves 94

Figure 4.4.4 RT-PCR analysis of gene expression in transgenic N. tabacum. 95

Figure 4.4.5 HPLC chromatogram of $N$. tabacum leaf extract. 96

Figure 4.4.6 Seedling survival test under salt stress..... 97

Figure 4.4.7 Percentage of seedlings that survived after severe salt stress treatment 98

Figure 4.4.8 Photos of leaf discs treated with different salt solutions 99

Figure 4.4.9 Relative total chlorophyll and carotenoids contents of $N$. tabacum leaf discs treated with salt solutions under $150 \mu \mathrm{mol} \mathrm{m} \mathrm{m}^{-2} \mathrm{~s}^{-1}$ and $450 \mu \mathrm{mol} \mathrm{m} \mathrm{m}^{-2} \mathrm{~s}^{-1}$ light. 100

Figure 4.4.10 Fv/Fm of leaf discs treated with water, $100 \mathrm{mM}$ or $200 \mathrm{mM}$ salt solutions under low or high light 102

Figure 4.4.11 Changes in Fv/Fm for WT, EV, and BtoE $N$. tabacum plants after treatment with $40 \mathrm{ml}$ water or $400 \mathrm{mM} \mathrm{NaC}$ 104 
Figure 5.1 Photomicrograph of a betacyanic leaf of $D$. australe showing salt glands ..........110

Figure 5.2 Proposed salt tolerance mechanism in $D$. australe .......................................... 114

Figure 4.5.3 Proposed role of betacyanin in salt tolerance of $D$. austral ............................. 116 


\section{List of Tables}

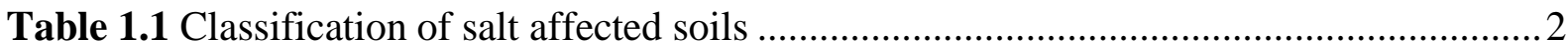

Table 2.1 Percentage of viable mesophyll cells in red and green $D$. australe leaves..............54

Table 3.1 Specific details of the back-filling solutions and LIX ......................................66

Table 3.2 Percentage of viable mesophyll cells in red and green $D$. crassifolium leaves ....... 73

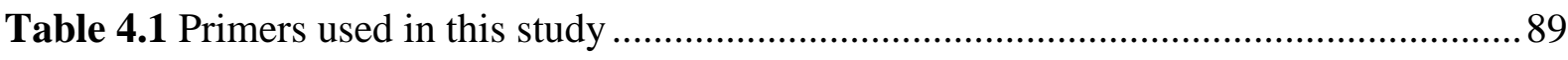

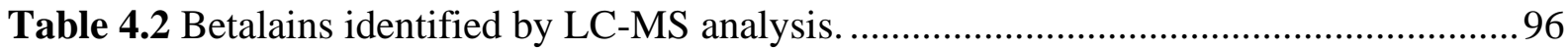




\section{Chapter 1 Introduction}

Mankind has shaped its environment since the beginning of its existence and humans still remain a major force changing our landscape. In the last decades these changes have severely altered the atmosphere and oceans, and the effects are experienced globally. These include changes in climate associated with elevated $\mathrm{CO}_{2}$ levels in the atmosphere, the acidification and pollution of oceans and fresh waterways and are widely known as climate change (Hooke et al., 2012). Human activities have resulted in a global scarcity of freshwater, as well as the contamination of arable soils. The growing population's need for food, fibre and fuel, as well as the increase in meat consumption are threatening agricultural sustainability (Shrivastava \& Kumar, 2015; Smith et al., 2016). Crop production is impaired by extreme temperatures, soil salinity, flood, and drought, the occurrence and intensities of which are increasing as a result of human-made global changes. Among these, increasing soil salinity is one of the main environmental stressors causing reductions in arable land, crop yield and food quality (Shrivastava \& Kumar, 2015).

\subsection{Soil Salinity}

Soil is considered saline when the electrical conductivity in the soil solution at the root zone exceeds $4 \mathrm{dS} / \mathrm{m}(40 \mathrm{mM} \mathrm{NaCl})$ at $25^{\circ} \mathrm{C}$. Under these conditions most crop plants have reduced yield (Jamil et al.,2011; Munns, 2005; Shrivastava \& Kumar, 2015). Abrol et al. (1988) defined different types of salt affected soils, namely, saline soils, sodic soils, and saline-sodic soils (Table 1.1). In saline soils the soluble salts are mainly sodium chloride and sodium sulphate, whereas in sodic soils sodium carbonate forms mostly due to groundwater containing carbonate and bicarbonate. While the $\mathrm{pH}$ in saline soils is below 8.5 , sodic soils generally are more alkaline and have a pH between 8.5 and 10. In sodic soils the exchangeable sodium is $15 \%$ or higher, whereas in saline soils it is $15 \%$ or lower. Although saline and sodic soils account for most of the salt-affected soils, there are soils with intermediate properties, called saline-sodic soils (Abrol et al., 1988; González-Núñez et al., 2004). 
Table 1.1 Classification of salt affected soils adapted form (González-Núñez et al., 2004)

\begin{tabular}{|c|c|c|c|}
\hline \multirow[t]{2}{*}{ Characteristics } & \multicolumn{3}{|l|}{ Soil Type } \\
\hline & Saline soils & Sodic soils & Saline-sodic soils \\
\hline EC of saturation extract & $<4 \mathrm{dS} / \mathrm{m}$ & $>4 \mathrm{dS} / \mathrm{m}$ & $>4 \mathrm{dS} / \mathrm{m}$ \\
\hline $\begin{array}{l}\text { Exchangeable sodium } \\
\text { percentage }\end{array}$ & $<15$ & $>15$ & $>15$ \\
\hline $\mathrm{pH}$ & $<8.5$ & $8.5-10$ & $<8.5$ \\
\hline Bivalent cations & $\begin{array}{l}\text { Considerable } \\
\text { quantities of } \mathrm{Ca}^{2+} \text { and } \\
\mathrm{Mg}^{2+}\end{array}$ & $\begin{array}{l}\text { Less quantities } \\
\text { of } \mathrm{Ca}^{2+} \text { and } \\
\mathrm{Mg}^{2+}\end{array}$ & $\begin{array}{l}\text { Considerable } \\
\text { quantities of } \mathrm{Ca}^{2+} \text { and } \\
\mathrm{Mg}^{2+}\end{array}$ \\
\hline $\begin{array}{l}\text { Presence of soluble } \\
\text { calcium components }\end{array}$ & $\begin{array}{l}\text { Meaningful quantities } \\
\text { of gypsum }\end{array}$ & $\begin{array}{l}\text { Gypsum is } \\
\text { absent }\end{array}$ & $\begin{array}{l}\text { Meaningful quantities } \\
\text { of gypsum }\end{array}$ \\
\hline Structure & Stable & Unstable & Stable \\
\hline
\end{tabular}

\subsubsection{The Impact of Salinity on Soil}

Increased salinity may lead to soil degradation and desertification in arid and semi-arid landscapes (Li, Qian, \& Wu, 2018; Yang \& Yu, 2017; Zewdu, Suryabhagavan, \& Balakrishnan, 2016). Soil salinity can cause soil compaction, resulting in crust formation and soil sealing (Machado \& Serralheiro, 2017; Yang \& Yu, 2017). Compact soils have lower rates of water infiltration and less oxygen available at the root zone, and cause hydraulic and drainage problems. This can lead to waterlogging and further salinization. Accumulation of excess salt can also damage the soil structure and cause particle aggregation due to slaking, swelling, and dispersion effects (Jesus et al., 2015; Machado \& Serralheiro, 2017). Additionally, high sodium content in soils can cause the increase of soil $\mathrm{pH}$, called alkalization, leading to decreases in nutrient concentrations, heavy metal mobility and bioavailability (Khodaverdiloo \& Hamzenejad Taghlidabad, 2014; Machado \& Serralheiro, 2017).

\subsubsection{The Impact of Soil Salinity on Plants}

Salinity reduced the agricultural revenues by approximately $\$ 3.7$ billion in 2014 and lead to 8.0 million tons of lost produce, as it negatively impacts growth and yield of most crop plants (Figure 1.1.1) (Munns \& Tester, 2008; Welle \& Mauter, 2017).The destructive affect from soil salinity on plants results from a complex interaction of physiological, morphological, and biochemical processes. These include seed germination, vegetative growth, root growth and morphology, reproductive development, and water and nutrient uptake (Bano \& Fatima, 2009; Akbarimoghaddam et al., 2011; Singh, 2015). Salinity can inhibit microsporogenesis and stamen filament elongation, ovule abortion, and senescence of fertilized embryos, thereby hindering reproduction (Shrivastava \& Kumar, 2015) 


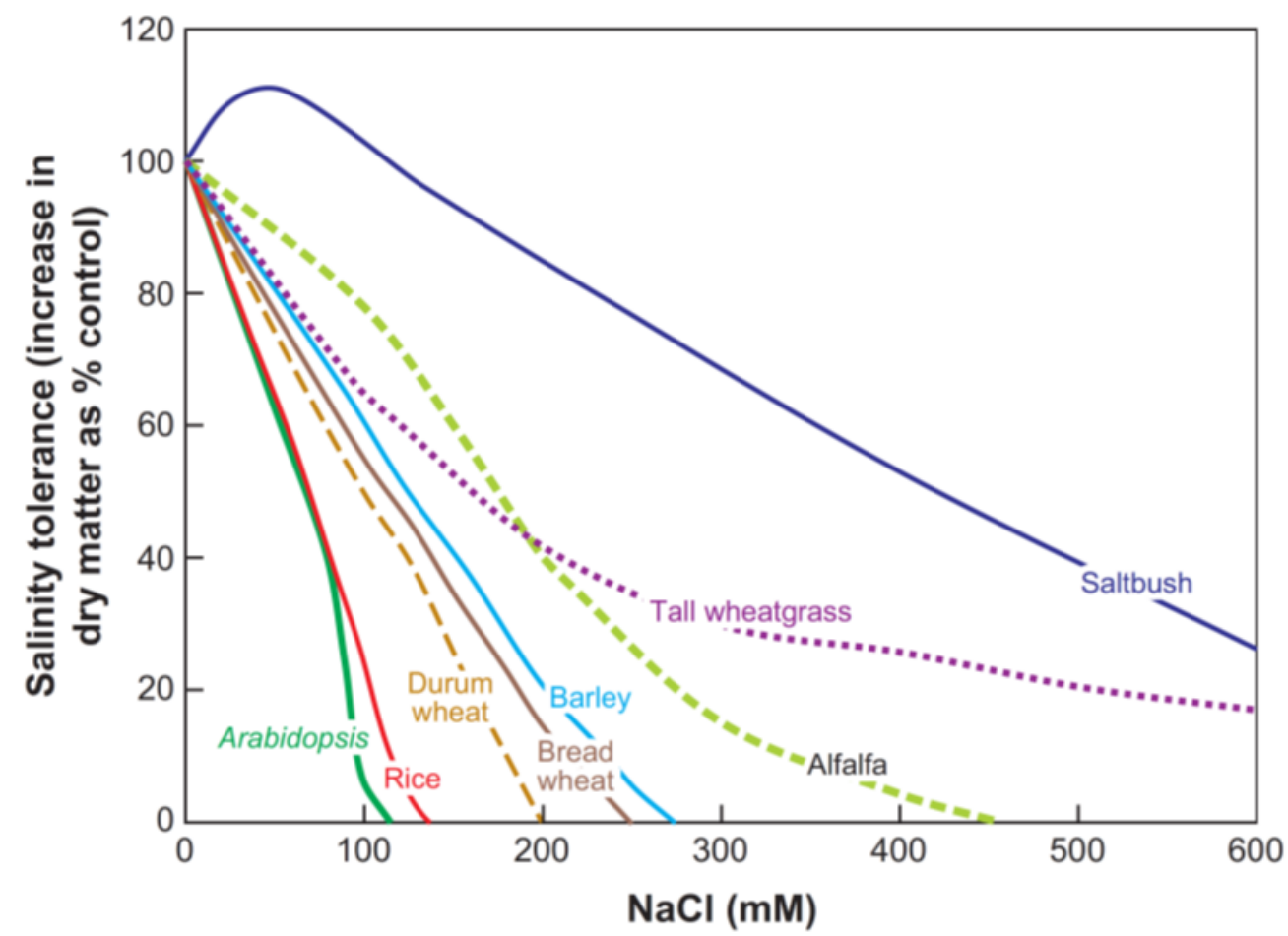

Figure 1.1.1 Diversity in the salt tolerance of various species, shown as increases in shoot dry matter after growth in solution or sand culture containing $\mathrm{NaCl}$ for at least three weeks, relative to plant growth in the absence of $\mathrm{NaCl}$ (Munns \& Tester, 2008).

Munns proposed a two-phase model of the response of plants to salinity (Figure 1.1.2) (Munns et al., 1995). The first phase is characterised by a rapid growth reduction attributable to decrease in soil water potential. Increasing soil salinity requires a lower water potential in plant tissues in order to maintain net water flux into the plant. Visible symptoms of salt-affected plants during this first rapid phase include wilting, leaf chlorosis, and stunted growth, are very similar to drought stress (Munns \& Tester, 2008; Läuchli \& Grattan, 2011; Machado \& Serralheiro, 2017). The inability to acquire sufficient amounts of water can lead to loss of turgor, cell degradation, and cell death (Ashraf, 2004). Additionally, the ion homeostasis is disrupted by salinity due to the inhibition of uptake of essential elements, such as $\mathrm{K}^{+}, \mathrm{Ca}^{2+}, \mathrm{NO}_{3}, \mathrm{PO}_{4}, \mathrm{Fe}$, and $\mathrm{Zn}$ and the accumulation of $\mathrm{Na}^{+}$and $\mathrm{Cl}^{-}$, as well as the leakage of $\mathrm{K}^{+}$upon salt stress (Paranychianakis \& Chartzoulakis, 2005; Bano \& Fatima, 2009; Wu et al., 2015). 


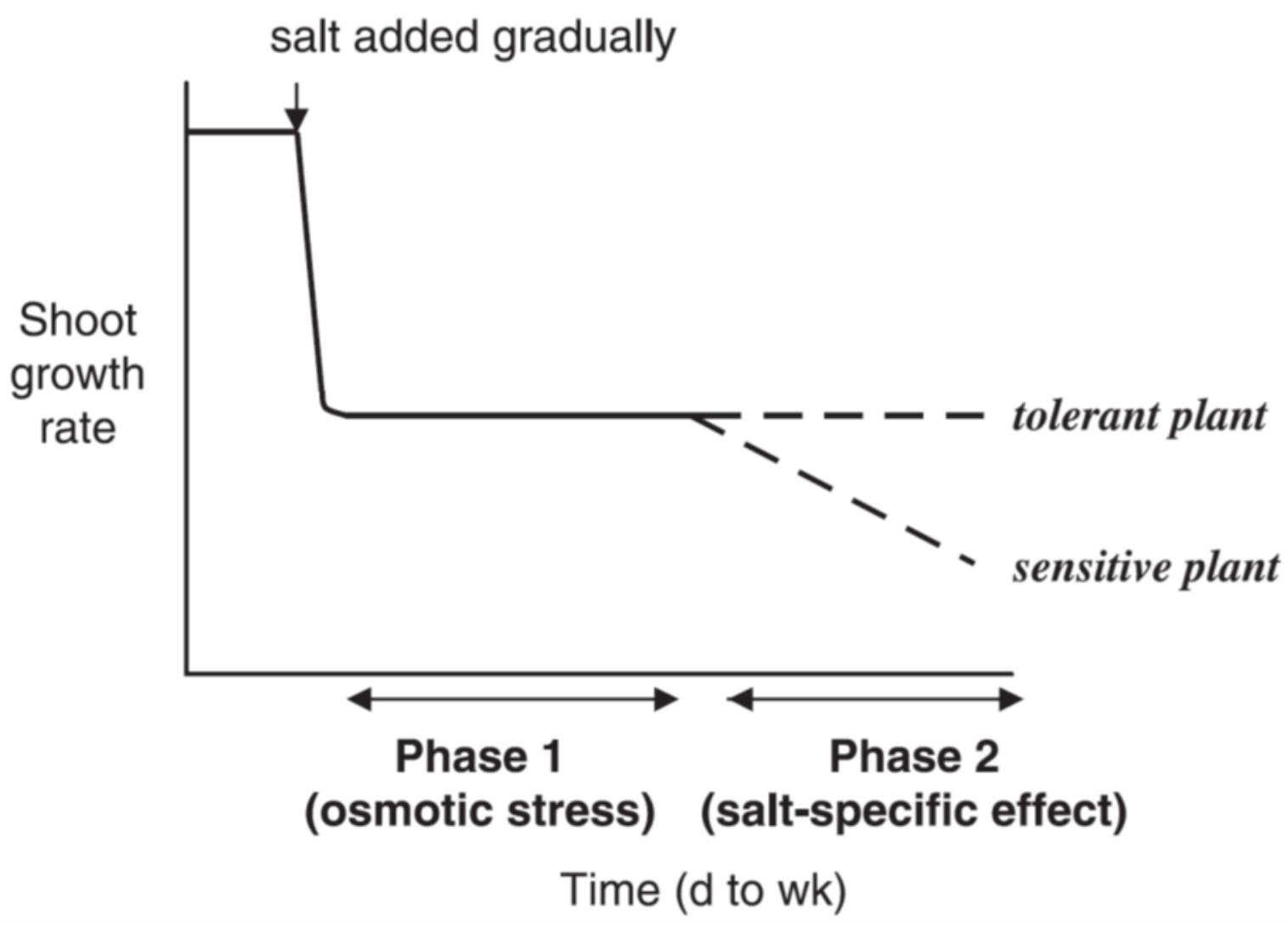

Figure 1.1.2 Schematic illustration of the two-phase growth response to salinity for genotypes that differ in salt tolerance. During phase one, growth of both genotypes is reduced because of the osmotic effect of the saline solution outside the roots. During phase two, leaves in the more sensitive genotype die and reduce the photosynthetic capacity of the plant. Adapted from (Munns, 2005)

During the second phase of Munns' model $\mathrm{Na}^{+}$and $\mathrm{Cl}^{-}$accumulation reaches cytotoxic levels (Munns et al., 1995). Visual symptoms of this phase include chlorosis and necrosis of leaves, leaf tip burning and the oldest leaves, which had the most time to accumulate high $\mathrm{Na}^{+}$ concentrations, often show the most severe symptoms, including scorching (Shannon \& Grieve, 1998; Shrivastava \& Kumar, 2015). Ion toxicity is caused by a high $\mathrm{Na}^{+} / \mathrm{K}^{+}$ratio leading to the replacement of $\mathrm{K}^{+}$with $\mathrm{Na}^{+}$in biochemical reactions (Zhu, 2002; Barragan et al., 2012; Almeida et al., 2017). $\mathrm{Na}^{+}$and $\mathrm{Cl}^{-}$can induce conformational changes in proteins. For several enzymes $\mathrm{K}^{+}$acts as a cofactor and can be replaced by $\mathrm{Na}^{+}$, if the $\mathrm{Na}^{+} / \mathrm{K}^{+}$ratio is too high, leaving the enzymes inactive. Additionally, high $\mathrm{K}^{+}$concentrations are crucial to bind tRNA to ribosomes. Thus, a high cytosolic concentration of $\mathrm{Na}^{+}$can inhibit protein synthesis (Zhu, 2002). Excessive accumulation of $\mathrm{Na}^{+}$can also cause oxidative stress and lead to cell death (Munns et al., 2002; Bano \& Fatima, 2009). Finally, salt stress can inhibit photosynthesis via 
reductions in leaf area, chlorophyll content, stomatal conductance, and photosystem II quantum efficiencies (Netondo et al., 2004). A reduced photosynthestic rate also results in insufficient supply of assimilates to growing tissue (Ashraf, 2004). Saline soil causes osmotic and ion toxicity stress leading to decreased productivity of crops and yield of fruits, root, tubers, and leaves with little to no commercial value (Shrivastava \& Kumar, 2015).

\subsubsection{Causes of Soil Salinization}

Soil salinization predominately affects developing countries in arid and semi-arid climate zones and has a deleterious effect on agricultural yields (Rozema \& Flowers, 2008). Currently saline soils are endangering rice yield in irrigated agriculture in the Songen Plain in northeast China and the Vinchuan Plain in north west China (Yang \& Yu, 2017; Li et al., 2018). The Indus Basin, a region in Pakistan heavily relying on irrigation for food production, and parts of southwest India are facing economic losses of up to $37 \%$ due to reduced yield of cotton, sunflower seeds, and paddy on saline soils (Janmaat, 2004; Qureshi et al., 2008). Africa is also affected by soil salinity, including the Tadla plain in central Morocco and southeast Ethiopia (El Harti et al., 2016; Zewdu et al., 2016). Europe is also affected, with the salt lake region in Turkey and Spain subjected to increasing soil salinity (Gorji et al., 2017; Machado \& Serralheiro, 2017) In Spain 3\% of irrigated land is currently considered saline and another 13\% is under risk of becoming saline (Machado \& Serralheiro, 2017). Large areas of agricultural land in California are affected by desertification and salinization (Welle \& Mauter, 2017). The same is true for Australia, leaving almost every continent affected by soil salinization (Rengasamy, 2006; Connor et al., 2012).

There are two main factors that drive soil salinization: primary soil salinization, due to natural factors, and secondary soil salinization caused directly or indirectly by anthropogenic activities (Gorji et al., 2017). Among the primary causes are the driving effects of wind and water on the weathering of salt and minerals from parent materials, and, in arid regions, high evaporation rates (Shrivastava \& Kumar, 2015; Singh, 2015; Gorji et al., 2017; Li et al., 2018). Additionally, sea water intrusion in coastal areas can cause the accumulation of salts in soil, and threaten costal ecosystems (Singh, 2015)

Secondary soil salinization is the most prominent cause for salinization of once-arable land. Leading factors include irrigation practices and fertilizer applications (Li et al., 2018), which can directly deposit salts on soils (Pérez-Sirvent et al., 2003; Singh, 2015; Gorji et al., 2017). Soil salinization is a threat especially in arid and semi-arid regions, because irrigation and 
fertilizer use is especially important to guarantee crop yield in these region, as evaporation is especially high due to low precipitation and high temperatures (Shrivastava \& Kumar, 2015; Singh, 2015). In Australia valley floors, such as the Murray basin, are often affected by salinization due to shallow water tables. There natural processes led to salt leaching from permeable soil and accumulating in the groundwater to very high salinity levels. (EC 15-150 $\mathrm{dS} / \mathrm{m})$. Introducing agricultural irrigation raised the shallow water tables and the replacement of deep-rooted species with shallow rooted crops has led to more water leaking from upper soil layers to the groundwater due to utilization of irrigation water. High evaporation rates can result in capillary rise of saline water from shallow water tables and increase salinity in the surface soils (Rengasamy, 2002)

Climate change is predicted to further enhance the rate of soil salinization via a combination of a scarcity of fresh water, rising sea levels, and increasing aridity, due to both more intense and prolonged periods of drought and larger portions of land now subjected to drought (Jesus et al., 2015). With less fresh water available, growers may need to consider using saline or brackish water for irrigation (Lhissou et al., 2014; Jesus et al., 2015; Li et al., 2015; El Harti et al., 2016; Machado \& Serralheiro, 2017). Higher air temperatures and protracted drought will increased evaporation from soils; this will further increase the amount of irrigation water needed to grow crops and also increase the capillary rise of saline groundwater (Jesus et al., 2015). In addition, the rising sea levels will cause an increase in ground water abstraction and the frequency of seawater inundation in coastal areas (Jesus et al., 2015; Zhou et al., 2017). With the growing urgency to feed the world's growing population and simultaneously to combat soil salinization and desertification, plant and soil research has become vital.

\subsubsection{Possible Solutions to Soil Salinity}

There are several ways to reclaim already saline soil. The soil permeability can be permanently improved, and the levels of exchangeable sodium can be reduced by applying gypsum $\left(\mathrm{CaSO}_{4}\right)$ and large quantities of water. When $\mathrm{CaSO}_{4}$ is mixed with water, $\mathrm{Ca}^{2+}$ ions are released, which replace sodium ions in the soil. The free $\mathrm{Na}^{+}$is then leached beyond the root zone with the downward moving water and moved out of the fields using drainage. On the one hand, this is the most effective and long-lasting method to reclaim saline soils and to eliminate the detrimental effects of soil salinity, but on the other hand, this is a slow and expensive process that requires large quantities of fresh water (Machado \& Serralheiro, 2017). 
One possible way to combat the advancing soil salinization is changing our agricultural practices. Developing new irrigation management methods, including irrigation scheduling, drip irrigation, leaching, and artificial drainage, can increase water and nutrient use efficiency and reduce salt accumulation. Responsible irrigation management can, therefore, mitigate the effects of soil salinization (Malash et al., 2008). Leaching is a particularly effective way to diminish soil salinity, but it requires large quantities of water to remove some of the salts from the root zone. (Letey et al., 2011). Fertilizers often introduce additional salts to the soil and increase soil salinity. The excessive application of fertilizers should be avoided. Instead, high quality, chloride-free and low saline fertilizers should be used. Applying those through irrigation water can increase water use efficiency and improve nutrient availability (Machado $\&$ Serralheiro, 2017). Additionally, plant growth and yield under saline soil conditions can be improved by applying biofertilizers. Biofertilizers usually are fertilizers containing microorganisms that can enhance the nutrient status of soils either by replacing nutrients in the soil or making nutrients more available to plants (Mahmood et al., 2016).

Rhizosphere organisms, including symbiotic fungi and bacteria, can improve plant growth and yield under an assortment of abiotic stressors including salinity, either directly or indirectly (Dimkpa et al., 2009; Shrivastava \& Kumar, 2015). Benevolent microorganisms can indirectly increase growth under saline conditions by protecting the plants from pathogenic microorganisms, as plants become more susceptible to pathogens under abiotic stress (Lugtenberg \& Kamilova, 2009; Shrivastava \& Kumar, 2015). Plant growth promoting bacteria can directly improve plant growth by providing soluble phosphate, fixed nitrogen, and ion sequestered by siderophores (Kohler et al., 2006; Hayat et al., 2010). Additionally, rhizobacteria can produce phytohormones including, auxin, cytokinin, and gibberellins, thereby increasing root length, root area, and the number of root tips, which enhances nutrient uptake and can lead to overall improved plant health under stress conditions (Kohler et al., 2006; Dimkpa et al., 2009; Egamberdieva \& Kucharova, 2009; Shrivastava \& Kumar, 2015). Some bacteria can also produce exopolysaccharides, which can bind soil particles and thus improve the soil structure of saline soils. Exopolysaccharides can also bind cations, such as $\mathrm{Na}^{+}$, and make them unavailable to plants, reducing $\mathrm{Na}^{+}$uptake under salt stress (Sandhya et al., 2009; Shrivastava \& Kumar, 2015). Thus far, studies have shown that both arbuscular mycorrhizae fungi and plant growth promoting bacteria can improve growth of plants, such as sorghum and lettuce, under saline conditions (Barassi et al., 2006; Cho et al., 2006). In 2013 a study found that halotolerant bacteria isolated from saline environments significantly reduced the effect of 
salt on the growth of wheat seedlings. These bacteria strains promoted plant growth via indole -3- acetic acid (IAA) production, siderophore, or P-solubilization. Wheat seedlings grown from seeds imbibed with bacteria solution showed more than $90 \%$ increase in root elongation and $17.4 \%$ increase in dry weight (Ramadoss et al., 2013).

\subsubsection{Saline Agriculture}

One way to ensure crop yield on saline soils or to successfully use brackish water or seawater for irrigation, is using salt-tolerant crops. To achieve this, traditional crop species could be crossed with naturally salt-tolerant relatives (Dagar \& Yadav, 2017). In the Triticeae, for example, durum wheat and bread wheat are very susceptible to soil salinity, but more than 30 related species show higher salt tolerance (Colmer et al., 2006; Cheeseman, 2016). While hybridising closer relatives is often easier, the halophytic relatives, such as tall wheatgrass (Thinopyrum spp.) and sea barley grass (Hordeum marinum), are more promising to gain salt tolerant crop species. Even though these hybrids showed enhanced salt tolerance, yields were still depressed under saline conditions (Colmer et al., 2006; Cheeseman, 2016).

To ensure future food security we will have to expand the species used in agriculture beyond the major grains, including especially salt tolerant crops that might already be used locally, but are mostly unheard of in other regions of the world. An alternative is to domesticate halophytes. Contrary to glycophytes halophytes can complete the life cycle in environments with a salt concentration of at least $200 \mathrm{mM} \mathrm{NaCl}$ (Flowers \& Colmer, 2008) Halophytes are phylogenetically diverse group of plants, that could be used as medical plants, for biofuel, oil, fodder and food production (Ventura \& Sagi, 2013; Dagar \& Yadav, 2017). Some medical and aromatic plants, including Aloe vera, liquorice (Glycyrrhiza glabra), and chamomile (Matricaria chamomilla) can be successfully irrigated with saline water up to $10 \mathrm{dSm}^{-1}$ (Dagar \& Yadav, 2017). Some halophytes from the coastal region of Pakistan, including Halopyrum mucronatum, Desmostachya bipinnata, Phragmites karka, Typha domingensis, and Panicum turgidum, and from China, such as Tamarix chinensis, Phragmites australis, and Spartina alterniflora, have been suggested as a biofuel crop for saline soils (Abideen et al., 2011; Ventura \& Sagi, 2013; Dagar \& Yadav, 2017). Additionally, halophytes have been tested as fodder for animals (Ventura \& Sagi, 2013). The dietary needs of small ruminants, such as goats and sheep, kept in arid and semi-arid regions can be met by a combination of salt tolerant grasses, such as Sorghum (Sorghum bicolor) and pearl millet (Pennisetum glaucum), legumes, including pigeon pea (Cajanus cajan) and Sesban (Sesbania sesban), and Atriplex species (El Shaer, 2010). Some halophytes are currently grown for human consumption. One successful 
example for this is Quinoa (Chenopodium quinoa), once an indigenous crop cultivated at high elevations in Bolivia, now a widely accepted highly nutritious alternative to common grains that is also highly salt tolerant (Cheeseman, 2016). There are not only halophytic grain alternatives, but also halophytes that can be used as leafy vegetables (Ventura \& Sagi, 2013). The most successful example is Salicornia bigelovii, an extremely salt tolerant salt-marsh pioneer plant. This halophyte can be watered with full strength seawater. Salicornia is already widely accepted by consumers who appreciate the young green plant shoots that are sold as samphire or sea asparagus (Ventura et al., 2011).

Compared to traditional plant breeding, genetic engineering is considered to be a more efficient and more fruitful approach to produce salt-tolerant crops, especially with new technologies, such as CRISPR/Cas9, becoming more affordable (Shah et al., 2018). There are various genes encoding organic osmolytes, antiporters, antioxidants, abscisic acid regulated genes and transcription factors, that are of special interest to researchers working on developing salt tolerant crop varieties. These genes have been successfully introduced to transgenic Brassica lines to enhance salt tolerance (Shah et al., 2018). There has been a lot of effort to develop salt tolerant grain producing crops, especially wheat and rice, focusing on ion transporters. One example is TmHKT1;5-A, a $\mathrm{Na}^{+}$transporter gene found in an ancestral wheat species. Transforming a durum wheat variety with this gene resulted in a wheat cultivar that showed significantly reduced $\mathrm{Na}^{+}$uptake to the leaves and could yield $24 \%$ more grains on saline soils than normal durum wheat (Munns et al., 2012). Another salt tolerance gene isolated from a salt tolerant wheat mutant is TaSR. Overexpressing this gene in rice and Arabidopsis increased the $\mathrm{Na}^{+}$secretion and led to increased intracellular $\mathrm{K}^{+}$and $\mathrm{Ca}^{2+}$ concentrations, thereby increasing salt tolerance in two glycophyte species (Ma et al., 2016). Another interesting transporter is a $\mathrm{Na}^{+}$pumping ATPase, called PpENA1, that was found in moss. Introducing this gene to rice resulted in more biomass production at $50 \mathrm{mM} \mathrm{NaCl}$ compared to cultivated rice varieties. However, the mechanism behind this is still unclear, as both the control and mutant plants had similar $\mathrm{Na}^{+}$concentration in leaves (Jacobs et al., 2011).

Producing genetically modified salt tolerant crops is currently an active field of research. However, the access of growers to this technology is in many countries restricted by political and bioethical issues (Tester \& Langridge, 2010). Tight restrictions on where GM crops may be grown hinders proper field studies. Most researchers, therefore, only test the salt tolerance of new crops in laboratories or glasshouses under controlled conditions, but tests under field conditions are needed to determine the salt tolerance of crops (Flowers, 2004). Additionally, 
most studies focus on only one trait, reducing $\mathrm{Na}^{+}$uptake, and less attention is paid to other traits, including tolerance to the osmotic effects of salt on roots, which greatly affect plant growth and yield. Therefore, increasing water use efficiency and osmotic adjustment should also be a included in generating salt tolerant crop species (Munns et al., 2006) Salt tolerance is a very complex trait and plants have developed a wide range of salt tolerance mechanisms. Instead of only relying on one tolerance mechanism plants may combine multiple mechanisms. Salinity tolerance, therefore is a trait, that includes a complex network of signalling pathways and different genes (Flowers, 2004). Environment-dependent gene regulation might also play a bigger role in salt tolerance than the genes themselves, as halophytes and glycophytes are often genetically very similar (Himabindu et al., 2016). Currently, many attempts at overexpressing salt tolerant genes have not resulted in salt tolerant crops. Often other factors must be considered, such as transformation of multiple genes, as salt tolerance is a multigenetic trait. Additionally, selecting the right promotor, the number of transgene copies and the subcellular localization of the resulting protein are important to consider while genetically modifying plants for salt tolerance. Therefore, there is still need for extensive transcriptomic, proteomic and metabolomic research to identify new candidate genes to improve salt tolerance of common crops (Himabindu et al., 2016). To date no GM crop with improved salt tolerance has been released commercially.

\subsection{Plant Salt Stress}

Soil salinity causes a variety of stresses on plants. First sodic soil affects the physical properties of soil, including crusting, reduced infiltration and aeration, which negatively affects nutrient availability, competitive uptake, transport and partitioning (Grattan \& Grieve, 1999; Läuchli \& Grattan, 2011). High saline conditions can inhibit the absorption of nitrate (Klobus et al., 1988; Läuchli \& Grattan, 2011) and can be deleterious for $\mathrm{Ca}^{2+}$ nutrition, as $\mathrm{Ca}^{2+}$ deficiency can affect membrane function and plant growth (Lauchli \& Epstein, 1970; Läuchli \& Grattan, 2011). However, the two main forms of stress salinity causes are osmotic stress, which causes similar symptoms to draught stress, and cytotoxic stress, which occurs after the ionic concentration within cells reaches toxic levels (Munns \& Tester, 2008).

\subsubsection{Osmotic Stress}

The osmotic phase of salt stress is induced after the salt concentration around the roots reaches a threshold of about $40 \mathrm{mM} \mathrm{NaCl}$ for most plants (Isayenkov \& Maathuis, 2019). High solute 
concentrations in the soil decrease the osmotic pressure in the medium and thermodynamically impede the water uptake from roots and lead to water deficit (Pardo, 2010; Läuchli \& Grattan, 2011; Roy et al., 2014; Almeida et al., 2017).

Within minutes the intracellular turgor is reduced, and cell expansion decreased (Munns, 2005; Munns \& Tester, 2008; Almeida et al., 2017). The rate of shoot growth, leaf expansion, and leaf generation is greatly reduced. In cereals salinity stress leads to a decreased number of tillers, while in dicotyledonous plants the main response is reduced leaf size and number of branches (Munns \& Tester, 2008; Isayenkov \& Maathuis, 2019). After the instantaneous decrease in cell expansion and growth rates, a gradual recovery can be observed that reaches a new steady rate after about $30 \mathrm{~min}$ (Munns, 2002). Both the instantaneous changes in growth and the gradual recovery also occur, if plants are exposed to other osmotica, such as $\mathrm{KCl}$, mannitol or polyethyleneglycol (PEG) (Chazen et al., 1995; Munns, 2002). This indicates that this initial response is not salt specific and rather due to osmotic stress.

Root to shoot signalling upon salt stress induces the synthesis of abscisic acid (ABA). This plant hormone reduces stomatal conductance causing decreased $\mathrm{CO}_{2}$ uptake, lower carbon assimilation rate, and biomass production (Munns, 2005; Munns \& Tester, 2008; Chaves et al., 2009; Hasegawa, 2013; Roy et al., 2014; Bose et al., 2017). Treating salt stressed plants with increased $\mathrm{CO}_{2}$ concentrations to overcome stomatal limitation did not result in increased photosynthetic rates. Therefore, there must be a non-stomatal component to the reduction in photosynthetic performance under salt stress (Cheeseman, 2013; Bose et al., 2017). Both, oxidative stress due to the production of reactive oxygen species (ROS) under salinity stress and the excessive accumulation of $\mathrm{Na}^{+}$and $\mathrm{Cl}^{-}$in the cytosol disrupting $\mathrm{K}^{+}$homeostasis, are likely responsible for these non-stomatal limitations of photosynthesis (Munns \& Tester, 2008; Bose et al., 2014a, 2017).

\subsubsection{Cytotoxic Stress}

In contrast to the first phase the second phase is ion specific. Over days or weeks $\mathrm{Na}^{+}$and $\mathrm{Cl}^{-}$ build up to toxic levels in the cytosol slowing down metabolic processes, inhibiting enzyme activity, causing early flowering, premature senescence and cell death (Munns \& Tester, 2008; Roy et al., 2014). $\mathrm{Na}^{+}$is transported to leaves via the transpiration stream and therefore reaches toxic concentrations in older leaves first, resulting in yellowing, tissue necrosis and premature senescence. The rate at which older leaves die is essential for plant survival (Munns, 2002). If older leaves die faster than new leaves are produced, the photosynthetic capacity of the plants 
can no longer supply enough carbohydrates to support the younger leaves resulting in death (Munns \& Tester, 2008).

$\mathrm{Cl}^{-}$is more inhibitory to protein synthesis than $\mathrm{Na}^{+}$, as cytosolic $\mathrm{Cl}^{-}$concentrations over $80 \mathrm{mM}$ inhibited the translation of mRNA, while $\mathrm{Na}^{+}$concentration of up to $100 \mathrm{mM}$ were tolerable (Flowers \& Dalmond, 1992; Flowers et al., 2015). However, for most plant species $\mathrm{Na}^{+}$appears to reach cytotoxic levels earlier than $\mathrm{Cl}^{-}$(Tester \& Davenport, 2003).

An increased $\mathrm{Na}^{+}$concentration, above $100 \mathrm{mM}$, in the cytoplasm negatively affects enzyme activity, which in turn negatively affects metabolic processes, as well as photosynthetic efficiency (Blumwald, 2000; Deinlein et al., 2014). The underlying cause for the ion toxicity of $\mathrm{Na}^{+}$is not only the increased $\mathrm{Na}^{+}$content, but also the disrupted $\mathrm{Na}^{+} / \mathrm{K}^{+}$ratio in the cytosol. $\mathrm{K}^{+}$is an important macronutrient, as it is involved in enzyme activation, turgor generation, osmotic adjustment, cytoplasmic $\mathrm{pH}$ homeostasis, and regulation of membrane potential (Barragan et al., 2012; Almeida et al., 2017). $\mathrm{Na}^{+}$and $\mathrm{K}^{+}$are so similar in size that $\mathrm{Na}^{+}$can act as a competitive inhibitor of $\mathrm{K}^{+}$and block $\mathrm{K}^{+}$binding sites of enzymes. The effect of this competitive inhibition increases with increasing $\mathrm{Na}^{+} / \mathrm{K}^{+}$ratio, because more $\mathrm{Na}^{+}$ions are present and are more likely to bind to an open binding site and therefore impair enzymatic activity (Munns et al., 2006; Lebaudy et al., 2007; Wu et al., 2015). Over 50 different cytoplasmic proteins, including pyruvate kinase, phosphofructokinase, membrane bound ATPases, and vacuolar pyrophosphatase, require $\mathrm{K}^{+}$for activation. Additionally, $\mathrm{K}^{+}$is involved in the binding of tRNA to ribosomes, stomatal regulation, and maintaining a $\mathrm{pH}$ gradient over the thylakoid membrane for ATP synthesis. Therefore, a disrupted $\mathrm{K}^{+}$homeostasis causes sever impairment of metabolism and protein biosynthesis (Marschner, 2012).

Moreover, high $\mathrm{Na}^{+}$concentrations can disrupt the transport of other ions, most notably $\mathrm{K}^{+}$, through plant cell membranes. In addition to competing with $\mathrm{K}^{+}$for uptake sites at the plasma membrane, enhanced $\mathrm{Na}^{+}$uptake leads to depolarization of the plasma membrane, which activates depolarization-activated outward-rectifying $\mathrm{K}^{+}$channels, leading to $\mathrm{K}^{+}$efflux (Shabala et al., 2006a). The resulting disruption of the $\mathrm{K}^{+} / \mathrm{Na}^{+}$ratio in the cytosol has several effects, since $\mathrm{K}^{+}$plays an important role in enzyme activation (Shabala \& Cuin, 2008). Additionally, low cytosolic $\mathrm{K}^{+}$content could activate enzymes involved in protein catabolism, which induce apoptosis. Therefore, it is crucial for plants to retain $\mathrm{K}^{+}$in the cytosol under high soil salinity. In contrast to glycophytes, the highly salt tolerant halophytes developed strategies to maintain a high total solute concentration and a low $\mathrm{Na}^{+} / \mathrm{K}^{+}$ratio under salinity stress 
(Schachtman, 2000). A better understanding of these salt tolerance mechanisms might be crucial in finding a way to increase salinity tolerance of crop plants.

\subsection{Salt Tolerance Mechanisms in Plants}

Halophytes are often found in coastal salt marshes, tidal zones, and saline deserts. As an adaption to those conditions they have developed various strategies that facilitate their survival in highly saline environments (Flowers \& Colmer, 2015). Halophytes can tolerate high intracellular $\mathrm{Na}^{+}$concentrations. However, tolerance varies greatly between species. While Suaeda maritima can accumulate $500-600 \mathrm{mM} \mathrm{Na}^{+}$in leaf tissue under optimal growth conditions, Tecticornia spp. can accumulate up to $1.5 \mathrm{M} \mathrm{Na}^{+}$and still continue growing (Flowers \& Yeo, 1986; English \& Colmer, 2013; Flowers et al., 2015). Some halophytes have developed salt glands to secrete excess salt, or bladder cells, which accumulate salt and then abscise (Dassanayake \& Larkin, 2017).

\subsubsection{Salt glands and bladders}

Halophytes that grow on dry saline soils, salt marshes and mangroves have developed specialized epidermal structures, called salt glands to store or secret salt (Flowers \& Yeo, 1986; Flowers \& Colmer, 2015; Dassanayake \& Larkin, 2017). There are four main types of salt glands (Figure 1.3.1). Firstly, salt bladders are large cells with or without one or two stalk cells. Salt is deposited into the vacuole of a large bladder cell, that might eventually rupture and release the excess salt or the bladder cell filled with salt is abscised.(Dassanayake \& Larkin, 2017). This type of salt gland can be found in Amaranthaceae and Aizoaceae (Figure 1.3.1 a). Studies on Mesembryanthemum crystallinum showed that mutant lines lacking salt bladders were more sensitive to salt stress resulting in severely limited growth compared to wild type plants. These results emphasise the important role of bladder cells in salt tolerance (Agarie et al., 2007; Dassanayake \& Larkin, 2017). The second type of salt glands found in eudicots are multicellular salt glands with secretory cells and distal collecting cells. The collecting cells create a salt efflux gradient and collect salt from the surrounding mesophyll cells. The salt is then actively transported onto the secretory cells, which are surrounded by a thick cuticle. The cuticle is either pierced by pores, that deposit the salt outside, or creates a cuticular chamber (Figure 1.3.1 b). These types of salt glands are found in the Tamaricaceae, Frankaniaceae, and Plumbaginaceae and often occur sunken into the epidermis (Figure 1.3.1 b) (Dassanayake \& Larkin, 2017). 
The other two types of salt glands are found in monocotyledons. In contrast to dicotyledons, monocotyledons have salt glands with a simpler structure consisting of only one or two cells without a cuticular boundary surrounding the secretory cells. Additionally, the basal cells in monocotyledons are not vacuolated. The third type of salt glands consists of a basal cell and a cap cell (Figure 1.3.1 b). Both are rich in mitochondria, plastids and vesicles. These salt glands are often found in epidermal depression within the folds of the leaf laminar structure of Chloridoideae (Céccoli et al., 2015; Dassanayake \& Larkin, 2017). The fourth type of salt glands are unicellular hairs that seem to lack organelles. Contrary to bladder cells in eudicot glands these unicellular hairs seem to be completely filled with vacuoles (Figure 1.3.1 b). These type of salt glands can be found, for example on the wild rice species Porteresia coarctata (Flowers et al., 1990; Dassanayake \& Larkin, 2017). 

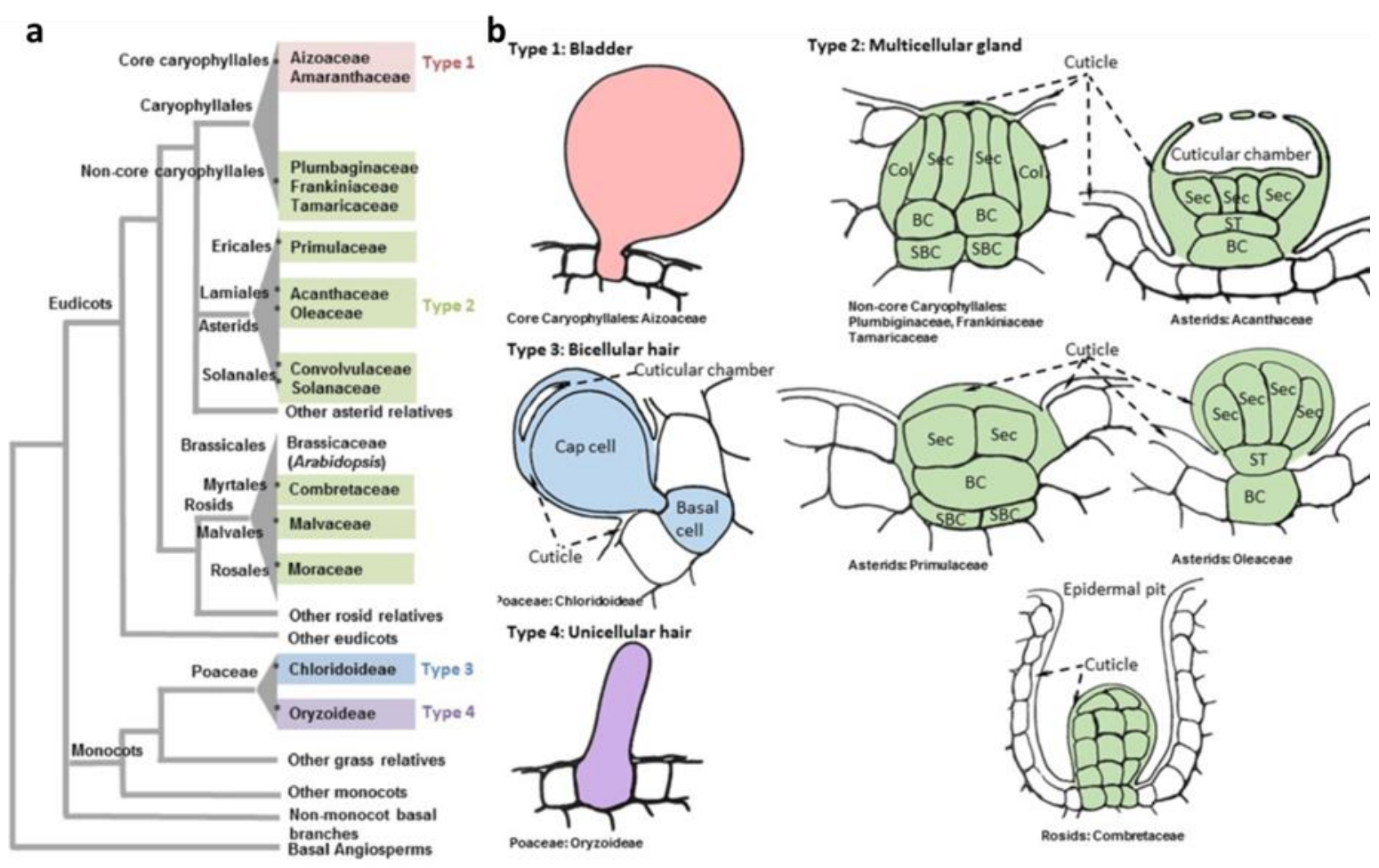

Figure 1.3.1 Phylogenetic distribution of angiosperm clades reported to have salt glands (a). Families associated with the four types of salt glands discussed in this review are grouped in the same colours used to distinguish salt gland types (b). Representative cellular organization of distinct salt gland structures found in angiosperms. Drawings are based on consensus representations of specie salt gland structures. The cells that constitute the salt gland are coloured while the adjacent cells are kept blank. The continuous cuticle around the salt gland is also coloured and changed to blank when the cuticle overlays the surrounding epidermis. The dynamic intracellular structures, such as vacuoles, vesicles, and laminated membranes are not depicted in the representative figures. Collecting cell $(\mathrm{Col})$, secretory cell $(\mathrm{Sec})$, basal cell (BC), sub-basal cell (SBC), stalk cell (ST). Adapted from Dassanayake \& Larkin (2017).

More than half of the halophytes have salt glands to sequester excess salts (Flowers \& Colmer, 2008; Shabala et al., 2014). Salt bladders, for example, can sequester 1000 times more $\mathrm{Na}^{+}$than vacuoles (Himabindu et al., 2016). However, there is not much information on the salt loading mechanism of salt bladders. Analysing the epidermal bladder cell transcriptomes of $M$. crystallinum showed that seven percent of the epidermal bladder cell reference transcriptome exhibited significant different expression patterns between salt treated and control plants. Additionally, changes in ion transport, energy generation, osmolyte production and stress signalling in response to salt stress were observed (Oh et al., 2015a). Introducing salt bladder 
cells to crops to remove excess salt might be a new way to increase the salt tolerance of normally salt-sensitive crop species (Himabindu et al., 2016).

\subsubsection{Osmotic Adjustment}

To combat the harmful effects of salt stress plants must keep the intracellular osmotic potential low and maintain water uptake, cell turgor, metabolic activity and growth. Consequently, plants must maintain a greater total solute concentration than the surrounding medium (Hasegawa, 2013; Deinlein et al., 2014; Flowers et al., 2015; Liang et al., 2018). To archive this plants can either synthesise organic osmolytes that function as compatible solutes, or accumulate inorganic ions (Flowers, 2004; Shabala \& Shabala, 2011). Plants synthesise proline, glycine, polyamines and sugar alcohols to facilitate osmotic adjustment (Deinlein et al., 2014). De novo synthesis organic osmolytes is associated with energetic costs, approximately an order of magnitude higher than the accumulation of $\mathrm{Na}^{+}$, but high $\mathrm{Na}^{+}$concentrations in the cytosol can disrupt metabolism (Raven, 1985; Munns, 2002). Therefore, many halophytes accumulate $\mathrm{Na}^{+}$ in vacuoles to maintain turgor and use compatible solutes only in the cytosol for osmotic adjustment (Glenn et al., 1999; Flowers \& Colmer, 2008; Adolf et al., 2013).

\subsubsection{Exclusion}

$\mathrm{Na}^{+}$and $\mathrm{Cl}^{-}$cannot be completely excluded from shoot and leaf cells, because plants accumulate both for osmotic adjustment. Thus, ion uptake must be highly regulated to avoid cytotoxic effects (Greenway \& Munns, 1980; Hasegawa, 2013). Plants have developed several mechanisms to reduce the $\mathrm{Na}^{+}$concentration in the transpiration stream and prevent $\mathrm{Na}^{+}$ accumulation in metabolically active cells (Adolf et al., 2013; Hasegawa, 2013; Flowers \& Colmer, 2015). Firstly, ion uptake by root cells is highly regulated and selective. Secondly, restricting xylem loading and preferential loading of $\mathrm{K}^{+}$over $\mathrm{Na}^{+}$by stellar cells. Lastly, xylem unloading, which means removing $\mathrm{Na}^{+}$from the xylem in the upper root parts and retaining $\mathrm{Na}^{+}$ in the root (Figure 1.3.2) (Munns, 2002). 


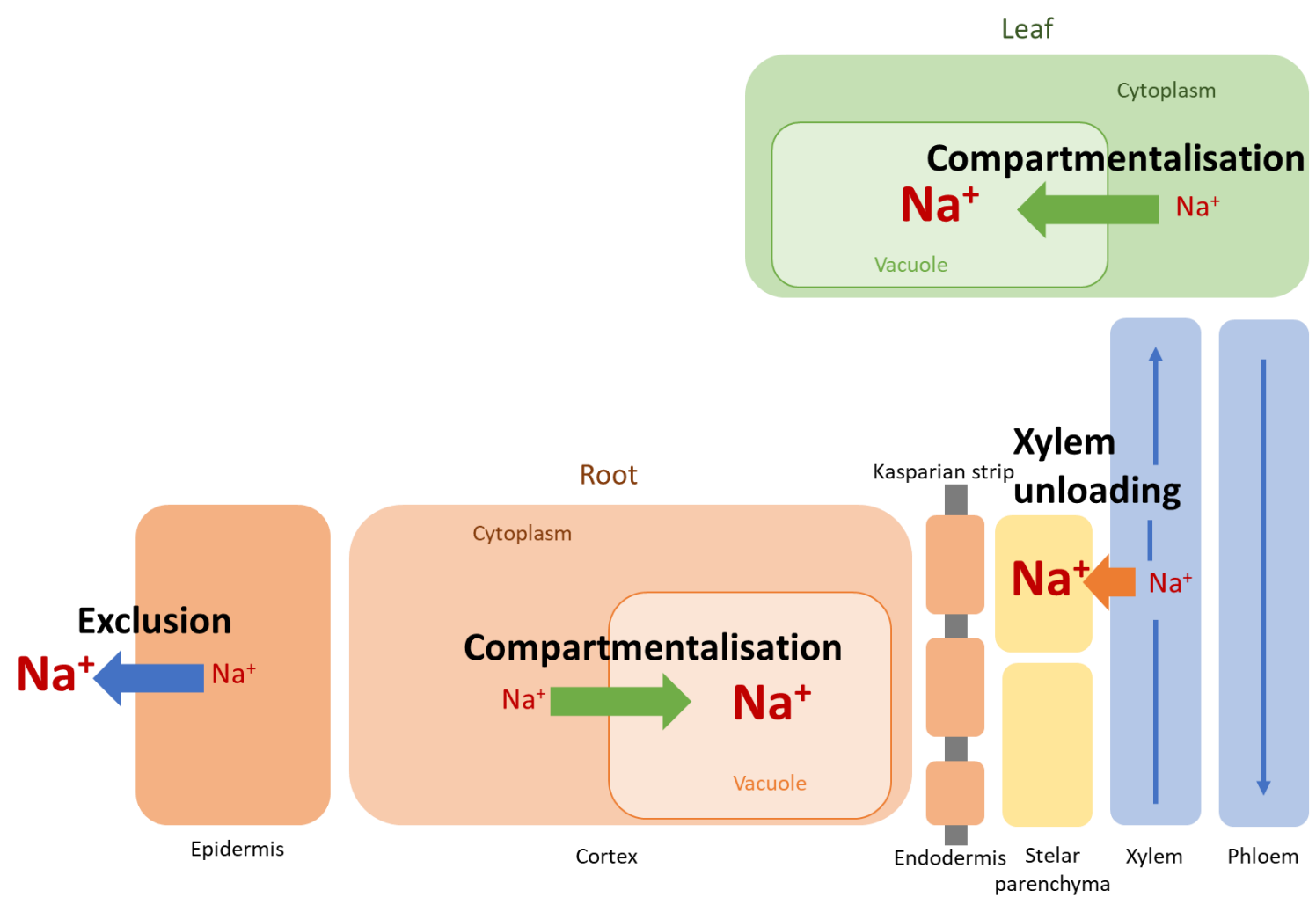

Figure 1.3.2 Overview of salt tolerance mechanisms. Storing $\mathrm{Na}^{+}$in the vacuole to avoid cytotoxic effects is called compartmentalisation. $\mathrm{Na}^{+}$is excluded from the xylem via unloading it back in to the stelar parenchyma. Most of the $\mathrm{Na}^{+}$that enters the roots is transported back out in a process called exclusion.

At high soil salinity $\mathrm{Na}^{+}$enters the roots via passive transport mainly mediated by non-selective cation channels (NSCCs) (Blumwald, 2000). Most of the $\mathrm{Na}^{+}$ions that enter the root are actively transported out again via an $\mathrm{Na}^{+} / \mathrm{H}^{+}$antiporter, called salt overly sensitive 1 (SOS1) (Maathuis \& Amtmann, 1999; Tester \& Davenport, 2003). The remaining $\mathrm{Na}^{+}$could be either transported to the xylem stream via symplastic flow across plasma membranes or apoplastic flow without crossing the plasma membrane (Figure 1.3.3) (Almeida et al., 2017). $\mathrm{Na}^{+}$exclusion is achieved by the Kasparian strip located at the root endodermis, a hydrophobic barrier which restricts apoplastic $\mathrm{Na}^{+}$movement into the stele (Figure 1.3.3). Therefore, $\mathrm{Na}^{+}$can only enter the xylem vessels via symplastic transport, which is strongly regulated (Flowers et al., 2015). $\mathrm{Na}^{+}$can also accumulate in the pericycle and xylem parenchyma cells, instead of being transported into the xylem vessels (Läuchli et al., 2008; Munns \& Tester, 2008; Plett \& Møller, 2010). Within these cells $\mathrm{Na}^{+}$mostly accumulates in the vacuole and $\mathrm{Na}^{+} / \mathrm{H}^{+}$antiporters (NHX) at the tonoplast are presumed to be responsible for this process (Apse \& Blumwald, 2007; Plett \& Møller, 2010; Hasegawa, 2013). Additionally, $\mathrm{Na}^{+}$that made its way into the xylem vessels can be reabsorbed 
from the xylem sap into the root cells to prevent $\mathrm{Na}^{+}$accumulation in the above ground tissue (Figure 1.3.2). In Arabidopsis thaliana, for example, the retrieval of $\mathrm{Na}^{+}$from the xylem is facilitated by the HKT 1 family of high-affinity $\mathrm{K}^{+}$transporters (HKTs) (Munns \& Tester, 2008; Rus et al., 2010; Hasegawa, 2013).

The $\mathrm{Na}^{+}$that remains in the xylem vessels is transported from root to shoot, a process that is driven by vapor pressure gradient (Flowers \& Yeo, 1986; Hasegawa, 2013). Therefore, reducing transpiration by decreasing stomatal aperture size or density also reduces the $\mathrm{Na}^{+}$ transfer rate and reduces water deficit. However, reduced transpiration also decreases carbon assimilation and nutrient uptake (Flowers, 2004; Flowers et al., 2010; Hasegawa, 2013).

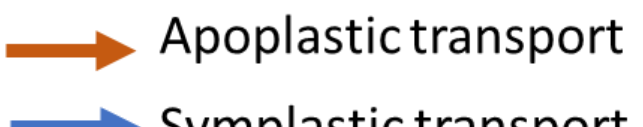

$\rightarrow$ Symplastic transport

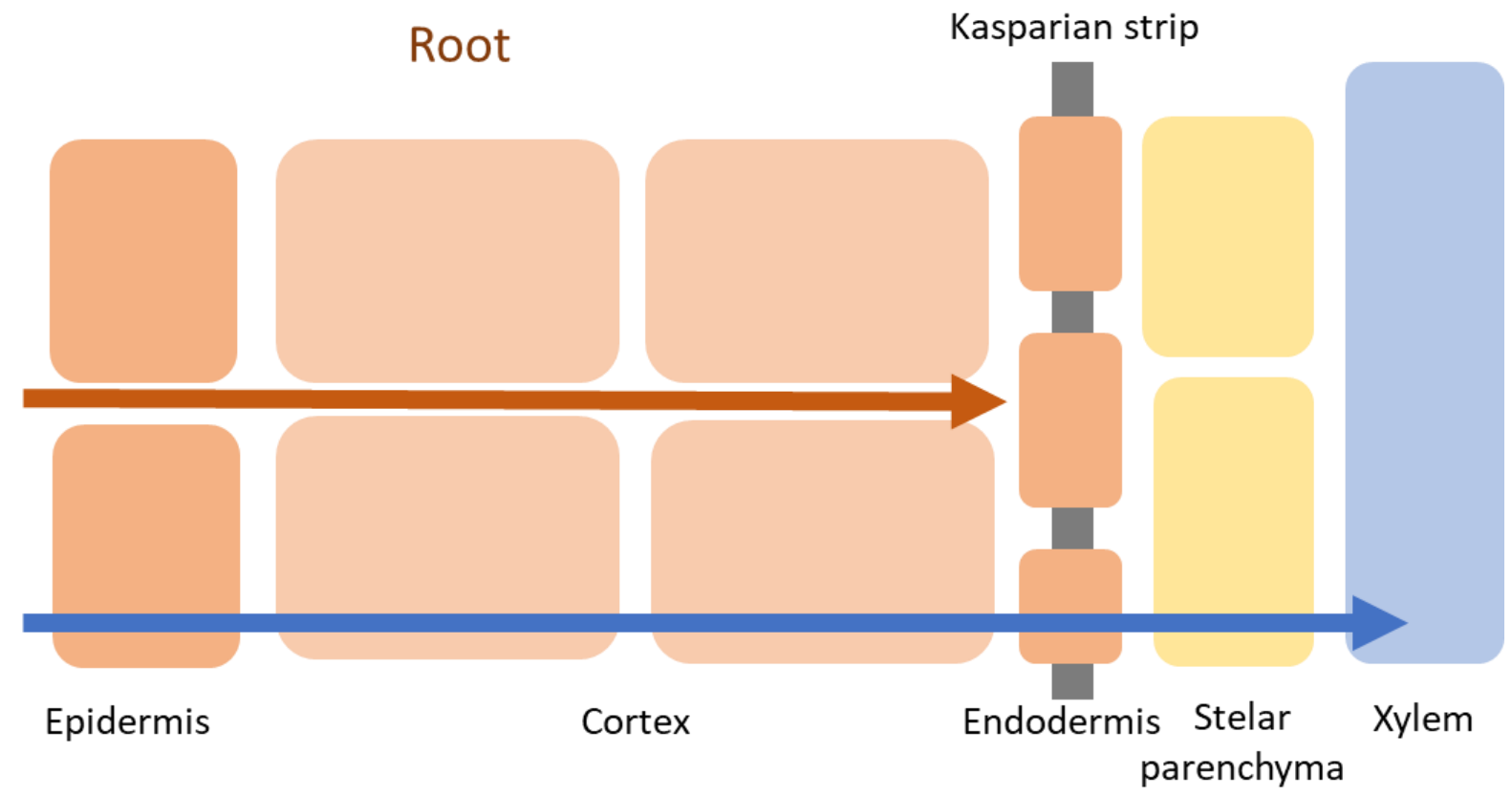

Figure 1.3.3 Schematic representation the two possible pathways for $\mathrm{Na}^{+}$and $\mathrm{Cl}^{-}$uptake at the roots. The blue arrow represents symplastic flow across plasmodesmata or plasma membranes, which is highly regulated. The red arrow represents apoplastic flow through the root without crossing plasma membranes. Apoplastic $\mathrm{Na}^{+}$and $\mathrm{Cl}^{-}$movement is restricted by the Kasparian strip. Adapted from Almeida (2017) and Isayenkov \&Maathuis (2019). 


\subsubsection{Compartmentalisation}

To avoid the cytotoxic effect of $\mathrm{Na}^{+}$and $\mathrm{Cl}^{-}$the cytoplasmic concentration must be low. This is achieved by compartmentalisation of $\mathrm{Na}^{+}$and $\mathrm{Cl}^{-}$into the vacuole or endosome, as well as the active transport of $\mathrm{Na}^{+}$from the cytosol back into the soil solution (Figure 1.3.2) (Munns \& Tester, 2008). Additionally, compartmentalisation of $\mathrm{Na}^{+}$and $\mathrm{Cl}^{-}$allows the plant to maintain water up take under salt stress.(Blumwald, 2000; Munns, 2002) For example, cells from tobacco grown in $430 \mathrm{mM} \mathrm{NaCl}$ had vacuolar concentrations of $\mathrm{Na}^{+}$and $\mathrm{Cl}^{-}$of about $780 \mathrm{mM}$ and 625 $\mathrm{mM}$, respectively, while both concentrations in the cytosol where below $100 \mathrm{mM}$ (Binzel et al., 1988; Munns, 2002).

The $\mathrm{Na}^{+} / \mathrm{H}^{+}$antiporters of the NHX and SOS1 types transport $\mathrm{Na}^{+}$out of the cytoplasm into the vacuole and apoplast, respectively. Both are active transport processes, since $\mathrm{Na}^{+}$is transported against the electrochemical gradient. Thus, $\mathrm{H}^{+}$-ATPase at the plasma membrane, as well as vacuolar-type inorganic pyrophosphatases (V-PPase) and V-ATPase

ATPase at the tonoplast are required to establish a proton gradient to fuel the compartmentalisation of $\mathrm{Na}^{+}$(Hasegawa, 2013). These also contribute to membrane potential which plays an important role in controlling ion channel transport activity (Flowers \& Colmer, 2008; Shabala, 2013; Flowers et al., 2015).

\subsection{5 $\mathrm{K}^{+}$retention}

Under salt stress conditions a $\mathrm{K}^{+}$leak from cytosol of root and leaf tissues occurs. The depleted cytosolic $\mathrm{K}^{+}$pool can trigger programmed cell death (Shabala, 2000, 2009; Shabala et al., 2005, 2006a; Shabala \& Cuin, 2008; Demidchik et al., 2010). In order to maintain a low cytosolic $\mathrm{Na}^{+} / \mathrm{K}^{+}$ration in leaves under salt stress, $\mathrm{K}^{+}$transport to the shoot and leaves is necessary to balance $\mathrm{Na}^{+}$accumulation (Cuin et al., 2009; Adolf et al., 2013). Loading $\mathrm{K}^{+}$into the xylem in order to be transported to the leaves is a passive process mediated by $\mathrm{K}^{+}$outwardly-rectifying channels of the NORC and SKOR types (Shabala et al., 2010; Adolf et al., 2013).

\subsubsection{Transporters involved in Salt Tolerance}

Most studies on salt stress tolerance in plants focuses on $\mathrm{Na}^{+}$exclusion from roots and xylem, long distance transport from root to shoot, and $\mathrm{Na}^{+}$compartmentalisation into vacuoles (Munns, 2005; Munns \& Tester, 2008; Almeida et al., 2017). All these processes are mediated by membrane transporters, thus understanding salt transport mechanisms and identifying ion transporters involved in salt tolerance are key in improving salt tolerance in crops (Brini \& Masmoudi, 2012; Almeida et al., 2017). 


\section{$H^{+}$-Pumps}

Contrary, to animal cells, higher plants do not have $\mathrm{Na}^{+} / \mathrm{K}^{+}$-ATPase to maintain a proton gradient across membranes. Plants have three primary proton transport proteins: (i) plasma membrane $\mathrm{H}^{+}$-ATPase and (ii) vacuolar $\mathrm{H}^{+}$-ATPase, that couple the proton transport with ATP hydrolysis, and (iii) $\mathrm{H}^{+}$-PPase that couples the proton transport with pyrophosphate hydrolysis (Figure 1.3.4) (Gaxiola et al., 2007; Fuglsang et al., 2011; Almeida et al., 2017). These $\mathrm{H}^{+}-$ Pumps create the proton-motive force to drive ion transport across plasma membrane and tonoplast and play an essential role in $\mathrm{Na}^{+}, \mathrm{Cl}^{-}$and $\mathrm{K}^{+}$transport under salt stress (Almeida et al., 2017).

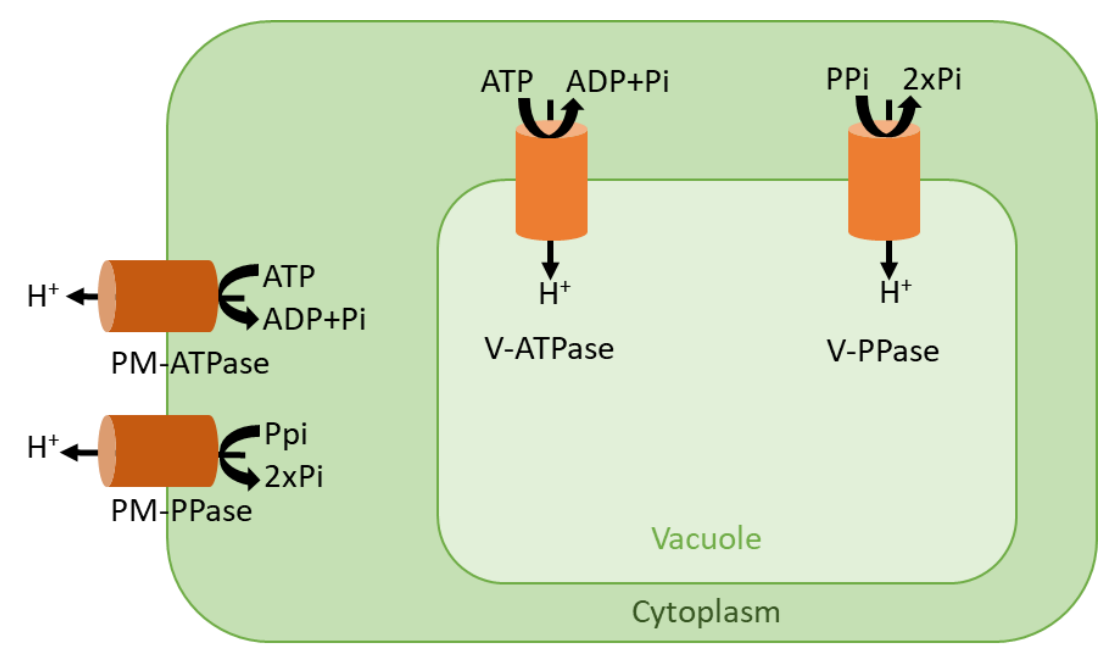

Figure 1.3.4 Overview of the cellular location of the two most common $\mathrm{H}^{+}$-pumps, ATPases and PPases, on either the plasma membrane or the tonoplast.

\section{Plasma Membrane $H^{+}$- ATPase}

The plasma membrane $\mathrm{H}^{+}$-ATPase consists of a single subunit protein, that contains ten transmembrane helices and a large cytoplasmic domain (Fuglsang et al., 2011). The cytoplasmic C-terminus consists of a threonine residue that can be phosphorylated or dephosphorylated to regulate the $\mathrm{H}^{+}$-ATPase activity. If the phosphorylated threonine residue binds a 14-3-3 protein the $\mathrm{H}^{+}$-ATPase is activated (Fuglsang et al., 2011; Almeida et al., 2017). The active $\mathrm{H}^{+}$-ATPase utilizes the energy from ATP hydrolysis to pump $\mathrm{H}^{+}$out of the cell and generate an electrochemical $\mathrm{H}^{+}$gradient. This $\mathrm{H}^{+}$-ATPase is largely responsible to generate a negative plasma membrane potential of about -120 to $-150 \mathrm{mV}$ (Blumwald, 2000; Hasegawa, 2013). $\mathrm{H}^{+}$-ATPases play a critical role in salt stress adaptation by combating $\mathrm{Na}^{+}$induced membrane depolarization reducing $\mathrm{Na}^{+}$and $\mathrm{K}^{+}$efflux via $\mathrm{K}^{+}$outwardly rectifying channels (KORCs) and NSCCs. This process helps to maintain or restore high cytoplasmic $\mathrm{K}^{+} / \mathrm{Na}^{+}$ratios 
(Sun et al., 2009b; Almeida et al., 2017). Additionally, a high $\mathrm{H}^{+}$-ATPase activity also energises the active transport of $\mathrm{Na}^{+}$back out of root cells, which is facilitated by the SOS $1 \mathrm{Na}^{+} / \mathrm{H}^{+}$antiporter (Gaxiola et al., 2007). In general, an increased $\mathrm{H}^{+}$-ATPase activity has been strongly associated with salt stress tolerance. Moreover, a higher activation of $\mathrm{H}^{+}$-ATPase upon salt stress in halophytes than glycophytes might correlate with salt stress tolerance (Almeida et al., 2017).

\section{Vacuolar $H^{+}$-ATPase}

Vacuolar H+-ATPase is a multi-subunit enzyme formed by two main subcomplexes, V1 and V0. The V1 subcomplex consists of three main structures: a globular hexameric head, a central rotation stalk and an outer stalk. The hexameric head consists of three alternating copies of subunits A and B forming a ring This structure mediated the hydrolysis of ATP at three reaction sites associated with subunit A. The central rotational stalk is made of a single copy of each subunit D and F. Finally, the outer stalk is composed of subunits C, E, G, and H. Both the central and the outer stalk connect the V1 subcomplex with the V0 subcomplex. The V0 complex is inserted to the membrane and consists of six c subunits forming a ring structure, as well as one single copy of subunits a, $\mathrm{d}$ and e. The V0 subcomplex is facilitating the $\mathrm{H}^{+}$transport across the tonoplast into the vacuole (Beyenbach \& Wieczorek, 2006; Gaxiola et al., 2007; Hanitzsch et al., 2009; Almeida et al., 2017). The vacuolar $\mathrm{H}^{+}$-ATPase acidifies the vacuole and generates a proton gradient across the tonoplast. Thus, vacuolar $\mathrm{H}^{+}$-ATPases play an important role in the storage of toxic ions and $\mathrm{Ca}^{2+}$ cytoplasmic homeostasis (Ratajczak, 2000; Almeida et al., 2017). Vacuolar H+-ATPase generates the driving force for $\mathrm{Na}^{+}$ compartmentalisation into the vacuole, thus playing an essential role in plant salt tolerance. This process is facilitated by $\mathrm{Na}^{+} / \mathrm{H}^{+}$-antiporter (NHX) (Almeida et al., 2017). An increase in vacuolar H+-ATPase activity upon salt stress has been reported in many plant species (Matsumoto \& Chung, 1988; Silva et al., 2009; Almeida et al., 2017)

\section{Plasma Membrane and Vacuolar $\mathrm{H}^{+}$-PPase}

$\mathrm{H}^{+}$-PPases are highly hydrophobic single subunit proteins. There are two phylogenetically distinct types of $\mathrm{H}^{+}$-PPases. Type $\mathrm{I}$ depends on $\mathrm{K}^{+}$for activation and is only mildly inhibited by $\mathrm{Ca}^{2+}$, while type II does not depend on $\mathrm{K}^{+}$, and is highly sensitive to inhibition by $\mathrm{Ca}^{2+} . \mathrm{H}^{+}-$ PPases use the energy of hydrolysing pyrophosphate to generate a proton gradient across the tonoplast, Golgi and plasma membrane. The type $\mathrm{I} \mathrm{H}^{+}$-PPases are mainly involved in acidifying the vacuole and generating a proton gradient across the tonoplast. Regulation mainly happens 
on a transcriptional level in response to different environmental conditions. One of those is salinity, which was reported to cause an increase in $\mathrm{H}^{+}$-PPase activity (Gaxiola et al., 2007; Almeida et al., 2017).

\section{SOS pathway}

Up to $77-99 \%$ of all $\mathrm{Na}^{+}$transported into the root cells is transported back out into the apoplast again (Tester \& Davenport, 2003; Munns, 2005; Almeida et al., 2017). This active transport mechanism is facilitated by an $\mathrm{Na}^{+} / \mathrm{H}^{+}$-antiporter, called Salt Overly Sensitive (SOS1). This transporter was discovered in 1996 when researchers found three salt overly sensitive Arabidopsis mutants. These mutants were lacking three different proteins, called SOS1, SOS2, and SOS3, that are all involved in one signalling pathway that plays a crucial role in salt tolerance (Figure 1.3.5) (Wu et al., 1996; Liu \& Zhu, 1997). SOS2 is a protein kinase of the SnRK (sucrose non-fermenting-related serine/threonine kinase) family and SOS3 is a calcineurin B and neuronal $\mathrm{Ca}^{2+}$ sensor-like protein, together with SOS1 they are the main components of the salt overly sensitive pathway. High external $\mathrm{Na}^{+}$concentrations cause an increase in cytoplasmic $\mathrm{Ca}^{2+}$, which can be detected by SOS3, which has an EF-hand $\mathrm{Ca}^{2+}$ binding site. SOS3 activation requires $\mathrm{Ca}^{2+}$ binding and $\mathrm{N}$-myristoylation. The activated SOS3 then binds to SOS2 and interacts with its autoinhibitory domain to activate the protein kinase activity. This leads to the relocalisation of the SOS2/SOS3 complex to the plasma membrane, where it associates with SOS1 and phosphorylates the SOS1 C-terminal autoinhibitory domain. Thus, SOS1 is activated and starts to transport $\mathrm{Na}^{+}$out of the cell (Pardo, 2010; Brini \& Masmoudi, 2012; Hasegawa, 2013; Ji et al., 2013; Almeida et al., 2017). While SOS3 functions primarily in the roots, in the shoots there is an SOS3-like calcium binding protein (SCABP8/CBL10) that interacts with SOS2 and regulates SOS1 activity in response to stress (Hasegawa, 2013; Almeida et al., 2017). Studies in Arabidopsis have shown that the SOS1 promotor is active in virtually all tissues, however its activity was higher in root epidermal cells and in root parenchyma cells lining the vascular bundle. This highlights the important role SOS1 plays in facilitating $\mathrm{Na}^{+}$efflux from the root back into the surrounding medium, thus delaying $\mathrm{Na}^{+}$accumulation in the cytoplasm. Finally, SOS1 plays a role in controlling long distance $\mathrm{Na}^{+}$transport from shoot to root by loading and unloading $\mathrm{Na}^{+}$into the xylem (Shi \& Zhu, 2002; Zhu, 2003; Conde et al., 2011; Kronzucker \& Britto, 2011; Almeida et al., 2017). 


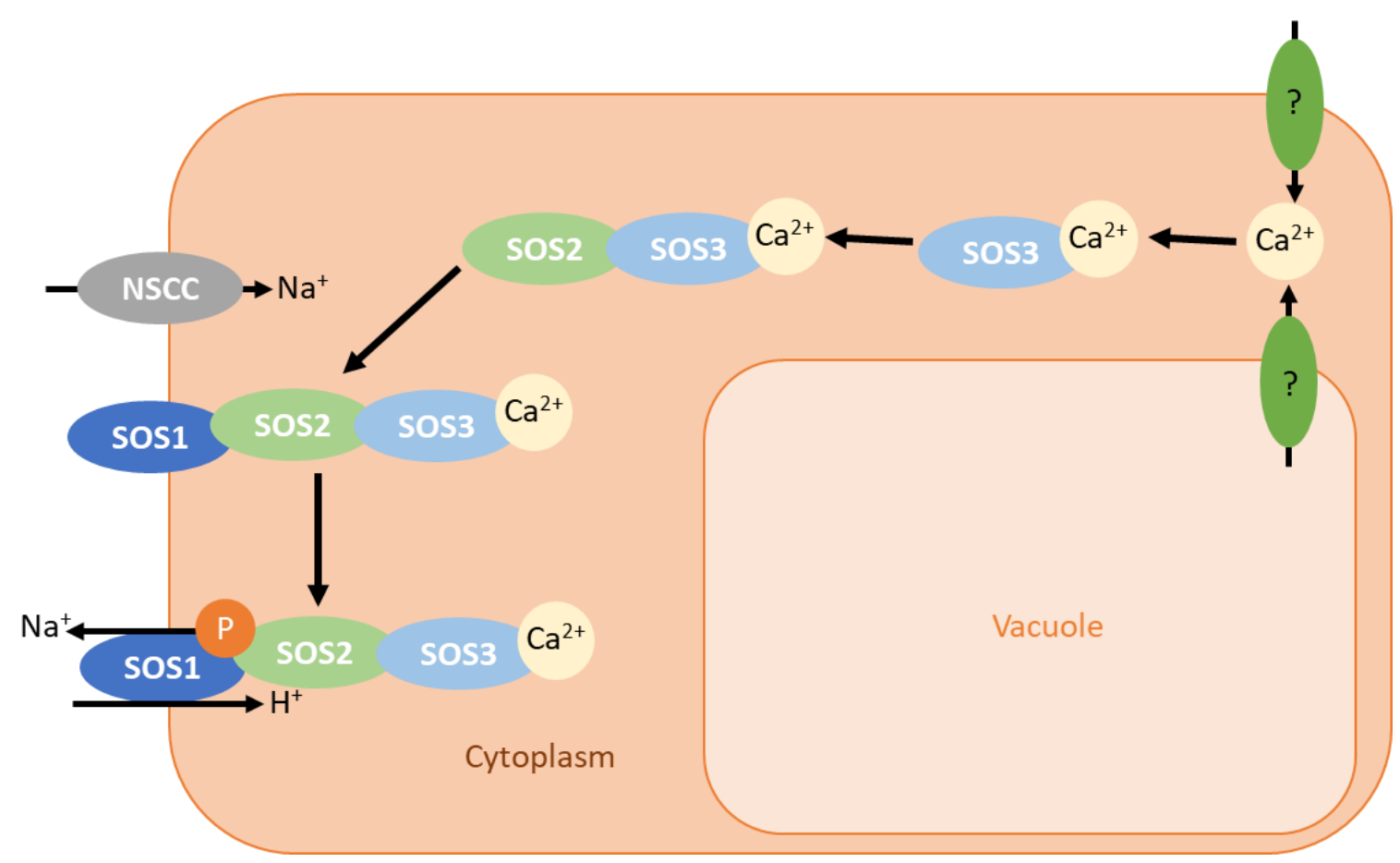

Figure 1.3.5 Schematic overview of the SOS pathway. High extracellular $\mathrm{Na}+$ concentrations lead to an intracellular increase of $\mathrm{Ca}^{2+}$. $\mathrm{Ca}^{2+}$ then binds to SOS3 and the activated SOS 3 then binds to SOS2. The SOS2/SOS3 complex then moves to the plasma membrane and phosphorylates SOS1. The activated SOS1 functions as a $\mathrm{Na}^{+} / \mathrm{H}^{+}$-antiporter and transports $\mathrm{Na}^{+}$out of the cell. Adapted from (Hasegawa, 2013).

\section{$N S C C$}

The membrane potential across the plasma membrane of root cells is very low, thus it promotes the passive transport of $\mathrm{Na}^{+}$into root cells, if the $\mathrm{Na}^{+}$concentration in the soil is high (Maathuis et al., 2014). Passive $\mathrm{Na}^{+}$uptake is mostly facilitated by non-selective cation channels (NSCCs) (Figure 1.3.6). High external $\mathrm{Ca}^{2+}$ concentrations can inhibit $\mathrm{Na}^{+}$uptake via NSCCs. However, under low external $\mathrm{Ca}^{2+}$ concentrations $\mathrm{Na}^{+}$uptake via NSCCs is the main component of $\mathrm{Na}^{+}$ uptake at the roots (Hasegawa, 2013)

$H K T$

High affinity potassium transporters (HKTs) are involved in xylem unloading (Figure 1.3.6). There are two distinct HKT classes with different transport characteristics (Munns \& Tester, 2008; Deinlein et al., 2014; Roy et al., 2014; Almeida et al., 2017). The amino acid sequence of the first pore domain is the main distinguishing feature of those classes. While most members of the class I transporter (HKT1) have a serine at the first position of that domain, forming a SG-G-G motif, most members of the class II transporter (HKT2) have a glycine instead of the 
serine, forming a G-G-G-G motive instead (Mäser et al., 2002; Almeida et al., 2017). Whether $\mathrm{G}$ or $\mathrm{S}$ is present at the first position of the motif, is critical for cation specificity of the HKT. If there is an $\mathrm{S}$ in the motif, as in HKT1, the transporter prefers $\mathrm{Na}^{+}$over other cations. In contrast, if there is a $\mathrm{G}$ at the first position of the motif, like in HKT2, there is no preference of either $\mathrm{Na}^{+}$or $\mathrm{K}^{+}$and the transport depends on the external cation concentrations (Blumwald, 2000; Platten et al., 2006; Kronzucker \& Britto, 2011; Hasegawa, 2013; Himabindu et al., 2016; Almeida et al., 2017).

\section{HKT1}

HKT1 is a $\mathrm{Na}^{+}$selective transporter that is represented in most of the higher plants (Himabindu et al., 2016; Almeida et al., 2017). The main function of HKT1 is to unload $\mathrm{Na}^{+}$from the xylem (Figure 1.3.6), thus removing $\mathrm{Na}^{+}$from the transpiration stream, avoiding the accumulation of $\mathrm{Na}^{+}$to cytotoxic levels in the photosynthetic tissues and increasing salt tolerance (Deinlein et al., 2014; Almeida et al., 2017). Another function of HKT1 was discovered in Arabidopsis with its version of the transporter, AtHKT1;1. AtHKT1;1 transports $\mathrm{Na}^{+}$into phloem cells and from there $\mathrm{Na}^{+}$is transported back to the roots. This represents another way to avoid $\mathrm{Na}^{+}$ overaccumulation in the shoot (Berthomieu et al., 2003; Almeida et al., 2017). Additionally, HKT1 transporters have also been identified in rice (OsHKT1;4 and OsHKT1;5) and wheat (Nax1 and Nax2) that have similar functions to AtHKT1;1 (Ren et al., 2005; James et al., 2006a; Almeida et al., 2013, 2017). However, in modern bread wheat cultivars Nax1 and Nax2 do not exist, but were found in the breeding line 149, that showed enhanced salt tolerance due to decreased $\mathrm{Na}^{+}$accumulation in leaves. Introducing Nax1 and Nax2 from breeding line 149 into a modern wheat cultivar reduced $\mathrm{Na}^{+}$accumulation in leaves, thus enhancing salt tolerance in the modern cultivar (James et al., 2006a; Munns et al., 2012; Himabindu et al., 2016).

\section{HKT2}

HKT2 is an unselective cation transporter, that can transport both $\mathrm{Na}^{+}$and $\mathrm{K}^{+}$and is only found in monocotyledons (Platten et al., 2006; Almeida et al., 2017). The main role of HKT2 is in $\mathrm{Na}^{+}$uptake form the external medium with low $\mathrm{K}^{+}$concentrations (Almeida et al., 2013). Homologues of HKT2 have been identified in rice (OsHKT2;1 and OsHKT2;2), wheat (TaHKT2;1) and barley (HvHKT2;1). All of these homologues have been reported to play a role in $\mathrm{Na}^{+}$uptake under $\mathrm{K}^{+}$limiting conditions. However, TaHKT2;1 and HvHKT2;1 mediate both $\mathrm{Na}^{+}$and $\mathrm{K}^{+}$transport (Haro et al., 2005; Mian et al., 2011; Almeida et al., 2013, 2017). 
Overexpressing HvHKT2;1 in barley could further increase salt tolerance, therefore HKT2 seems to be involved in salt tolerance (Mian et al., 2011).

NHX

$\mathrm{Na}^{+} / \mathrm{H}^{+}$-antiporters (NHXs) mediate the $\mathrm{Na}^{+}$compartmentalisation into the vacuole, driven by the electrochemical gradient generated by V-ATPase and V-PPase (Figure 1.3.6) (Jiang et al., 2010; Bassil \& Blumwald, 2014; Almeida et al., 2017). NHX proteins in plants belong to a large family of monovalent cation/proton antiporter (CPAs) formed by two subgroups, CPA1 and CPA2. The CPA2 subgroup is made up of cation/ $\mathrm{H}^{+}$exchangers $(\mathrm{CHXs})$ and $\mathrm{K}^{+}$efflux antiporters (KEAs), while the CPA1 subgroup includes NHXs. NHX-type transporters are found ubiquitously in all eukaryotic organisms (Rodríguez-Rosales et al., 2009; Bassil et al., 2012; Almeida et al., 2017). NHX antiporters do not only play a role of $\mathrm{Na}^{+}$ compartmentalisation, but also in mediating $\mathrm{K}^{+}$accumulation in the vacuole, thus regulating osmotic adjustment, cell expansion, and intracellular $\mathrm{K}^{+}$homeostasis (Jiang et al., 2010; Hasegawa, 2013; Himabindu et al., 2016; Almeida et al., 2017). Studies in Arabidopsis and rice have shown that the NHX genes AtNHX1 and 2 as well as OsNHX1, 2, 3 and 5 are induced by hyperosmotic stress, ABA treatment and salt stress, thus strongly suggesting that NHX plays a crucial role in salinity stress response.(Yokoi et al., 2002; Fukuda et al., 2011; Almeida et al., 2017). While the AtNHX1 and 2 promotors contain MYC/MYB cis-regulatory elements, the OsNHX1 promotor also contains several ABA-responsive elements in addition to the MYC/MYB cis-regulatory elements. Thus, NHX genes in both rice and Arabidopsis seem to transcriptionally regulated by an ABA-dependent pathway (Yokoi et al., 2002; Qiu et al., 2004; Almeida et al., 2017). Whether AtNHX1 transports $\mathrm{K}^{+}$or $\mathrm{Na}^{+}$is regulated by a calmodulin-like protein 15 (AtCaM15) located in the vacuole. AtCaM15 binds to the C-terminus of AtNHX1leading to a higher $\mathrm{K}^{+} / \mathrm{H}^{+}$exchange activity, if the vacuolar $\mathrm{pH}$ is acidic (5.5) and the $\mathrm{Ca}^{2+}$ concentration high. However, under salt stress condition the vacuole is often alkalised, which causes a reduction in AtCaM15 binding rate to AtNHX1, resulting in an increased $\mathrm{Na}^{+} / \mathrm{H}^{+}$exchange activity (Yamaguchi et al., 2003; Rodríguez-Rosales et al., 2009; Almeida et $a l ., 2017)$. This means that under salt stress $\mathrm{Na}^{+}$is compartmentalised into the vacuole and less $\mathrm{K}^{+}$is transported into the vacuole, thus maintaining a high $\mathrm{K}^{+} / \mathrm{Na}^{+}$ratio in the cytosol. 


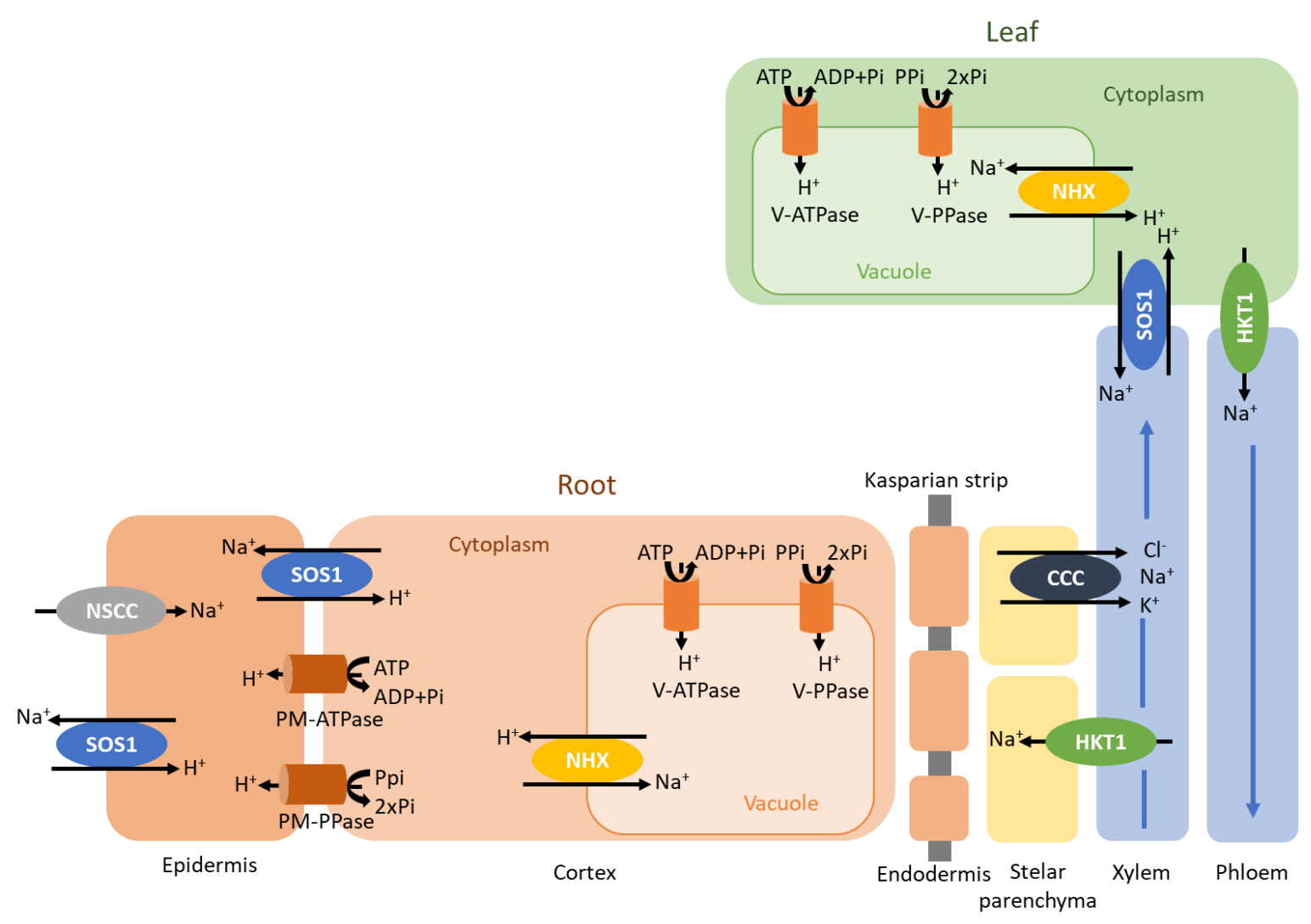

Figure 1.3.6 Schematic representation showing key plasma and tonoplast membrane transporters, channels, and pumps mediating $\mathrm{Na}+$ homeostasis in plants under salt stress. $\mathrm{Na}^{+}$ ions enter the cells via non-selective cation channels (NSCCs). The $\mathrm{Na}^{+} / \mathrm{H}^{+}$antiporter SOS1 extrudes $\mathrm{Na}^{+}$at the root soil interface, thus reducing the $\mathrm{Na}^{+}$net influx of $\mathrm{Na}^{+}$. At the xylem parenchyma cells, HKT1-like proteins retrieve $\mathrm{Na}+$ from the xylem sap, thereby restricting the amount of $\mathrm{Na}^{+}$reaching the photosynthetic tissues. To translocate $\mathrm{Na}^{+}$back to the root, ions unloaded from xylem may be transported into phloem via additional HKT1-like proteins. In addition, HKT1-like proteins also load $\mathrm{Na}^{+}$into shoot phloem, and then $\mathrm{Na}^{+}$is transferred into roots via phloem, preventing $\mathrm{Na}^{+}$accumulation in shoots. SOS1, localized in the xylem parenchyma cells, is also suggested to mediate $\mathrm{Na}^{+}$efflux from xylem vessels under high salinity. Incoming $\mathrm{Na}^{+}$, in root and shoots, is stored in the large central vacuole by tonoplast localized NHX exchangers. Cation $\mathrm{Cl}^{-}$cotransporters (CCC) retrieve $\mathrm{Cl}^{-}$from the xylem, while loading $\mathrm{Na}^{+}$or $\mathrm{K}^{+}$into the xylem. Plasma membrane $\mathrm{H}^{+}$-ATPase (PM-ATPase), plasma membrane $\mathrm{H}^{+}$-PPase (PM-PPase), tonoplast $\mathrm{H}^{+}$-ATPase (V-ATPase) and tonoplast $\mathrm{H}^{+}$-PPase (V-PPase) generate the electrochemical potential gradient for secondary active transport. Adapted from Almeida et al., (2017). 


\section{GORK and SKOR}

Guard cell outward rectifying $\mathrm{K}^{+}$channels (GORKs) are not only expressed in guard cells, but also in the root epidermis (Figure 1.3.7). These channels play an important role in guard stomatal closure, while in roots they might be one of the major channels involved in $\mathrm{K}^{+}$leakage upon salt stress. GORKs are activated by plasma membrane depolarization, which can be induced by the increased uptake of $\mathrm{Na}^{+}$under salt stress, and by ROS, which also can be induced by salt stress (Hosy et al., 2003; Véry et al., 2014; Shabala, 2017). GORKs are proteins with a transmembrane core that is formed by four subunits. The pore loops of GORKs bear a specific T-X-G-Y-G motif that conveys its $\mathrm{K}^{+}$selectivity (Sharma et al., 2013; Shabala, 2017).

Stele $\mathrm{K}^{+}$outward rectifying channels (SKORs) are expressed in parenchyma cells that face xylem vessels (Figure 1.3.7) (Véry et al., 2014; Zhu et al., 2017). Knock out mutant studies have shown that SKORs are involved in $\mathrm{K}^{+}$shoot transport, by loading $\mathrm{K}^{+}$into the xylem (Gaymard et al., 1998; Zhu et al., 2017). However, SKORs are down regulated by high cytosolic $\mathrm{Ca}^{2+}$ concentrations and ABA. Therefore, these channels might not play an essential role in salt tolerance (Zhu et al., 2017) but might contribute to a decreasing cytosolic $\mathrm{K}^{+}$content in leaf tissues that results in a low $\mathrm{K}^{+} / \mathrm{Na}^{+}$ratio under salt stress.

\section{KORC and NORC}

$\mathrm{K}^{+}$outward rectifying channels (KORCs) open upon the depolarisation of the plasma membrane, this can be for example induce by salt stress, and can mediate the efflux of both $\mathrm{K}^{+}$ and $\mathrm{Na}^{+}$(Figure 1.3.7) (Maathuis et al., 1997; Blumwald, 2000).

Non-selective $\mathrm{K}^{+}$outward rectifying channels (NORCs) are permeable for both $\mathrm{Na}^{+}$and $\mathrm{K}^{+}$. NORCs can mediate $\mathrm{Na}^{+}$uptake, as well as $\mathrm{K}^{+}$efflux (Figure 1.3.7). These channels are activated by increased cytosolic $\mathrm{Ca}^{2+}$ concentrations, which do occur under salt stress. They can contribute to plasma membrane depolarization and provoke further $\mathrm{K}^{+}$leaking via voltagegated channels, such as KORCs and NSCCs (Zepeda-Jazo et al., 2008).

$C C C$

A Na$: \mathrm{K}^{+}: \mathrm{Cl}^{-}$cotransporter (CCC for cation $\mathrm{Cl}^{-}$cotransporter) was identified in Arabidopsis where it is preferentially expressed in the xylem/symplast boundary of the shoot and root vascular bundle. AtCCC was suggested to be involved in long distance $\mathrm{Cl}^{-}$transport and at the same time also loading $\mathrm{Na}^{+}$or $\mathrm{K}^{+}$into the xylem (Figure 1.3.7) (Colmenero-Flores et al., 2007; Zhu et al., 2017). 


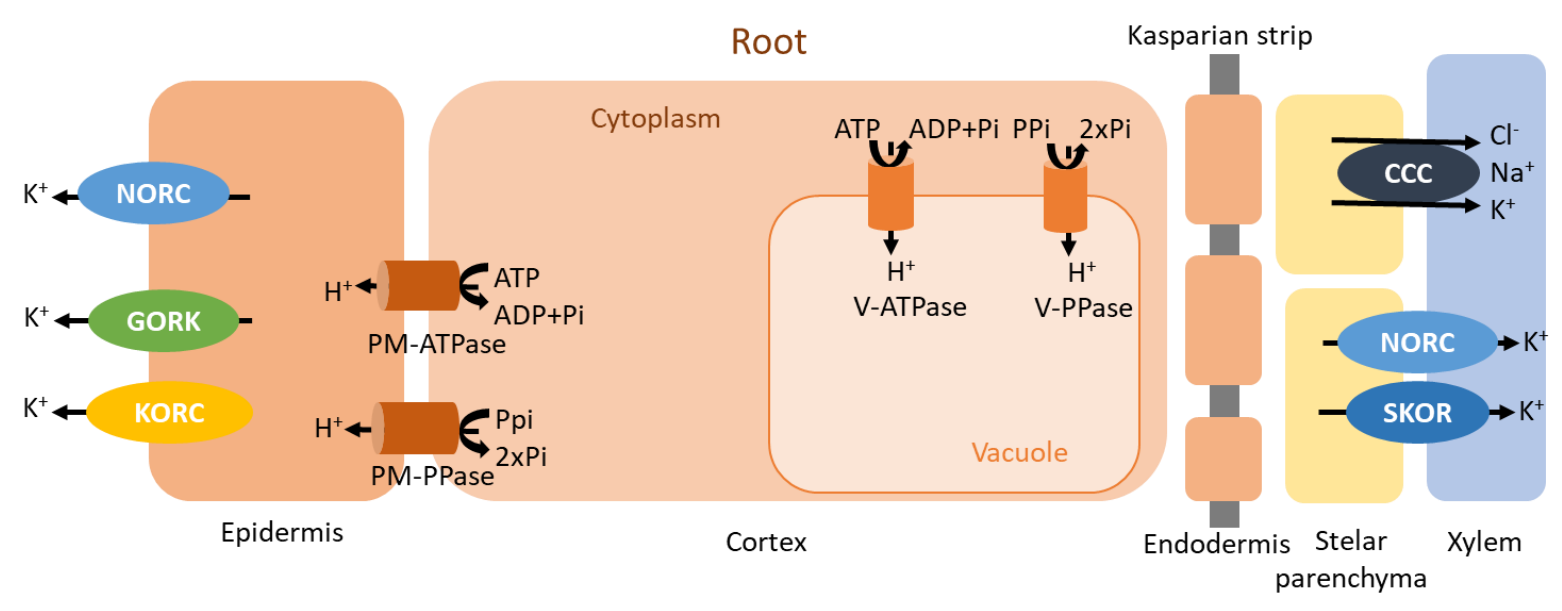

Figure 1.3.7 Schematic overview showing key plasma and tonoplast membrane transporters of $\mathrm{K}^{+}$homeostasis under salt stress. $\mathrm{K}^{+}$outward rectifying channels (KORC), Non-selective $\mathrm{K}^{+}$outward rectifying channels (NORC) and Guard cell outward rectifying $\mathrm{K}^{+}$channels (GORK) all facilitate $\mathrm{K}^{+}$efflux at the root soil interface and contribute to $\mathrm{K}^{+}$leakage upon salt stress. Stele $\mathrm{K}^{+}$outward rectifying channels (SKOR) are loading $\mathrm{K}^{+}$into the xylem and maintain $\mathrm{K}^{+}$root to shoot transport. Under high salt stress the intracellular $\mathrm{Ca}^{2+}$ concentration increases and inhibits SKOR activity. Cation $\mathrm{Cl}^{-}$cotransporters retrieve (CCC) $\mathrm{Cl}^{-}$from the xylem, while loading both $\mathrm{Na}^{+}$or $\mathrm{K}^{+}$into the xylem.

In General salt tolerance is a complicated mechanism, that varies greatly between different species and involves many different ion transporters and signalling pathways. Manipulating membrane transporters is one of the most discussed and most promising methods to maintain yield and biomass production of crop plants under high soil salinity. Understanding ion transport mechanisms and signalling pathways under salt stress is crucial to find out which transporters might be the most promising candidates (Brini \& Masmoudi, 2012; Almeida et al., 2017).

\subsection{Betalains}

Betalains are water soluble, tyrosine-derived plant pigments ranging in colour from yellow to purple. These pigments are only synthesized by some Basidiomycetes and 13 plant families in the order Caryophyllales, namely Achatocarpaceae, Aizoaceae, Amaranthaceae, Basellaceae, Cactaceae, Chenopodiaceae, Didiereaceae, Halophytaceae, Hectorellaceae, Nyctaginaceae, Phytolaccaceae, Portulacacceae, and Stegnospermaceae (Clement \& Mabry, 1996; Miguel, 2019). Betalains can be found in leaves, stems, roots fruits, flowers ,and seeds (Khan \& 
Giridhar, 2015; Miguel, 2019). Betalains accumulate in several cell types, for example in bladder cells as observed on M. crystallinum (Ibdah et al., 2002). Additionally, betalains were found in the hypodermis and outer layers of chlorenchyma in cactus stems (Mosco, 2012; Khan \& Giridhar, 2015).

The optical and chemical properties of betalains are usually similar to those of the much more abundant class of pigments, the anthocyanins. So similar that they were considered as nitrogenous anthocyanins until 1957, when crystallisation studies of betanin provided evidence, that betalains are a different set of plant pigments (Wyler \& Dreiding, 1957; Peterson \& Joslyn, 1958; Khan \& Giridhar, 2015). Currently, no plant species is known that produces both betalains and anthocyanins, which may indicate that the two pigment types are functional homologues (Jain \& Gould, 2015a). Betalain and anthocyanin occur mutually exclusive within the Caryophyllales. Most families belonging to the core Caryophyllales produce betalain, except the Caryophyllaceae, Molluginaceae, Kewaceae, and Macarthuriaceae (Clement \& Mabry, 1996; Brockington et al., 2011, 2015; Khan \& Giridhar, 2015; Polturak \& Aharoni, 2018; Miguel, 2019). It has been suggested in the past that within the Molluginaceae certain genera, including Lophiocarpus, Corbichonia, and Limeum might not only accumulate anthocyanins, but also betalains (Cuenoud et al., 2002; Khan \& Giridhar, 2015). However, these suggestions have not been verified with pigment analysis data yet (Khan \& Giridhar, 2015). Recent phylogenetic analyses suggest that the ancestor of the Caryophyllales produced anthocyanin and that the capability to synthesize betalains most likely arose once early in the evolution of this plant order. Nevertheless, two families of this order have switched back from betalain production to anthocyanin synthesis due to the loss of genes encoding key enzymes of betalain synthesis (Brockington et al., 2015).

\subsubsection{Synthesis of Betalains}

Betalains are generally classified into two groups based on structural characteristics and light absorption properties. The yellow betaxanthins have an absorption maximum at approximately $460-480 \mathrm{~nm}$, while the red-violet betacyanins typically show the highest absorption at 535 538 nm (Stintzing \& Carle, 2004; Polturak \& Aharoni, 2018). All betalains are based on betalamic acid, which either condensates with cyclo-DOPA derivates to form betacyanins or with amino acids or amines to form betaxanthins (Stintzing \& Carle, 2004; Polturak \& Aharoni, 2018). 
Unlike the anthocyanins, which are derived from phenylalanine, betalains are synthesized from tyrosine, which is produced via the shikimate acid pathway (Herrmann, 1995; Tzin \& Galili, 2011; Polturak \& Aharoni, 2018). During the first step of betalain synthesis tyrosine is hydroxylated to L-3,4-dihydroxyphenylalanine (L-DOPA). This step is catalysed by cytochrome P450. In beet root (Beta vulgaris) three cytochromes: CYP76AD1, CYP76AD5 and CYP76AD6 have been identified (Hatlestad et al., 2015; Polturak et al., 2016; Sunnadeniya et al., 2016). L-DOPA can either be converted to betalainic acid by DOPA 4,5-dioxygenase (DODA), or L-DOPA is converted to cyclo-DOPA by the enzyme CYP76AD1. Betalainic acid can react spontaneously with cyclo-DOPA to form betanidin. Therefore, CYP76AD1 is essential for betacyanin synthesis (Sunnadeniya et al., 2016). Next betanidin is glycosylated by betanidin-5-O-glycosyltransferase forming betanin and betanin may go through further glycosylation or acylation reactions resulting in the formation of a wide assortment of betacyanins (Strack et al., 2003; Polturak \& Aharoni, 2018). In some Caryophyllales species, such as Mirabilis jalapa and Celosia cristata, cyclo-DOPA is first glycosylated at the 5'O position and then cyclo-DOPA-5-O-glucoside condensates with betalainic acid to directly form betanin, skipping the formation of betanidin (Sasaki et al., 2004, 2005; Polturak \& Aharoni, 2018). Alternatively, betalainic acid can form yellow betaxanthins by condensing with amino acids or other amine groups (Figure 1.4.1). 


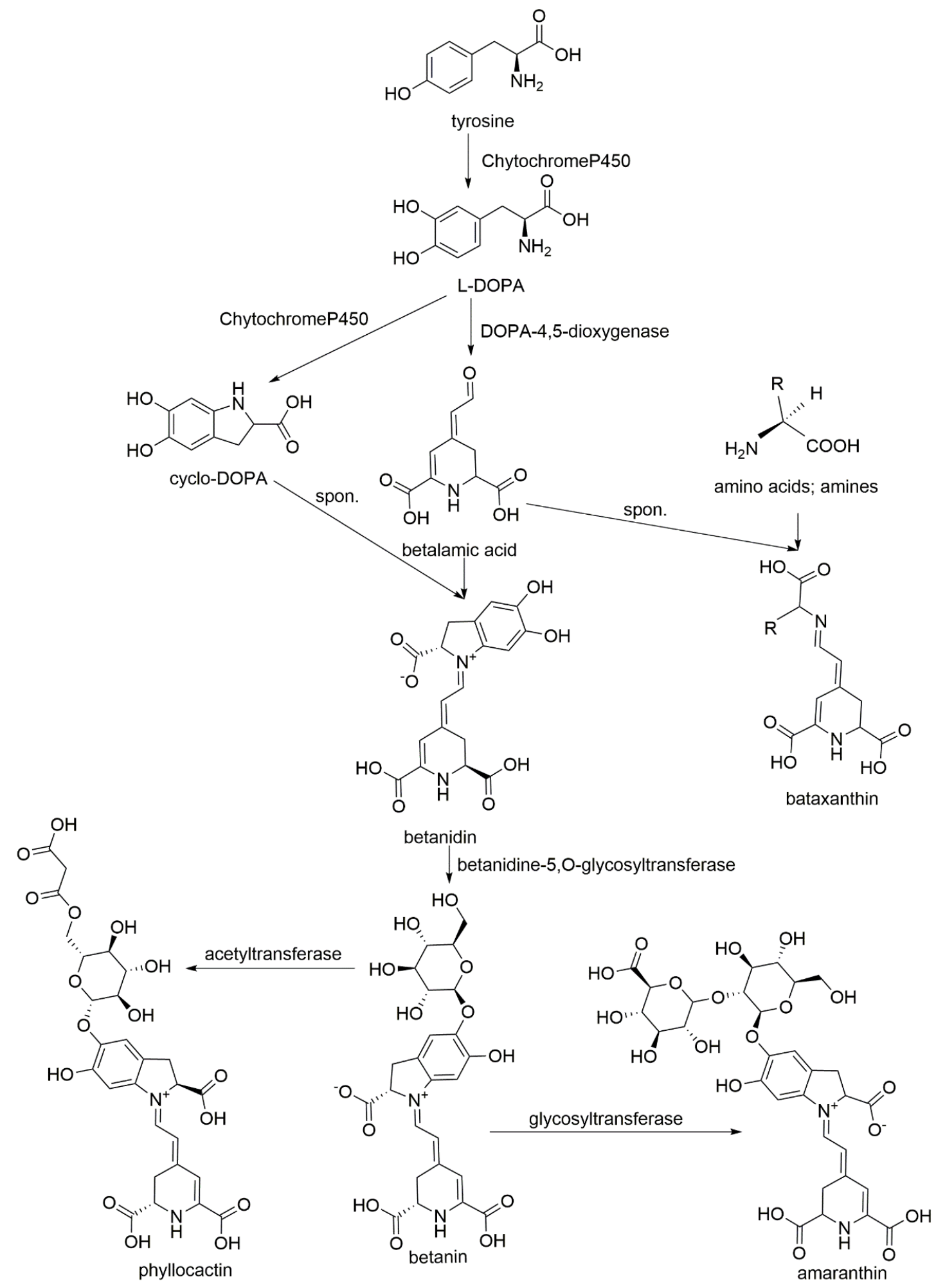

Figure 1.4.1 The betalain biosynthetic pathway. The first committed step in the pathway, tyrosine 3-hydroxylation, is catalysed by cytochrome P450. Betanin, a betacyanin, is formed when cyclo-DOPA condenses with betalamic acid by spontaneous condensation reaction (spon). The formation of betaxanthins occurs when betalamic acid spontaneously condenses with amino acids or amines (Polturak et al., 2016) 
Betaxanthins can be divided into amino an acid- derived conjugate group and an amine-derived conjugate group, depending on whether betalainic acid spontaneously reacts with an amino acid or an amine (Stintzing \& Carle, 2004; Polturak \& Aharoni, 2018). Betacyanins can be further divided into four subgroups, namely betanin-, gomphrenin-, amaranthin-, and bougainvilleintype pigments (Steglich \& Strack, 1990; Polturak \& Aharoni, 2018). Betanin-type betacyanins are formed, if betanidin is glycosylated at the 5'O position. However, if betanidine is acylated at the 6'O position, gomphrenin-type betacyanins are formed. Amaranthin-type pigments have a glucuronylglucosyl moity or derivate linked to the C5 of betanidin. When carboxylated or decarboxylated betanidin is linked to a diglucosyl moity or derivate at the C5 or C6 position (Slimen et al., 2017; Miguel, 2019). Both betacyanins and betaxanthins are synthesized in the cytoplasm and endoplasmic reticulum and stored as glycosides in vacuoles (Christinet et al., 2004; Grotewold, 2006; Deloache et al., 2015; Polturak \& Aharoni, 2018).

We still do not fully understand the regulation of betalain biosynthesis. However, in seedlings and cell culture betalain production changed in response to plants hormones, such as ABA, gibberellic acid (GA), and cytokinin, and changes in environmental conditions, particularly light and UV radiation (Kinsman et al., 1975; Bianco-Colomas, 1984; Kishima et al., 1991, 1995; Hirano et al., 1996; Vogt et al., 1999; Ibdah et al., 2002; Polturak \& Aharoni, 2018). Upstream of two DOD gene sequences binding sites of MYB, a basic helix-loop-helix (bHLH) transcription factor that responds to environmental stress, were detected (Takahashi et al., 2009; Polturak \& Aharoni, 2018). Based on homology to known MYB transcription factors related to anthocyanin synthesis, two R2R3-MYB-type transcription factors were found upstream of the R-locus, that codes for CYP76AD1, in B. vulgaris (Stracke et al., 2014; Polturak \& Aharoni, 2018). Another MYB transcription factor, named BvMYB1 was identified in the Y-locus of $B$. vulgaris. BvMYB1 is a positive regulator of betalain synthesis, that activates CYP76AD1 by directly binding to their promoter regions (Hatlestad et al., 2015; Polturak \& Aharoni, 2018). In Suaeda salsa seedlings $\mathrm{Ca}^{+}$, calmodulin play an important role in regulating betacyanin production. $\mathrm{Ca}^{2+}$ is a second messenger that is also responsive to abiotic stress, such as salinity stress, and could be a link between both betacyanin synthesis and salt stress (Wang \& Wang, 2007; Khan \& Giridhar, 2015).

\subsubsection{Functions of Betacyanins in Plant Defence Against Biotic and Abiotic Stress}

Betalains like other plant pigments play an important role in pollinator attraction and in attracting frugivores for seed dispersal. Additionally, betalains might be involved in plant defence against biotic and abiotic stresses (Jain \& Gould, 2015a; Polturak \& Aharoni, 2018). 
In B. vulgaris betalain synthesis was induced after infection with Pseudomonas syringe and Agrobacterium tumefaciens (Sepúlveda-Jiménez et al., 2004; Polturak \& Aharoni, 2018). Moreover, betalain-producing Nicotiana tabacum showed increased resistance against infection with a fungus called Botrytis cinereal. The increased resistance against fungal infection might be due to the ROS scavenging properties of betalains (Polturak et al., 2017; Polturak \& Aharoni, 2018).

There is evidence that foliar betacyanins are involved in photoprotection. Exposure to high light can cause oxidative stress, which damages photosystem II and I (PSII, PSI) and can inhibit their repair (Takahashi \& Badger, 2011). The maximum quantum efficiency of PSII has been repeatedly found to decline less in betacyanic leaves than in green leaves following exposures to saturating light. Betalains can combat oxidative stress due to reactive oxygen species (ROS) in two different ways. First, the light screening effects of betalain can reduce the production of ROS. Second, the antioxidant effects of betalain can eliminate ROS that have been generated.

In vitro assays have shown that betalain extracts exhibit potent antioxidant properties and therefore protect the plant against oxidative damage. The antioxidant activity may protect cells from damage to DNA, proteins, and membranes (Stintzing et al., 2005; Taira et al., 2015). In contrast, Jain and Gould (2015) showed that less ROS was produced in vivo. However, ROS production significantly decreased in betacyanic leaves compared to green leaves, which confirms the antioxidant activity of betacyanin in vivo. Nevertheless, the vacuolar location of betacyanins seems to be suboptimal for ROS scavenging, because most ROS originate from cytoplasmic organelles. Perhaps betacyanins mainly neutralize vacuolar $\mathrm{H}_{2} \mathrm{O}_{2}$ (Jain et al., 2015). In addition, betacyanins accumulate in epidermal cells and are spatially separated from chloroplasts (Jain, 2016). ROS scavenging by betacyanins therefore seems to play a minor role, if any, in the protection of PSII. However, the photoprotective effect of betacyanin could be imitated by covering green leaves with red foil (Jain et al., 2015). Therefore, it seems to be more likely that betacyanin has an umbrella effect and protects the PSII by absorbing green light and thus reducing the overall amount of light stress on the PSII (Jain et al., 2015). Moreover, an increase in betalain accumulation under salt and drought stress also supports the potential role of betalains in protection against abiotic stresses (Hayakawa \& Agarie, 2010; Nakashima et al., 2011; Jain \& Gould, 2015a,b; Polturak \& Aharoni, 2018). Additionally, many members of the Caryophyllales, that produce betalains, grow in arid and semi-arid regions with saline soils, which again suggests that betalain might be involved in protection against abiotic stress (Polturak \& Aharoni, 2018) 


\subsubsection{The Role of Betacyanin in Response to Salt Stress}

Many betalainic plants increase betacyanin production upon salt treatment (Wang et al., 2006; Hayakawa \& Agarie, 2010; Nakashima et al., 2011). The effect of betacyanin and salt stress has been studied in $S$. salsa and highly betacyanic plants have been compared with control plants containing moderate amounts of betacyanin. Highly betacyanic plants were able to produce more fresh weight under salt stress than control plants (Wang et al., 2001, 2008b). Additionally, the V-ATPase activity in S. salsa seedlings increased dramatically after exposure to high salinity. This increase in V-ATPase activity was much higher in highly betacyanic seedlings compared to control plants (Wang et al., 2001, 2008b). Considering, that the VATPase plays a role in providing the electrochemical gradient to drive ion transport into the vacuole, these findings strongly suggest that betacyanins have a critical role in salt tolerance by increasing $\mathrm{Na}^{+}$uptake into the vacuole. It is far from clear how betacyanins might redirect $\mathrm{Na}^{+}$ movement. One exciting possibility proposed by Wang (2008b) is that the biosynthesis of betalain might correlate with an upregulation in V-ATPase activity and thus could increase the transport of betacyanin into the vacuole. At the same time the enhanced V-ATPase activity could cause a more efficient $\mathrm{Na}^{+}$sequestration into betalainic vacuoles (Wang et al., 2008b). The studies on $S$. salsa only compared plants with high betacyanin content with plants with moderate content, lacking a control plant that does not produce any betacyanin. However, recently a study has shown that green Disphyma australe plants, that do not produce any betacyanin in vegetative tissues, show more stress symptoms than the betacyanin producing plants under salinity stress (Jain \& Gould, 2015a).

\subsection{Disphyma australe}

The New Zealand ice plant (Disphyma australe) belongs to the plant family Aizoaceae in the order Caryophyllales (Chinnock, 1971). It was first collected from New Zealand and illustrated on Cook's first voyage. In 1789 Aiton first described this plant as Mesembryanthemum australe (Aiton, 1789). Brown set up the genus Disphyma in 1925 und in 1932 Black transferred M. australe to the genus Disphyma. Today in New Zealand we recognize four species: i) D. australe which can be found on the mainland of New Zealand and the Chatham Islands.; ii) Disphyma papillatum which exclusively occurs on the Chatham Islands; iii) Disphyma clavellatum an Australian ice plant, which appears to have recently colonised New Zealand; and iv) Disphyma crassifolium which refers to the South African ice plants ('Disphyma australe subsp. australe | New Zealand Plant Conservation Network') (private correspondence with Dr. 
Leon Perrie). The Tasmanian position on this matter is vastly different from that of New Zealand. They call their ice plant $D$. crassifolium subsp. clavellatum and claim that it was previously wrongly called $D$. australe without clarifying whether it is distinct form the $D$. australe found in New Zealand or not. Additionally, there is a third position on this matter contradicting both the New Zealand and Tasmanian position and recognizing only one species in the world (private correspondence with Dr. Leon Perrie). However, this thesis will stick to the respective local naming conventions and call the ice plant found on the mainland of New Zealand $D$. australe and the Tasmanian ice plant D. crassifolium.

\subsubsection{Disphyma australe as a Model Organism to Study the Role of Betacyanins on Salt Tolerance}

D. australe is a succulent halophyte endemic to New Zealand and is commonly found throughout both the North and South Islands on coastal cliffs and sandy dunes (Chinnock, 1971, 1972; Madawala et al., 2014; Jain \& Gould, 2015b). In these costal environments plants are exposed to airborne and substrate salinity (Madawala et al., 2014). D. australe can maintain growth under highly saline condition and even shows salt-induced growth stimulations under moderate salinity (200 mM NaCl) (Madawala et al., 2014). The $\mathrm{Na}^{+}$and $\mathrm{Cl}^{-}$distribution pattern of $D$. australe is that of a typical halophyte. More than $90 \%$ of the $\mathrm{NaCl}$ absorbed by the roots is transported up the shoot and accumulates in the leaves. In contrast, glycophytes restrict the ion transport to the shoot and accumulate $\mathrm{Na}^{+}$and $\mathrm{Cl}^{-}$in the upper root and lower stem (Neales \& Sharkey, 1981). While the $\mathrm{K}^{+} / \mathrm{Na}^{+}$ratio in leaves is decreasing under salt stress, D. australe leaves are able to keep the $\mathrm{K}^{+} / \mathrm{Na}^{+}$ratio consistently greater than that of the external solution (Neales \& Sharkey, 1981). Similar to other halophytes this plant seems to maintain a preferential affinity of $\mathrm{K}^{+}$over $\mathrm{Na}^{+}$even in highly saline environments (Flowers et al., 1977; Wyn Jones \& Storey, 1978; Ahmad et al., 1979; Storey \& Jones, 1979; Neales \& Sharkey, 1981).

Red and green forms of $D$. australe co-occur at the costal cliffs around Wellington (Chinnock, 1971; Jain \& Gould, 2015b; Jain et al., 2015). The colour dimorphism found in D. australe provides a good system for comparative analysis of the salt stress response of betacyanic and green morphs. The red colour in D. australe is caused by five structurally different betacyanins present in the epidermis of the triquetrous leaves and the fleshy stem, namely betanin, isobetanin, betanidin, isobetanidin, lampranthin-II, and isolampranthin, which appear to be associated with enhanced salinity tolerance (Jain \& Gould, 2015b). However, no betacyanins have been found to be in the vegetative parts of the green $D$. australe morph. Yet, both red and 
green plants have lilac flowers with petals that contain betacyanins (Figure 1.5.1) (Jain \& Gould, 2015b). The green morph was unable to react to salinity stress with betacyanin production in shoots and leaves (Jain \& Gould, 2015b; Jain et al., 2015).
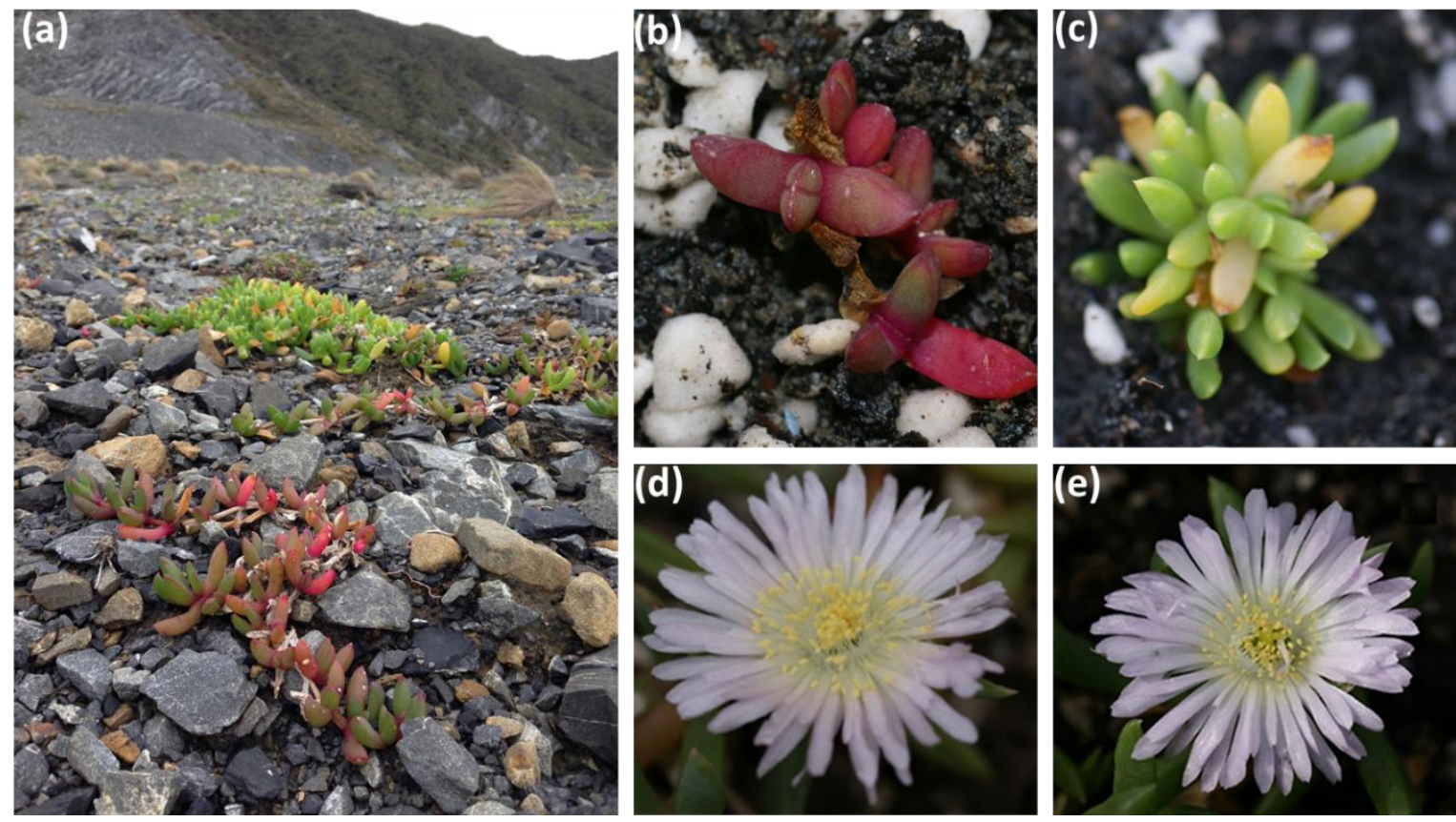

Figure 1.5.1 Both $D$. australe morphs (a) growing side by side at Te Kopahou Reserve,

Wellington. Vegetative shoots of betacyanic (b) and green (c) D. australe morphs and the betacyanin containing flowers of both the red (d) and green (e) morphs. Adapted from Jain and Gould (2015).

Moreover, the betacyanic morph was more abundant closer to the shore where the soil would be more saline and the plants would be more exposed to seawater, while the green morph became more abundant further away from the shore line (Jain \& Gould, 2015b). The decline in PSII quantum efficiency after exposure to high light was greater in green leaves than in betacyanic leaves. This indicates that epidermal betacyanins in $D$. australe have a photoprotective effect and reduce the photoinhibition and photooxidative stress in the mesophyll (Jain et al., 2015). After $\mathrm{NaCl}$ treatment the photosynthetic $\mathrm{CO}_{2}$ assimilation rate and water use efficiency were greater in betacyanic leaves compared to green leaves, while the stomatal conductance was lower (Jain \& Gould, 2015b). Together these results indicate that betacyanin not only accumulates upon exposure to salinity but might also play an active role in salt stress tolerance in D. australe (Jain \& Gould, 2015b; Jain et al., 2015).

Betacyanin has been shown to have an enhancing effect on salt tolerance in halophytes, such as S. salsa and D. australe (Wang et al., 2001, 2008b; Jain \& Gould, 2015b; Jain et al., 2015). If 
this effect could be transferred to naturally non-betacyanic plants, by genetically engineering these plants to synthesis betacyanins, this might be a promising option to generate salt tolerant crop plants. So far, research in enhancing the salt tolerance of crop plants has focused on overexpression of certain ion transporters or introducing ion transporters from halophytes into crop plants. This has proven to be very complicated, due to the complexity of salt tolerance mechanisms involving numerous ion channels and transporters that are regulated by various signalling pathways. In contrast, the synthesis of simple betacyanins relies on view key enzymes and has already been successfully introduced to non-betalainic plants (Harris et al., 2012). Understanding how betacyanin might increase salt tolerance is the first step in generating new salt tolerant crops.

\subsection{Aims and Objectives of this Thesis}

The main aims of this thesis were (i) to investigate the functional role of betacyanin during salt stress tolerance and (ii) to show that the beneficial effect of betacyanin production during salt stress can be transferred to natural non-betacyanic plants by introducing betacyanin synthesis.

The following hypotheses were tested in this thesis:

1. In the presence of epidermal betacyanins, $\mathrm{Na}^{+}$is preferentially transported away from mesophyll chlorenchyma into the epidermis, thereby avoiding the cytotoxic effects of sodium on photosynthetically active tissues (Chapter 2).

2. In the presence of betacyanin mesophyll cells will show increased $\mathrm{K}^{+}$retention under salt stress conditions than in green leaves (Chapter 3).

3. The introduction of betacyanin production enhances salt tolerance in N. tabacum, normally a glycophytic and non-betacyanic plant (Chapter 4).

To test these hypotheses experiments were designed with the following objectives:

1. Identify the intracellular distribution of $\mathrm{Na}^{+}$within betacyanic and green $D$. australe leaves during salt stress and investigate potential differences in salt secretion. Compare the mesophyll viability in betacyanic and green leaves after salt treatment.

2. Establish the similarity in salt tolerance of $D$. australe and D. crassifolium. Examine the ion flux response of mesophyll cells to salt stress and compare the responses 
between both species. Investigate what role betacyanins and the presence of $\mathrm{Na}^{+}$and $\mathrm{Cl}^{-}$have on ion flux responses during salt stress.

3. Introduce betacyanin synthesis into $N$. tabacum, resulting in a betacyanin overexpression mutant. Compare the physiological responses, such as photoinhibition, chlorophyll degradation and seedling establishment, of betacyanic and wild type $N$. tabacum. Examine the possible role of betacyanin in salt tolerance in N. tabacum. 


\section{Chapter 2 The Betacyanins in Epidermal Cells Protect Leaf Mesophyll from Effects of Salt Stress in Disphyma australe}

\subsection{Abstract}

Many halophytes, including Disphyma australe, produce a red pigment called betacyanin, which has been suggested to have a beneficial function in salt tolerance. However, the mechanism through which betacyanin might exert this effect remains unknown. Therefore, the hypothesis that in the presence of epidermal betacyanins, $\mathrm{Na}^{+}$is preferentially transported away from mesophyll chlorenchyma into the epidermis, thereby avoiding the cytotoxic effects of sodium on photosynthetically active tissues, was tested. Fluorescence microscopy, cryoscanning electron microscopy with energy dispersive X-ray analysis, and atomic absorption spectrometry were used to locate and quantify $\mathrm{Na}^{+}$in red and green $D$. australe leaves. $\mathrm{Na}^{+}$ accumulated predominantly in the epidermal cells of betacyanic leaves but was more uniformly distributed in green leaves. Relative to the green leaves, the betacyanic leaves maintained higher $\mathrm{K}^{+} / \mathrm{Na}^{+}$ratios in mesophyll cells, had higher mesophyll cell viability counts, and had higher salt secretion rates from bladder cells. The diversion of salt to betacyanin-containing cells in the epidermis effectively protects photosynthetically active tissues. These data indicate a previously undocumented mechanism for avoiding salt toxicity in plants

\subsection{Introduction}

Almost $20 \%$ of all irrigated arable land is now considered so saline that it impedes the growth of traditional crops (Munns \& Tester, 2008), and because of rising sea levels and increasing demand for irrigation, this is predicted to increase by 0.5 - $1 \%$ per annum (Rozema \& Flowers, 2008; Dassanayake \& Larkin, 2017). Indeed, vast areas of previously fertile land in Australia, USA, and South East Asia are now so saline that the soil is considered unusable (Swarajyalakshmi et al., 2003; Wang et al., 2008a; Hasegawa, 2013). It is not surprising, therefore, that there has been concerted scientific effort worldwide to understand how increased salinity affects plants at the cellular level, and to introduce genes that may increase salinity tolerance in crop plants.

For glycophytes, saline soils can both limit water uptake, and lead to toxic concentrations of $\mathrm{Na}^{+}$ions in plant cells. High cytosolic $\mathrm{Na}^{+}$concentrations impair enzyme activities, which in 
turn negatively affect key metabolic processes, such as photosynthesis (Blumwald, 2000; Deinlein et al., 2014). By competing with $\mathrm{K}^{+}$for binding sites on enzymes (Barragan et al., 2012; Almeida et al., 2017), $\mathrm{Na}^{+}$can interfere with over 50 different cytoplasmic proteins that require $\mathrm{K}^{+}$for activation, including pyruvate kinase, phosphofructokinase, membrane-bound ATPases, and vacuolar pyrophosphatase (Marschner, 2012). In addition, the accumulation of apoplastic $\mathrm{Na}^{+}$causes the efflux of cytosolic $\mathrm{K}^{+}$from mesophyll cells (Percey et al., 2014), and because $\mathrm{K}^{+}$is involved in maintaining a $\mathrm{pH}$ gradient across the thylakoid membrane for ATP synthesis, the capacities for chloroplasts to process light energy are diminished (Marschner, 2012).

Halophytic species, by contrast, often thrive in highly saline environments, such as coastal regions and salt marshes. Their survival can be attributed to: (i) mechanisms that exclude $\mathrm{Na}^{+}$ from the shoot or else prevent $\mathrm{Na}^{+}$transport to salt-sensitive photosynthetic tissues within the shoot; (ii) intracellular compartmentalisation of $\mathrm{Na}^{+}$inside cell vacuoles; and/or (iii) a variety of structural, physiological and biochemical modifications that permit plant cellular activities to tolerate relatively high $\mathrm{Na}^{+}$concentrations (Munns \& Tester, 2008; Flowers \& Colmer, 2015). Halophytes from diverse taxonomic groups often share similar adaptive features, such as succulent stems, bladder cells, and/or salt glands. Many of them are also pigmented red (Hasegawa, 2013). For some of these species, their red leaves and stems result from the accumulation of anthocyanins, the most abundant class of red pigment. For others, the colour is produced by betacyanins, a relatively small family of tyrosine-derived alkaloids restricted to certain families of the Caryophyllales and to some Basidiomycetes (Brockington et al., 2015). In comparison with the anthocyanins, the possible functions of betacyanins have been largely neglected by the scientific community (Jain \& Gould, 2015b). However, recent evidence indicates that betacyanin accumulation may be associated with salinity tolerance.

Betacyanin biosynthesis in vegetative shoots is inducible by high light and/or high salinity treatments (Ibdah et al., 2002; Wang \& Liu, 2007; Hayakawa \& Agarie, 2010; Nakashima et al., 2011; Jain et al., 2015). Saline conditions potentiate photo-oxidative damage in plants under high light stress (Percey et al., 2014), and betacyanins have been postulated to contribute to the suite of mechanisms that protect against this (Nakashima et al., 2011). By absorbing the incident yellow-green light (Nakashima et al., 2011; Jain et al., 2015), betacyanins located in the shoot epidermis would effectively reduce excitation pressure on the chloroplasts in subjacent tissues for which their capacities to process quanta would have been compromised by salinity. Accordingly, the ratio of maximum to variable quantum efficiencies of photosystem 
II (PSII) have been repeatedly found to decline less in betacyanic leaves than in green leaves following exposures to saturating light in combination with salinity stress (Jain et al., 2015).

Compelling evidence for a role of betacyanins in salinity tolerance has been obtained recently for $D$. australe, a succulent halophyte common on coastal dunes and rocky outcrops throughout New Zealand. The species is dimorphic for betacyanin pigmentation; individuals with red shoots are most abundant close to the shoreline where the substrate is saltier, whereas the green morphs, which lack the capacity to synthesise betacyanins, are generally located at less saline locations (Jain \& Gould, 2015b). When treated with $\mathrm{NaCl}$ in the laboratory, betacyanic plants grew faster, and had higher maximum $\mathrm{CO}_{2}$ assimilation rates, water use efficiencies, photochemical quantum yields of PSII, and photochemical quenching values than did the green plants. However, non-photochemical quenching values were generally lower in the red than in the green plants, indicating that the excess quanta had not been dissipated via the xanthophyll cycle (Jain \& Gould, 2015). Moreover, when green morphs were fed with L-DOPA, an intermediate of the betacyanin synthesis pathway, they produced betacyanins; the newly reddened shoots exhibited greater salinity tolerance and, consistent with the photoprotective hypothesis, incurred less photo-oxidative stress under actinic light (Jain et al., 2015).

Photoabatement by epidermal betacyanins potentially explains how the red morphs of $D$. australe maintain net carbon assimilation on its highly saline substrates, which are repeatedly washed by sea-spray. However, a photoprotective function per se is insufficient to explain how the ground tissues in these shoots, which lack betacyanin, escape $\mathrm{Na}^{+}$toxicity. To understand why, in contrast to the green $D$. australe, the red morphs can quickly establish, grow, and flower on the salty substrate without exhibiting obvious cytotoxic symptoms, the distributions of $\mathrm{Na}^{+}$ inside red and green leaves before and after saline treatment was examined. I hypothesised that in the presence of epidermal betacyanins, $\mathrm{Na}^{+}$is preferentially transported away from mesophyll chlorenchyma into the epidermis, thereby avoiding the cytotoxic effects of sodium on photosynthetically active tissues.

\subsection{Materials and Methods}

\subsubsection{Plant material}

Healthy red and green $D$. australe shoots were collected from south-facing costal dunes at Te

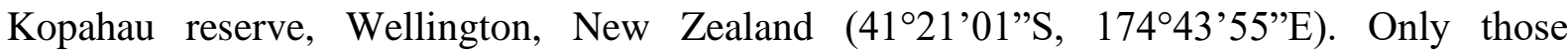
individuals that were accessible from the footpath or could be reached after a short climb were 
selected. Shoot cuttings bearing at least two mature pairs of opposite leaves were potted in a 2:1 (v/v) mix of commercial potting compost and pre-washed sand, and were grown in an unheated glasshouse under natural light during the autumn and winter months at Victoria University of Wellington, New Zealand and watered with tap water.

For fluorescence microscopy, conductivity measurements, salt gland counts, and viability staining five different plants from each morph were used per treatment. Leaves from nine different plants and stems from three different plants from each morph per treatment were used for cryo-SEM coupled with EDS. For the atomic absorption spectrometry eight different plants from each morph were used per treatment. However, these samples had to be pooled later on, resulting in a sample size of only one.

\subsubsection{Salinity treatment}

Shoot tips bearing two pairs of fully expanded leaves were removed from the rooted cuttings, and their cut bases submerged in $200 \mathrm{mM} \mathrm{NaCl}$ or distilled water for $3 \mathrm{~d}$ at $25^{\circ} \mathrm{C}$ under 300 $\mu \mathrm{mol} \mathrm{m} \mathrm{m}^{-2} \mathrm{~s}^{-1}$ white light supplied by fluorescent tubes

\subsubsection{Fluorescence microscopy}

The distribution of vacuolar $\mathrm{Na}^{+}$among tissues in control and saline-treated leaves was examined by fluorescence microscopy using the Sodium Green fluorophore (Hamaji et al., 2009). Shoot tips from 5 red and 5 green morphs per treatment were each transferred to an Eppendorf tube containing $1 \mathrm{ml}$ of $10 \mu \mathrm{M}$ Sodium Green tetraacetate (Thermofisher Scientific, Waltham, Massachusetts, USA), $10 \mu \mathrm{M}$ CoroNa ${ }^{\mathrm{TM}}$, AM, cell perment (Thermofisher Scientific, Waltham, Massachusetts, USA) or $10 \mu \mathrm{M}$ SBFI, AM, cell permeant (Thermofisher Scientific, Waltham, Massachusetts, USA) in dimethyl sulfoxide (Sigma-Aldrich, St. Louis, Missouri, USA) and held in the dark at room temperature for $3 \mathrm{~h}$. Thin transverse-sections were hand-cut from the central portion of one of the most basal leaves and per cutting, and examined by epifluorescence in an Olympus AX70 compound microscope (Olympus Optical Co., Hamburg, Germany) using a 460-490 nm excitation waveband and collecting emission between $515 \mathrm{~nm}$ and $550 \mathrm{~nm}$.

\subsubsection{Cryo-SEM with EDS}

The control and saline-treated leaves from 8 red morphs, 8 green morphs, and 8 red morphs that had turned green after $2 \mathrm{wk}$ in the greenhouse were snap-frozen in nitrogen slush at $-198{ }^{\circ} \mathrm{C}$ and then transferred into a Gatan Alto 2500 cryo-unit (Gatan Inc., Pleasanton, USA) at -120 ${ }^{\circ} \mathrm{C}$. Central portions of leaves were fractured transversely, and the fractured surfaces sputter- 
coated with platinum using a current of $10 \mathrm{~mA}$ for $240 \mathrm{sec}$. The samples were inserted into a JEOL JSM-6500 field emission scanning electron microscope (SEM; JEOL Ltd., Tokyo, Japan) and examined with an accelerating voltage of $15 \mathrm{kV}$ and a probe current of $22 \mathrm{nA}$. Energy dispersive X-ray spectroscopy (EDS) was performed on three epidermal cells and three mesophyll cells per leaf using a Gatan 666 EDX spectrometer (Gatan Inc., Pleasanton, USA). For EDS analysis, only cells from areas that were free of debris and which gave counts $\geq 1200$ were selected. The EDS spectra were analysed as described by Ryan and Drysdale (1988), with data being expressed as ratios of peak height to 'white', the white being a wide region of the Xray spectrum that lacked peaks $(6-8 \mathrm{keV})$.

\subsubsection{Atomic absorption spectrometry}

Shoot cuttings with at least three fully expanded pairs of leaves from 24 green and 24 red morphs were held under white light at $900 \mu \mathrm{mol} \mathrm{m} \mathrm{m}^{-2}$ to induce betacyanin production in the red morphs. After two weeks, the base of 8 shoot cutting of each morph were either submerged in water, 200, or $400 \mathrm{mM} \mathrm{NaCl}$ for $3 \mathrm{~d}$ and kept under the same light conditions. Additionally, 24 shoots of each of the green and red morphs, that were not pre-treated, were subjected to the same salt treatment as described above and kept under shaded light at $10 \mu \mathrm{mol} \mathrm{m}^{-2} \mathrm{~s}^{-1}$. The red morph in this case had lost their red pigmentation in the glasshouse and betacyanin production was not induced during the 3-d salt treatment.

Following these treatments, the epidermis of 4-6 leaves per shoot was peeled off and the main vascular bundle was removed. Epidermis and mesophyll tissues were weighed and then freeze dried using a FreeZone ${ }^{\circledR}$ Plus ${ }^{\mathrm{TM}} 4.5$ Litre Cascade (Labconco Corporation, Kansas City, USA) for $3 \mathrm{~d}$. After freeze-drying, the samples were weighed again, then ground and digested in $10 \%$ $\mathrm{HNO}_{3}$ and $5.2 \% \mathrm{HCl}$ at reflux temperature for $30 \mathrm{~min}$ and then diluted with distilled water to $1.4 \% \mathrm{HNO}_{3}$ and $0.74 \% \mathrm{HCl}$. A calibration curve for $\mathrm{Na}$ and $\mathrm{K}$ measurements was made with $0,1.25,2.5,3.75,5,6.25,7.5,8.75$ and $10 \mu \mathrm{g} / \mathrm{ml} \mathrm{NaCl}$ or $\mathrm{KCl}$ in distilled water with $1.4 \%$ HNO3 and $0.74 \% \mathrm{HCl}$. The $\mathrm{Na}$ and $\mathrm{K}$ content was determined with a ICE3000 Series AAspectrometer (ThermoScientific, Waltham, Massachusetts, USA) combined with an ASX520 Autosampler (CETAC Technologies, Omaha, Nebraska, USA).

\subsubsection{Conductivity measurements}

To quantify the salt secreted by $D$. australe leaves, ten shoot tips per morph, each shoot bearing two pairs of fully-expanded leaves, were harvested from plants grown outdoors in pots over the summer to ensure the red morphs maintain pigment production. The plants were originally 
collected as described in 1.2.1. The bases of five red and five green morphs were submerged in $800 \mathrm{mM} \mathrm{NaCl}$ or distilled water and held under $450 \mu \mathrm{mol} \mathrm{m}^{-2} \mathrm{~s}^{-1}$ white light at room temperature for $3 \mathrm{~d}$. One leaf was collected from each shoot and washed in deionized water, and the conductivity of the washing solution was measured using an InLab 751-4MM probe and a SevenCompact pH/Cond S213 conductivity meter (Mettler Toledo, Greifensee, Switzerland).

\subsubsection{Salt gland counts}

Epidermal peels were removed from the mature leaves from 5 red and 5 green morphs. Salt glands were counted under an Olympus CX33 compound microscope (Olympus Optical Co., Tokyo, Japan)

\subsubsection{Viability staining}

The viability staining protocol was adapted from Bose et al., (2014b). Fully expanded leaves of red and green $D$. australe plants were incubated in basic salt medium (BSM) $\left(0.1 \mathrm{mM} \mathrm{CaCl}_{2}\right.$, $0.5 \mathrm{mM} \mathrm{KCl}, \mathrm{pH} 5.7)$ or in $400 \mathrm{mM} \mathrm{NaCl}$ in BSM for $24 \mathrm{~h}$ under white light $\left(1400 \mu \mathrm{mol} \mathrm{m} \mathrm{s}^{-2}\right.$

$\left.{ }^{1}\right)$. Transverse cross-sections of the central part of the leaf were hand cut and stained in the dark with $5 \mu \mathrm{g} / \mathrm{ml}$ fluorescein diacetate (FDA) for $7 \mathrm{~min}$ and then with $3 \mu \mathrm{g} / \mathrm{ml}$ propidium iodine (PI) for $12 \mathrm{~min}$. FDA is a viability probe to test for enzymatic activity and membrane integrity; PI cannot permeate living cells, and therefore only stains dead cells. The sections were rinsed in distilled water, and then examined in a fluorescence microscope (Leica MZ12; Leica Microsystems, Wetzlar, Germany) with I3-wavelength filter (Leica Microsystems) and illuminated by an ultra-high-pressure mercury lamp (Leica HBO Hg 100 W; Leica Microsystems). The excitation and emission wavebands were 450-495 nm for FDA and 495$570 \mathrm{~nm}$ for PI. Photographs were taken using a Leica DFC295 digital camera, and images processed using LAS V3.8 software (Leica Microsystems).

\subsubsection{Statistics}

R (R Core Team, 2018) and the lmerTest (Kuznetsova et al., 2017) and emmeans (Lenth, 2018) packages were used for statistical data analysis. The Fligner-Killeen test was used to test for homogeneity of variance. To analyse the EDX data a linear mixed effects regression was fitted, predicting $\mathrm{Na}$ and $\mathrm{K}$ content from tissue type (mesophyll, epidermis), treatment (water, 200 $\mathrm{mM} \mathrm{NaCl}$ ) and morph (G, RG, R), and their interactions, including a random effect (leaf) to account for nesting of observations. Differences in conductivity were based on two factors treatment (water, $800 \mathrm{mM} \mathrm{NaCl}$ ) and were analysed using a two-way ANOVA. Pairwise comparisons of estimated marginal means using the emmeans function were performed for 
between treatment comparisons. A t-test was used to compare the numbers of salt glands per leaf between red and green morphs.

\subsection{Results}

Green fluorescence indicating the presence of vacuolar sodium was recorded in transverse sections of leaves or internodes from both red and green $D$. australe after treatment with 200 $\mathrm{mM} \mathrm{NaCl}$ for $3 \mathrm{~d}$ (Figure 2.4.1). Cross-sections from green control plants treated with distilled water did not show green fluorescence, while those of the red morphs under the same conditions showed a weak fluorescence signal. Red plants are usually collected from rather saline soils and most likely still contained small amounts of residual salt after the treatment with distilled water. For the salt treated leaves of the green morph the green fluorescence was visible in both the mesophyll and the epidermis, indicating a relatively uniform distribution of sodium across both tissues (Figure 2.4.1 f). In contrast, for the red leaves treated with $200 \mathrm{~mm} \mathrm{NaCl}$ the green fluorescence was largely confined to epidermal cells, indicating that sodium had accumulated predominantly in the betacyanin-containing epidermis (Figure 2.4.1 b). Stems from both red and green morphs showed green fluorescence only in epidermal cells and not in the cortex (Figure 2.4.1). 


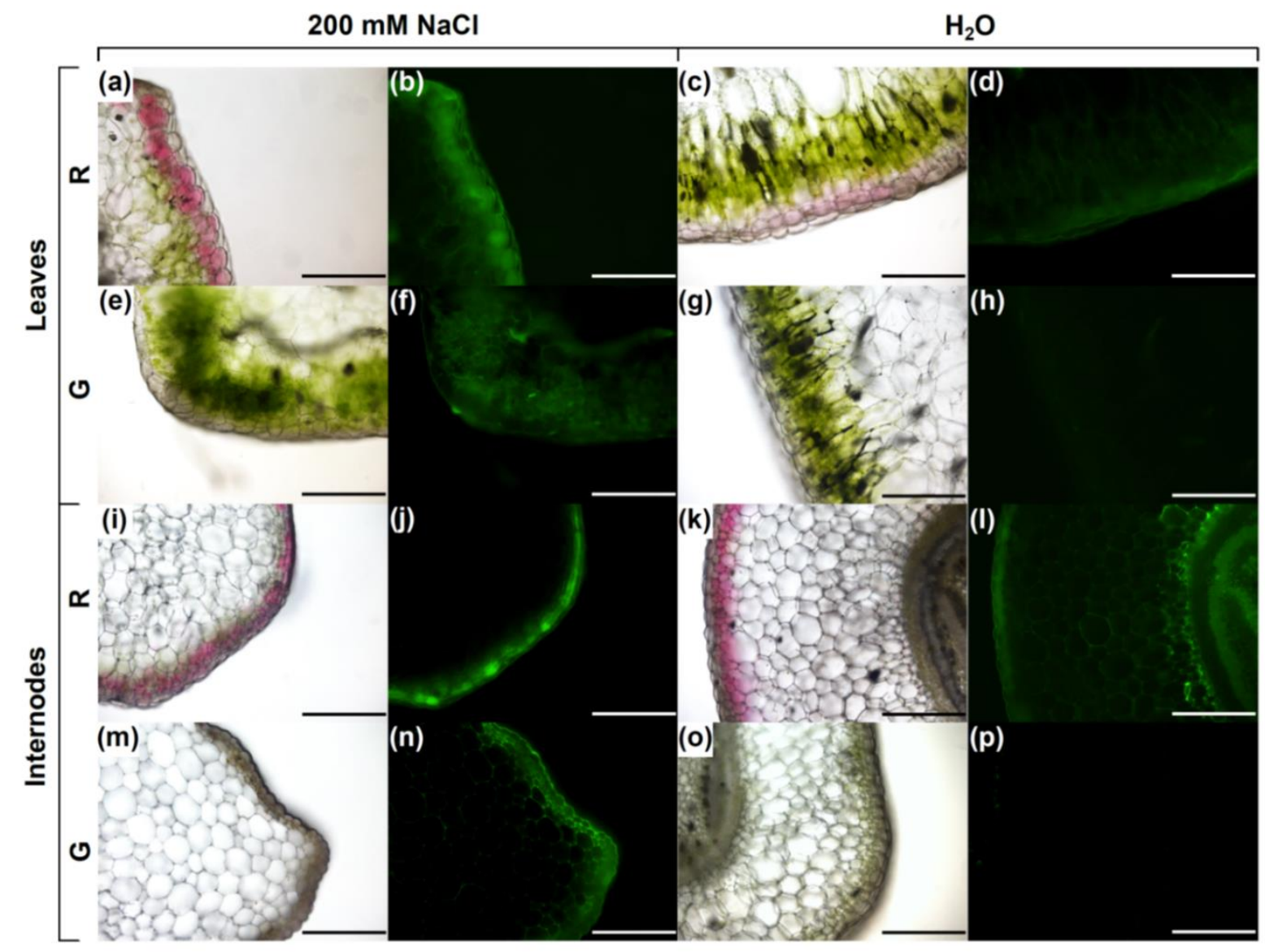

Figure 2.4.1 Light- and fluorescence micrographs of transverse sections through red (a-d, i1) and green (e-h, m-p) D. australe leaves (a-h) and internodes (i-m). Shoots were treated for 3 d with $200 \mathrm{mM} \mathrm{NaCl}$ (a, b, e, f, i, j, m, n) or $\mathrm{H}_{2} \mathrm{O}$ (c, d, g, h, k, 1, o, p). Green fluorescence indicates cytosolic $\mathrm{Na}^{+}$using SBFI fluorophore. Bars $=400 \mu \mathrm{m}$

The vacuolar $\mathrm{Na}^{+}$content after salt treatment was determined by EDX. $\mathrm{Na}^{+}$concentrations were significantly greater for both epidermal and mesophyll cells in the red morphs (R) than in the red morphs that had turned green in the glasshouse (GR), but did not differ significantly from the levels in the green morph $(\mathrm{G})$ (Figure 2.4.2 a). In both the $\mathrm{R}$ and $\mathrm{G}$ morphs there was a slightly higher $\mathrm{Na}^{+}$content in the vacuoles of epidermis cells compared to mesophyll cells. However, in the GR morph there was no difference in vacuolar $\mathrm{Na}^{+}$content between mesophyll and epidermis cells. The levels of $\mathrm{Na}^{+}$were consistently lower in the water-treated plants than in the salt-treated plants, and there were no differences among morphs (Figure 2.4.2 b).

The stems of salt treated red morphs showed significantly higher $\mathrm{Na}^{+}$concentrations in the vacuoles of epidermis and cortex cells than the green morph (Figure 2.4.2 c). The red morph had more $\mathrm{Na}^{+}$in the epidermis than in the cortex, but there was none in the green morph. In the control plants the stems of the red morph had significantly more $\mathrm{Na}^{+}$of vacuoles in the cortex 
than in the epidermis, whereas there was no significant difference between the two tissues in the green morph (Figure 2.4.2 d).
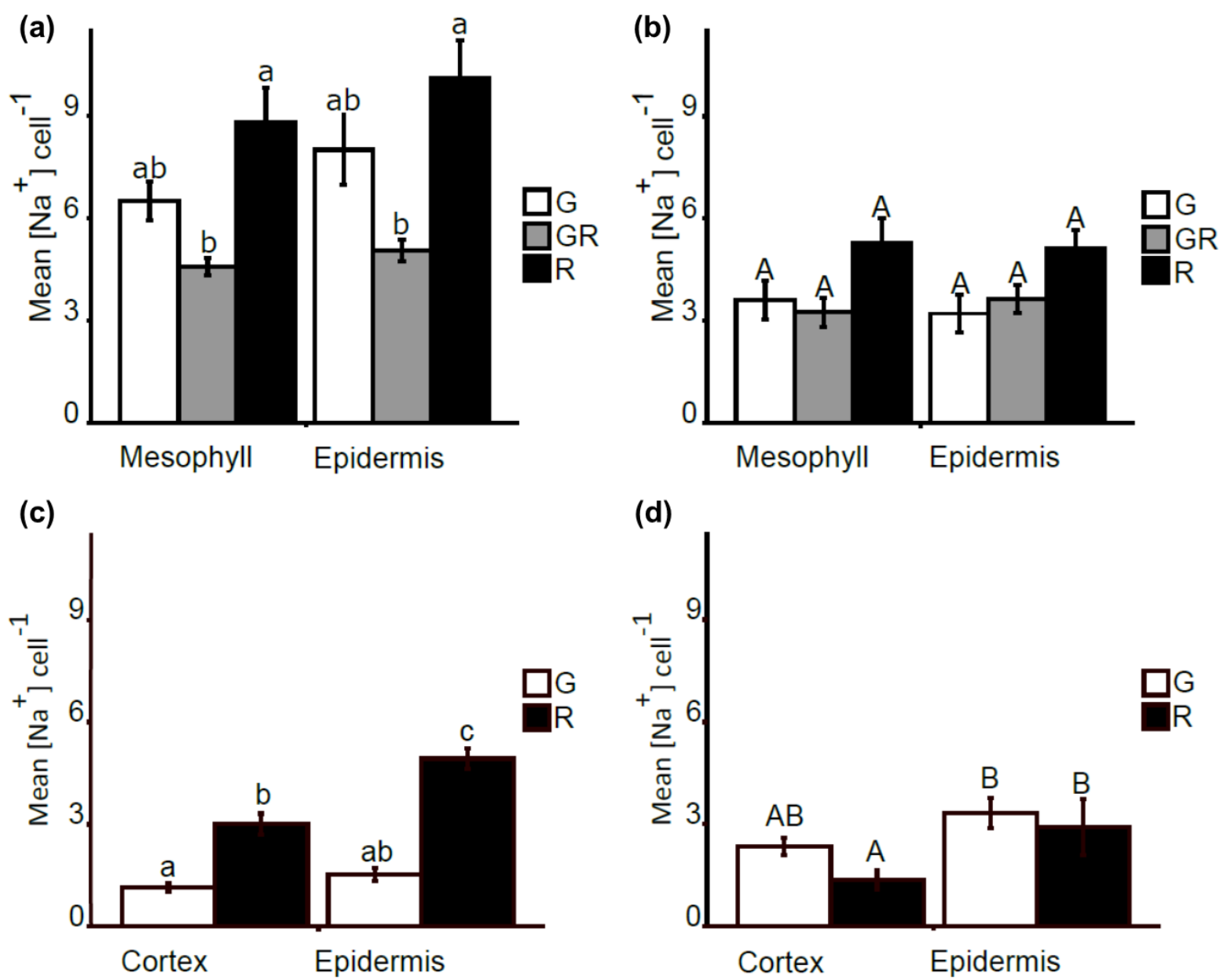

Figure 2.4.2 Mean relative sodium content per cell (arbitrary units) in epidermis (a, c) and mesophyll (b, d) of leaves (a, b) and stems (c, d) treated with $200 \mathrm{mM} \mathrm{NaCl}$ or distilled water for $3 \mathrm{~d}$. Means $\pm \mathrm{SE}$ of three cells per tissue measured using EDX. Different letters represent significant differences between the mean values $(\mathrm{P}<0.05)$. Means were calculated from 9 leaves or 3 stems of each green morph $(\mathrm{G})$, red morph $(\mathrm{R})$, and red morphs that turned green (GR) under no-stress conditions.

Consistent with the fluorescence microscopy observations, the epidermal cells in the $\mathrm{R}$ morphs tended to have higher $\mathrm{Na}^{+}$levels than did those in the $\mathrm{G}$ morphs. However, there was considerable variability in Na content among the three cells selected randomly from within any one leaf, and the differences between $\mathrm{G}$ and $\mathrm{R}$ morphs were not statistically significant. The high variability in $\mathrm{Na}^{+}$content in the epidermis might, indicate that there is a gradient in sodium content across the epidermis and the sodium concentration might be higher in epidermis cells surrounding salt glands than in cells further away from sat glands. Therefore, a third method, 
atomic absorption spectroscopy, was used to enumerate possible differences in $\mathrm{Na}^{+}$content between the entire epidermal and mesophyll tissues. Unfortunately, I had to pool the epidermis of 8 plants together to get enough epidermis tissue for AAS analysis. Therefore, I could not run any statistical analysis on this data and the following results must be interpreted with caution.

Under low light conditions the $\mathrm{Na}^{+}$content was $115.59 \mathrm{mg} / \mathrm{g}$ dry weight in the epidermis of the green morph compared to $88.42 \mathrm{mg} / \mathrm{g}$ dry weight in the red morph after treatment with $200 \mathrm{mM}$ $\mathrm{NaCl}$ (Figure 2.4.3 a). If treated with $400 \mathrm{mM} \mathrm{NaCl}$ the mesophyll of the green morph had a sodium content of $213.77 \mathrm{mg} / \mathrm{g}$ dry weight compared to $182.25 \mathrm{mg} / \mathrm{g}$ dry weight in the red morph (Figure $2.4 .3 \mathrm{c}$ ). The $\mathrm{K}^{+}$content of plants treated with $400 \mathrm{mM} \mathrm{NaCl}$ was $61.81 \mathrm{mg} / \mathrm{g}$ dry weight in the epidermis of the red morph compared to $93.11 \mathrm{mg} / \mathrm{g}$ dry weight in the green morph (Figure 2.4.3 e) The mesophyll tissue had a $\mathrm{K}^{+}$content of $186.33 \mathrm{mg} / \mathrm{g}$ dry weight in the red morph and $118.80 \mathrm{mg} / \mathrm{g}$ dry weight in the green morph, when treated with $200 \mathrm{mM} \mathrm{NaCl}$ and kept under low light conditions (Figure 2.4.3 g).

If the plants were exposed to both high light and $200 \mathrm{mM} \mathrm{NaCl}$, the $\mathrm{Na}^{+}$concentration in the epidermis of betacyanic plants was $78.27 \mathrm{mg} / \mathrm{g}$ dry weight and 62.45 in green plants (Figure 2.4.3 e). After exposure to both high light and high salt stress the sodium content in both epidermis and mesophyll was $131.15 \mathrm{mg} / \mathrm{g}$ dry weight and $197.52 \mathrm{mg} / \mathrm{g}$ dry weight in the green morph, while it was only $85.95 \mathrm{mg} / \mathrm{g}$ dry weight and $80.79 \mathrm{mg} / \mathrm{g}$ dry weight in the red morph (Figure $2.4 .3 \mathrm{~b}, \mathrm{~d}$ ). The $\mathrm{K}^{+}$content in the mesophyll of green morphs treated with $200 \mathrm{mM}$ $\mathrm{NaCl}$ was $190.87 \mathrm{mg} / \mathrm{g}$ dry weight compared to $163.61 \mathrm{mg} / \mathrm{g}$ dry weight in the red morphs (Figure $2.4 .3 \mathrm{~h}$ ). After treatment with $400 \mathrm{mM} \mathrm{NaCl}$ the epidermal $\mathrm{K}^{+}$content was $108.77 \mathrm{mg} / \mathrm{g}$ dry weight in the red morph and $70.82 \mathrm{mg} / \mathrm{g}$ dry weight in the green morph (Figure 2.4.3 $\mathrm{f}$ ). 

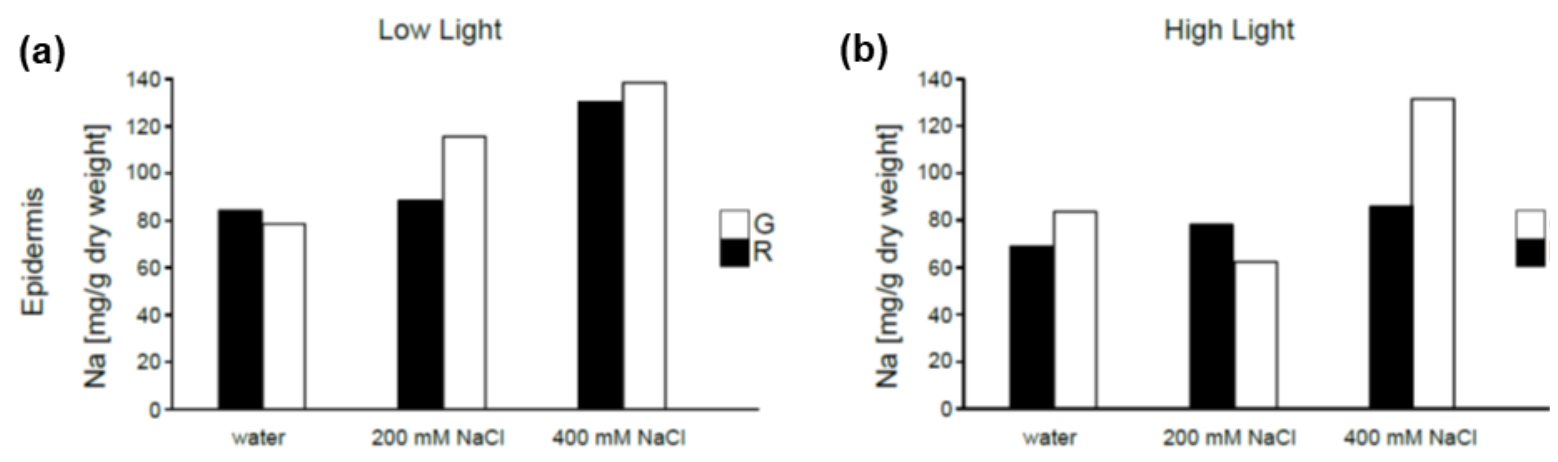

(c)

(d)
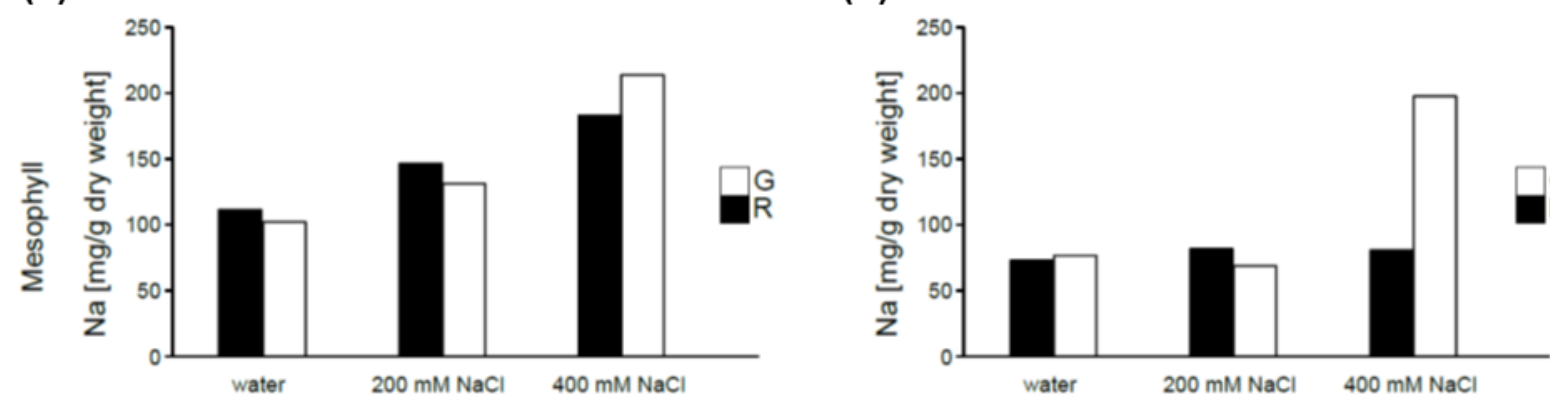

(e)

(f)
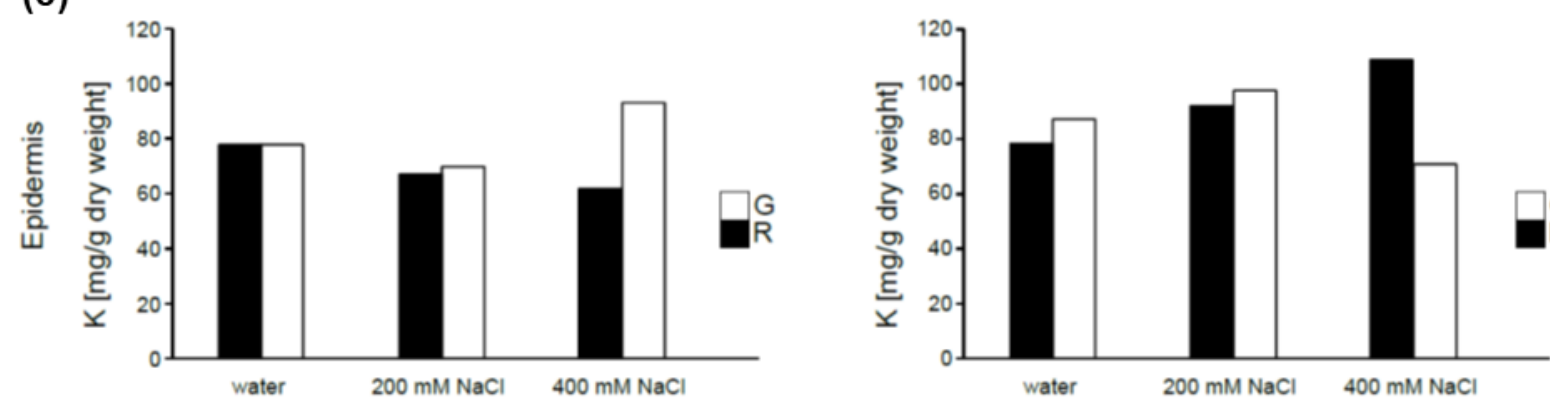

(g)

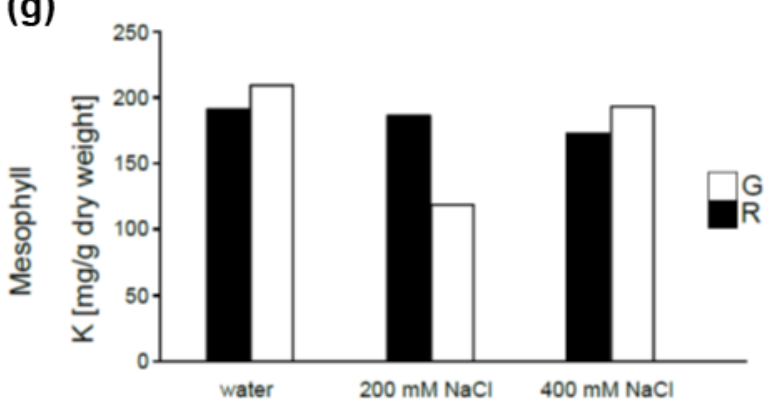

(h)

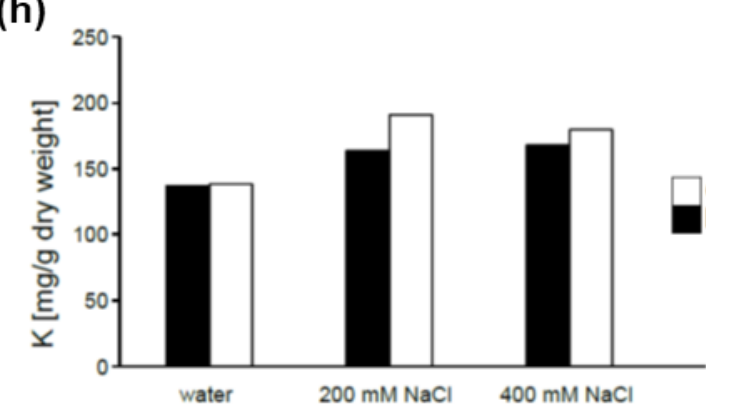

Figure 2.4.3 Mean $\mathrm{Na}(\mathrm{a}-\mathrm{d})$ and $\mathrm{K}(\mathrm{e}-\mathrm{h})$ content of epidermis (a, b, e, f) and mesophyll (c, $\mathrm{d}, \mathrm{g}, \mathrm{h})$ tissue of red $(\mathrm{R})$ and green $(\mathrm{G})$ D. australe leaves treated with 0,200 , or $400 \mathrm{mM}$ $\mathrm{NaCl}$ and held under low light $\left(10 \mu \mathrm{mol} \mathrm{m} \mathrm{m}^{-2} \mathrm{~s}^{-1}\right)(\mathrm{a}, \mathrm{c})$ or high light $\left(900 \mu \mathrm{mol} \mathrm{m}^{-2} \mathrm{~s}^{-1}\right)(\mathrm{b}, \mathrm{d})$ for $3 \mathrm{~d}$. Shoots treated under high light were kept under high light conditions for 2 wk to induce pigment production in the red morphs. Each bar shows the pooled value from 8 replicates analysed with AAS. 
As I was most interested in the sodium content of epidermis compared to mesophyll tissue, I calculated the ratio of sodium content in epidermis to sodium content in mesophyll. Without high light treatment prior to the treatment with $400 \mathrm{mM} \mathrm{NaCl}$ or distilled water, there was no obvious difference between the ratio of sodium content in epidermal to mesophyll tissues. However, the ratio was 0.88 in the green morph and 0.60 in the red morph after treatment with $200 \mathrm{mM} \mathrm{NaCl}$ (Figure 2.4.4 a). A similar pattern was observed for potassium concentrations, where the ratio was 0.59 in the green morph and 0.36 in the red morph after treatment with 200 $\mathrm{mM} \mathrm{NaCl}$ (Figure 2.4.4 c). Differences between the red and green morph under low light conditions were unlikely to be due to the presence of betacyanins, as the red morph had lost pigmentation prior to the start of this experiment and remained green during the $3 \mathrm{~d}$ of treatment. Under high light, however, the red morph produced betacyanic leaves, and after treatment with $400 \mathrm{mM} \mathrm{NaCl}$ the ratio of sodium concentration in epidermis to mesophyll tissues was 1.06 , while in green leaves it was only 0.66 (Figure 2.4 .4 b). If treated with distilled water or 200 $\mathrm{mM} \mathrm{NaCl}$, there were no major differences between red and green leaves. A similar pattern was observed for the ratio of potassium content in epidermis to mesophyll tissue. In betacyanic leaves the ratio of potassium concentration in epidermis to mesophyll tissues was 0.65 and in green leaves it was 0.39 (Figure 2.4.4 d). 
(a)

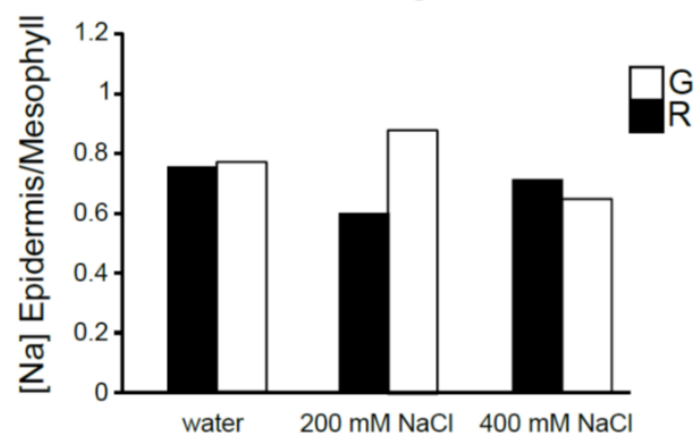

(c)

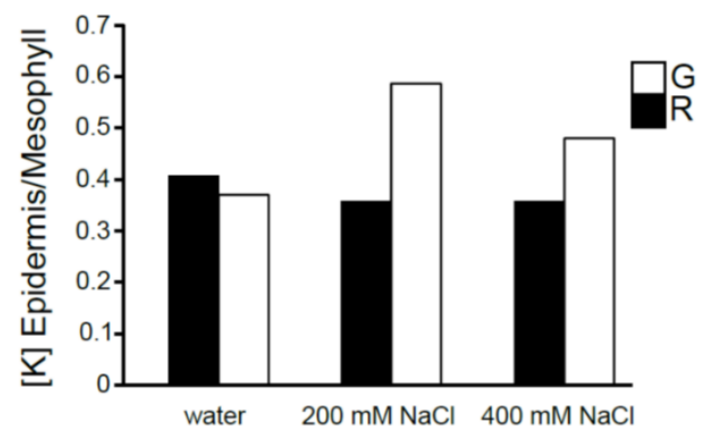

(b)

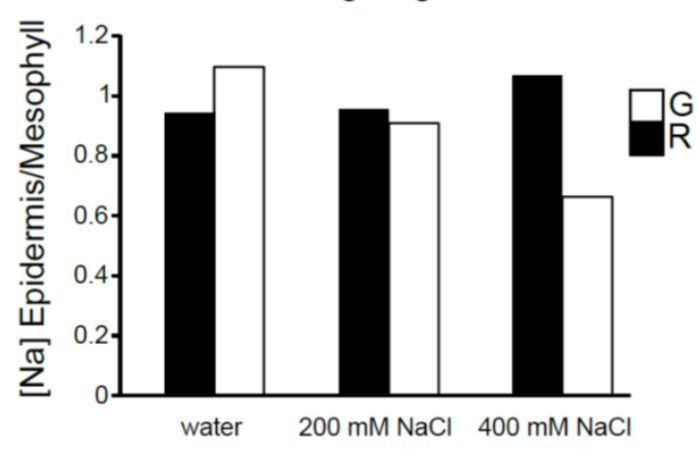

(d)

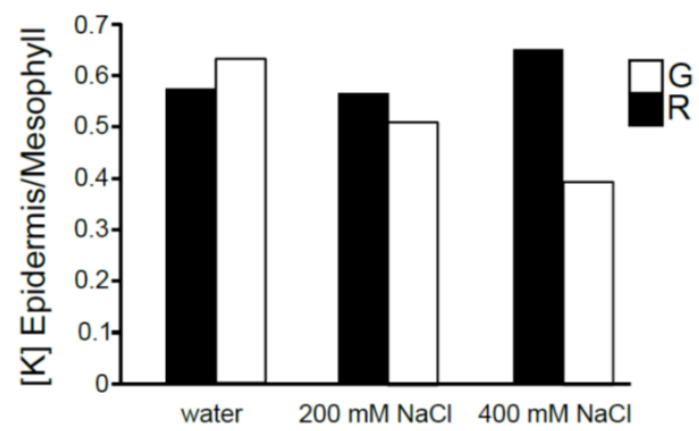

Figure 2.4.4 Ratio of mean $\mathrm{Na}(\mathrm{a}, \mathrm{b})$ and $\mathrm{K}(\mathrm{c}, \mathrm{d})$ content in epidermis to mesophyll tissue of leaves from red $(\mathrm{R})$ and green $(\mathrm{G})$ morphs treated with 0,200 , or $400 \mathrm{mM} \mathrm{NaCl}$ and held under low light $\left(10 \mu \mathrm{mol} \mathrm{m}^{-2} \mathrm{~s}^{-1}\right)(\mathrm{a}, \mathrm{c})$ or high light $\left(900 \mu \mathrm{mol} \mathrm{m}^{-2} \mathrm{~s}^{-1}\right)(\mathrm{b}, \mathrm{d})$ for $3 \mathrm{~d}$. Shoots treated under high light were kept under high light conditions for 2 wk to induce pigment production in the red morphs. Each bar shows the pooled value from 8 replicates analysed with AAS.

Under salinity stress maintaining a high $\mathrm{K}^{+} / \mathrm{Na}^{+}$ratio in the cytosol is essential for key metabolic processes, including photosynthesis protein biosynthesis. Therefore, the $\mathrm{K}^{+} / \mathrm{Na}^{+}$ratio of both epidermis and mesophyll from red and green morphs after treatment with 0,200 or $400 \mathrm{mM}$ $\mathrm{NaCl}$ for $3 \mathrm{~d}$ was calculated from the AAS data. Under low light conditions the epidermal $\mathrm{K}^{+} / \mathrm{Na}^{+}$ratio was ratio was 0.67 in green morphs compared to 0.47 in red morphs after treating the plants with $400 \mathrm{mM} \mathrm{NaCl}$. However, if treated with $200 \mathrm{mM}$ the epidermis of red morphs had a K $\mathrm{K}^{+} \mathrm{Na}^{+}$ratio of 0.75 and the epidermis of green leaves had a $\mathrm{K}^{+} / \mathrm{Na}^{+}$ratio of 0.60 (Figure 2.4.5 a). The $\mathrm{K}^{+} / \mathrm{Na}^{+}$ration in the mesophyll tissue was 1.27 in the red morph and 0.91 in the green morph after the plants were treated with $200 \mathrm{mM} \mathrm{NaCl}$.

If pigment production was induced by high light conditions and the plants were kept in $200 \mathrm{mM}$ $\mathrm{NaCl}$ the green leaves had a $\mathrm{K}^{+} / \mathrm{Na}^{+}$ratio 1.56 and 2.78 in epidermis and mesophyll, 
respectively, while the red morph had 1.18 and 2.00 (Figure 2.4.5 b, d). However, if the plants were exposed to both high light and high salt stress the betacyanic leaves had a $\mathrm{K}^{+} / \mathrm{Na}^{+}$ratio of 1.27 and 2.08 in epidermis and mesophyll tissue, respectively. In contrast, the green leaves had a $\mathrm{K}^{+} / \mathrm{Na}^{+}$ratio of only 0.54 and 0.91 in epidermis and mesophyll tissue (Figure 2.4.5 b, d).
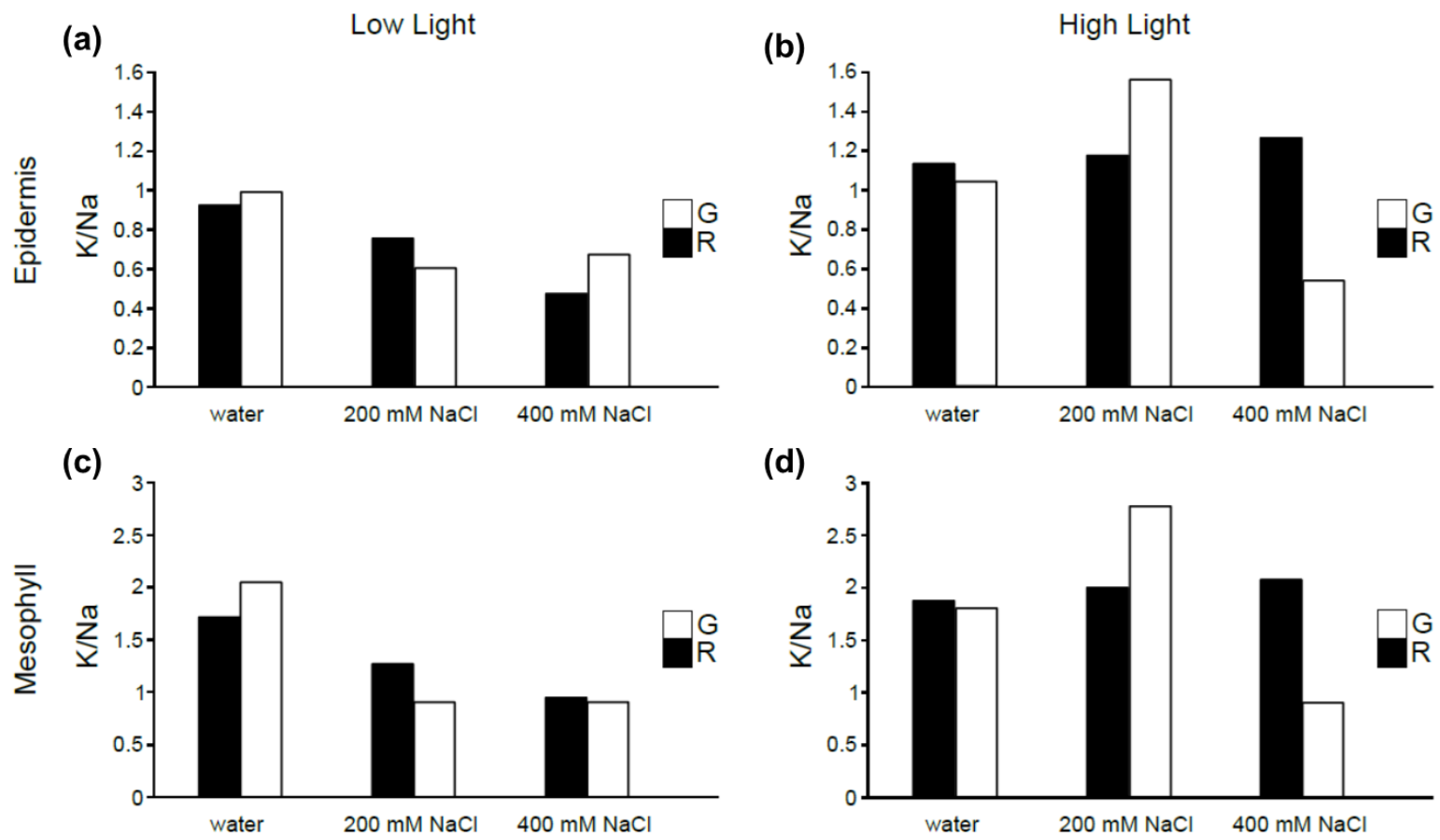

Figure 2.4.5 Ratio of mean $\mathrm{K}$ to Na content in epidermis $(\mathrm{a}, \mathrm{b})$ and mesophyll $(\mathrm{c}, \mathrm{d})$ tissue of leaves from red (R) and green (G) morphs treated with 0,200 , or $400 \mathrm{mM} \mathrm{NaCl}$ and held under low light $\left(10 \mu \mathrm{mol} \mathrm{m}^{-2} \mathrm{~s}^{-1}\right)(\mathrm{a}, \mathrm{c})$ or high light $\left(900 \mu \mathrm{mol} \mathrm{m} \mathrm{m}^{-2} \mathrm{~s}^{-1}\right)(\mathrm{b}, \mathrm{d})$ for $3 \mathrm{~d}$. Shoots treated under high light were kept under high light conditions for 2 wk to induce pigment production in the red morphs. Each bar shows the pooled value from 8 replicates analysed with AAS

Salt glands were present on the leaf epidermis in similar numbers in the red and green morphs (Figure 2.4.6 a). The glands were on average 4.6-fold bigger than epidermis cells, and were located exclusively on the three ridges of the triangular leaves (Figure 2.4.6 b, d). There was a significant difference in conductivity of the leaf washes of red and green morphs treated with $800 \mathrm{mM} \mathrm{NaCl}$. The conductivity of leaf washes from red morphs were almost two-fold higher compared to green morphs (Figure 2.4.6 c). This cannot be explained by a higher number of salt secreting cells; therefore, a higher secretion rate is the more plausible explanation. 
(a)

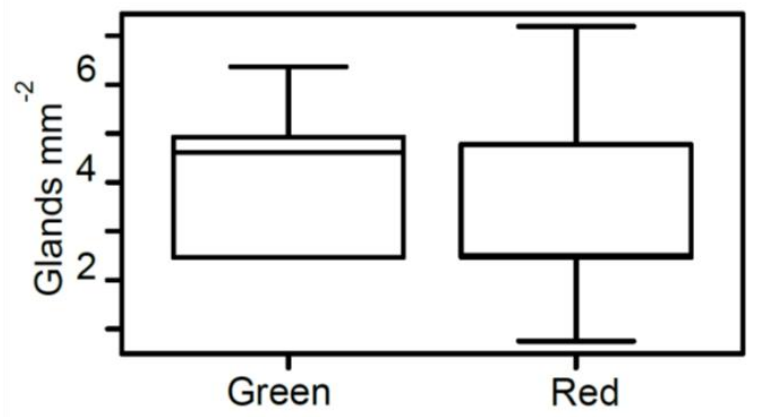

(c)

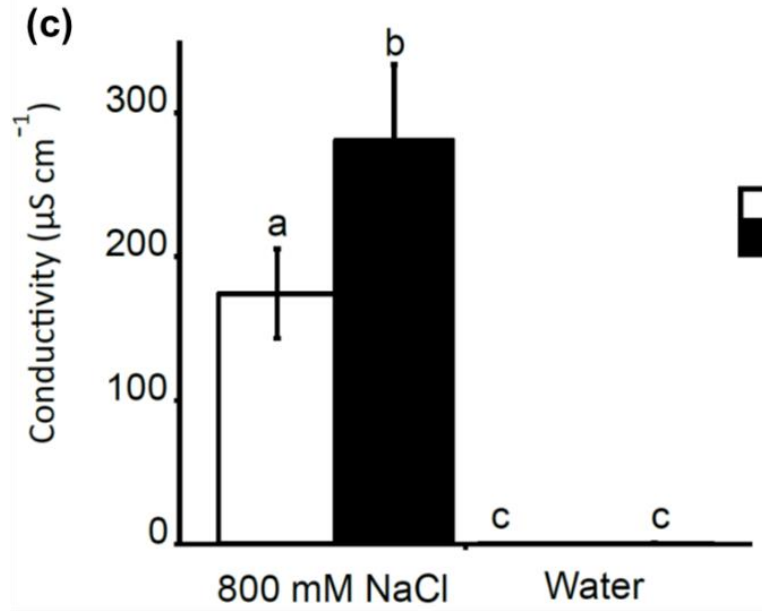

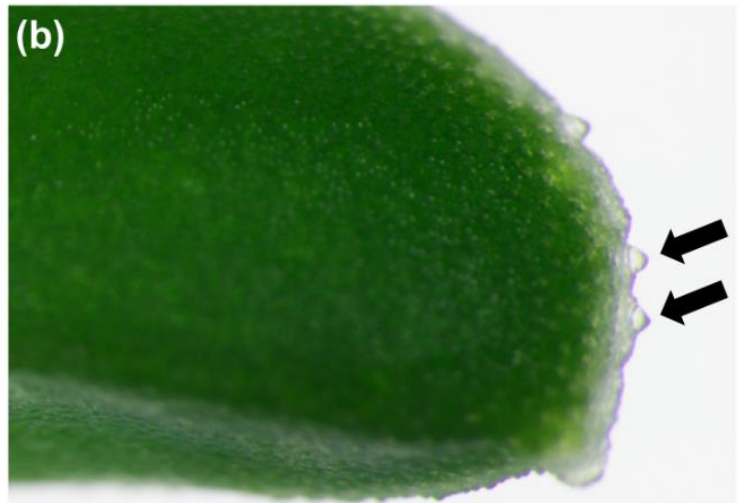

$\overline{400 \mu \mathrm{m}}$

\section{(d)}

Figure 2.4.6 Mean conductivity of leaf washes from shoot cuttings treated with $800 \mathrm{mM}$ $\mathrm{NaCl}$ or water for $3 \mathrm{~d}$. Means $\pm \mathrm{SE}$ of 5 leaves of each green morph $(\mathrm{G})$ and red morph $(\mathrm{R})$. Different letters represent significant differences between the mean values $(\mathrm{P}<0.05)$. Micrographs showing salt glands of green (b) and betacyanic (d) D. australe leaves.

Green and red fluorescence indicating living and dead cells, respectively, was recorded in transverse sections of red and green D. australe leaves after 24 h treatment with BSM or 400 $\mathrm{mM} \mathrm{NaCl}$ (Figure 2.4.7). Under control conditions $96 \%$ and $98 \%$ of the mesophyll cells were viable in the green and red morph, respectively. After $24 \mathrm{~h}$ in $400 \mathrm{mM} \mathrm{NaCl} 96 \%$ of the mesophyll cells were still alive in betacyanic leaves, while in green leaves only $30 \%$ of mesophyll cells were still viable (Table 2.1). 


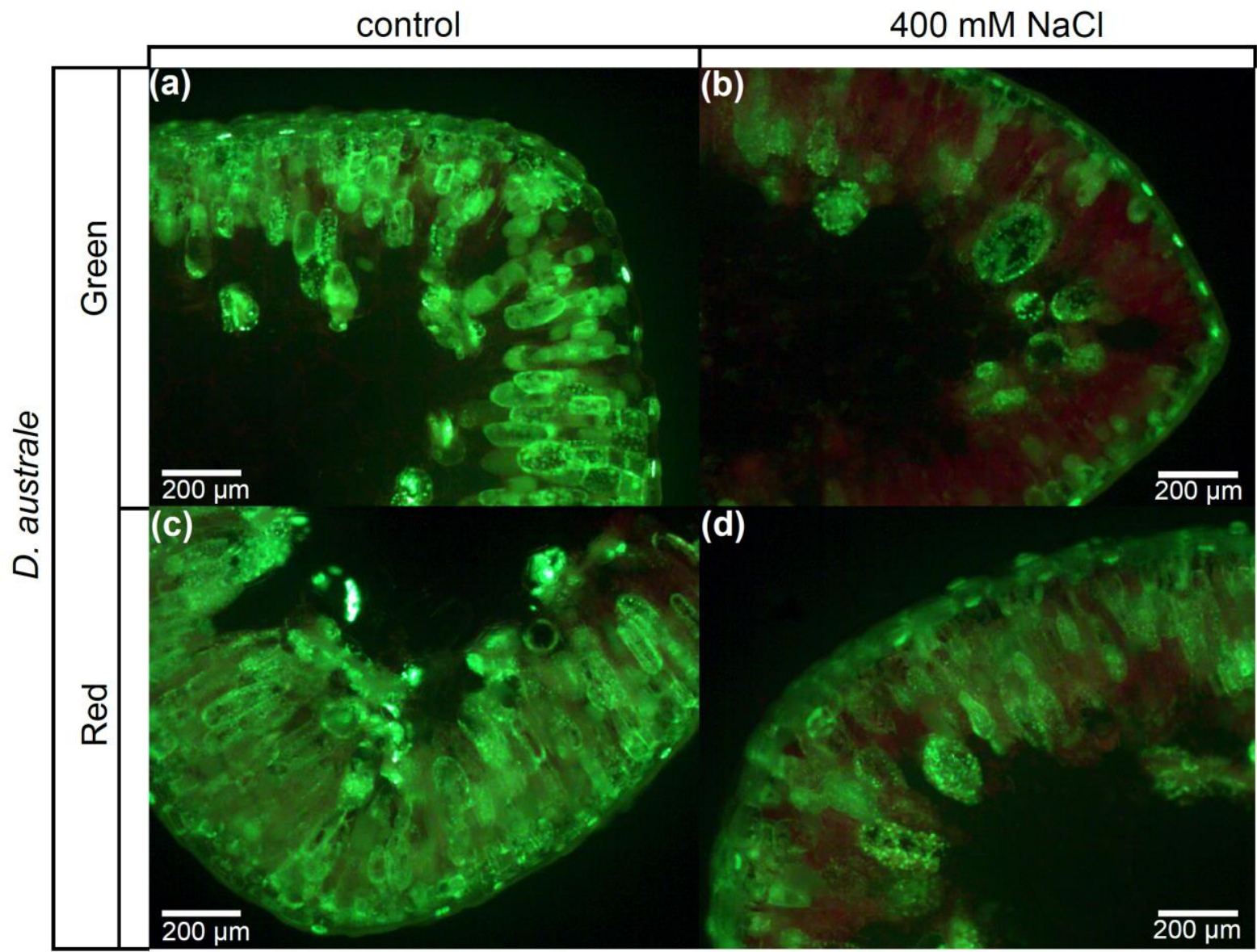

Figure 2.4.7 Fluorescence micrographs of cross-sections of green $(\mathrm{a}, \mathrm{b})$ and red $(\mathrm{c}, \mathrm{d}) D$. australe leaves; co-stained with fluorescein diacetate and propidium iodide after $24 \mathrm{~h}$ in BSM (a, c) or $400 \mathrm{mM} \mathrm{NaCl}$ (b, d). Green fluorescence indicates viable cells; red fluorescence indicates dead cells.

Table 2.1 Percentage of viable mesophyll cells in red and green $D$. australe leaves after $24 \mathrm{~h}$ treatment with BSM or $400 \mathrm{mM} \mathrm{NaCl}$, Means, $\mathrm{n}=5+$ SE. Different letters represent significant differences between the mean values $(\mathrm{P}<0.05)$

\begin{tabular}{lcc}
\hline Morph & Treatment & \% Viable mesophyll \\
\hline Green & $400 \mathrm{mM} \mathrm{NaCl}$ & $30 \pm 9.60 \mathrm{a}$ \\
Green & Control & $96 \pm 1.14 \mathrm{~b}$ \\
Red & $400 \mathrm{mM} \mathrm{NaCl}$ & $96 \pm 2.01 \mathrm{~b}$ \\
Red & Control & $98 \pm 0.97 \mathrm{~b}$
\end{tabular}




\subsection{Discussion}

Previous research has shown that betacyanic $D$. australe plants are able to complete their life cycle under saline conditions and are able to maintain net carbon assimilation under light stress, while green plants show symptoms of salt and light stress (Jain \& Gould, 2015b; Jain et al., 2015). As a photoprotective effect of betacyanins is insufficient in explaining the lack of cytotoxic symptoms of salt stress in non-betacyanic tissues, we proposed that red plants avoid the cytotoxic effects of sodium by preferentially transporting sodium way from mesophyll chlorenchyma when betacyanins are present in the epidermis.

Our fluorescence microscopy results for betacyanic and green leaves support this hypothesis (Figure 2.4.1). Green fluorescence indicating the presence of sodium was detected mainly in the epidermis of betacyanic leaves, but not in the photosynthetically active mesophyll tissue. In contrast, green leaves showed green fluorescence both in the epidermis and mesophyll, thus indicating a more uniform distribution of sodium. However, cryo-SEM coupled with EDX showed that even in the green leaves the sodium content in epidermal cells was slightly higher than in mesophyll cells (Figure 2.4.2). AAS confirmed the sodium distribution pattern observed using fluorescence microscopy and showed that the ratio of sodium content in epidermis to mesophyll tissues was higher in betacyanic leaves than in green leaves (Figure 2.4.4) and found that the $\mathrm{K}^{+} / \mathrm{Na}^{+}$ratio was higher in the mesophyll cells of betacyanic leaves compared to green leaves (Figure 2.4.5). Transporting excess sodium into the vacuole to avoid the cytotoxic effects of sodium is a well-known salt tolerance mechanism known as compartmentalisation (Munns $\&$ Tester, 2008; Flowers \& Colmer, 2015). Partitioning ions between different leaf tissues upon salt stress has been observed previously in barley (James et al., 2006b). This study compared the photosynthetic capacity and cellular and sub-cellular $\mathrm{Na}^{+}, \mathrm{K}^{+}$, and $\mathrm{Cl}^{-}$partitioning of durum wheat and barley. Barley was more successful at cellular and sub-cellular $\mathrm{Na}^{+}$and $\mathrm{K}^{+}$ partitioning, which resulted in a higher cytosolic $\mathrm{K}^{+} / \mathrm{Na}^{+}$ratio in mesophyll tissue. A higher $\mathrm{K}^{+} / \mathrm{Na}^{+}$ratio in the cytosol of mesophyll cells was associated with maintaining a higher photosynthetic capacity under salt stress (James et al., 2006b). However, the focus has mainly been on $\mathrm{Cl}^{-}$with several studies showing that $\mathrm{Cl}^{-}$increased preferentially in epidermal vacuoles compared to vacuoles in mesophyll cells (Fricke et al., 1994, 1996; Wei et al., 2003; James et al., 2006b). However, for $\mathrm{Na}^{+}$partitioning the results have been contradictory. While some studies found no difference in sodium distribution within salt treated leaves, Fricke and colleagues (1996) observed higher $\mathrm{Na}^{+}$concentrations in vacuoles of epidermis cells than mesophyll cells. Within the epidermis the $\mathrm{Na}^{+}$concentration was highest in cells closest to 
stomata, suggesting that $\mathrm{Na}^{+}$follows a passive pathway in the transpiration stream. This might explain the high variability in epidermal $\mathrm{Na}^{+}$concentration we observed via EDX, as it is entirely possible that the $\mathrm{Na}^{+}$concentration is higher closer to salt glans, in $D$. australe. Passive transport via the transpiration stream could similarly explain the slightly higher sodium content of epidermis cells than mesophyll cells in green $D$. australe plants. The more prominent difference in vacuolar sodium content between those two tissues in betacyanic $D$. australe plants indicates that there might be an active process that involves betacyanins. Previous studies found that the presence of betacyanins increased V-ATPase activity, which is necessary to maintain the proton-gradient across the tonoplast, allowing active transport processes into the vacuole (Wang et al., 2001, 2008b). The water-soluble betacyanins accumulate in the same cell vacuoles as $\mathrm{Na}^{+}$. Thus, Wang and colleagues (2008) suggested that betacyanins and $\mathrm{Na}^{+}$may share a similar transport mechanism; the increased V-ATPase activity resulting from betacyanin accumulation might also energise the active transport of $\mathrm{Na}^{+}$into the vacuole. This mechanism could explain the increased vacuolar sodium content in betacyanic cells we have observed.

Both green and betacyanic leaves secreted salt during salt treatment and we found salt glands on each of the three ridges of the triangular leaves of both morphs. There was no difference in salt gland abundance per leaf area, yet the betacyanic morph had an almost two-fold higher salt secretion rate than did the green morph (Figure 2.4.6). The salt glands found in the Aizoaceae, the family $D$. australe belongs to, are all of the salt bladder type, consisting of large vacuolated cells with or without stalk cells (Dassanayake \& Larkin, 2017). Mesembryanthemum crystallinum (ice plant), a close relative of $D$. australe, has been used to study epidermal bladder cells. A comparison of wild type $M$. crystallinum with a mutant that lacks epidermal bladder cells, has shown that the mutant plants accumulate higher levels of $\mathrm{Na}^{+}$in mesophyll cells, which leads to greater salt damage, lower growth rates, and lower reproductive capacity; by contrast, the wild type plants were able to partition $\mathrm{Na}^{+}$into salt bladders and secrete excess $\mathrm{Na}^{+}$(Agarie et al., 2007). In D. australe the higher salt secretion rate in betacyanic leaves might partially explain the lower $\mathrm{Na}^{+}$content in mesophyll cells, as the excess $\mathrm{Na}^{+}$is secreted instead of accumulated in the vacuoles of mesophyll cells. The higher salt secretion rate might also result from the preferential accumulation of $\mathrm{Na}^{+}$in betacyanin containing epidermis cells resulting in higher $\mathrm{Na}^{+}$concentrations in the tissue surrounding salt bladders and in more efficient sodium secretion. This might be a mechanism to keep cytosolic $\mathrm{Na}^{+}$concentration in the mesophyll low, thereby avoiding the cytotoxic effects of $\mathrm{Na}^{+}$on the photosynthetically active tissue. Viability staining confirmed that for salt-treated betacyanic leaves, mesophyll 
viability was substantially higher than that in green plants (Figure 2.4.7). This indicates that betacyanic plants are indeed more successful in protecting the photosynthetically active tissue form the cytotoxic effects of $\mathrm{Na}^{+}$. Therefore, this could explain the previously observed higher salt tolerance of betacyanic $D$. australe plants compared to green morphs.

In conclusion, this study showed that the presence of betacyanins altered the $\mathrm{Na}^{+}$distribution within leaves, leading to $\mathrm{Na}^{+}$accumulation in epidermal cells and higher $\mathrm{Na}^{+}$secretion rates compared to non-betacyanic leaves. Therefore, I suggest that betacyanins might play an important role in salt tolerance in D. australe. However, more studies are needed to investigate the mechanism how betacyanins can alter sodium distribution or effect salt secretion. 


\section{Chapter 3 Salt Stress Induced $\mathrm{K}^{+}$Uptake into Leaf Mesophyll Cells of Disphyma australe and Disphyma crassifolium}

\subsection{Abstract}

Saline soils severely reduce yields of crop plants, yet halophytes naturally thrive in salty environments. An understanding of salt tolerance mechanisms in halophytes has become vital. Ion flux responses to salt stress were studied in Disphyma australe and Disphyma crassifolium using the non-invasive microelectrode ion flux estimation technique to test the hypothesis that that in the presence of betacyanin mesophyll cells would show increased $\mathrm{K}^{+}$retention under salt stress conditions, explaining the observed increase in $\mathrm{Na}^{+} / \mathrm{K}^{+}$ratio in red leaves. Mesophyll cells of both species showed a highly unusual $\mathrm{K}^{+}$flux response to salt stress; while in most crop plants $\mathrm{K}^{+}$leaks out of root and mesophyll cells upon salt stress, the Disphyma species showed $\mathrm{K}^{+}$influx into mesophyll cells. This salt-induced $\mathrm{K}^{+}$uptake only occurred in the presence of $\mathrm{Cl}^{-}$ , but not if only $\mathrm{Na}^{+}$was present. Taking up both cations and anions at the same time could avoid membrane depolarisation and the resulting activation of voltage-gated channels, which facilitate salt induced $\mathrm{K}^{+}$efflux in glycophytes. The energy dependent $\mathrm{K}^{+}$uptake from the apoplast to maintain a high cytosolic $\mathrm{K}^{+} / \mathrm{Na}^{+}$ratio during salt stress might be an entirely new mechanism to combat the cytotoxic effect of $\mathrm{Na}^{+}$during salt stress in these halophytes.

\subsection{Introduction}

Soil salinity caused the loss of about 8 million tons of produce in 2014 and a reduction in agricultural revenues of about US\$ 3.7 billion (Welle \& Mauter, 2017). Currently, soil salinization predominantly affects countries in arid and semi-arid climate zones. Previously fertile land in Australia, USA and South East Asia are now too saline to grow crops (Swarajyalakshmi et al., 2003; Rozema \& Flowers, 2008; Wang et al., 2008a; Hasegawa, 2013). Moreover, climate change is predicted to lead to rising sea levels, scarcity of fresh water, and an increase in aridity; the more intense and prolonged periods of drought are further enhancing the rate of soil salinization (Jesus et al., 2015). To combat advancing soil salinization while maintaining food security for the world's growing population, understanding plant salt tolerance has become vital. 
On saline substrates plants suffer from two types of stress: osmotic and cytotoxic. Osmotic stress is induced when the solute concentration in the soil exceeds about $40 \mathrm{mM} \mathrm{NaCl}$ for most plants and the water potential in the medium surrounding the roots decreases. A low osmotic pressure thermodynamically impedes the water uptake from roots, resulting in water deficit (Pardo, 2010; Läuchli \& Grattan, 2011; Roy et al., 2014; Almeida et al., 2017). Moreover, osmotic stress causes stomatal closure, resulting in reduced $\mathrm{CO}_{2}$ assimilation (Munns \& Sharp, 1993). With a reduction in $\mathrm{CO}_{2}$ assimilation rate, photooxidation and thus $\mathrm{H}_{2} \mathrm{O}_{2}$ production increases, causing oxidative stress (Noctor et al., 2002; Percey et al., 2014).

Cytotoxic stress, on the other hand, occurs when $\mathrm{Na}^{+}$and /or $\mathrm{Cl}^{-}$accumulate in the cytosol and reach toxic levels (Munns \& Tester, 2008; Roy et al., 2014). Cytosolic $\mathrm{Cl}^{-}$concentrations over $80 \mathrm{mM}$ can inhibit protein synthesis, while $\mathrm{Na}^{+}$can accumulate up to $100 \mathrm{mM}$ before causing substantial damage to the plant (Flowers \& Dalmond, 1992; Flowers et al., 2015). However, in most plants, $\mathrm{Na}^{+}$reaches cytotoxic levels earlier than $\mathrm{Cl}^{-}$(Tester \& Davenport, 2003). The underlying cause for the ion toxicity of $\mathrm{Na}^{+}$is that the accumulation of $\mathrm{Na}^{+}$disrupts the $\mathrm{Na}^{+} / \mathrm{K}^{+}$ ratio in the cytosol. In plants, $\mathrm{K}^{+}$plays an essential role in enzyme activation, turgor generation, osmotic adjustment, cytoplasmic $\mathrm{pH}$ homeostasis, and regulation of membrane potential (Barragan et al., 2012; Almeida et al., 2017). $\mathrm{K}^{+}$and $\mathrm{Na}^{+}$are so similar in size that $\mathrm{Na}^{+}$can block $\mathrm{K}^{+}$binding sites of enzymes and act as a competitive inhibitor of $\mathrm{K}^{+}$. The higher the $\mathrm{Na}^{+}$ concentration in relation to $\mathrm{K}^{+}$concentration, the more likely it is that $\mathrm{Na}^{+}$instead of $\mathrm{K}^{+}$binds to an open binding site, resulting in impaired enzymatic activity (Munns et al., 2006; Lebaudy et al., 2007; Wu et al., 2015). $\mathrm{K}^{+}$is required for activation of over 50 cytoplasmic proteins, such as pyruvate kinase, phosphofructokinase, membrane bound ATPases, and vacuolar pyrophosphatase. Thus, a disrupted $\mathrm{K}^{+}$homeostasis causes severe impairment of metabolism and protein synthesis (Marschner, 2012).

Despite the immense stress salt causes, there are plants, called halophytes, that naturally grow in saline environments, such as coastal salt marshes, tidal zones, and saline desserts. These plants have adopted various strategies to combat salt stress and survive in those challenging environments (Flowers \& Colmer, 2015). Some halophytes have developed specialized epidermal structures, such as salt bladders or salt glands, to store or secrete salt (Dassanayake \& Larkin, 2017). To combat osmotic stress, some plants produce either compatible solutes, including proline, glycine, polyamines and sugar alcohols, or accumulate inorganic ions to facilitate osmotic adjustment (Flowers, 2004; Shabala \& Shabala, 2011; Deinlein et al., 2014). To protect themselves from ionic stress, plants prevent $\mathrm{Na}^{+}$accumulation in metabolically 
active tissue and maintain low $\mathrm{Na}^{+}$concentrations in the transpiration stream; this process is known as exclusion (Adolf et al., 2013; Hasegawa, 2013; Flowers et al., 2015). To achieve this, ion uptake by roots via channels and transporters is highly regulated and selective. Additionally, xylem loading of $\mathrm{Na}^{+}$is restricted and $\mathrm{K}^{+}$is loaded preferentially to maintain a low $\mathrm{Na}^{+} / \mathrm{K}^{+}$ ratio. Moreover, some plants even unload $\mathrm{Na}^{+}$from the xylem into the cortical parenchyma at the upper parts of the roots to avoid $\mathrm{Na}^{+}$transport to the shoot and leaves (Munns, 2002). To avoid the cytotoxic effects of $\mathrm{Na}^{+}$, plants may compartmentalise $\mathrm{Na}^{+}$into the vacuole and endosome, thus maintaining a low $\mathrm{Na}^{+} / \mathrm{K}^{+}$ratio in the cytosol (Munns \& Tester, 2008). This process is especially important in the photosynthetically active mesophyll tissue, where the ability of a cell to pump $\mathrm{Na}^{+}$out of the cytosol is limited. High cytosolic $\mathrm{Na}^{+}$concentrations in mesophyll cells can inhibit primary photosynthetic reactions in the chloroplasts, which is known as non-stomatal limitation (Rajendran et al., 2009; Sirault et al., 2009; Percey et al., 2014).

Maintaining normal $\mathrm{K}^{+}$homeostasis under salt stress is essential for plant survival. However, most plants leak $\mathrm{K}^{+}$from the cytosol of root and leaf cells upon salt stress. In turn, the depleted cytosolic $\mathrm{K}^{+}$pool can impair key metabolic processes or even trigger programmed cell death (Shabala, 2000, 2009; Shabala et al., 2005, 2006b; Shabala \& Cuin, 2008; Demidchik et al., 2010). The $\mathrm{K}^{+}$leak is facilitated by different channels. Guard cell outward rectifying $\mathrm{K}^{+}$ channels (GORKs), for example, might be one of the major channels involved, as they are not only expressed in guard cells, but also in the root epidermis. GORKs are activated by plasma membrane depolarisation, which can be induced by increased $\mathrm{Na}^{+}$uptake or excess ROS and, therefore, often occurs under salt stress (Hosy et al., 2003; Véry et al., 2014; Shabala, 2017). $\mathrm{K}^{+}$outward rectifying channels (KORCs) are also opened upon plasma membrane depolarisation. (Maathuis et al., 1997; Blumwald, 2000). Moreover, non-selective $\mathrm{K}^{+}$outward rectifying channels (NORCs) are activated by high cytosolic $\mathrm{Ca}^{2+}$ levels. Under salt stress cytosolic $\mathrm{Ca}^{2+}$ concentrations increase and the resulting activation of NORCs leads to both $\mathrm{Na}^{+}$ uptake and $\mathrm{K}^{+}$efflux. NORCs can contribute to plasma membrane depolarisation and cause further $\mathrm{K}^{+}$leakage due to activating voltage gated channels, such as, GORKs, KORCs, and nonselective cation channels (NSCCs).

Under salt stress, plant performance and ultimately survival largely depends on the efficiency of the photosynthetic machinery. Salinity-induced $\mathrm{K}^{+}$deficiency leads to decreased photosynthetic capacity (Ball et al., 1987; Chow et al., 1990; Wu et al., 2015).Thus, $\mathrm{K}^{+}$ homeostasis in mesophyll cells is essential for maintaining an optimal photosynthesis rate, 
during salinity stress (Wu et al., 2015). In both mesophyll and epidermis cells, $\mathrm{K}^{+}$is actively transported into the vacuole (Cuin et al., 2003; Bassil et al., 2011; Wu et al., 2015). From there it can potentially be released into the cytosol to compensate for the decreasing cytosolic $\mathrm{K}^{+}$ content during salt stress. In barley mesophyll, for example, vacuolar $\mathrm{K}^{+}$concentrations decreased during salt treatment, while the cytosolic $\mathrm{K}^{+}$barely (Hordeum vulgare) changed (Fricke et al., 1996; Cuin et al., 2003; Wu et al., 2015). However, not the complete $\mathrm{K}^{+}$pool seems to be available to combat the salt-induced $\mathrm{K}^{+}$leak (Fricke et al., 1996; Wu et al., 2015). Therefore, mesophyll cells need an extracellular source of $\mathrm{K}^{+}$, which most likely is the epidermis (Wu et al., 2015). A study using barley identified three $\mathrm{K}^{+}$transport systems, but no significant changes in the expression levels of the genes for these transport systems during salt stress. Thus, the authors suggested that $\mathrm{K}^{+}$retention is essential in mesophyll cells, instead of $\mathrm{K}^{+}$uptake from neighbouring epidermis cells (Boscari et al., 2009; Wu et al., 2015). Wu et al., (2015) showed that in broad beans (Vicia faba) there was a strong correlation between overall salinity tolerance and $\mathrm{K}^{+}$retention in the mesophyll.

Studies on ionic balances in mesophyll tissues have mainly focused on crop species, ignoring halophytes. Halophytes survive on saline soils where normal crop plants are unable to grow. Therefore, understanding salt tolerance mechanisms in halophytes is crucial for identifying new potential salt tolerance genes (Mishra \& Tanna, 2017). A promising line of research reported recently involves a small group of red pigments called betacyanins, which are found in some halophytes. Betacyanins are tyrosine-derived alkaloids, that only occur in certain families of the Caryophyllales and some Basidiomycetes (Brockington et al., 2015). Recent studies have shown that betacyanins might play a role in salt tolerance. For example, betacyanin biosynthesis can be induced by high light and /or high salt treatment (Ibdah et al., 2002; Wang \& Liu, 2007; Hayakawa \& Agarie, 2010; Nakashima et al., 2011; Jain et al., 2015). Moreover, betacyanins have been suggested to confer a photoprotective effect by absorbing yellow-green light and reducing the excitation pressure on chloroplasts, under salinity stress (Nakashima et al., 2011; Jain et al., 2015).

The putative benefit of betacyanins on plant salt tolerance have been studied in $D$. australe, a succulent halophyte occurring on costal dunes throughout New Zealand. The presence of betacyanins in $D$. australe correlated with a higher growth rate under salt stress, as well as higher maximum $\mathrm{CO}_{2}$ assimilation rates, water use efficiency, and photochemical quantum yields of PSII (Jain \& Gould, 2015b). Additionally, in Chapter 2, I showed that betacyanic $D$. australe leaves had a higher mesophyll viability under salt stress than do non-betacyanic leaves 
(Figure 2.3.7); the red leaves also had lower $\mathrm{Na}^{+}$concentrations (Figure 2.3.3) and a lower $\mathrm{Na}^{+} / \mathrm{K}^{+}$ratio in mesophyll cells (Figure 2.3.5). These differences could be explained by differences in $\mathrm{Na}^{+}$and/or $\mathrm{K}^{+}$transport during salt stress in red and green leaves. However, nothing has been documented about the regulation of ion fluxes in the red and green leaves of this halophyte. To examine possible effects of betacyanin on $\mathrm{K}^{+}$homeostasis and ion relations in mesophyll cell, we measured ion fluxes of mesophyll cells from betacyanic and green $D$. australe leaves, as well as leaves from $D$. crassifolium, a close relative. So close in fact that there is a controversy, whether D. australe and D. crassifolium are separate species (see 1.5). $D$. crassifolium is native to Tasmania, where the ion flux studies were conducted, thus $D$. crassifolium was used for ion flux experiments, after establishing that both spices are similar in salt tolerance and show similar ion flux responses to salinity. I hypothesised that in the presence of betacyanin mesophyll cells would show increased $\mathrm{K}^{+}$retention under salt stress conditions, explaining the observed increase in $\mathrm{Na}^{+} / \mathrm{K}^{+}$ratio in red leaves.

\subsection{Materials and Methods}

\subsubsection{Plant Material}

Healthy betacyanic D. crassifolium plants were collected from the Ralph's Bay Conservation Area in Lauderdale, Tasmania (42 $\left.55^{\prime} 26.4^{\prime \prime S} 147^{\circ} 29^{\prime} 16.9^{\prime \prime} \mathrm{E}\right)$ where the plants were regularly flooded with sea water. Green D. crassifolium plants were collected from Sandford, Tasmania $\left(42^{\circ} 56^{\prime} 13.3^{\prime \prime S} 147^{\circ} 30^{\prime} 43.3^{\prime \prime E}\right)$ near a freshwater pond, where the plants were not exposed to salt stress. In contrast to $D$. australe, D. crassifolium does not have a betacyanic and a green morph; all D. crassifolium plants are able to produce betacyanins when they experience a combination of salinity and high light. The plants were potted in commercial potting compost. The green plants were grown in an unheated glasshouse during the summer months at the University of Tasmania, in Hobart, Australia, and watered with tap water daily. The betacyanic plants were watered with $400 \mathrm{mM} \mathrm{NaCl}$ and kept outside under natural light to ensure continued betacyanin production.

Healthy red and green $D$. australe shoots were collected from the cost at Te Kopahau reserve, Wellington, New Zealand ( $\left.41^{\circ} 21^{\prime} 01^{\prime \prime} S, 174^{\circ} 43^{\prime} 55^{\prime \prime E}\right)$. Only plants that were accessible from the footpath or could be reached after a short climb were collected. Shoot cuttings bearing at least two mature pairs of opposite leaves were potted in a 2:1 (v/v) mix of commercial potting compost and pre-washed sand, and were grown in an unheated glasshouse under natural light 
at Victoria University of Wellington, New Zealand, and watered with tap water for at least 3 month before shipping to Hobart, Tasmania. Shoot cuttings bearing at least five pairs of mature leaves were shipped separately with wet paper towels in centrifugation tubes. Upon arrival in Hobart the plants were fumigated with $32 \mathrm{mg} / \mathrm{m}^{3}$ methyl bromide for $2.5 \mathrm{~h}$. After fumigation, the plants were potted in commercial potting compost and grown in an unheated glasshouse during the summer month at the University of Tasmania, in Hobart, Tasmania. After 8 wks additional lights were installed and both the red and green morph were kept at $970 \mu \mathrm{mol} \mathrm{m} \mathrm{m}^{-2}$ ${ }^{1}$ light and were either watered with tap water (green morph) or $400 \mathrm{mM} \mathrm{NaCl}$ (red morph) daily.

For each of the experiments five different plants of each red and green $D$. australe or $D$. crassifolium were used per treatment.

\subsubsection{The Non-Invasive MIFE Technique}

\section{Theoretical background}

Net ion flux across membranes was measured using the non-invasive MIFE technique University of Tasmania, Australia. In theory, if a cell takes up an ion, the ion's concentration in proximity of the plasma membrane would be lower than further away. On the other hand, if there is ion efflux, the ion concentration would be higher near the plasma membrane than further away (Figure 3.3.1). The MIFE technique measures the electrochemical potential with an ion specific electrode at two positions - near the cell surface (Position 1) and further away (Position 2) - and determines the electrochemical potential gradient between them (Figure 3.2.1). Using the Nernst equation, the net ion flux $J\left(\mathrm{~mol} \mathrm{~m}^{-2} \mathrm{~s}^{-1}\right)$ can be calculated from the gradient (Newman, 2001; Shabala et al., 2006b).

$$
J=\operatorname{cuz} F g\left(\frac{d V}{d x}\right)
$$

Where $c$ is the measured ion concentration $\left(\mathrm{mol} \mathrm{m}^{-3}\right) ; u$ is the ion mobility $\left(\mathrm{m} \mathrm{s}^{-1}\right.$ per Newton $\left.\mathrm{mol}^{-1}\right) ; z$ is the ion's valence; $F$ is the Faraday number $\left(96500 \mathrm{C} \mathrm{mol}^{-1}\right) ; g$ is an electrode specific factor determined by the measured Nernst slope during electrode calibration; $d V$ is the measured voltage gradient between two positions $(\mathrm{V}) ; d x$ is the distance between these two positions. The MIFEFLUX software (University of Tasmania, Australia) automatically calculates the net ion fluxes $\left(\mathrm{nmol} \mathrm{m} \mathrm{s}^{-2} \mathrm{~s}^{-1}\right)$ based on the geometry of the cell, such as cylindrical or spherical, the cell diameter, probe distance from the cell surface (Shabala et al., 2006b). 


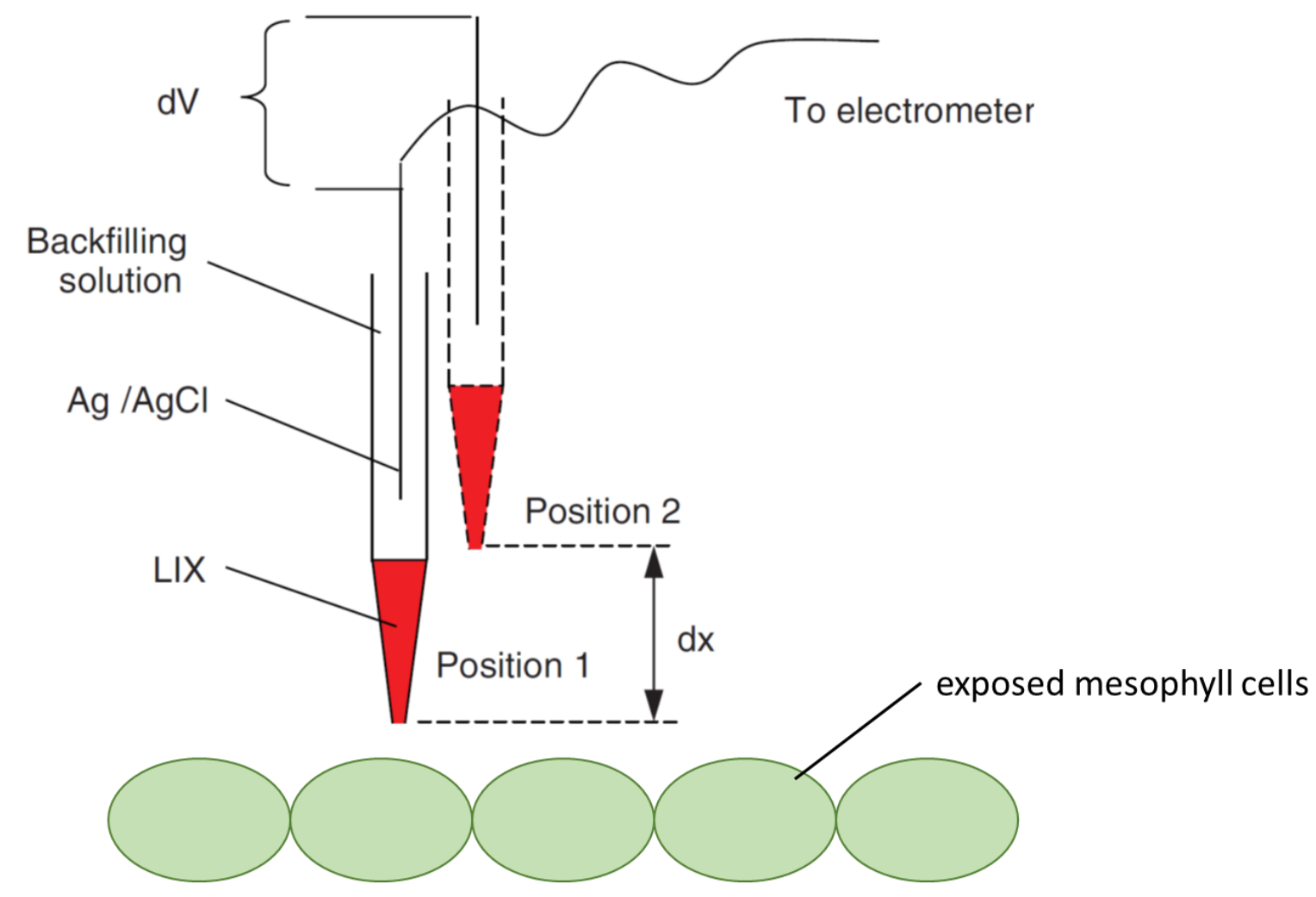

Figure 3.3.1 Principle of the non-invasive MIFE technique. The microelectrode is backfilled with an ion-specific backfilling solution and the tip is filled with liquid ion exchanger (LIX). This electrode is moved in a square-wave manner between two positions near the exposed mesophyll layer. A voltage gradient $(d V)$ is measured between two positions over a distance $(d x)$. Adapted from (Shabala et al., 2006b).

\section{MIFE set-up}

The MIFE set-up uses an inverted microscope with long-distance objectives that allow the use of an open measuring chamber for easy access to the measured sample (Figure 3.3.2). The whole MIFE set up is placed in a Faraday cage. The ion-specific microelectrodes are held by electrode holders (WI 64-0918, SDR Clinical Technology, Middle Cove, Australia), which are in turn mounted on a three-dimensional hydraulic micromanipulator. The micromanipulator is driven by a stepper motor to oscillate the microelectrodes at $0.1 \mathrm{~Hz}$ between two positions, one close to the cell surface $(\sim 20 \mu \mathrm{m})$ and one further away $(70-100 \mu \mathrm{m})$. Three different ions were measured at the same time and the electrode tips were spaced 3-4 $\mu \mathrm{m}$ apart. An analogueto-digital interface card (DAS 08, Measurement Computing Co., Middleboro, MA) on an IBMcompatible PC is used to amplify and digitalize the voltage output measured by the microelectrodes and to for offset adjustment of the electrometer. The same card also controls 
the stepper motor. The CHART program (University of Tasmania, Australia) is used to control the interface, data collection and storage (Shabala et al., 2006b).

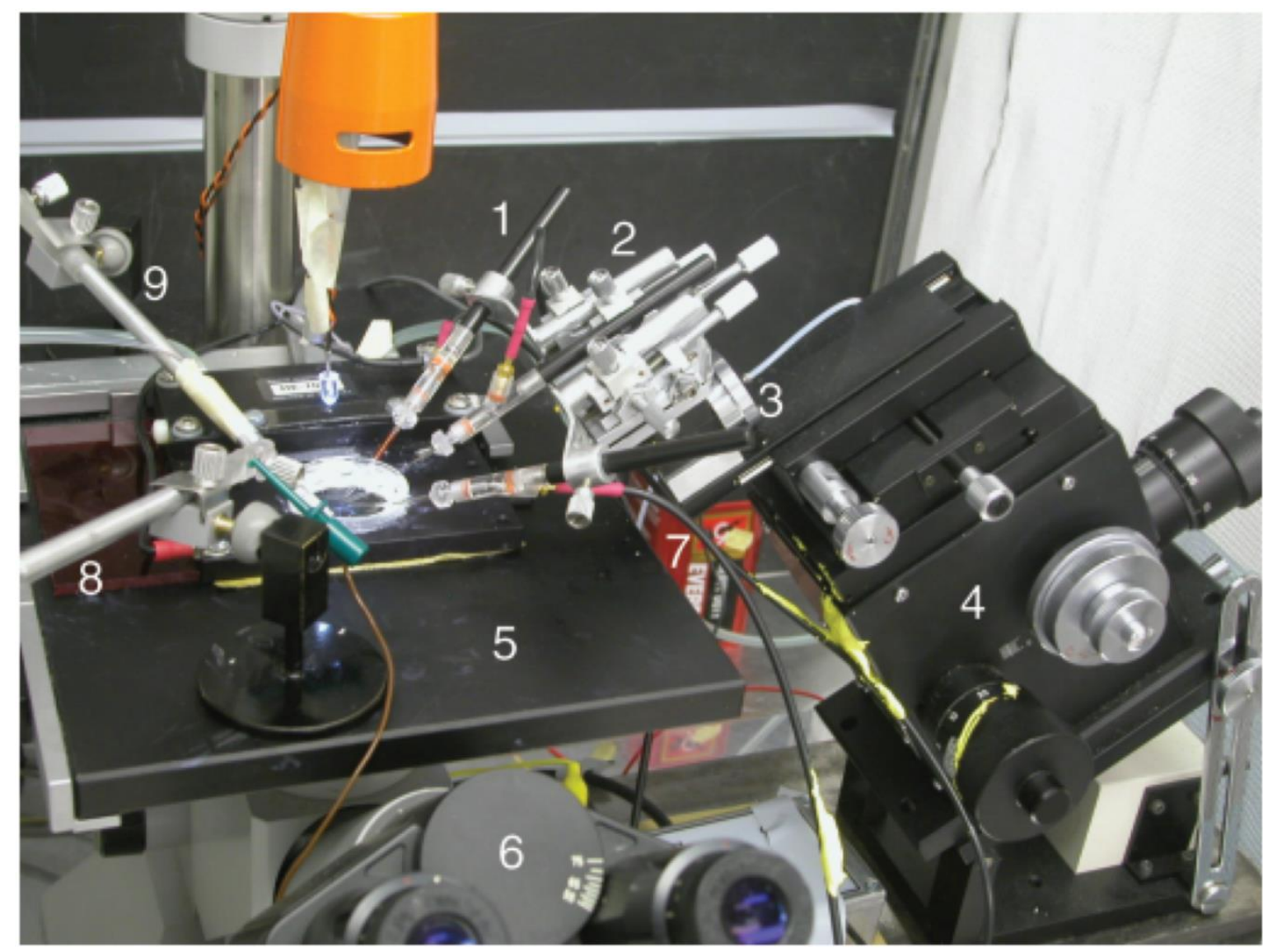

Figure 3.3.2 An assembled MIFE system. The leaves with exposed mesophyll cells were placed in the petri dish. Three ion-selective microelectrodes are mounted in electrode holders (1). Electrode holders are assembled on an MMT-5 micromanipulator (2), allowing fine electrodetip adjustment. The manipulator is mounted on the cartridge (3) of the computer-driven hydraulics manipulator (not shown). The assembled electrode unit is mounted on a 3D mechanical manipulator (4), allowing precise positioning of electrode tips near the surface of the bacterial monolayer. All manipulations are performed under high (x 200 or x 500) magnification of the microscope (6). Microscope stage (5) also contains the reference electrode holder (8) and another holder with syringe needle (9), connected to a peristaltic pump and used for rapid solution replacement. The whole unit is located within the Faraday cage. To reduce electrical noise, a battery (7) and an LED are used for illumination instead of the normal microscope lighting system adapted from Shabala et al., (2006b). 


\section{Microelectrode preparation}

Microelectrode blanks were made from $1.5 \mathrm{~mm}$ (OD) non-filamentous borosilicate glass capillaries (GC 150-10, CDR Clinical Technology, Middle Cove, Australia). With a vertical pipette puller (PP 830, Narishige, Tokyo, Japan) the glass capillaries are pulled to a tip diameter $<1 \mu \mathrm{m}$. The blanks were then dried overnight in a microwave oven at $225^{\circ} \mathrm{C}$. and then silanised with 60-75 $\mu 1$ tributylchlorosaline (Fluka Chemicals, Busch, Switzerland). The resulting blanks have a hydrophobic surface that allows the hydrophobic LIXs to be taken up into the microelectrode tip. After the electrode blanks have cooled down, the electrode tips were broken to a diameter of 2-3 $\mu \mathrm{m}$. A syringe with a thin metal needle (MF34G-5, WPI, Sarasota, FL) was then used to backfill the electrodes with the appropriate back-filling solution (Table 3.1). The electrodes were then front-filled with the appropriate LIX (Table 3.1) using a glass microcapillary with a 30-50 $\mu \mathrm{m}$ tip diameter containing the LIX. The $\mathrm{K}^{+}$electrodes could be used immediately, while $\mathrm{Na}^{+}$and $\mathrm{Cl}^{-}$electrodes had to be conditioned in $1 \mathrm{~h}$ to ensure a stable response (Shabala et al., 2006b).

Additionally, a reference electrode was fabricated in a similar way. A glass microcapillary was pulled, the tip was broken, and then the electrode was filled with $1 \mathrm{M} \mathrm{KCl}$ in $2 \%$ agar. A silver wire was galvanised in $0.25 \mathrm{~N} \mathrm{HCl}$ for $2-3 \mathrm{~min}$ and then inserted in the agar filled glass capillary and sealed with parafilm (Bemis Company, Inc, Neenah, US) The reference electrode was used for both microelectrode calibration and MIFE experiments (Shabala et al., 2006b).

Table 3.1 Specific details of the back-filling solutions and the commercially available LIX used for these experiments. All Ionophores were purchased from Fluka (Busch, Switzerland). Adapted from (Shabala et al., 2006b)

\begin{tabular}{|c|c|c|c|}
\hline Ion & $\begin{array}{l}\text { Catalogue } \\
\text { no. }\end{array}$ & LIX & $\begin{array}{l}\text { Back-filling } \\
\text { solution }\end{array}$ \\
\hline $\mathrm{K}^{+}$ & 60031 & Valinomycin & $200 \mathrm{mM} \mathrm{KCl}$ \\
\hline $\mathrm{Na}^{+}$ & 71176 & $\begin{array}{l}\text { N,N0,N00-Triheptyl-N,N0,N00-trimethyl-4,40,400- } \\
\text { propylidynetris(3-oxabutyramide) }\end{array}$ & $500 \mathrm{mM} \mathrm{NaCl}$ \\
\hline $\mathrm{Cl}^{-}$ & 24902 & $\begin{array}{l}\text { 5,10,15,20-Tetraphenyl-21H,23H-porphin } \\
\text { manganese(III) chloride }\end{array}$ & $500 \mathrm{mM} \mathrm{NaCl}$ \\
\hline
\end{tabular}




\section{Microelectrode calibration}

The filled electrodes were calibrated against a set of three standards covering the expected range of ion concentrations. The $\mathrm{Na}^{+}$and $\mathrm{Cl}^{-}$electrodes were calibrated using six instead of three standard solutions, as the expected ion concentrations ranged from 0 to $300 \mathrm{mM} \mathrm{NaCl}$ in the following MIFE experiments. Only electrodes with correlation coefficients $\geq 0.999$ and responses of $\leq 50 \mathrm{mV}$ per decade for monovalent ions and $\leq 25 \mathrm{mV}$ per decade for divalent ions were used for experiments (Shabala et al., 2006b).

\subsubsection{Non-Invasive Ion Flux Measurements}

For all MIFE experiments the epidermis of fully expanded leaves was removed with fine forceps and the leaves with exposed mesophyll were kept in basic salt medium (BSM) (0.1 mM $\mathrm{CaCl}_{2}, 0.5 \mathrm{mM} \mathrm{KCl}, \mathrm{pH} 5.7$, unbuffered) overnight to allow all wounding responses to subside before measurements (Shabala \& Newman, 1999). Approximately $30 \mathrm{~min}$ before measurements the leaves were immobilized in a $20 \mathrm{ml}$ petri dish to acclimate to light and ionic conditions.

To record the responses to different salts, the peeled leaves were placed in $20 \mathrm{ml}$ petri dishes containing $13 \mathrm{ml} \mathrm{BSM}$ and net ion fluxes were recorded for ca. 5 min under control conditions. Then the concentration of $\mathrm{NaCl}, \mathrm{KCl}$ or $\mathrm{LiCl}$ was gradually increased by adding the respective amount of salt solution made up in BSM to the measuring chamber and thoroughly mixing with a pipette. Measurements were taken for $3 \mathrm{~min}$ at each salt concentration.

To study the importance of $\mathrm{Cl}^{-}$for $\mathrm{K}^{+}$homeostasis under salt stress sodium gluconate was added instead of $\mathrm{NaCl}$. That experiment was conducted on my behalf by staff at University of Tasmania.

To determine possible effects of betacyanin and betaxanthin on the responses to salt stress, aqueous extracts of red and yellow beet root were used. For pigment extraction beet roots were cut into ca. $0.5 \mathrm{~cm}^{2}$ cubes. Distilled water was added at a ratio of $2 \mathrm{ml}$ per $\mathrm{g}$ tissue and the extract was shaken at $200 \mathrm{rmp}$ for $1 \mathrm{~h}$ at room temperature. Both pigment extracts were added to BSM at physiologically relevant concentrations according to the absorbance measurements by Jain \& Gould (2015b) and the leaves with exposed mesophyll were again immobilized for $30 \mathrm{~min}$ in $16 \mathrm{ml}$ buffered $\mathrm{BSM}\left(0.1 \mathrm{mM} \mathrm{CaCl}_{2}, 0.5 \mathrm{~mm} \mathrm{KCl}, 0.4 \mathrm{mM} \mathrm{MES}\right.$, Tris to adjust $\mathrm{pH}$ to 5.6) with betacyanin or betaxanthin extract, before measurements started. After recording net ion fluxes under control conditions for $5 \mathrm{~min}$, the $\mathrm{NaCl}$ concentration was increased to $300 \mathrm{mM}$ and mixing thoroughly. The net ion flux measurements were continued for at least another 30 $\min$. 


\subsubsection{Viability Staining}

The viability staining protocol was adapted from Bose et al., (2014b). Fully expanded leaves of red and green $D$. crassifolium and $D$. australe plants were incubated in BSM or in $400 \mathrm{mM}$ $\mathrm{NaCl}$ in BSM for $24 \mathrm{~h}$ under high light $\left(1400 \mu \mathrm{mol} \mathrm{m} \mathrm{m}^{-2} \mathrm{~s}^{-1}\right)$. Transverse cross-sections of the central part of the leaf were hand cut and stained in the dark in $5 \mu \mathrm{g} / \mathrm{ml}$ fluorescein diacetate (FDA) for $7 \mathrm{~min}$ and in $3 \mu \mathrm{g} / \mathrm{ml}$ propidium iodine (PI) for $12 \mathrm{~min}$. Afterwards the cross-sections were rinsed in distilled water before examination under a fluorescence microscope (Leica MZ12; Leica Microsystems, Wetzlar, Germany) with I3-wavelength filter (Leica Microsystems) and illuminated by an ultra-high-pressure mercury lamp (Leica HBO Hg 100 W; Leica Microsystems). The excitation and emission wavelengths for FDA and PI were 450 $495 \mathrm{~nm}$ and 495-570 nm, respectively. Photographs were taken by a digital camera (Leica DFC295, Leica Microsystems). Images were acquired and processed by LAS V3.8 software (Leica Microsystems). FDA is a viability probe to test for enzymatic activity and membrane integrity. PI is non cell-permeable in living cells and can only stain dead cells.

\subsubsection{Chlorophyll Fluorescence}

Shoot cuttings of red and green D. australe and D. crassifolium with at least two fully expanded pairs of leaves were kept in distilled water, $400 \mathrm{mM} \mathrm{NaCl}, 800 \mathrm{mM} \mathrm{NaCl}$, or $35 \%$ polyethylene glycol (PEG) for $8 \mathrm{~d}$ at $25{ }^{\circ} \mathrm{C}$ and $1500 \mu \mathrm{mol} \mathrm{m} \mathrm{s}^{-1}$ white light. The osmolarity of $35 \%$ PEG is similar to $800 \mathrm{mM} \mathrm{NaCl}$ and functions as an osmotic control to ensure that the observed responses are salt specific and not due to osmotic stress. The ratio of variable to maximum chlorophyll fluorescence $(\mathrm{Fv} / \mathrm{Fm})$ was measured using a OS-30p chlorophyll fluorometer (OPTI-Sciences, Hudson, USA) after 30 min dark adaption. Chlorophyll fluorescence measurements were taken every second day.

\subsubsection{Chlorophyll Content}

Shoot cuttings of red and green $D$. australe and D. crassifolium with at least two fully expanded pairs of leaves were kept in distilled water, $400 \mathrm{mM} \mathrm{NaCl}, 800 \mathrm{mM} \mathrm{NaCl}$, or $35 \%$ polyethylene glycol (PEG) at $25^{\circ} \mathrm{C}$ and $1500 \mu \mathrm{mol} \mathrm{m} \mathrm{m}^{-2} \mathrm{~s}^{-1}$ wite light. After $8 \mathrm{~d} 100 \mathrm{mg}$ fresh leaf tissue from each shoot was finely chopped and added to $10 \mathrm{ml} 96 \%$ methanol and kept at $4{ }^{\circ} \mathrm{C}$ in the dark for $3 \mathrm{~d}$. The absorbance of the samples at $665 \mathrm{~nm}$ and $649 \mathrm{~nm}$ was analysed in a spectrophotometer and the chlorophyll content was determined using the following equations (Wintermans \& Mots, 1965). 


$$
\begin{gathered}
C_{a}=13.7 O D_{665}-5.76 O D_{649} \\
C_{b}=25.8 O D_{649}-7.6 O D_{665}
\end{gathered}
$$

\subsubsection{Statistics}

For statistical analysis R (R Core Team, 2018) and the emmeans (Lenth, 2018) package were used. The Fligner-Killeen test was used to test for homogeneity of variance. Differences in chlorophyll content and Fv/Fm values were based on treatment (control, $400 \mathrm{mM} \mathrm{NaCl}, 800$ $\mathrm{mM} \mathrm{NaCl}, 35 \%$ PEG) and were analysed with a one-way ANOVA. Peak fluxes of leaves from red and green $D$. australe and D. crassifolium after treatment with $300 \mathrm{mM} \mathrm{NaCl}$ were analysed based on plants (red D. australe, green D. australe, red D. crassifolium, green D. crassifolium) with a one-way ANOVA. Differences in Peak fluxes of leaves from red and green $D$. crassifolium leaves were based on treatment ( $300 \mathrm{mM} \mathrm{NaCl}, 300 \mathrm{mM} \mathrm{LiCl}, 300 \mathrm{mM} \mathrm{KCl}$ ) with a one-way ANOVA. Peak fluxes after $\mathrm{NaCl}$ treatment of leaves from red and green $D$. crassifolium treated with beetroot extracts were analysed based on colour (red, green) and treatment (red beetroot extract, golden beetroot extract) with a two-way ANOVA. Pairwise comparisons of estimated marginal means using the emmeans function were performed for between treatment comparisons.

\subsection{Results}

Like in the red morph of $D$. australe, betacyanin production can be induced by a combination of light and salt stress in D. crassifolium. However, the shoot cuttings from D. australe were already red at the start of the 8-day-treatment, while the shoot cuttings from D. crassifolium and the green morph of D. australe were not. (Figure 3.4.1 a, f, k) Shoot cuttings held in water and $35 \%$ PEG only accumulated betacyanins at the leaf nodes (Figure 3.4.1 b, e); cuttings treated with $400 \mathrm{mM} \mathrm{NaCl}$ only showed pigmentation at the nodes and very faintly on some of the older leaves and the shoot (Figure 3.4.1 c). By contrast, shoot cuttings held under high light and salt stress accumulated betacyanins in both leaves and shoot (Figure 3.4.1 d). Thus, in $D$. crassifolium pigment production could be induced by a combination of high light and salt stress, as previously observed in $D$. australe. 


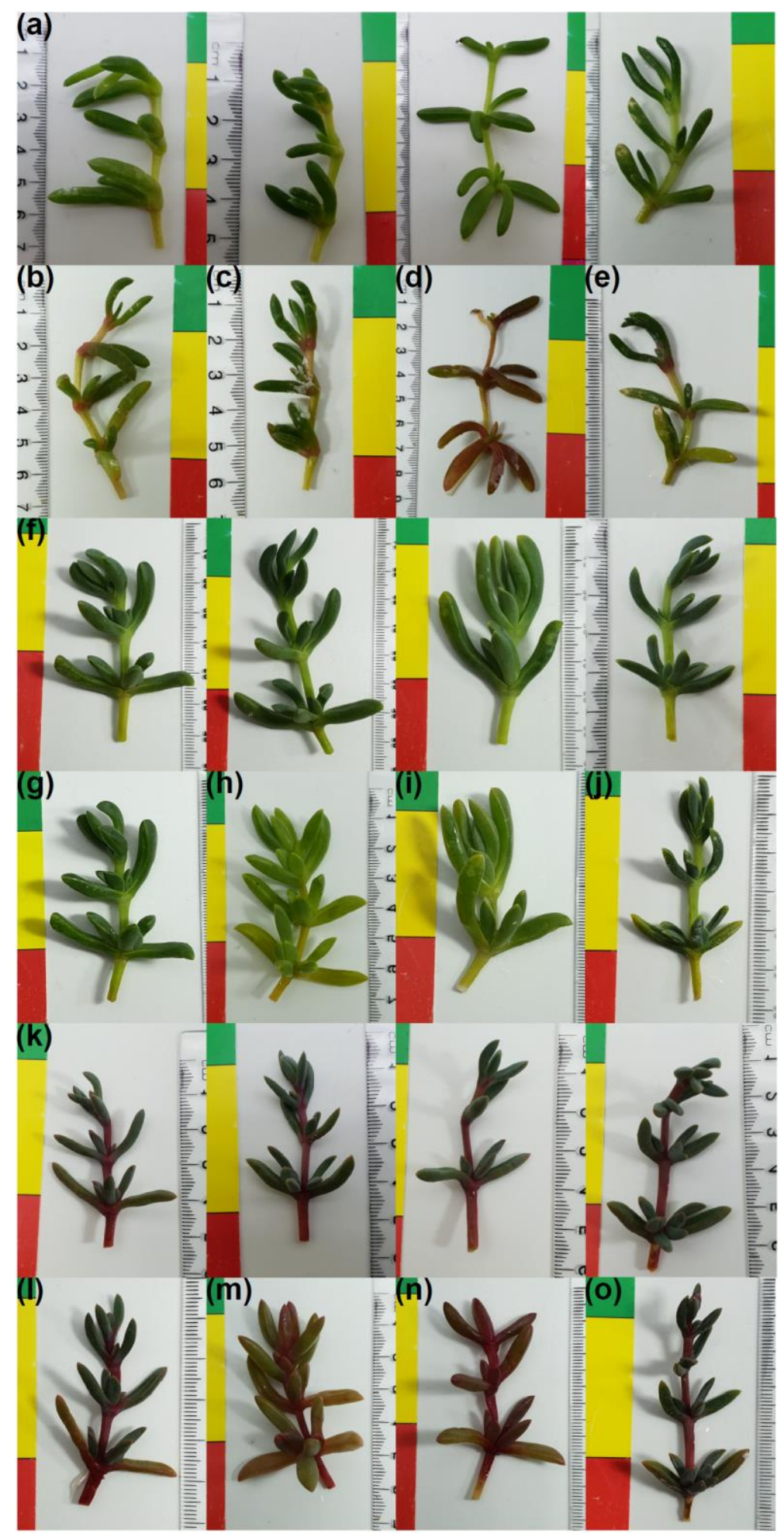

Figure 3.4.1 Photographs of D. crassifolium (a - e), and the green (f - j) and red (k - o) morph of D. australe shoot cuttings before (a, f, k ) and after treatment with $400 \mathrm{mM} \mathrm{NaCl}(\mathrm{c}, \mathrm{h}, \mathrm{m})$, $800 \mathrm{mM} \mathrm{NaCl}(\mathrm{d}, \mathrm{i}, \mathrm{n}), 35 \%$ PEG (e, j, o) and water (b, g, l) for $8 \mathrm{~d}$.

Fv/Fm declined significantly after $6 \mathrm{~d}$, but only in the leaves of $D$. crassifolium and the green morph of $D$. australe treated with $800 \mathrm{mM} \mathrm{NaCl}$ (Figure 3.4 .2 a, c, e). After $8 \mathrm{~d}$ the total chlorophyll content was determined for the leaves of all shoots. For D. crassifolium chlorophyll 
levels only declined significantly in leaves treated with $800 \mathrm{mM} \mathrm{NaCl}$ (Figure 3.4.2 b). By comparison, for both morphs of D. australe chlorophyll content had declined significantly with both 400 and $800 \mathrm{mM} \mathrm{NaCl}$ (Figure 3.4.2 d, f).

(a)

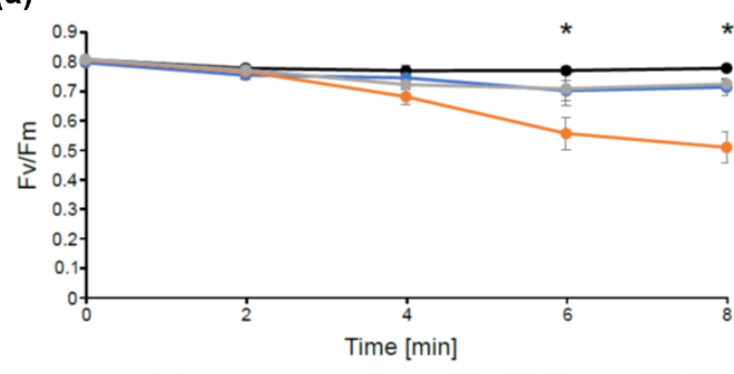

(c)

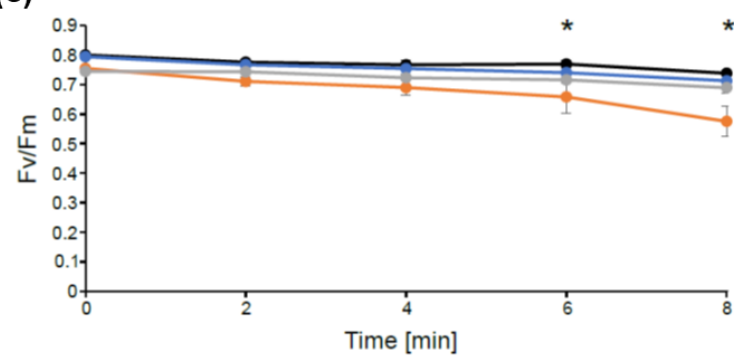

(e)

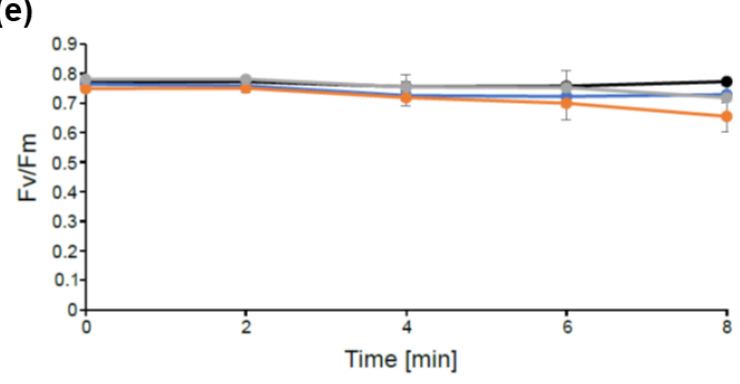

(b)

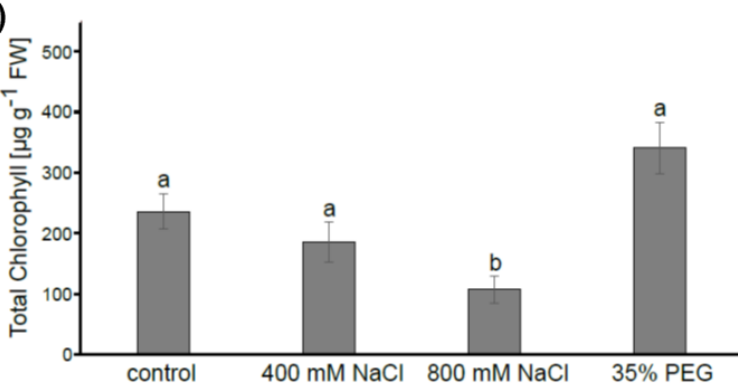

(d)

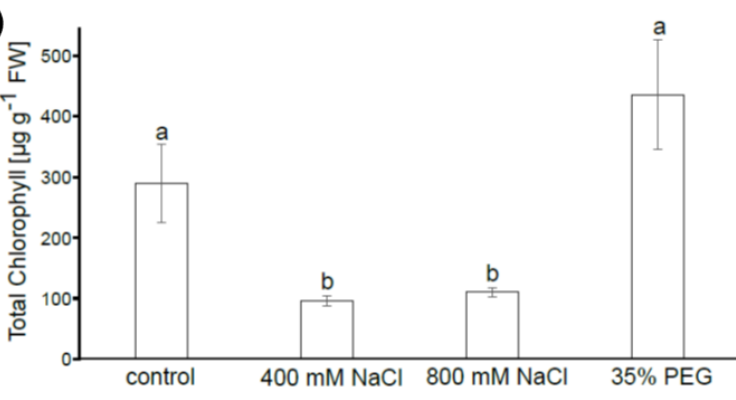

(f)

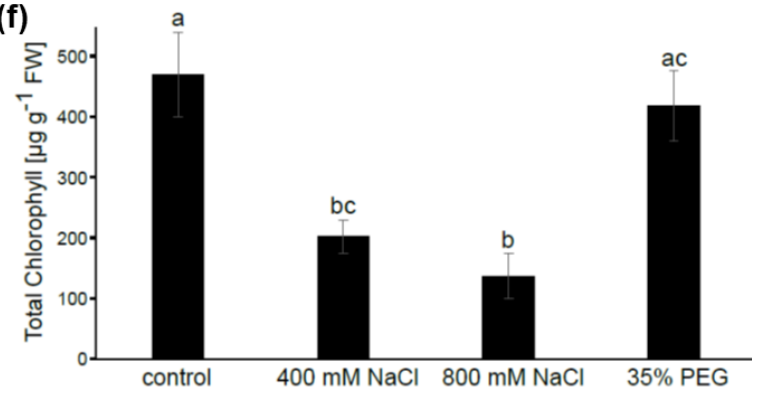

Figure 3.4.2 Fv/Fm (a, c, e) of D. crassifolium (a, b), the green(c, d), and red (e, f) morph of D. australe leaves over $8 \mathrm{~d}$ under treatment with $35 \%$ PEG, 0,400 ,and $800 \mathrm{mM} \mathrm{NaCl}$. Measurements were taken every other day after dark adaption for 30 min. Means $\pm S E, n=5$. Asterisks indicate a significant difference between $800 \mathrm{mM}$ and $400 \mathrm{mM}$, water control and $35 \%$ PEG. Mean chlorophyll content \pm SE after $8 d$ treatment, $n=5(b, d, f)$. Different letters represent significant differences between the mean values $(\mathrm{P}<0.05)$.

Viability staining using fluorescein diacetate, with which viable cells fluoresced green, and with propidium iodide, with which dead cells fluoresced red, showed stark differences between betacyanic and green leaves (Table 3.2). The mesophyll of betacyanic D. crassifolium leaves was more viable after $24 \mathrm{~h}$ in $400 \mathrm{mM} \mathrm{NaCl}$ than the mesophyll of green leaves (Figure 3.4.3). In green leaves kept under control conditions $95 \%$ of the mesophyll cells were viable, while only $15 \%$ of the mesophyll cells from leaves treated with $400 \mathrm{mM} \mathrm{NaCl}$ were still alive (Table 
3.2). In betacyanic leaves both the ones kept under control conditions and the ones treated with $400 \mathrm{mM} \mathrm{NaCl} 99 \%$ of the mesophyll cells were viable. Viability staining in D. australe led to similar results (Figure 2.4.7). Mesophyll viability decreased markedly in green leaves after salt treatment, while it did not change in betacyanic leaves (Table 3.2). Both D. crassifolium and D. australe were highly salt tolerant and showed symptoms of severe salt stress only at $800 \mathrm{mM}$ $\mathrm{NaCl}$ and in both plants the presence of betacyanin in leaves resulted in an increase of mesophyll viability under salinity.

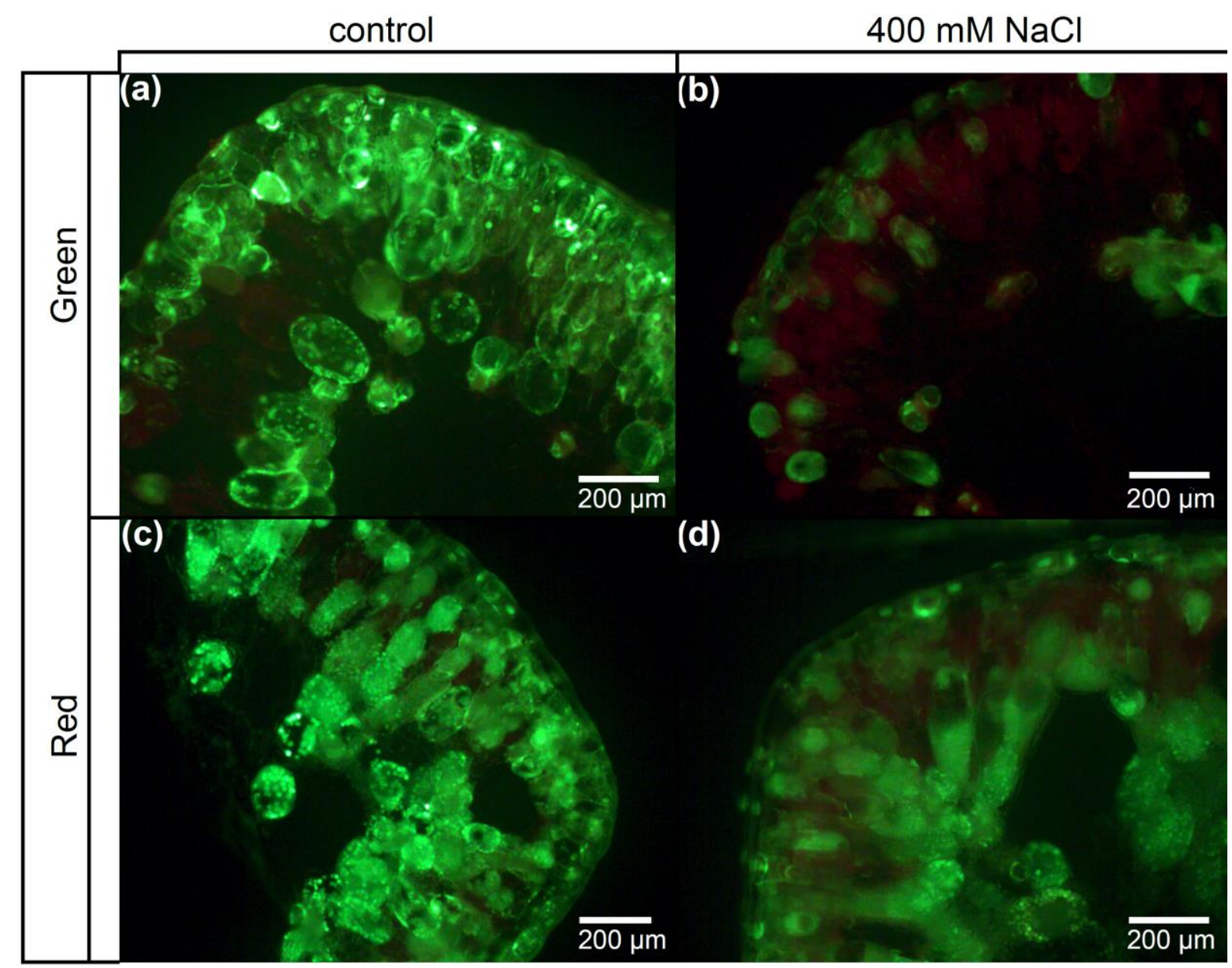

Figure 3.4.3 Fluorescence micrographs of cross-sections of green $(\mathrm{a}, \mathrm{b})$ and red $(\mathrm{c}, \mathrm{d}) D$. crassifolium leaves; co-stained with fluorescein diacetate and propidium iodide after $24 \mathrm{~h}$ in BSM (a, c) or $400 \mathrm{mM} \mathrm{NaCl} \mathrm{(b,} \mathrm{d).} \mathrm{Green} \mathrm{fluorescence} \mathrm{indicates} \mathrm{viable} \mathrm{cells;} \mathrm{red}$ fluorescence indicates dead cells. 
Table 3.2 Percentage of viable mesophyll cells in red and green $D$. crassifolium leaves after 24 h treatment with $\mathrm{BSM}$ or $400 \mathrm{mM} \mathrm{NaCl}$, Means $\pm \mathrm{SE}, \mathrm{n}=5$. Different letters represent significant differences between the mean values $(\mathrm{P}<0.05)$

\begin{tabular}{lcc}
\hline Colour & Treatment & \% Viable mesophyll \\
\hline Green & $400 \mathrm{mM} \mathrm{NaCl}$ & $15 \pm 3.01 \mathrm{a}$ \\
Green & Control & $95 \pm 2.53 \mathrm{~b}$ \\
Red & $400 \mathrm{mM} \mathrm{NaCl}$ & $99 \pm 3.55 \mathrm{~b}$ \\
Red & Control & $99 \pm 2.84 \mathrm{~b}$ \\
\hline
\end{tabular}

To study possible effects of apoplastic $\mathrm{NaCl}$ on trans-membrane transport in mesophyll tissue the $\mathrm{NaCl}$ concentration in the measuring chamber was gradually increased und the ion fluxes were recorded using the MIFE technique. Adding $\mathrm{NaCl}$ induced $\mathrm{Na}^{+}$uptake in both $D$. crassifolium and D. australe. (Figure 3.4.4 a). However, there was a significant difference in peak $\mathrm{Na}^{+}$flux upon treatment with $300 \mathrm{mM} \mathrm{NaCl}$ between $D$. crassifolium and D. australe. Mesophyll cells of green $D$. crassifolium leaves did take up significantly more $\mathrm{Na}^{+}$than the mesophyll cells of red leaves, while there was no significant difference in $\mathrm{Na}^{+}$uptake between mesophyll cells from red and green D. australe leaves (Figure 3.4 .5 a). $\mathrm{K}^{+}$uptake up on increasing the $\mathrm{NaCl}$ concentration was observed in both $D$. crassifolium and D. australe (Figure 3.4.4 b). Increasing the $\mathrm{NaCl}$ concentration to $100 \mathrm{mM}$ also induced $\mathrm{Cl}^{-}$uptake in both $D$. crassifolium and D. australe (Figure $3.4 .4 \mathrm{c}$ ). There was no significant difference in peak $\mathrm{K}^{+}$ and $\mathrm{Cl}^{-}$fluxes upon treatment with $300 \mathrm{mM} \mathrm{NaCl}$ between D. crassifolium and D. australe (Figure $3.4 .5 \mathrm{~b}, \mathrm{c}$ ). 

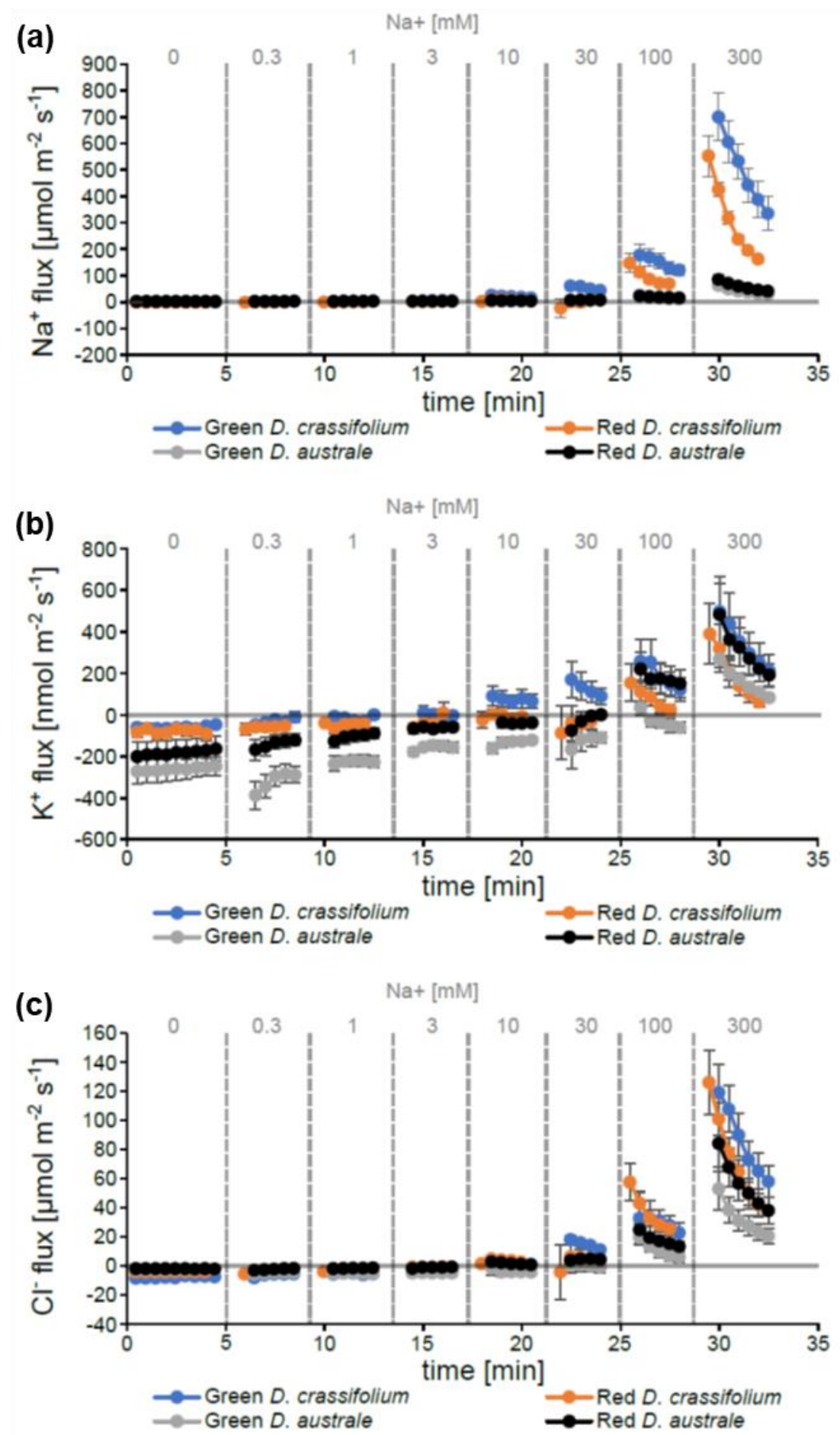

Figure 3.4.4 Transient net $\mathrm{Na}^{+}(\mathrm{a}), \mathrm{K}^{+}(\mathrm{b})$, and $\mathrm{Cl}^{-}$(c) flux kinetics measured from mesophyll of betacyanic and green leaves from $D$. australe and $D$. crassifolium in response to increasing $\mathrm{NaCl}$ concentration. Mean $\pm \mathrm{SE}, \mathrm{n}=5$. Positive flux values indicate ion influx into mesophyll cells, while negative flux values indicate ion efflux. 
(a)

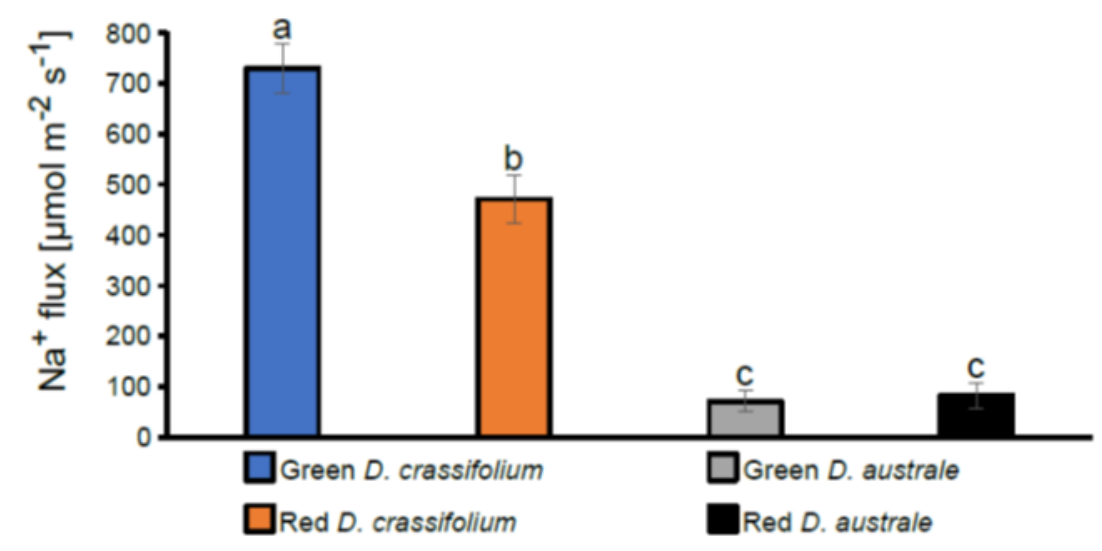

(b)

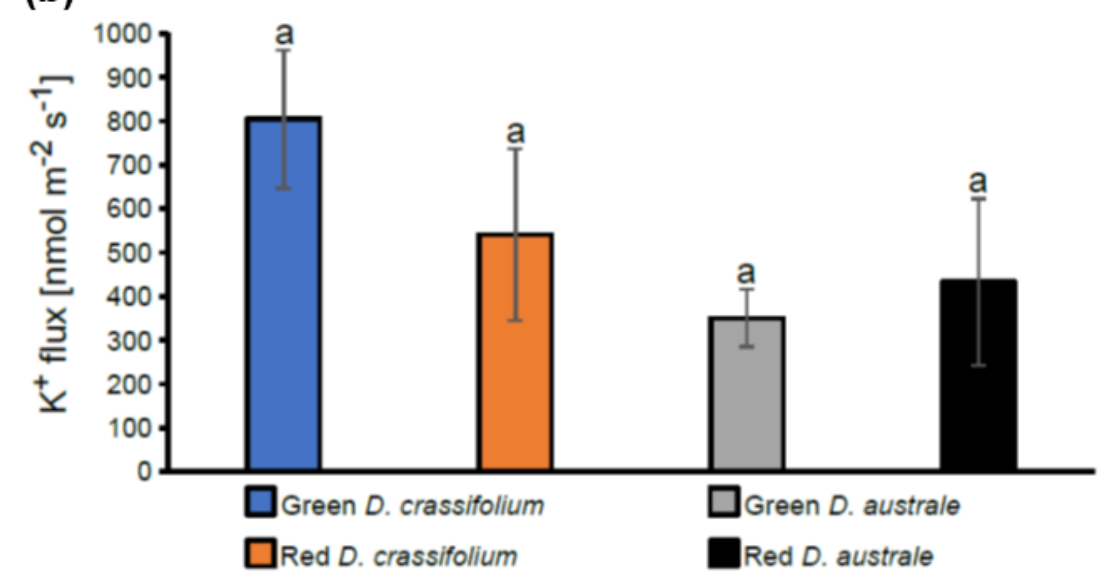

(c)

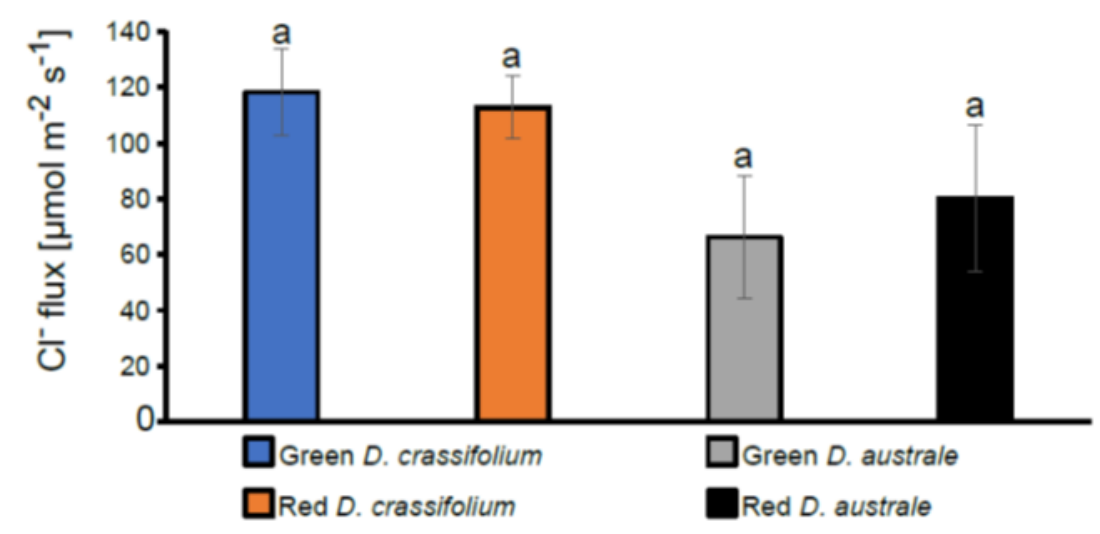

Figure 3.4.5 $\mathrm{Peak} \mathrm{Na}^{+}(\mathrm{a}), \mathrm{K}^{+}(\mathrm{b})$, and $\mathrm{Cl}^{-}$(c) flux measured from mesophyll of betacyanic and green leaves from $D$. australe and D. crassifolium in response to treatment with $300 \mathrm{mM}$ $\mathrm{NaCl}$. Mean $\pm \mathrm{SE}, \mathrm{n}=5$.

To test whether the observed ion flux responses are specific for $\mathrm{NaCl}$ stress, the ion fluxes of mesophyll cells from green and betacyanic $D$. crassifolium leaves were monitored while the concentration or $\mathrm{KCl}$ or $\mathrm{LiCl}$ was gradually increased. $\mathrm{Na}^{+}$uptake could be induced by increasing $\mathrm{NaCl}$ and $\mathrm{KCl}$ concentrations in the medium. In both red and green leaves, the $\mathrm{Na}^{+}$ 
uptake was 12.4-fold higher after treatment with $300 \mathrm{mM} \mathrm{NaCl}$ than $300 \mathrm{mM} \mathrm{KCl}$ (Figure 3.4.6 a, b). Adding $\mathrm{LiCl}$ could only induce minor $\mathrm{Na}^{+}$uptake at $300 \mathrm{mM}$ into the mesophyll cells of green leaves. However, the $\mathrm{Na}^{+}$uptake was 67 -fold smaller than in $300 \mathrm{mM} \mathrm{KCl}$ or 828 -fold lower than in $300 \mathrm{mM} \mathrm{NaCl}$ (Figure 3.4.6 b). $\mathrm{LiCl}$ treatment did not induce $\mathrm{Na}^{+}$uptake into the mesophyll cells of betacyanic leaves at all (Figure 3.4.6 a). In both red and green leaves $\mathrm{Na}^{+}$ uptake was significantly higher after treatment with $300 \mathrm{mM} \mathrm{NaCl}$ compared with the same concentrations of $\mathrm{KCl}$ and $\mathrm{LiCl}$ (Figure 3.4.7 a, b). In both red and green leaves, mesophyll cells $\mathrm{K}^{+}$uptake was induced by $\mathrm{NaCl}$ and $\mathrm{KCl}$ (Figure 3.4.6 c, d). However, $\mathrm{LiCl}$ did not induce $\mathrm{K}^{+}$uptake in red or green leaf mesophyll at all Figure 3.4.6c, d). $\mathrm{K}^{+}$uptake was significantly higher after treatment with $300 \mathrm{mM} \mathrm{KCl}$ than $300 \mathrm{mM} \mathrm{NaCl}$ (Figure 3.4. 7 c, d). In mesophyll cells of both red and green leaves the $\mathrm{Cl}^{-}$uptake was induced by $\mathrm{NaCl}, \mathrm{LiCl}$, and $\mathrm{KCl}$. (Figure 3.4.6 e, f). In both green and red leaves $\mathrm{Cl}^{-}$uptake was significantly higher after treatment with $300 \mathrm{mM} \mathrm{KCl}$ compared to $\mathrm{NaCl}$. $\mathrm{LiCl}$ treatment only led to significantly higher $\mathrm{Cl}^{-}$uptake in comparison with $\mathrm{NaCl}$ in red leaves (Figure 3.4.7 e, f). 


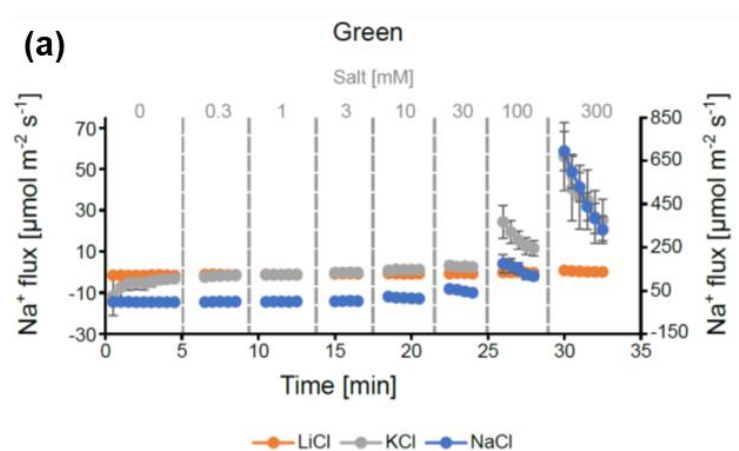

(c)

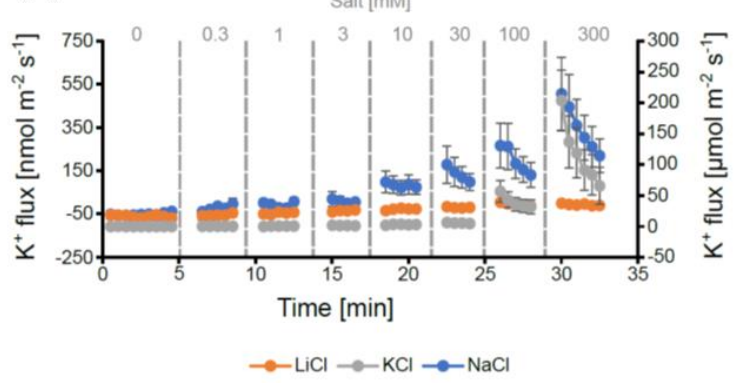

(e)

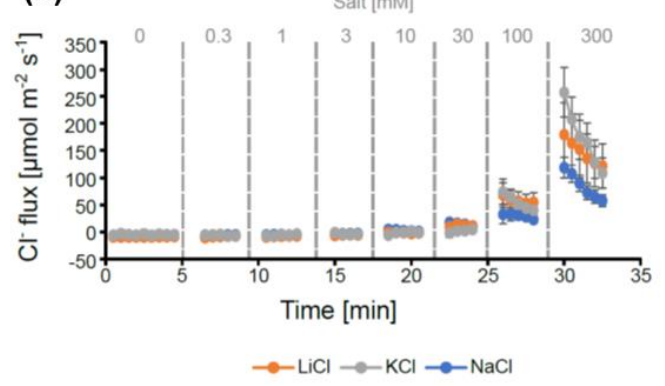

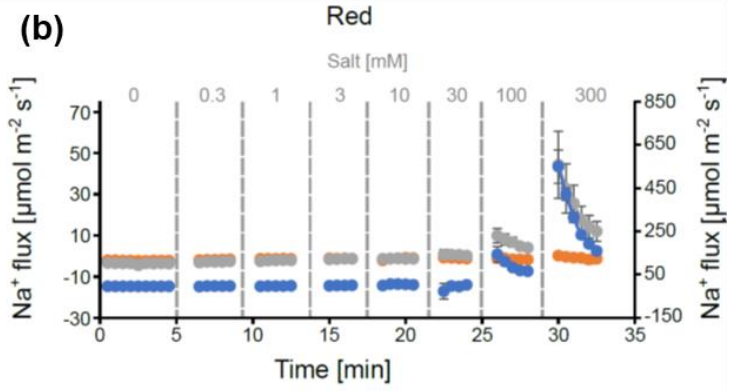

(d)

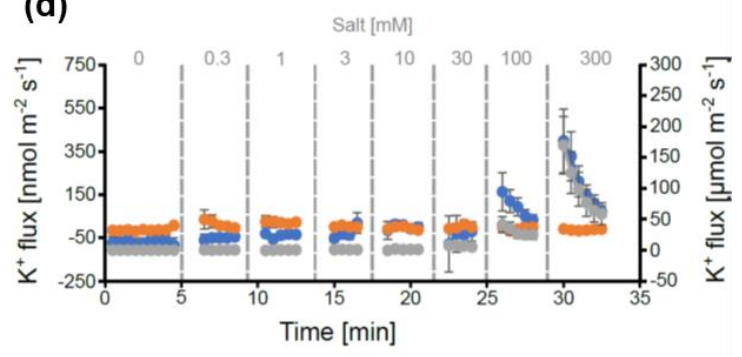

(f)

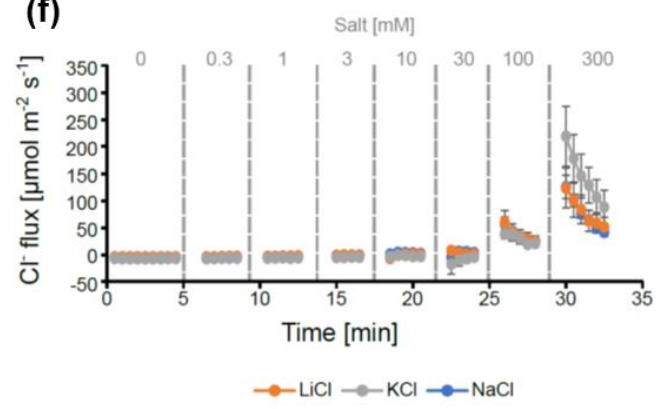

Figure 3.4.6 Transient net $\mathrm{Na}^{+}(\mathrm{a}, \mathrm{b}), \mathrm{K}^{+}(\mathrm{c}, \mathrm{d})$, and $\mathrm{Cl}^{-}(\mathrm{e}, \mathrm{f})$ flux kinetics measured from mesophyll of betacyanic (b, d, f) and green (a, c, e) leaves from D. crassifolium in response to increasing $\mathrm{LiCl}, \mathrm{KCl}$, and $\mathrm{NaCl}$ concentration Mean $\pm \mathrm{SE}, \mathrm{n}=5 . \mathrm{Na}^{+}$fluxes $(\mathrm{a}, \mathrm{b})$ after $\mathrm{NaCl}$ treatment (blue) were plotted against the left y-axis. $\mathrm{K}^{+}$fluxes (c, d) after $\mathrm{KCl}$ treatment (grey) were plotted against the left y-axis. Positive flux values indicate ion influx into mesophyll cells, while negative flux values indicate ion efflux. 

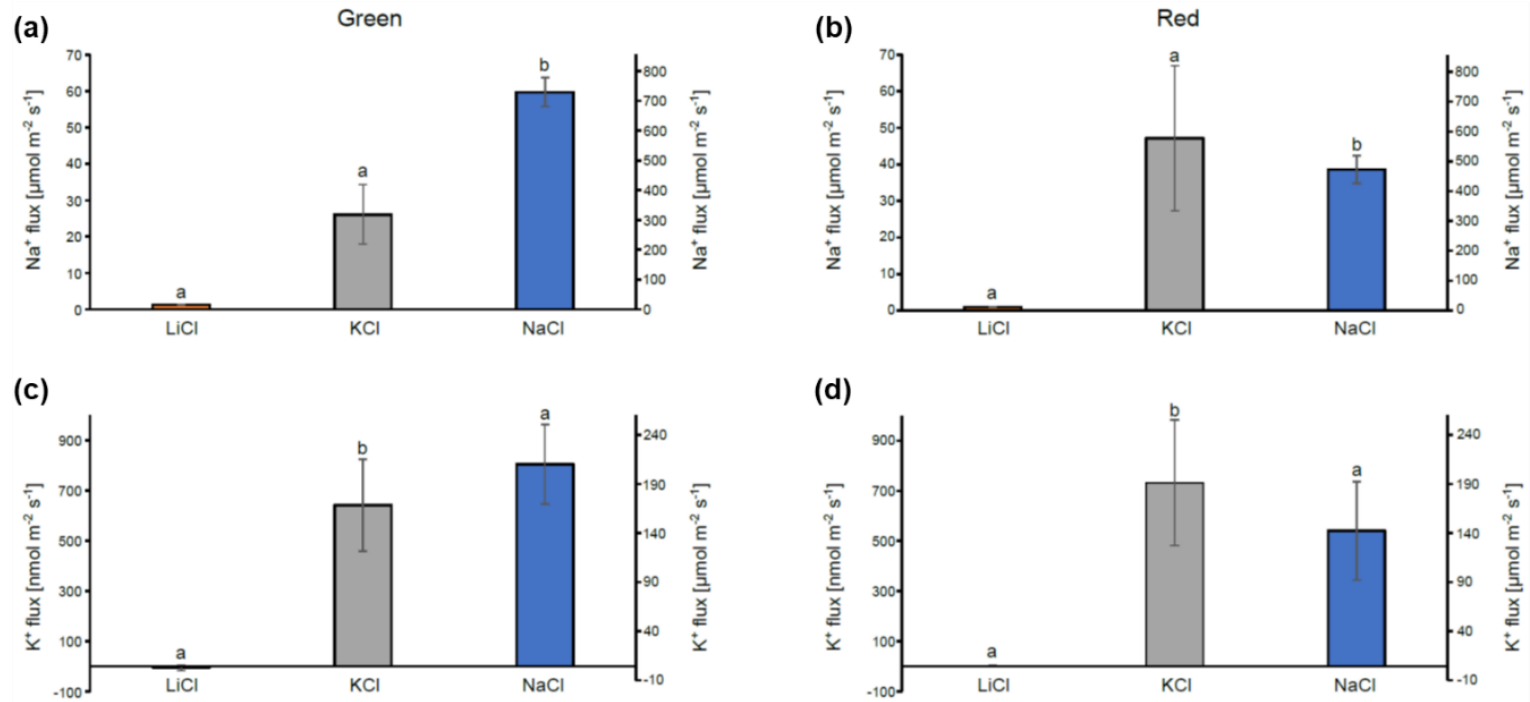

(d)
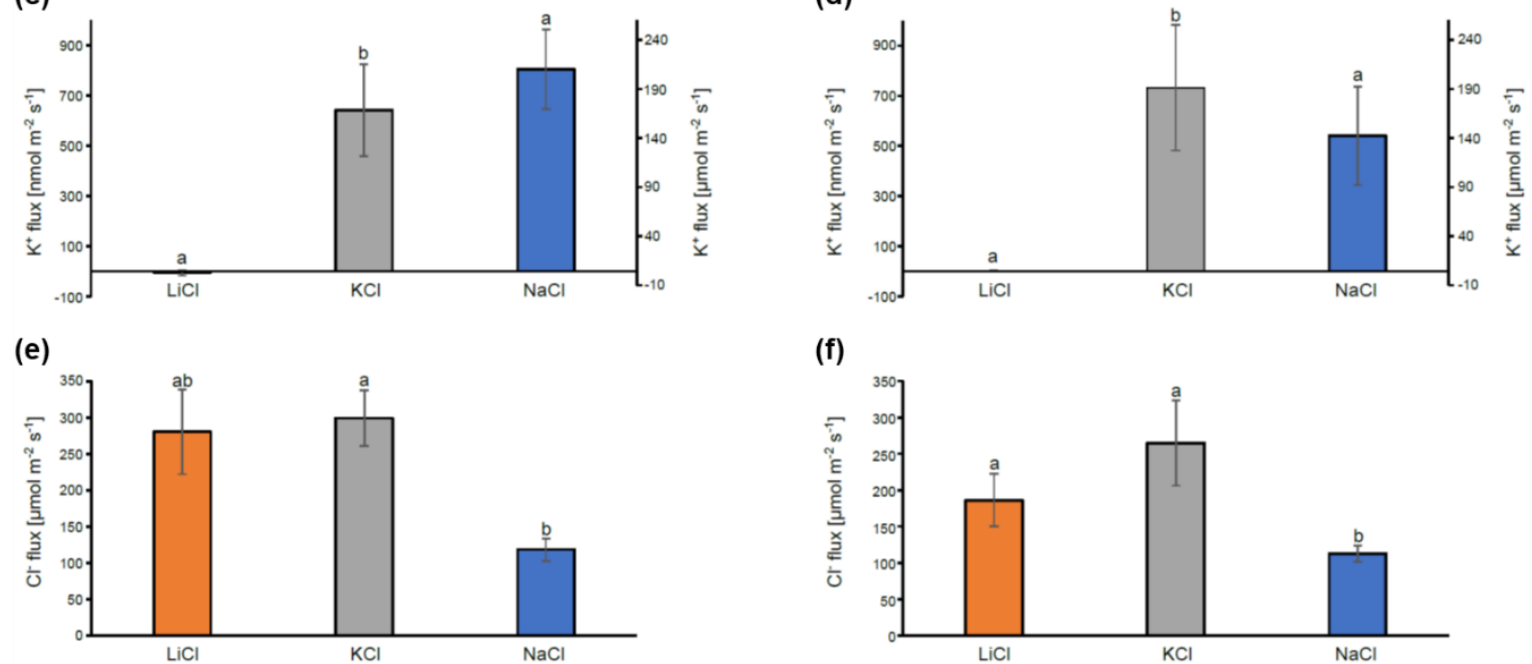

Figure 3.4.7 Peak $\mathrm{Na}^{+}(\mathrm{a}, \mathrm{b}), \mathrm{K}^{+}(\mathrm{c}, \mathrm{d})$, and $\mathrm{Cl}^{-}(\mathrm{e}, \mathrm{f})$ flux kinetics measured from mesophyll of betacyanic (b, d, f) and green (a, c, e) leaves from D. crassifolium in response to treatment with $300 \mathrm{mM} \mathrm{LiCl}, \mathrm{KCl}$, and $\mathrm{NaCl}$. Mean $\pm \mathrm{SE}, \mathrm{n}=5$. $\mathrm{Na}^{+}$fluxes (a, b) after $\mathrm{NaCl}$ treatment (blue) were plotted against the left $\mathrm{y}$-axis. $\mathrm{K}^{+}$fluxes (c, d) after $\mathrm{KCl}$ treatment (grey) were plotted against the left y-axis.

To determine whether $\mathrm{Cl}^{-}$plays an important role in $\mathrm{K}^{+}$homeostasis during salt stress, the sodium gluconate concentration in the surrounding medium of mesophyll cells was gradually increased and the net $\mathrm{K}^{+}$and $\mathrm{Na}^{+}$fluxes were measured. Sodium gluconate allowed us to theoretically trigger the $\mathrm{NaCl}$-specific $\mathrm{K}^{+}$uptake without adding $\mathrm{Cl}^{-}$. Both red and green plants did take up $\mathrm{Na}^{+}$into the mesophyll (Figure 3.4 .8 a) as recorded earlier after adding $\mathrm{NaCl}$ (Figure 3.4.4 a). $\mathrm{Na}^{+}$uptake was again higher in the green leaves than in betacyanic leaves. However, increasing the sodium gluconate concentration in the medium did not induce $\mathrm{K}^{+}$uptake, instead $\mathrm{K}^{+}$leaked out of the mesophyll cells of both red and green leaves (Figure 3.4.8 b). The $\mathrm{K}^{+}$efflux was higher in betacyanic leaves compared to green leaves. Thus, this experiment confirmed that $\mathrm{Cl}^{-}$plays an important role in the $\mathrm{K}^{+}$homeostasis during salinity stress. 


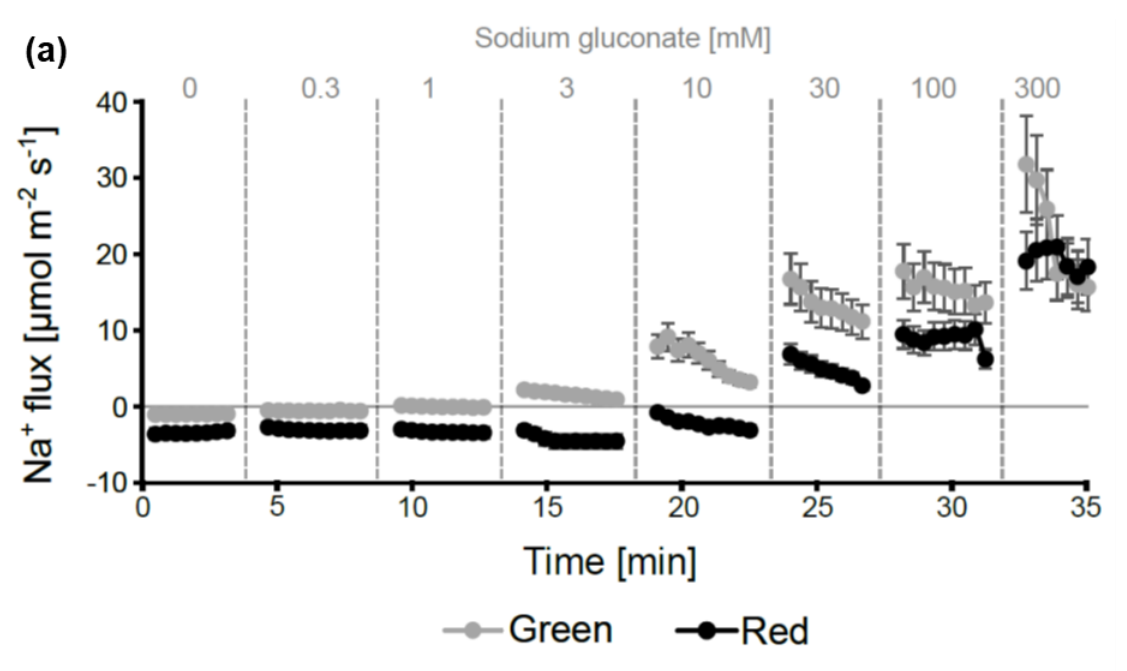

(b) Sodium gluconate $[\mathrm{mM}]$

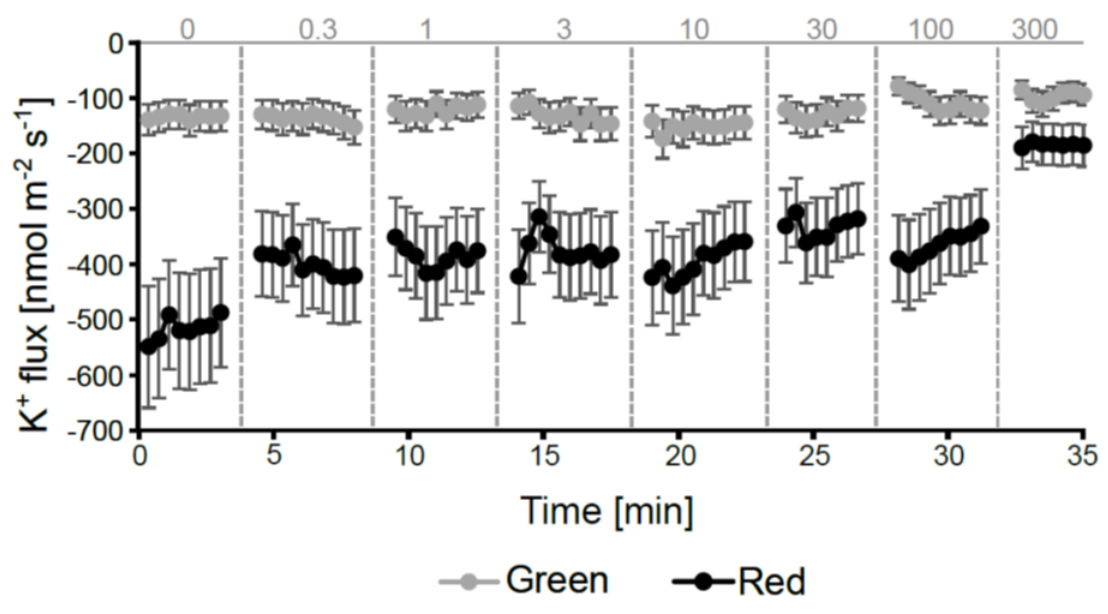

Figure 3.4.8 Transient net $\mathrm{Na}^{+}(\mathrm{a}), \mathrm{K}^{+}$(b) flux kinetics measured from mesophyll of betacyanic and green leaves from $D$. australe in response to increasing sodium gluconate concentration. Mean \pm SE, $n=5$. Positive flux values indicate ion influx into mesophyll cells, while negative flux values indicate ion efflux.

Incubating green and red leaves with exposed mesophyll in physiologically relevant concentrations of betacyanin or betaxanthin from aqueous beetroot extracts had no significant effect on the initial $\mathrm{Na}^{+}$flux in response to $300 \mathrm{mM} \mathrm{NaCl}$ treatment (Figure 3.4.9 a, b). Incubating green leaves in red or yellow beet root extract reduced $\mathrm{K}^{+}$uptake significantly compared to the green leaves that were kept in BSM. There was also no significant difference in $\mathrm{K}^{+}$uptake in response to salt stress between red leaves and green leaves that were held in medium containing betacyanin and/or betaxanthin (Figure 3.4.9 c). Incubating the leaves in medium containing red beet root extract had no significant effect on the $\mathrm{Cl}^{-}$uptake in response to $300 \mathrm{mM} \mathrm{NaCl}$. However, in the presence of betaxanthin there was a significant increase in 
$\mathrm{Cl}^{-}$uptake upon salt stress in the mesophyll cells of red leaves, but not in the mesophyll cells of green leaves (Figure 3.4.9 d).
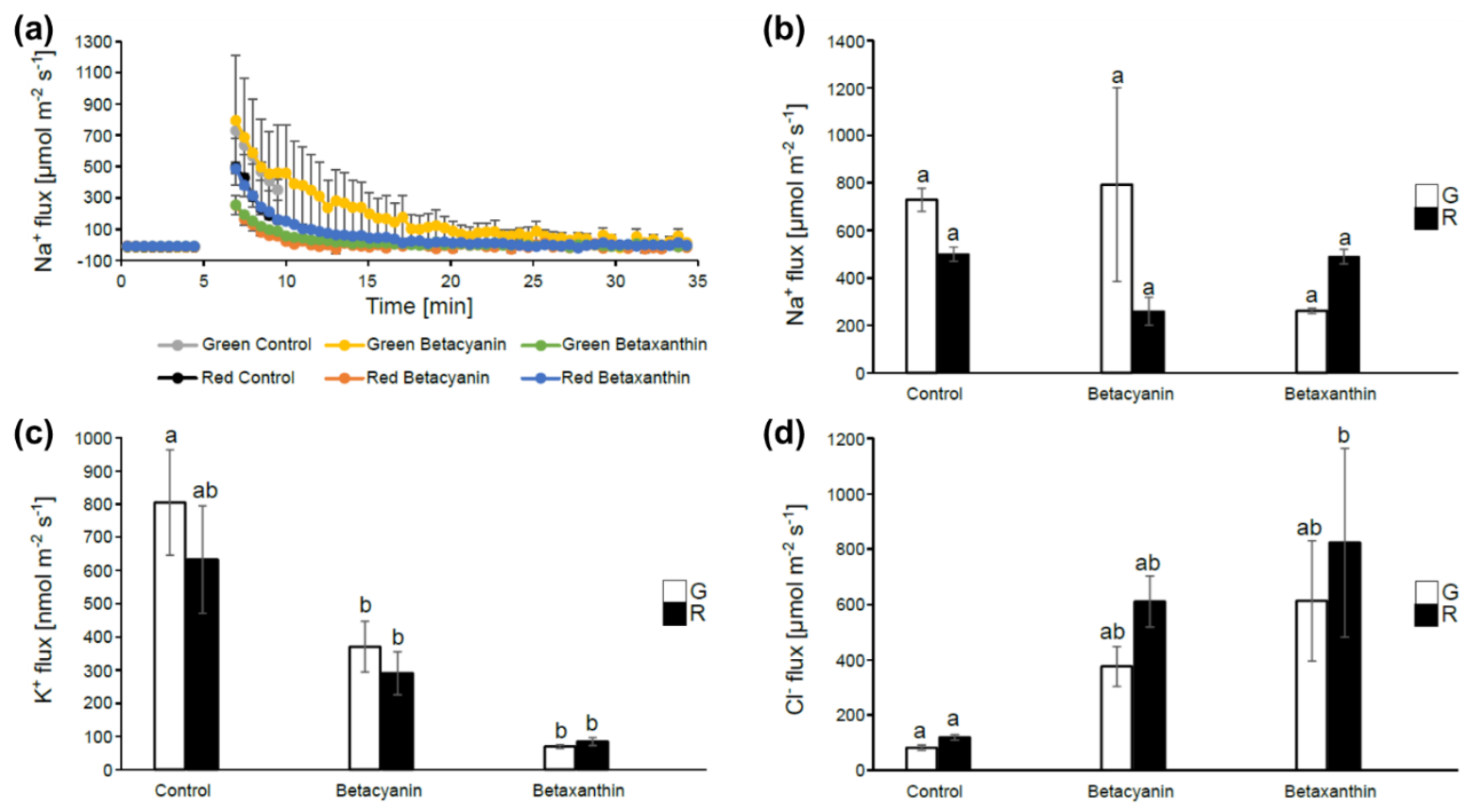

Figure 3.4.9 Transient net $\mathrm{Na}^{+}$fluxes (a) and peak $\mathrm{Na}^{+}$(b), $\mathrm{K}^{+}$(c), and $\mathrm{Cl}^{-}$(d) fluxes in mesophyll cells from green $(\mathrm{G})$ and red (R) D. crassifolium leaves, incubated with BSM, betacyanin (red beet root extract), or betaxanthin (golden beet root extract), in response to treatment with $300 \mathrm{mM} \mathrm{NaCl}$. Mean $\pm \mathrm{SE}, \mathrm{n}=5$. Different letters represent significant differences between the mean values $(\mathrm{P}<0.05)$.

\subsection{Discussion}

This study explored the possible effects of betacyanin pigment on ion fluxes across mesophyll cell membranes. Using a combination of MIFE experiments and measuring the decline in chlorophyll content and Fv/Fm under salt stress and both $D$. australe morphs and $D$. crassifolium the study revealed three important new findings on plant stress tolerance: (i) $\mathrm{NaCl}$ induced $\mathrm{K}^{+}$uptake into mesophyll in both $D$. australe and D. crassifolium (ii) $\mathrm{Cl}^{-}$plays a role in $\mathrm{K}^{+}$homeostasis during salt stress (iii) betacyanin does not impact the ion flux responses in both species. (iv) D. australe and $D$. crassifolium are similar in salt tolerance.

The mesophyll cells of both $D$. australe and $D$. crassifolium stated taking up $\mathrm{K}^{+}$upon salt stress. $\mathrm{K}^{+}$leak upon exposure to salinity is a common response that has been recorded in mesophyll of broad bean (Vicia faba L.) (Shabala, 2000; Percey et al., 2014; Wu et al., 2015), seedling roots of bread wheat (Triticum aestivum L.), durum wheat (Triticum turgidum L. ssp. durum) 
(Cuin et al., 2009), and barley (Hordeum vulgare) (Chen et al., 2005, 2007). A plant's ability to retain $\mathrm{K}^{+}$under salt stress is essential for survival, as $\mathrm{K}^{+}$is essential for the regulation of nearly 70 metabolic enzymes (Chen et al., 2005; Cuin et al., 2009; Dreyer \& Uozumi, 2011; Shabala et al., 2016). However, in both $D$. crassifolium and D. australe increasing the $\mathrm{NaCl}$ concentration in the surrounding medium resulted in the net uptake of $\mathrm{K}^{+}$into mesophyll cells (Figure 3.4.4 b). To my knowledge, this is a response to salinity that has been never recorded previously. Taking up $\mathrm{K}^{+}$instead of retaining $\mathrm{K}^{+}$in the mesophyll could be a new and highly effective mechanism to maintain a high $\mathrm{K}^{+} / \mathrm{Na}^{+}$ratio and avoid the cytotoxic effects of $\mathrm{Na}^{+}$ especially in the photosynthetically active tissue.

$\mathrm{Cl}^{-}$might play an important role in salt induced in $\mathrm{K}^{+}$uptake. The uptake of considerable amounts of cations such as $\mathrm{K}^{+}$and $\mathrm{Na}^{+}$could lead to membrane depolarization. However, in $D$. crassifolium and D. australe salt treatment also induced $\mathrm{Cl}^{-}$uptake into mesophyll cells (Figure 3.4.6 c). $\mathrm{Cl}^{-}$influx could balance the uptake of $\mathrm{K}^{+}$and $\mathrm{Na}^{+}$during salt stress and prevent membrane depolarisation. This important role that $\mathrm{Cl}^{-}$plays in $\mathrm{K}^{+}$homeostasis during salt stress was experimentally confirmed by gradually increasing the concentration of sodium gluconate in the surrounding medium. While sodium gluconate treatment could induce $\mathrm{Na}^{+}$uptake, it could not induce $\mathrm{K}^{+}$uptake. Upon sodium gluconate treatment we observed a $\mathrm{K}^{+}$leak, similar to the responses recorded in wheat, barley and broad bean (Chen et al., 2005, 2007; Cuin et al., 2009; Percey et al., 2014; Wu et al., 2015). Thus, we confirmed that the presence of $\mathrm{Cl}^{-}$is essential for $\mathrm{K}^{+}$uptake during high salinity stress in D. australe. There are cation chloride cotransporters (CCCs), which could directly couple $\mathrm{K}^{+}$uptake with $\mathrm{Cl}^{-}$uptake (Li et al., 2017b; Bazihizina et al., 2019). This would also reduce the energy requirements to take up $\mathrm{K}^{+}$under saline conditions. Blocking CCCs in the halophyte Suaeda maritima resulted in reduced $\mathrm{Na}^{+}$ concentrations in roots (Zhang et al., 2010). Taking up $\mathrm{Cl}^{-}$might have another advantage, as it functions as an osmotic solute and minimises the need to produce organic solutes (Munns \& Gilliham, 2015; Bazihizina et al., 2019).

Upon salt treatment the mesophyll cells of both species took up $\mathrm{Na}^{+}$, as is expected (Figure 3.4.4 a). With increasing concentrations of $\mathrm{NaCl}$ in the medium, $\mathrm{Na}^{+}$was taken up into the mesophyll cells along the electrochemical gradient. Increasing the cytosolic $\mathrm{Na}^{+}$content leads to a decreasing $\mathrm{K}^{+} / \mathrm{Na}^{+}$ratio, which in turn can result in enzymatic inhibition and a decreased photosynthesis rate (Blumwald, 2000; Percey et al., 2014). 
There was, however, no difference in ion flux responses between betacyanic and green leaves in D. australe, while in D. crassifolium both $\mathrm{K}^{+}$and $\mathrm{Na}^{+}$uptake were induced at lower concentrations in green leaves than in the red leaves (Figure 3.4.4). In addition, $\mathrm{Na}^{+}$uptake was considerably higher in green leaves at $300 \mathrm{mM} \mathrm{NaCl}$ than in betacyanic leaves (Figure 3.4.4 a). To test if the presence of betacyanin has any effect on ion fluxes, leaves with exposed mesophyll cells were incubated with beetroot extracts containing betacyanins and betaxanthins. The extracts did not influence $\mathrm{Na}^{+}$uptake, however both red and yellow beetroot extracts significantly reduced $\mathrm{K}^{+}$uptake (Figure 3.4.8). Betalains have ROS scavenging properties (Sepúlveda-Jiménez et al., 2004; Slimen et al., 2017) and ROS in turn have been reported to regulate the activity of plant ion channels (Köhler et al., 2003; Demidchik et al., 2010; Dreyer \& Uozumi, 2011). The antioxidant properties of betalains might prevent the activation of ion channels and thus reduce $\mathrm{K}^{+}$uptake.

D. crassifolium was similar in salt tolerance to $D$. australe. In both plants, the total chlorophyll content decreased significantly after treatment with $800 \mathrm{mM} \mathrm{NaCl}$. However, in the green $D$. australe morph treatment with $400 \mathrm{mM} \mathrm{NaCl}$ also lead to a significant decrease in total chlorophyll content, suggesting that the absence of betacyanin negatively impacts the salt tolerance. There was no significant difference between the shoot cuttings treated with $400 \mathrm{mM}$ $\mathrm{NaCl}$ and the osmotic control in the red morph of $D$. australe. This could indicate that in the presence of betacyanin the osmotic component of salt stress is only marginal at $400 \mathrm{mM} \mathrm{NaCl}$. Previous studies have shown that betacyanic leaves of $D$. australe had a significantly increased total soluble sugar and proline content after $400 \mathrm{mM} \mathrm{NaCl}$ treatment compared to green leaves (Jain, 2016). Both soluble sugars and proline function as compatible solutes and are often produced under salt stress to combat the increased osmotic pressure (Flowers, 2004; Deinlein et al., 2014). Thus, an increased production of compatible solutes at $400 \mathrm{mM} \mathrm{NaCl}$ in red leaves could explain how the betacyanic leaves are able to mitigate the effects of salt stress. Both salt and high light stress can cause photooxidation and the generation of $\mathrm{H}_{2} \mathrm{O}_{2}$ derived from $\mathrm{O}_{2}{ }^{-}$and $\mathrm{O}_{2}^{-}$in chloroplasts (Hernández et al., 1995; Mitsuya et al., 2003). In excess, reactive oxygen species can disrupt the membrane integrity of thylakoids and cause the observed chlorophyll degradation (Mitsuya et al., 2003). Studies in Suaeda salsa and Beta vulgaris have shown that betacyanin synthesis was inducible by $\mathrm{H}_{2} \mathrm{O}_{2}$ (Sepúlveda-Jiménez et al., 2004; Wang et al., 2007). The presence of betacyanin in leaves of $D$. australe correlated with a decrease in $\mathrm{H}_{2} \mathrm{O}_{2}$ production under salt stress (Jain et al., 2015). 
Additionally, Fv/Fm decreased significantly after $4 \mathrm{~d}$ in $800 \mathrm{mM} \mathrm{NaCl}$ in shoot cuttings of $D$. crassifolium and the green $D$. australe morph, compared to shoot cuttings kept in water, 400 $\mathrm{mM} \mathrm{NaCl}$, or $35 \%$ PEG. However, in shoot cuttings of the red D. australe morph there was no decrease of $\mathrm{Fv} / \mathrm{Fm}$ after treatment with $800 \mathrm{mM} \mathrm{NaCl}$ compared to water, $400 \mathrm{mM} \mathrm{NaCl}$ and $35 \%$ PEG (Figure 3.4.2). The reduced Fv/Fm is not only a direct result of the oxidative damage salt stress causes in chloroplasts and the chlorophyll degradation; salt stress also leads to stomata closure, reduced water use efficiency and decrease photosynthesis rate (Munns, 2005; Munns \& Tester, 2008; Hasegawa, 2013; Roy et al., 2014; Bose et al., 2017). Previous research has shown that in salt-treated $D$. australe, betacyanic leaves have a higher water use efficiency, stomatal conductance, and higher maximum rates of $\mathrm{CO}_{2}$ assimilation compared to green leaves (Jain \& Gould, 2015b). The authors suggested that the beneficial effect of betacyanin on photosynthetic performance under salt stress might be due to a photoprotective effect of epidermal betacyanins (Jain \& Gould, 2015b).

In $D$. crassifolium betacyanin production was induced by high salinity and high light (Figure 3.4.1). This has been observed in D. australe previously (Jain \& Gould, 2015b), further indicating that betacyanin has a similar role in salt tolerance in both species. However, the red morph of $D$. australe was already producing betacyanins before the experiment started, while D. crassifolium shoots were still green and pigment production was induced during the experiment rather than before it. This might explain the differences in Fv/Fm and chlorophyll content we observed between $D$. crassifolium and the red morph of $D$. australe and at the same time explain the similar decrease in $\mathrm{Fv} / \mathrm{Fm}$ in $D$. crassifolium and the green morph of $D$. australe. This experiment should be repeated and D. crassifolium plants that already produce betacyanins, as well as red morphs of $D$. australe, that have turned green due to a lack of salt and light stress, should be included in the experiment as well.

When betacyanins were present in the leaf epidermis, the mesophyll viability did not decrease under salt stress in D. crassifolium, while in green leaves the mesophyll viability decreased significantly (Figure 3.4.3, Table 3.2). Viability staining in D. australe led to similar results; salt stress decreased mesophyll viability considerably, while there was only a minor decrease in the betacyanic leaves (Figure 2.4.7, Table 2.1). Again, both species show similar responses to salt stress and betacyanic leaves seem to be able to protect the photosynthetically active mesophyll tissue under salt stress, in contrast to green leaves. Not only are D. crassifolium and D. australe similar in salt tolerance, the presence of betacyanin seems to play a similar role in enhancing salt tolerance in both species. 
I had to reject the hypothesis that mesophyll cells retain more $\mathrm{K}^{+}$in the presence of betacyanins, as there was (i) no $\mathrm{K}^{+}$retention, instead mesophyll cells of $D$. crassifolium and D. australe took up $\mathrm{K}^{+}$upon salt treatment, and (ii) there was no convincing evidence that betacyanin affects the $\mathrm{K}^{+}$flux response to salt stress. However, this study could show that betacyanin has beneficial effects on salt tolerance, particularly on mesophyll viability and maintaining the maximum quantum efficiency of PSII during salt stress, in both D. crassifolium and D. australe. Moreover, a completely new $\mathrm{Cl}^{-}$-dependent $\mathrm{K}^{+}$flux response to salinity was observed. The salt induced $\mathrm{K}^{+}$uptake could also explain how these halophytes maintain a high $\mathrm{K}^{+} / \mathrm{Na}^{+}$ratio in mesophyll cells and avoid the cytotoxic effects of $\mathrm{Na}^{+}$. More research is needed to find out how betacyanic plants are able to maintain a higher $\mathrm{K}^{+} / \mathrm{Na}^{+}$ratio during salt stress than green leaves, despite similar ion flux responses. 


\section{Chapter 4 Increased Salt Tolerance by Betacyanin Synthesis in Transgenic Nicotiana tabacum}

\subsection{Abstract}

Recent work has indicated a role for betacyanin pigments in the tolerance of some halophyte species to saline soils. Here, I used transgenic betacyanin over-expression mutants of Nicotiana tabacum to test whether the beneficial effect of betacyanins on salt tolerance can be transferred to a naturally non-betacyanic plant. Betacyanic $N$. tabacum leaf discs showed less decline in maximum quantum efficiency of PSII after high light and salt treatment. Additionally, photoinhibition by saturating light was lower in betacyanic leaves, and recovery from photoinhibition was swifter compared to green leaves. The beneficial effect of betacyanin production could be emulated by placing a polycarbonate filter with an absorption spectrum similar to that of betacyanin over green leaves indicating that betacyanin lowers the excitation pressure on PSII and has a photoprotective effect during high light and salt stress. The successful transfer of salt tolerance by introducing betacyanins to leaves presents an opportunity to increase the salt tolerance of common crops

\subsection{Introduction}

Currently soil salinity is one of the major threats to future food stability. Almost $20 \%$ of irrigated land is too saline to grow traditional crops, and because of rising sea levels, higher temperatures, and increasing aridity the demand for irrigation is growing (Munns \& Tester, 2008; Rozema \& Flowers, 2008; Dassanayake \& Larkin, 2017). Soil salinity heavily impacts plant growth and in 2014 lead to the loss of about 8 million tons of produce (Welle \& Mauter, 2017). Thus, there has been an increased effort by scientists worldwide to enhance crop salt tolerance.

Saline soils present two different forms of stress, osmotic and ionic (Munns \& Tester, 2008). Halophytes combat osmotic stress by producing compatible solutes such as proline, glycine, polyamines, and sugar alcohols (Deinlein et al., 2014). To avoid the accumulation of $\mathrm{Na}^{+}$up to cytotoxic levels, plants may compartmentalise excess ions in the cell vacuoles, exclude ions from the roots by transporting them back into the soil solution, or else offload ions from the xylem in the roots to avoid their transport to the salt-sensitive photosynthetic tissues in the 
leaves (Munns \& Tester, 2008; Hasegawa, 2013; Flowers et al., 2015). Many halophytes share adaptive features, such as salt glands or succulence. Additionally, many salt-tolerant plants produce red pigments in their vegetative organs (Hasegawa, 2013).

The red coloration can be caused by anthocyanins, the most abundant red pigments in plants, or by the less common pigment, the betacyanins. Betacyanins are a group of tyrosine-derived alkaloids which only occurs in one plant order, the Caryophyllales, and in some Basidiomycetes (Brockington et al., 2015). Research on plant pigments has mainly focused on anthocyanins, the functional role of betacyanins being largely neglected (Jain \& Gould, 2015a). However, betalains have recently attracted scientific attention, especially in relation to their potential for mitigating the effects of abiotic stress. High light and/or concentrated salt treatments can induce the synthesis of betacyanins in Mesembryanthemum crystallinum, Suaeda salsa, Suaeda japonica, Amaranthus cruentus, and Disphyma australe (Ibdah et al., 2002; Wang \& Liu, 2007; Hayakawa \& Agarie, 2010; Nakashima et al., 2011; Jain et al., 2015). A combination of high salinity and high light stress can cause photo-oxidative damage in plants and thus reduce the chloroplasts' capacities to process quanta (Percey et al., 2014). Betacyanins in the epidermis of shoots and leaves absorb incident yellow-green light and thereby efficiently reduce the excitation pressure in the chloroplasts (Nakashima et al., 2011; Jain et al., 2015).

In D. australe, a succulent halophyte that commonly occurs on coastal dunes throughout New Zealand, betacyanins have been associated with higher salt tolerance. Betacyanic plants grow faster than non-betacyanic plants when treated with salt, and also have a higher water use efficiency, maximum $\mathrm{CO}_{2}$ assimilation rate, and higher photochemical quantum yield of PSII under salt stress. Moreover, the decrease in maximum quantum efficiency of PSII after exposure to saturating light and high salinity is less in betacyanic plants compared to nonbetacyanic plants (Jain \& Gould, 2015b). These results indicate that betacyanins might have a role in maintaining growth and normal photosynthetic activity in highly saline environments. Therefore, introducing betacyanin into crop species might have beneficial effects on crop salt tolerance.

Betacyanin synthesis requires three key enzymes. The first one is cytochrome P450 (CYP76AD1 or CYP76AD6) that catalyses the formation of 3,4-dihydroxyphenylalanine (LDOPA) from tyrosine (Polturak et al., 2016). Then, either cytochrome P450 (CYP76AD1) oxidises L-DOPA to cyclo-DOPA, or else DOPA 4,5-dioxygenase (DODA1) cleaves L-DOPA at the 4,5 aromatic ring to form betalamic acid (Christinet et al., 2004; Sasaki et al., 2005). 
Betalamic acid then spontaneously condenses with L-DOPA or cyclo-DOPA to form betacyanins (Strack et al., 2003). The whole betalain synthesis pathway is described in detail under 1.4.1 synthesis of betalains (Figure 1.4.1). It has been possible to introduce betacyanin production in plants that would otherwise only produce anthocyanin by overexpressing DOPA dioxygenases (DODAs) and substrate feeding (Harris et al., 2012). After identifying the first step in betacyanin synthesis, the hydroxylation of tyrosine to L-DOPA by CYP76AD1 or CYP76AD6 (Sunnadeniya et al., 2016), heterologous production of betalains in plants without substrate feeding was possible (Polturak et al., 2017; Polturak \& Aharoni, 2019). It remains to be demonstrated, however, whether the introduction of the genes for betacyanin biosynthesis might enhance the tolerance of the recipient plants to stressors.

Here, I describe how betacyanin production has been transferred into N. tabacum, which would not normally synthesise any betalains, by introducing three key enzymes of the betalain synthesis pathway, namely CYP76AD1, cDOPA5GT, and BvDODA1. By subjecting these plants to high salt concentrations and monitoring their maximum chlorophyll fluorescence and ability to recover form photoinhibition, I tested the hypothesis that the introduction of betacyanin production enhances salt tolerance in $N$. tabacum, normally a glycophytic plant.

\subsection{Materials and Methods}

\subsubsection{Plant Material}

The N. tabacum plants (cultivar: Samsun) used in these experiments, were grown in a greenhouse in Palmerston North, New Zealand, under ambient light conditions and the glasshouse was heated at $15{ }^{\circ} \mathrm{C}$ and vented at $25^{\circ} \mathrm{C}$. The plants were grown in the greenhouse and watered with an automated watering system before salt treatment started.

For the leaf disc assay and the photo recovery assay four independent plants of each genotype were used per treatment.

\subsubsection{Binary Vector Construction}

This binary vector contains three key enzymes of the betacyanin synthesis pathway, namely the Beta vulgaris cytochrome P450, CYP76AD1 (GenBank accession: HQ656023.1); the Mirabilis jalapa cyclo-DOPA-5-O-glucosyltrensferase, cDOPA5GT (AB182643.1); and the B. vulgaris DOPA-4,5-dioxygenase, DODA1 (HQ656027.1). The CYP76AD1 was located between the $35 \mathrm{SCaMV}$ promotor (35S) and the octopine synthase terminator (OCS), followed by 
cDOPA5GT located between the ubiquitin 10 promotor (UBQ10) and the OCS terminator, followed by DODA1, located between the $35 \mathrm{~S}$ promotor and the nopaline synthase terminator (NOS) (Figure 4.3.1). After this fragment was synthesized by GenScript (www.genscript.com), it was ligated into a pART27 vector. This vector contains a kanamycin selectable marker (nptII). The resulting vector pYF1 was used to transform $N$. tabacum plants to generate plants that synthesise betacyanins.

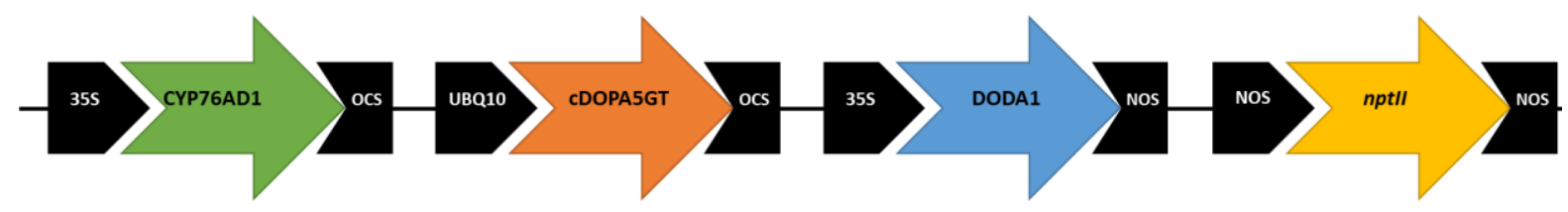

Figure 4.3.1 Schematic overview of betalain overexpression vector. CYP76AD1, B. vulgaris cytochrome P450 (HQ656023.1); cDOPA5GT, Mirabilis jalapa cyclo-DOPA-5-Oglucosyltransferase (AB182643.1); DODA1, B. vulgaris DOPA 4,5-dioxygenase (HQ656027.1); nptII, kanamycin resistance marker. Unpublished data from Dr Yanfei Zhou; reproduced with permission

\subsubsection{Plant Transformation}

Stable transgenic $N$. tabacum plants were generated with Agrobacterium tumefaciens (Strain GV3101) transformation of leaf discs as described in (Horsch et al., 1985). In addition to the betacyanin overexpression mutant (BtOE) that was generated using the binary vector $\mathrm{pVF} 1$, an empty vector control (EV) was generated using the pART27 vector. As an additional control wild type (WT) plants were regenerated through the same process as the transgenic plants.

\subsubsection{Confirmation of Expression of Transgenes}

To confirm that the transgenic $N$. tabacum lines are expressing CYP76AD1, cDOPA5GT, DODA1, and nptII RNA was isolated from frozen and ground leaves using CTAB/chloroform extraction as described in (Gambino et al., 2008). With SuperScript ${ }^{\mathrm{TM}}$ II Reverse Transcriptase (Invitrogen, Thermo Fisher Scientific, Waltham, Massachusetts, USA) first strand cDNA was made from $1 \mu \mathrm{g}$ RNA treated with DNase1 (Roche, Basel, Switzerland) (Table 4.1). 
Table 4.1 Primers used in this study. Unpublished data from Dr Yanfei Zhou; reproduced with permission

\begin{tabular}{|c|c|c|c|c|}
\hline Primers & & Sequence $\left(5^{\prime} \rightarrow 3^{\prime}\right)$ & $\begin{array}{c}\text { Annealing } \\
\text { Temperature } \\
\left({ }^{\circ} \mathbf{C}\right)\end{array}$ & $\begin{array}{c}\text { Target } \\
\text { Size } \\
\text { (bp) }\end{array}$ \\
\hline \multirow{2}{*}{ CYP76AD1 } & Forward & АCСАААСТTСТTССТСCTGG & \multirow{2}{*}{54} & \multirow{2}{*}{733} \\
\hline & Reverse & CACATCATCAGTCGTCGTTG & & \\
\hline \multirow{2}{*}{ cDOPA5GT } & Forward & GCATTTACGTCCTTTCCTTG & \multirow{2}{*}{52} & \multirow{2}{*}{560} \\
\hline & Reverse & ACCAATCATCTGATCCATCG & & \\
\hline \multirow{2}{*}{ DODA1 } & Forward & CGAAACGGCGGAAACTGATC & \multirow{2}{*}{56} & \multirow{2}{*}{110} \\
\hline & Reverse & GGCTGAACTGAGAGCTGACATA & & \\
\hline \multirow{2}{*}{ nptII } & Forward & GCCGAGAAAGTATCCATCAT & \multirow{2}{*}{52} & \multirow{2}{*}{560} \\
\hline & Reverse & AGCCCAACCTTTCATAGAAG & & \\
\hline
\end{tabular}

\subsubsection{Betalain analysis}

$100 \mathrm{mg}$ fresh leaf or seedling tissue was ground with $2 \mathrm{ml}$ methanol: water: formic acid (80:19:1) in liquid nitrogen to extract betalains. The betalains were separated by Ultra HighPerformance Liquid Chromatography (UHPLC) and the identity of the different compounds was confirmed with Liquid chromatography - High Resolution Accurate Mass - mass spectrometry (LC-HRAM-MS) and LC-HRAM-MS/MS.

For UHPLC a Dionex Ultimate® 3000 Rapid Separation LC system equipped with a binary pump (HPR3400RS), autosampler (WPS-3000RS), column compartment (TCC-3000RS), and a diode array detector (DAD-3000RS) was used together with a Luna Omega C18 $100 \mathrm{~mm} \times$ $2.1 \mathrm{~mm}, 1.6 \mu \mathrm{m}$ (Phenomenex, Torrance, CA, USA) analytical column and maintained at 40 ${ }^{\circ} \mathrm{C}$. With $0.1 \%$ formic acid as solvent $\mathrm{A}$ and acetonitrile as solvent $\mathrm{B}$ a binary solvent program with a flow rate of $300 \mu \mathrm{min}^{-1}$ was used. The initial solvent composition was $100 \%$ A $0-0.5$ min; linear gradient to 85\% A 15\% B 0.5-10 min.; linear gradient to 40\% A 60\% B 10-20 min.; linear gradient to 5\% A 95\% B 20-22 min.; composition held at 5\% A 95\% B 22-25 min.; linear gradient to $100 \%$ A $25-25.5$ min.; to return to the initial conditions before another sample injection of $2 \mu \mathrm{l}$ at $30 \mathrm{~min}$. Spectral data were collected at $260-600 \mathrm{~nm}$ for the entire analysis.

For the LC-HRAM-MS/MS a Dionex Ultimate ${ }^{\circledR} 3000$ Rapid Separation LC and a micrOTOF QII high resolution mass spectrometer (Bruker Daltonics, Bremen, Germany) fitted with an electrospray ion source were used. Again, a Luna Omega C18 $100 \mathrm{~mm} \times 2.1 \mathrm{~mm}, 1.6 \mu \mathrm{m}$ (Phenomenex, Torrance, CA, USA) column was used and maintained at $40{ }^{\circ} \mathrm{C}$. The two solvents used were $0.2 \%$ formic acid and $100 \%$ acetonitrile and the flowrate and solvent 
gradients were the same as above. For both the samples and standards the injection volume was $1 \mu \mathrm{l}$. The micrOTOF QII parameters were: temperature $225^{\circ} \mathrm{C}$; drying $\mathrm{N}_{2}$ flow $61 \mathrm{~min}^{-1}$; nebulizer $\mathrm{N}_{2} 1.5$ bar, endplate offset $500 \mathrm{~V}$, mass range $100-1500 \mathrm{Da}$, data were acquired at 5 scans s$^{-1}$. A capillary voltage of $3000 \mathrm{~V}$ was used for the positive ion electrospray. Postacquisition internal mass calibration used sodium formate clusters with the sodium formate delivered by a syringe pump at the start of each chromatographic analysis. For data processing Target Analysis for Screening and Quantitation software (TASQ) (Bruker Daltonics, Bremen, Germany) were used.

\subsubsection{Chlorophyll and Carotenoid Quantification}

Carotenoid and chlorophyll $\mathrm{a}$ and $\mathrm{b}$ were extracted in $80 \%$ acetone. For spectrophotometric pigment quantification a Microplate Reader (SpectraMax Plus 384, Molecular Devices, California, USA) was used as described in (Lichtenthaler \& Buschmann, 2001).

\subsubsection{Seedling Survival Assay}

To compare the effect of salinity on betacyanic and non-betacyanic N. tabacum plants, 2-wkold seedling of three independent lines of WT, EV and BtOE were transferred to Murashige and Skoog (MS) medium (Sigma-Aldrich, St. Louis, Missouri, United States) containing 800 $\mathrm{mM} \mathrm{NaCl}$. Three technical replicates with 8 seedlings each were grown at $22{ }^{\circ} \mathrm{C}$ under continuous white light $\left(450 \mu \mathrm{mol} \mathrm{m}^{-2} \mathrm{~s}^{-1}\right)$ provided by cool white LEDs, with a photoperiod of $12 \mathrm{~h}$ for $8 \mathrm{~d}$. The seedlings were then transferred to $\mathrm{MS}$ medium containing no $\mathrm{NaCl}$ for recovery for $2 \mathrm{wk}$.

\subsubsection{Leaf Disc Assay}

For the leaf disc assay healthy and fully expanded leaves of similar age from four independent lines of each WT, EV and BtOE plants were used. With a leaf puncher leaf discs with a diameter of $1.8 \mathrm{~cm}$ were cut from the leaves and floated on $5 \mathrm{ml}$ of distilled water, 100 , or $200 \mathrm{mM} \mathrm{NaCl}$ at $22{ }^{\circ} \mathrm{C}$ for $48 \mathrm{~h}$. The leaf discs were kept under two different light conditions, low light with $150 \mu \mathrm{mol} \mathrm{m}^{-2} \mathrm{~s}^{-1}$ or high light with $450 \mu \mathrm{mol} \mathrm{m}^{-2} \mathrm{~s}^{-1}$, provided by cool white LED lights. Both light conditions had a photoperiod of $12 \mathrm{~h}$. Additionally, leaf discs of WT and EV leaves were covered with a polycarbonate filter (Rosco Supergel \#346 Tropical Magenta, KEL-LPS, Auckland, New Zealand) with a similar absorption spectrum to betacyanins. After $48 \mathrm{~h}$ the ratio of variable to maximum chlorophyll fluorescence (Fv/Fm) was measured using a Walz 2500 (Effeltrich, Germany) pulse amplitude modulated (PAM) after $12 \mathrm{~h}$ in darkness. Additionally, betalain, carotenoid, and chlorophyll a and b content were determined from the leaf discs. 


\subsubsection{Photo Recovery Assay}

WT, EV and BtOE seedlings of four independent lines each were generated from tissue culture and then grown in a greenhouse in Palmerston North, New Zealand, under natural light conditions and watered by an automatic watering system for 2 months. The plants were then watered daily with $50 \mathrm{ml}$ water or $400 \mathrm{mM} \mathrm{NaCl}$ for $2 \mathrm{wk}$. Leaves of a similar size and age were used to monitor chlorophyll fluorescence before during and after treatment with saturating light. Fv/Fm was determined of one leaf per plant. Leaves were dark adapted for $30 \mathrm{~min}$ before the initial Fv/Fm measurements using a Walz 2500 (Effeltrich, Germany) pulse amplitude modulated (PAM). Then the leaves were treated with $1000 \mu \mathrm{mol} \mathrm{m}^{-2} \mathrm{~s}^{-1}$ cold with light for 30 min and Fv/Fm measurements were taken again. The plants were then returned to darkness and the Fv/Fm measurement were taken every hour for $5 \mathrm{~h}$.

Experiments described under 4.2.1 - 4.2.7 were carried out by Dr. Yanfei Zhou. Experiments 4.2.8 and 4.2.9 were mainly carried out be me.

\subsubsection{Statistics}

For statistical analysis R (R Core Team, 2018) and the emmeans (Lenth, 2018) package were used. The Fligner-Killeen test was used to test for homogeneity of variance. Fv/Fm measurements from leaf discs, as well as photoinhibition and recovery were analysed based on genotype (WT, EV, BtOE) using one-way ANOVAs. Pairwise comparisons of estimated marginal means using the emmeans function were performed for comparisons across treatments.

\subsection{Results}

\subsubsection{Generation of betacyanin producing $N$. tabacum plants}

To test if the previously described effect of betacyanin in reducing salt stress in D. australe (Jain \& Gould, 2015b; Jain et al., 2015) is transferable to naturally non-betacyanic plants, Dr Yanfei Zhou introduced the pYF1 vector (Figure 4.3.1) containing the three betacyanin biosynthesis genes, CYP76AD1, cDOPA5GT and DODAl into N. tabacum, resulting in a betacyanin over expression line (BtOE). Additionally, an empty vector control (EV) was generated by introducing the empty pART27 vector into $N$. tabacum. BtOE seeds were darker than seeds from wild type (WT) and EV (Figure 4.4.1 a) and red pigments were extracted with $80 \%$ methanol (Figure 4.4.1 b). The presence of red pigments in the testa and embryo was confirmed with cross sections of the seeds (Figure 4.4.1 c) and the cotyledon of germinated 
seeds had red-violet colour (Figure 4.4.1 d). Four-week-old seedlings of BtOE showed a strong red-violet colouration in leaves, stem and roots (Figure 4.4.1 e). The production of this pigment did not appear to affect plant development and growth. The mature plants retained the red-violet colour in leaves, stems, and roots; they were able to complete their life cycle as normal, initiated flowers, and produced seeds (Figure 4.4.1 f) The flowers of BtOE had a strong red-violet colouration compared to the white and pink flowers of WT and EV (Figure 4.4.1 g). The red pigment was present in BtOE leaves in parenchyma associated with xylem (Figure 4.4.2 a), the palisade mesophyll, the spongy mesophyll (Figure 4.4.2 b), and guard cells (Figure 4.4.3 b), but was absent in WT (Figure 4.4.2 c - d). At the subcellular level, the red pigments were located in the cell vacuoles (Figure 4.4.3 a). 


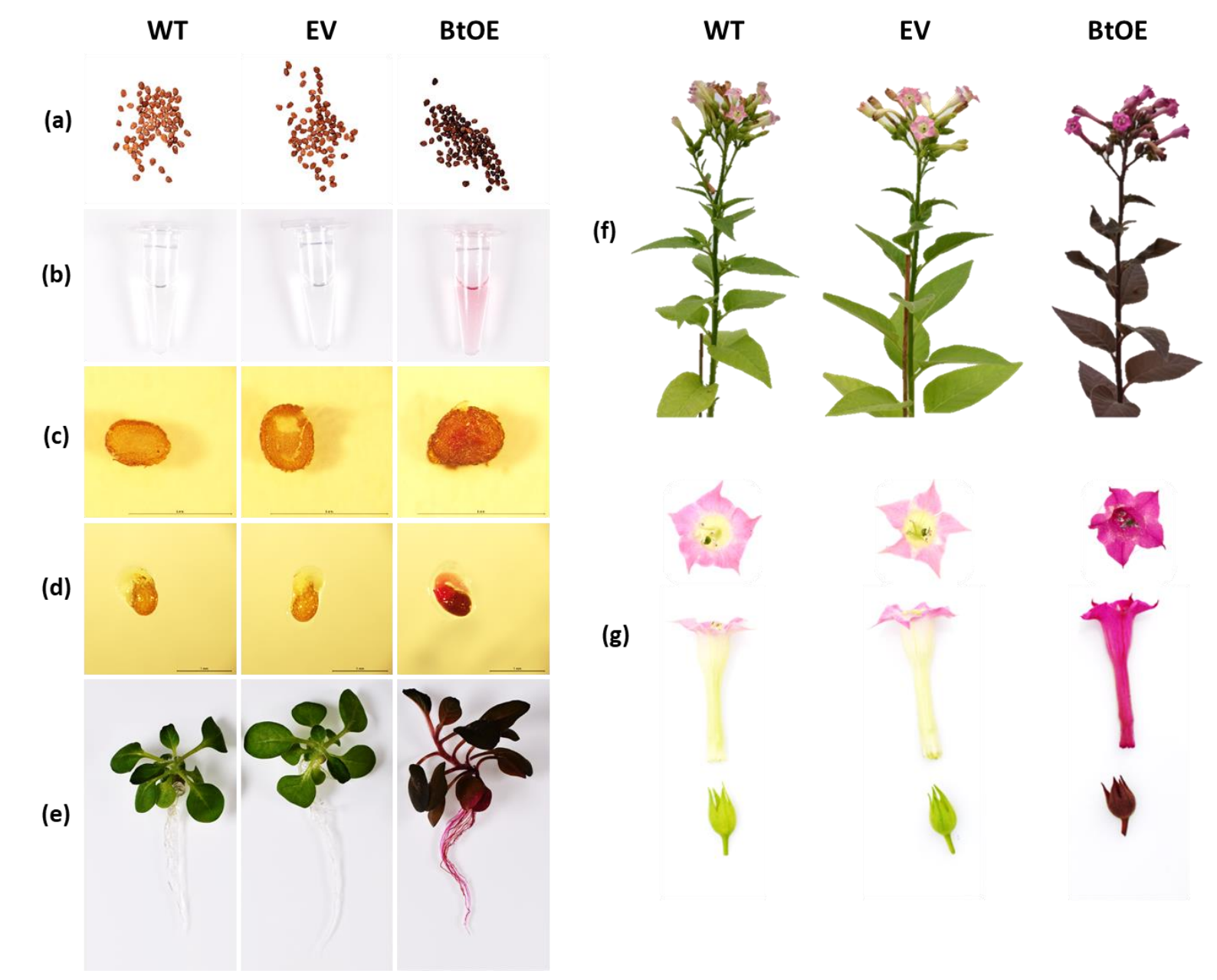

Figure 4.4.1 Transformation with the betalain over-expressing vector resulted in formation of violet-red pigmented plants in N. tabacum. WT, wild type; EV, pART27 empty vector control; BtOE, betacyanin over-expressing transgenic line. (a) T3 seeds; (b) seed extracts in $80 \%$ methanol; (c) cross section of T3 seeds; (d) germinated seeds; (e) 4-week-old seedling; (f) mature plants; (g) flowers. Unpublished data from Dr Yanfei Zhou; reproduced with permission 


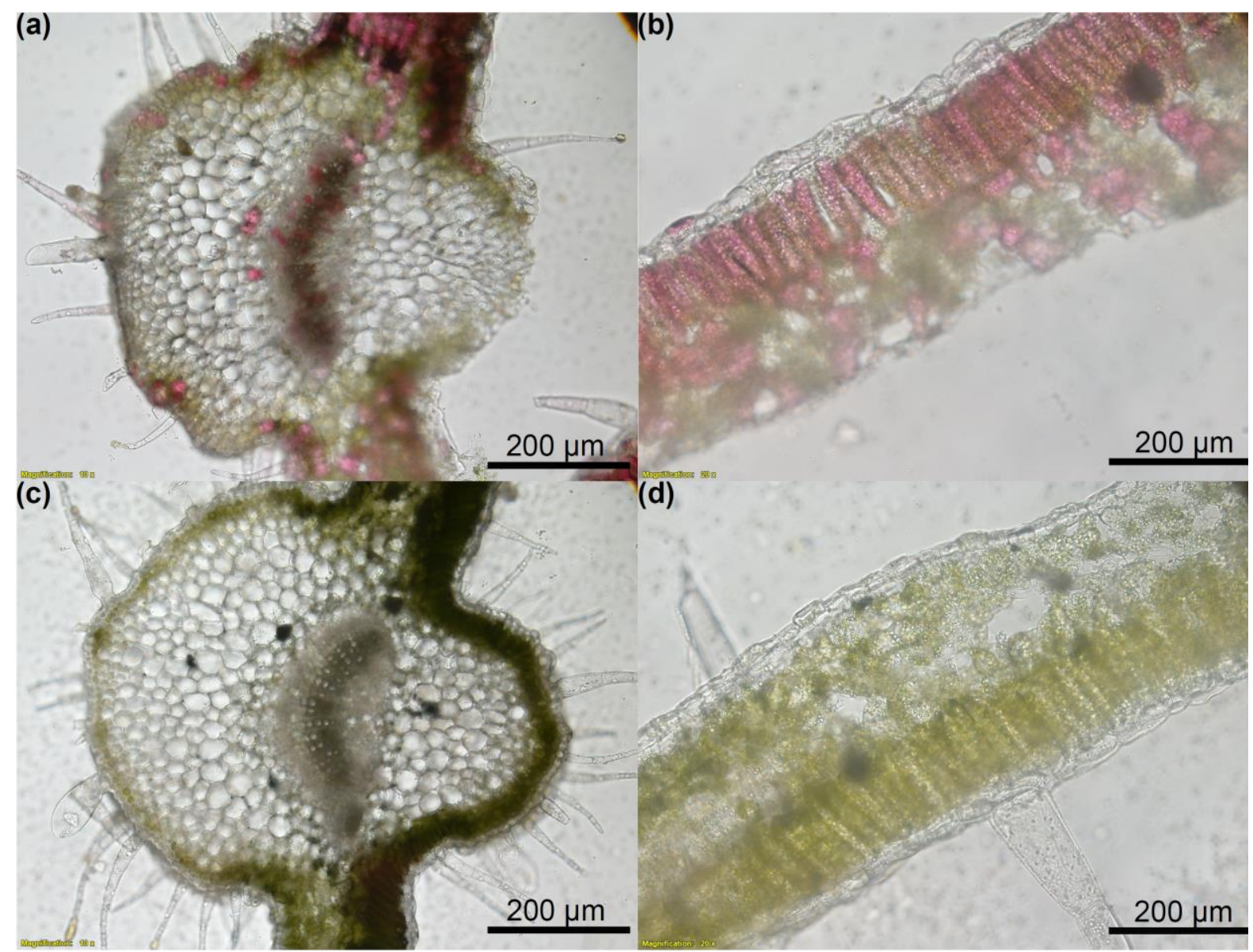

Figure 4.4.2 Transverse sections through leaves of $\operatorname{BtOE}(\mathrm{a}, \mathrm{b})$ and WT (c, d) N. tabacum, illustrating the location of betacyanins around the vascular bundle (a) and the palisade and spongy mesophyll (b).
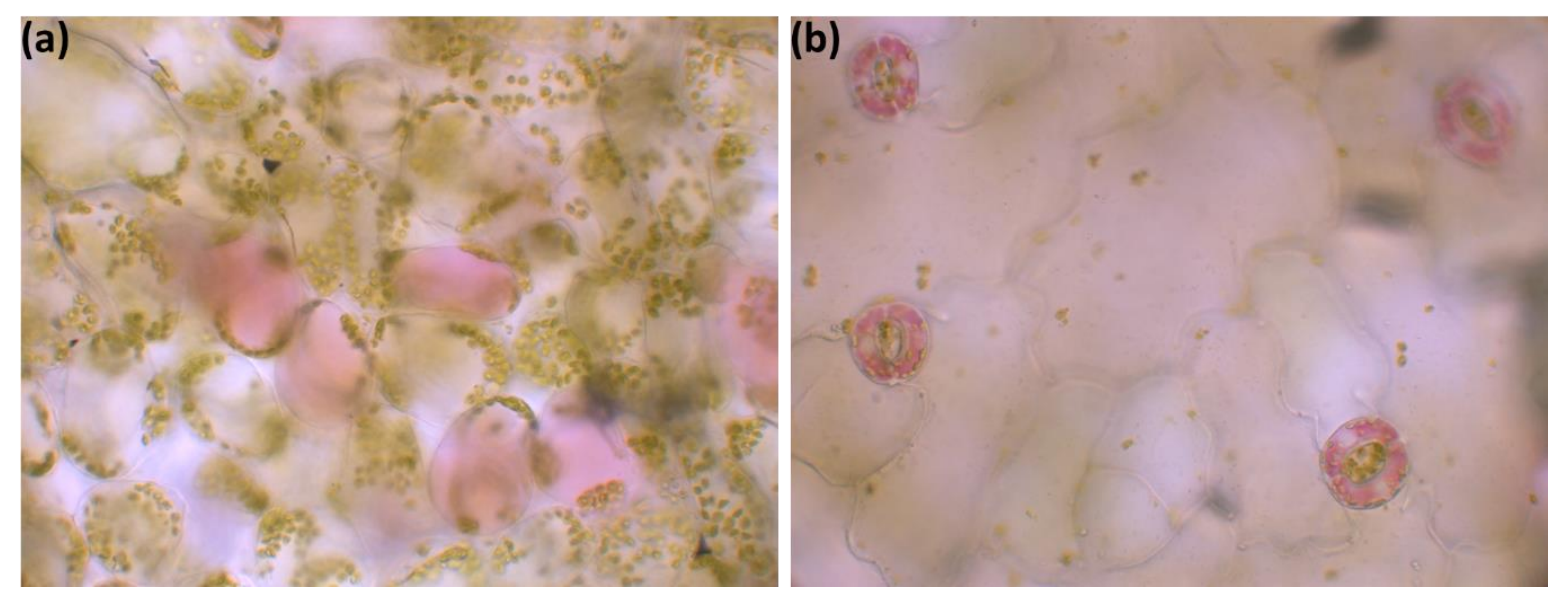

Figure 4.4.3 The location of betacyanin pigments in mesophyll cells (a) and guard cells (b) of BtOE N. tabacum leaves. Unpublished data from Dr Yanfei Zhou; reproduced with permission 
RT-PCR confirmed that three betacyanin synthesis genes, namely CYP76AD1, cDOPA5GT and DODAl, and a kanamycin selection marker (nptII), were expressed in BtOE plants while in EV plants only nptII was expressed and none was expressed in WT plants (Figure 4.4.4). HPLC/LCMS analysis showed that BtOE plants produced two different betacyanins: betanin and isobetanin, but no betaxanthins (Figure 4.4.5, Table 1.1).

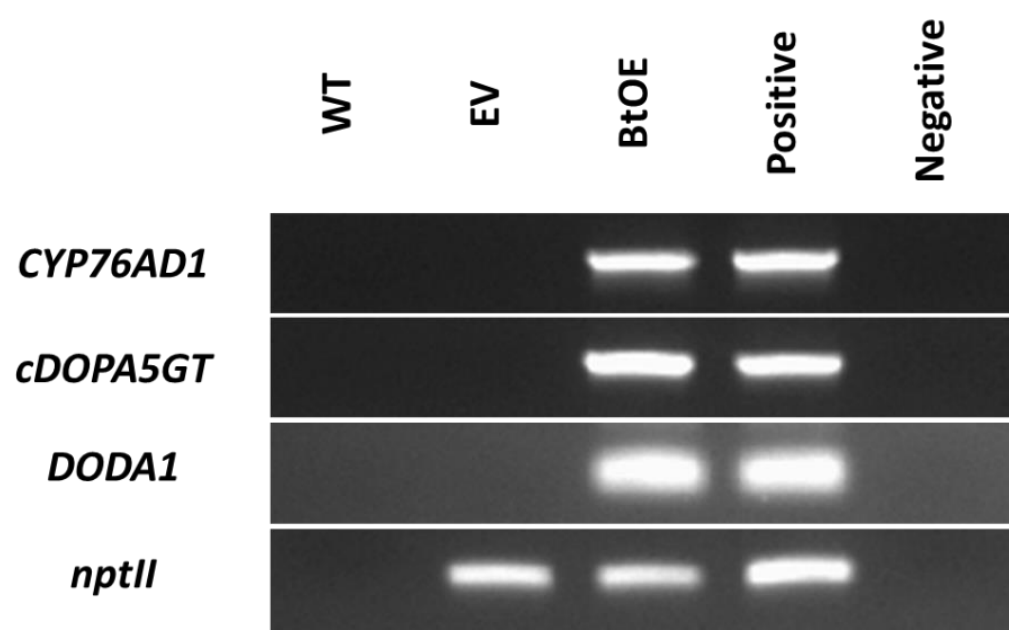

Figure 4.4.4 RT-PCR analysis of gene expression in transgenic N. tabacum leaf. WT, wild type; EV, pART27 empty vector control; BtOE, betacyanin over-expressing transgenic line; Positive, betalain binary plasmid; Negative, DNA free water. CYP76AD1, B. vulgaris cytochrome P450 (HQ656023.1); cDOPA5GT, M. jalapa cyclo-DOPA-5-Oglucosyltransferase (AB182643.1); DODA1, B. vulgaris DOPA 4,5-dioxygenase (HQ656027.1); nptII, kanamycin resistance marker. Unpublished data from Dr Yanfei Zhou; reproduced with permission 


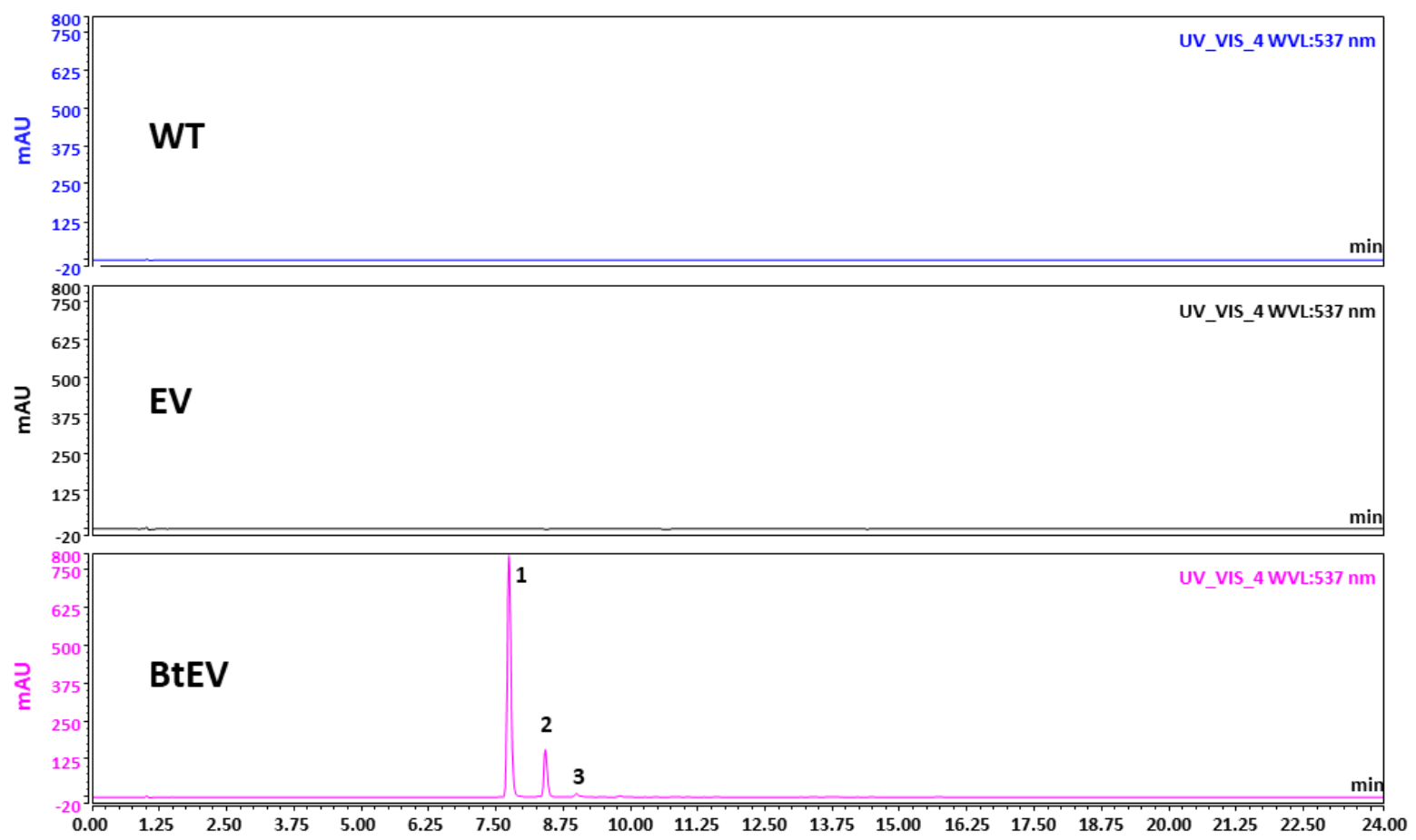

Figure 4.4.5 HPLC chromatogram of $N$. tabacum leaf extract. The horizontal axis indicates the retention time $(\mathrm{min})$, whereas the vertical axis indicates the signal intensity (IV); Unpublished data from Dr Yanfei Zhou; reproduced with permission

Table 4.2 Betalains identified by LC-MS analysis. Unpublished data from Dr Yanfei Zhou; reproduced with permission

\begin{tabular}{lllllll}
\hline & Identified & & & & \\
No. & Compound & Formula & $\mathbf{M} / \mathbf{Z}$ & $\mathbf{\Delta M} / \mathbf{Z}$ & $\mathbf{m} \boldsymbol{\Sigma}$ & $\mathbf{M S} \mathbf{M} \mathbf{Z}$ \\
\hline $\mathbf{1}$ & Betanin & $\mathrm{C}_{24} \mathrm{H}_{26} \mathrm{~N}_{2} \mathrm{O}_{13}$ & 551.1474 & 3.4 & 7.4 & 389.0974 \\
$\mathbf{2}$ & Isobetanin & $\mathrm{C}_{24} \mathrm{H}_{26} \mathrm{~N}_{2} \mathrm{O}_{13}$ & 551.1477 & -3.1 & 12.5 & 389.0979 \\
\hline
\end{tabular}

\subsubsection{Increased Survival of Betacyanic Seedlings under Severe Salt Stress}

To assess whether betacyanin production might increase salt tolerance in N. tabacum, seedling survival rates were quantified under high salinity. Seedlings of BtOE, EV, and WT were healthy when grown on MS medium. However, if grown on MS with $800 \mathrm{mM} \mathrm{NaCl}$ for $8 \mathrm{~d}$, most of the WT and EV seedlings were chlorotic, while most of the BtOE seedlings still had pigmented leaves (Figure 4.4.6). After transferring the seedlings back to MS medium without additional 
salt and grown for $2 \mathrm{wk}$, about $35 \%$ of BtOE seedlings recovered, while fewer than $5 \%$ of WT and EV seedlings were able to recover from salt stress (Figure 4.4.7).

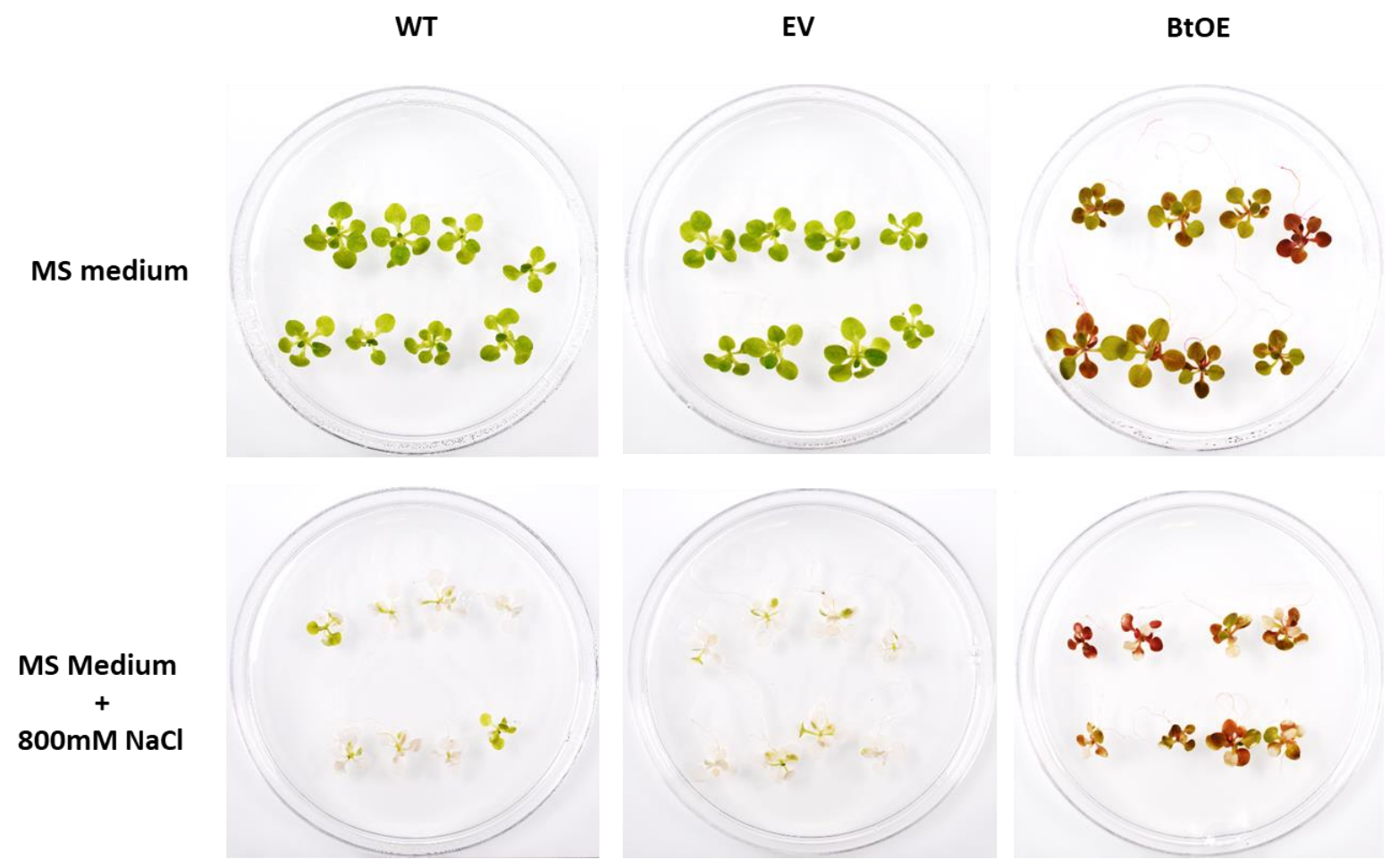

Figure 4.4.6 Seedling survival test under salt stress. WT, wild type; EV, pART27 empty vector control; BtOE, betacyanin over expressing transgenic line. Unpublished data from Dr Yanfei Zhou; reproduced with permission 


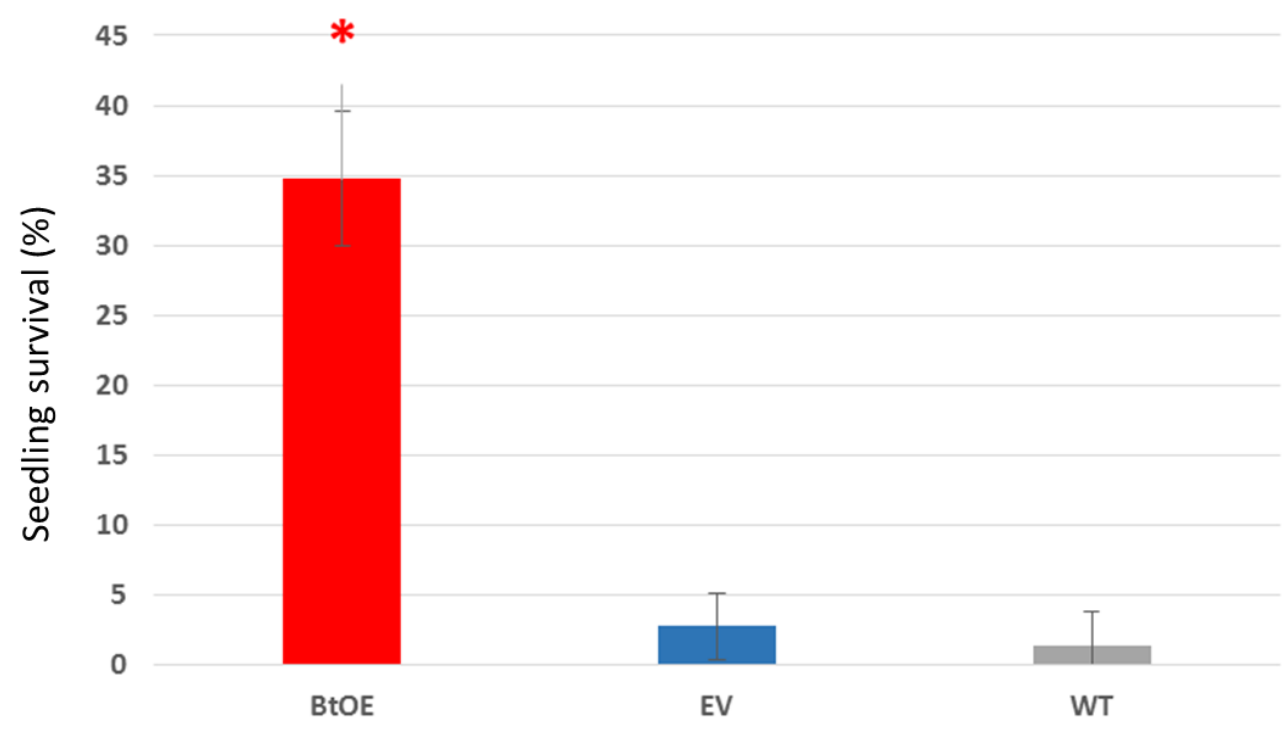

Figure 4.4.7 Percentage of seedlings that survived after severe salt stress treatment. WT, wild type; EV, pART27 empty vector control; BtOE, betacyanin over expressing transgenic line. Asterisks indicate significant difference relative to WT and EV (t-test: $\mathrm{P}<0.05)$. Unpublished data from Dr Yanfei Zhou; reproduced with permission

\subsubsection{Delayed Leaf Senescence under Salt Stress in Betacyanic N. tabacum}

To test whether betacyanin synthesis also increases salt tolerance of mature $N$. tabacum plants, leaf discs from 8-wk-old BtOE, EV and WT plants were floated on distilled water, $100 \mathrm{mM}$ and $200 \mathrm{mM} \mathrm{NaCl}$ for $48 \mathrm{~h}$. The leaf discs were kept under 150 or $450 \mu \mathrm{mol} \mathrm{m}{ }^{-2} \mathrm{~s}^{-1}$ light provided by cool white LEDs, with a photoperiod of 12 hours.

Under both low and high light, the salt treated leaf discs of WT and EV turned chlorotic and the margins were bleached, suggesting that the chlorophyll content decreased under salt stress. The BtOE leaf discs floated on $200 \mathrm{mM} \mathrm{NaCl}$ had bleached margins under both low and high light (Figure 4.4.8). However, the bleached area seemed to be smaller in BtOE leaf discs compared to WT and EV leaf discs. 


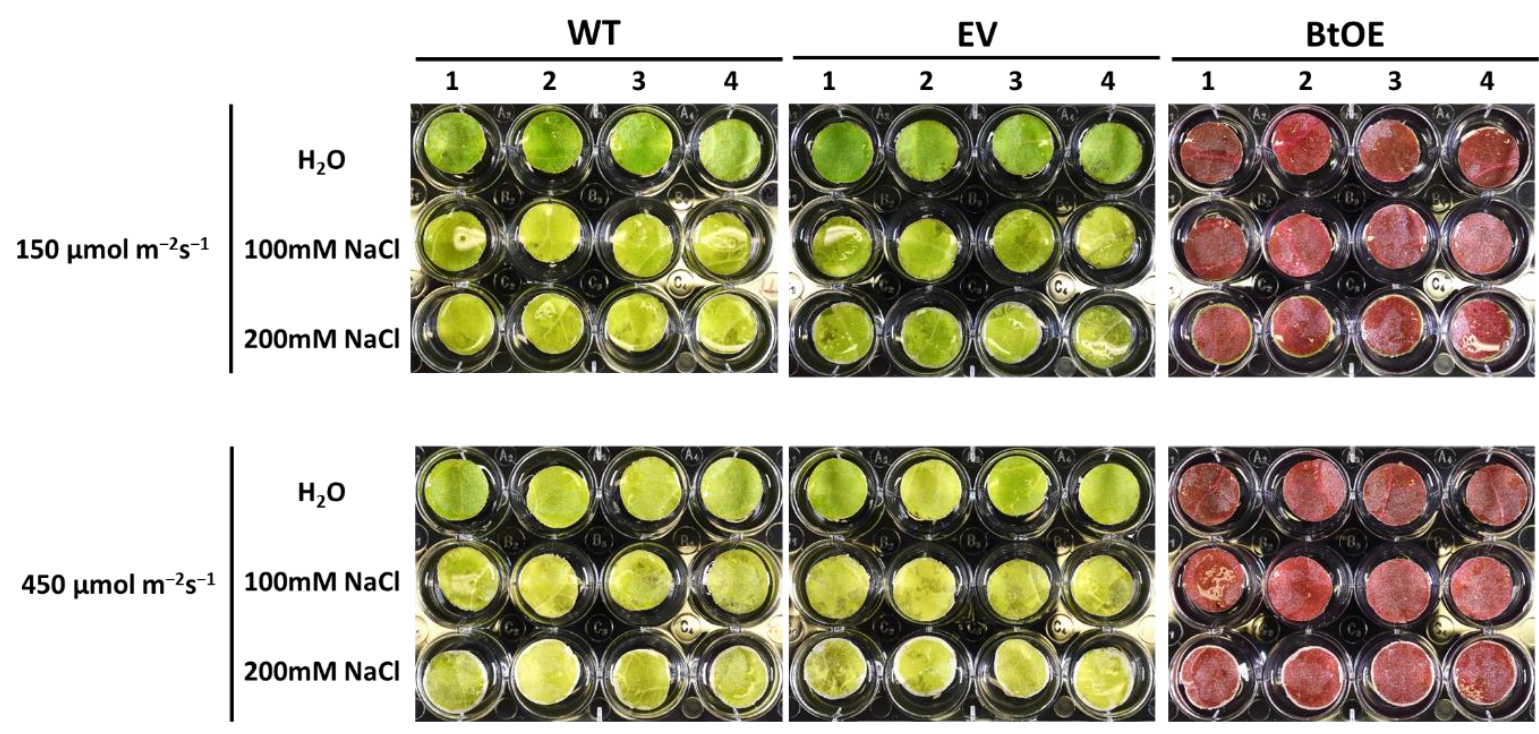

Figure 4.4.8 Photos of leaf discs treated with different salt solutions under high or low light. WT, wild type; EV, pART27 empty vector control; BtOE, betacyanin over expressing transgenic line. Photographs by Dr Yanfei Zhou; reproduced with permission

To assess leaf senescence chlorophyll and carotenoid degradation was determined. Chlorophylls and carotenoids were extracted and quantified from the leaf discs after the salt treatment. Under both low and high light, the total chlorophyll content decreased in WT, EV and BtOE leaf discs under salt stress. In the BtOE leaf discs the chlorophyll content decreased slower than in WT and EV leaf discs, and after $48 \mathrm{~h}$ the relative chlorophyll content in BtOE leaf discs was significantly higher than in WT and EV leaf discs (Figure 4.4.9 a-b). Independently form light intensity and salt treatment, carotenoids content decreased significantly in WT and EV leaf discs while in BtOE leaf discs it did not change (Figure 4.4.9 c - d). 
(a)

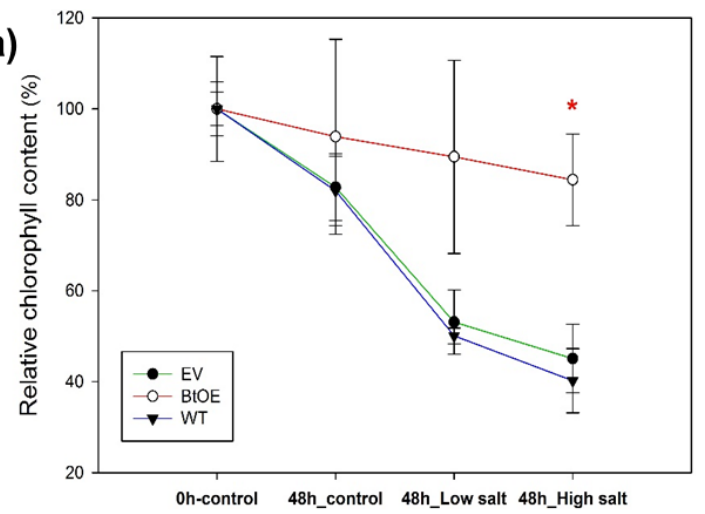

(c)

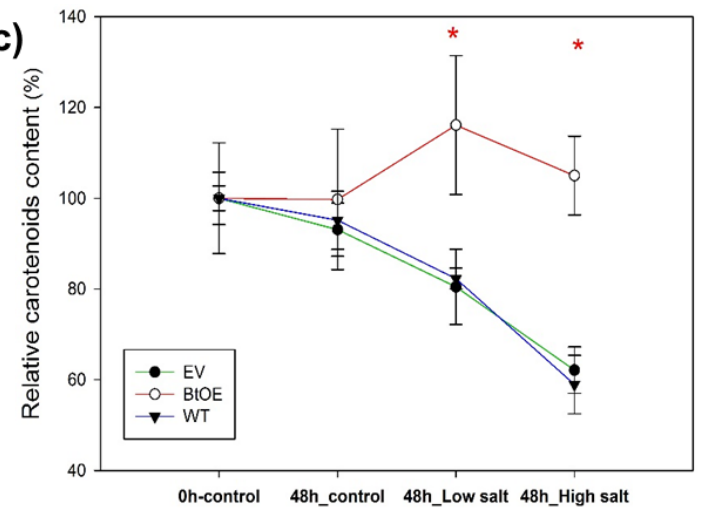

(b)

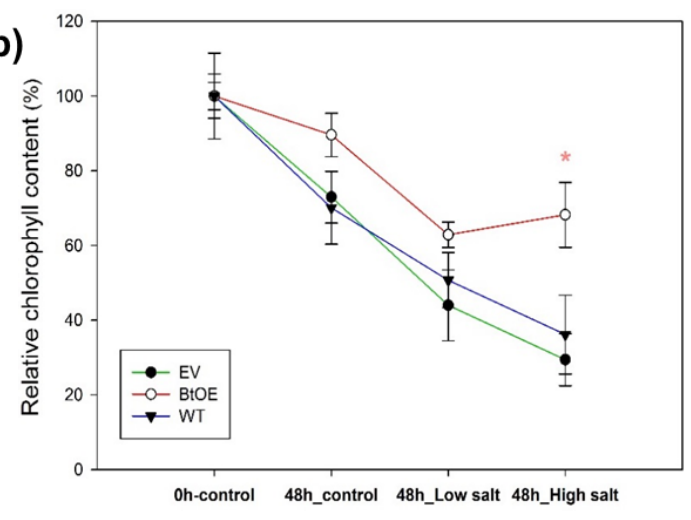

(d)

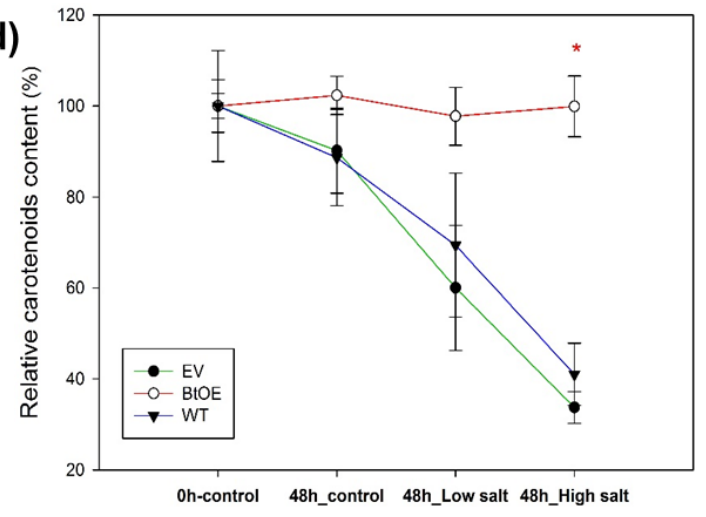

Figure 4.4.9 Relative total chlorophyll ( $\mathrm{a}$ and $\mathrm{b}$ ) and carotenoids (c and d) contents of $N$. tabacum leaf discs treated with salt solutions under $150 \mu \mathrm{mol} \mathrm{m}^{-2} \mathrm{~s}^{-1}$ (a and c) and $450 \mu \mathrm{mol}$ $\mathrm{m}^{-2} \mathrm{~s}^{-1}$ (b and d) light. WT, wild type; EV, pART27 empty vector control; BtOE, betacyanin over expressing transgenic line. Data was expressed as percentage of compounds contents in treated leaf discs versus that in untreated leaf discs. Unpublished data from Dr Yanfei Zhou; reproduced with permission

\subsubsection{Reduced Response to Salt Stress of Betacyanic N. tabacum}

To assess whether salt and light stress damage the leaf discs and impair photosynthesis, Fv/Fm was measured after $22 \mathrm{~h}$. Some WT and EV leaf discs were covered with a red filter for which the absorbance spectrum was similar to that of betacyanins to test whether photoabatement by these pigments might explain the reduced chlorophyll degradation under salt stress and high light.

The Fv/Fm of all three genotypes decreased after salt treatment. Under low light there was a significant difference in $\mathrm{Fv} / \mathrm{Fm}$ between $\mathrm{BtOE}$ and WT discs that were covered with a red filter under control conditions, and between $\mathrm{BtOE}$ and WT under $100 \mathrm{mM} \mathrm{NaCl}$ (Figure 4.4.10 a). However, there was no significant difference in Fv/Fm between any of the plant types covered with a filter or not under $200 \mathrm{mM} \mathrm{NaCl}$. 
Under high light there was no significant difference in Fv/Fm in the leaf discs that were not salt stressed (Figure 4.4.10 b). If the leaf discs were floated on $100 \mathrm{mM} \mathrm{NaCl}$, the Fv/Fm decreased more significantly in the WT than in BtOE, but there was no significant difference between BtOE, EV, and both EV and WT covered with a red filter. Under $200 \mathrm{mM} \mathrm{NaCl}$ the Fv/Fm was significantly lower in WT and EV than in BtOE, while there was no significant difference between BtOE and the WT and EV leaf discs that were covered with a red filter. These results showed that under high light, covering the green leaves with a red filter had a similar effect as betacyanins on the leaves' ability to withstand salt and light stress, suggesting that the protective effect of betacyanins may be related to photoabatement. 


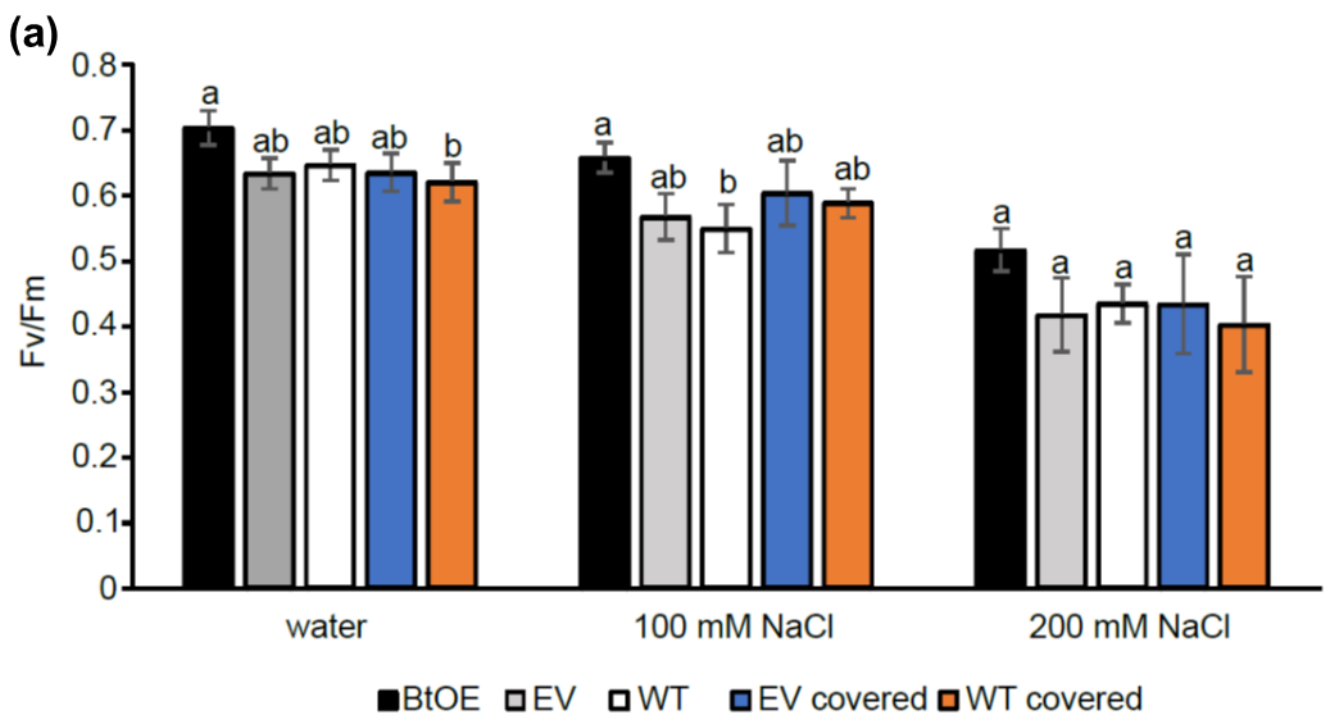

(b)

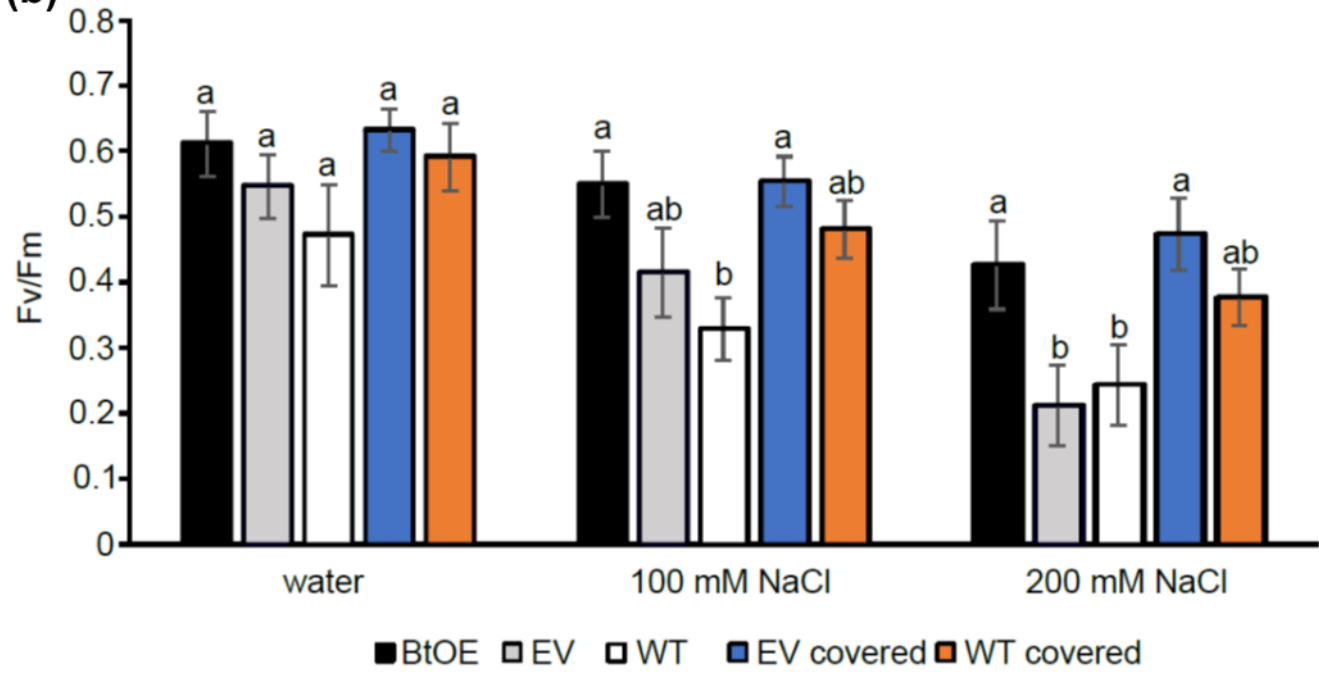

Figure 4.4.10 The ratio of variable to maximum fluorescence $(\mathrm{Fv} / \mathrm{Fm})$ of leaf discs treated with water, $100 \mathrm{mM}$ or $200 \mathrm{mM}$ salt solutions under low (a) or high light (b). WT, wild type; EV, pART27 empty vector control; BtOE, betacyanin over expressing transgenic line. Means $\pm S E, n=4$. Different letters indicate a statistically significant difference $(P<0.05)$.

To assess if the salt tolerance enhancing effect of betacyanin production observed in the leaf disc assay translated to the intact $N$. tabacum plants, the ability to recover from exposure to saturating light was assessed in salt-stressed WT, EV and BtOE plants growing in pots. Fv/Fm measurements were taken before, during, and after exposure to $1000 \mu \mathrm{mol} \mathrm{m}{ }^{-2} \mathrm{~s}^{-1}$ light. Before the salt stress treatment started Fv/Fm of WT, EV and BtOE was measured. All three genotypes had similar Fv/Fm values (WT: $0.797 \pm 0.009$; EV: $0.796 \pm 0.006$; BtOE: $0.816 \pm 0.009$ ) confirming that the presence of betacyanin had no influence on Fv/Fm under no stress conditions. Photosynthesis recovery was assessed after $2 \mathrm{wk}$ of salt treatment. 
The decrease in Fv/Fm after exposure to saturating light for 30 min was significantly higher in WT and EV compared to BtOE in both the water control (Figure 4.4.11 a) and the plants treated with $400 \mathrm{mM} \mathrm{NaCl}$ (Figure 4.4.11 b). If not salt stressed, the Fv/Fm decreased by $68 \%$ (Fv/Fm: $0.24 \pm 0.044)$ and by $69 \%$ (Fv/Fm: $0.23 \pm 0.030)$, in WT and EV, respectively, while in BtOE the Fv/Fm only decreased by $23 \%$ (Fv/Fm: $0.60 \pm 0.013$ ). In the salt treated plants exposure to saturating light reduced the Fv/Fm by $69 \%$ (Fv/Fm: $0.22 \pm 0.026), 68 \%$ (Fv/Fm: $0.22 \pm 0.029$ ), and $26 \%$ (Fv/Fm: $0.47 \pm 0.018$ ), in WT, EV, and BtOE, respectively. The betacyanic plants recovered significantly quicker from photo stress than WT and EV in both salt treated and control plants, it took $4 \mathrm{~h}$ for EV and WT to recover, while it took BtOE only $1 \mathrm{~h}$.

Under control conditions, both WT and EV made a relative steep initial recovery; after $1 \mathrm{~h}$ Fv/Fm: $0.57 \pm 0.031$ and $0.53 \pm 0.017$, after $2 \mathrm{~h} \mathrm{Fv/Fm:} 0.58 \pm 0.006$ and $0.59 \pm 0.023$, after 3 h Fv/Fm: $0.66 \pm 0.017$ and $0.61 \pm 0.016$, respectively. However, after salt treatment the initial recovery was reduced; after $1 \mathrm{~h} \mathrm{Fv/Fm:} 0.35 \pm 0.036$ and $0.35 \pm 0.027$, after $2 \mathrm{~h} \mathrm{Fv/Fm:} 0.45 \pm$ 0.023 and 0.44 \pm 0.009 , after $3 \mathrm{~h} \mathrm{Fv} / \mathrm{Fm}: 0.54 \pm 0.010$ and $0.52 \pm 0.014$, respectively. Betacyanic plants showed less reduction in the ratio of variable to maximum chlorophyll fluorescence after exposure to saturating light and a swifter recovery compared to WT and EV, suggesting that betacyanin might have a photoprotective effect. 
(a)

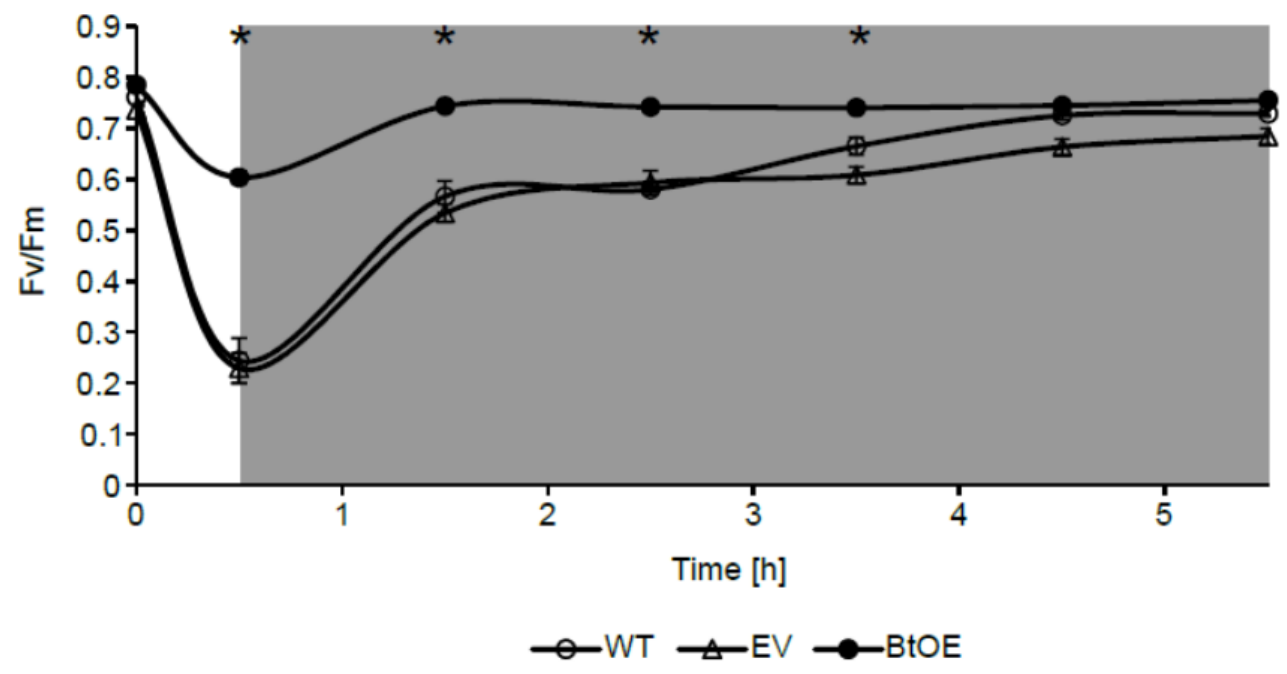

(b)

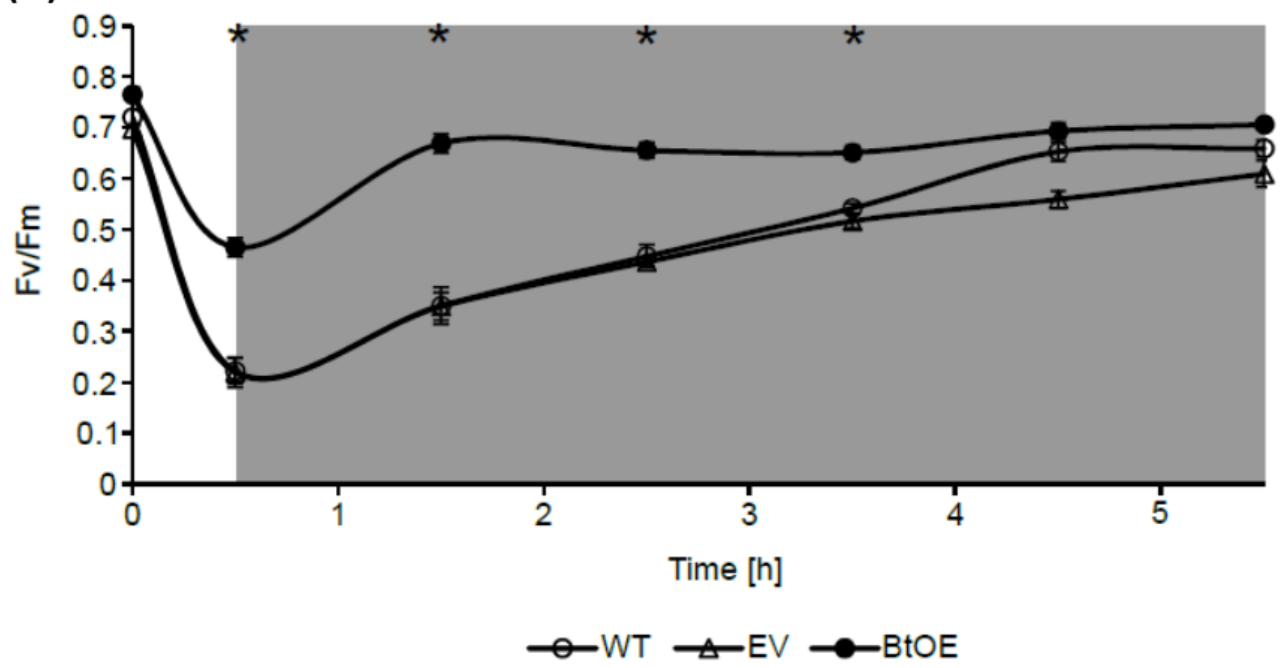

Figure 4.4.11 Changes in Fv/Fm for wild type (WT), empty vector control (EV), and betacyanin over expression (BtoE) $N$. tabacum plants after 2 wk treatment with $40 \mathrm{ml}$ water (a) or $400 \mathrm{mM} \mathrm{NaCl}$ (b) daily. Plants were exposed to $1000 \mu \mathrm{mol} \mathrm{m}^{-2} \mathrm{~s}^{-1}$ with light for 30 min (white areas) and then recovered for $5 \mathrm{~h}$ in darkness (shaded areas). Means $\pm \mathrm{SE}, \mathrm{n}=4$. Asterisks indicate a significant difference between BtOE and both WT and EV $(\mathrm{P}<0.05)$.

\subsection{Discussion}

While previous studies on D. australe have shown that betacyanin production can increase salt tolerance (Jain \& Gould, 2015b; Jain et al., 2015), there are no studies investigating whether the advantages in salt tolerance of betacyanin synthesis can be transferred to a non-betacyanic species. Therefore, betacyanin synthesis was introduced into N. tabacum, a non-betalainic species and then the salt tolerance of the betacyanic plants was assessed in comparison with the 
non-betalainic plants. Overexpressing three betalain synthesis genes, CYP76AD1, cDOPA5GT and DODA, resulted in a heterologous betalain production in $N$. tabacum. These three betalain synthesis genes have been previously used to introduce betalain synthesis in non-betalainic plants and microorganisms (Polturak et al., 2016, 2017; Polturak \& Aharoni, 2019). The presence of three betacyanins, betanin, isobetanin and betanidin, in BtOE plants was confirmed, but no betaxanthins or anthocyanins were detectable. Betanin and isobetanin are two of the five betacyanins that occur in D. australe (Jain \& Gould, 2015b).

In the presence of abiotic stressors, such as drought or salinity, seedling establishment is a critical process during the life cycle of a plant (Bohnert et al., 1995; Adolf et al., 2013). At this life stage, halophytes have a particular advantage compared to glycophytes on saline soils (Malcolm et al., 2003; Debez et al., 2004). Thus, seedling survival of WT, EV, and BtOE under severe salt stress was assessed. In betacyanin-producing $N$. tabacum, seedling survival was significantly higher than in WT and EV plants. Similarly, BtOE seedlings were able to recover after exposure to high salinity, while WT and EV seedlings were not (Figure 4.7). Similar results have been shown for $D$. australe. The betacyanic morphs had a higher germination and seedling survival rates than did the green morphs.

Salt stress in combination with high light led to a higher reduction in chlorophyll and carotenoid content in WT and EV leaf discs compared to BtOE leaf discs (Figure 4.10). Only WT and EV leaf discs became yellow and showed sever depigmentation under salt stress (Figure 4.4.9). These results indicate that under severe salt stress betacyanin production could reduce chloroplast damage and delay leaf senescence. Moreover, betacyanic leaf discs maintained a higher Fv/Fm under salt stress compared to WT and EV (Figure 4.4.11). Additionally, covering WT and EV leaf discs with a red filter had a similar effect on the Fv/Fm as betacyanin production, thus, indicating that betacyanins might have a photoprotective effect in N. tabacum. Similar studies in A. cruentus have shown that the extent of photoinhibition was greater in betacyanic leaves than in green leaves. Therefore, the authors suggested that in A. cruentus betacyanin lowers the excitation pressure on PSII by attenuating the harmful excess light (Nakashima et al., 2011).

This photoprotective effect of betacyanin was also observed on a whole plant level, when BtOE showed significantly less photoinhibition after exposure to saturating light in comparison to WT and EV plants. In addition, BtOE plants were also able to recover quicker from photoinhibition than both WT and EV plants (Figure 4.12). Again, these results suggest that 
betacyanin protects the leaf from photoinhibition. Studies in S. salsa also suggested a photoprotective effect of betacyanin. S. salsa seedlings that accumulated betacyanins not only showed a higher resistance to photoinhibition they also recovered quicker from photoinhibition (Wang \& Liu, 2007). Photoprotection has already been suggested to be one of the mechanisms betacyanins can increase salt tolerance in $D$. australe, after the red morph showed greater PSII quantum yields and photochemical quenching than the green after salt treatment (Jain \& Gould, 2015b). Moreover, betalainic D. australe leaves absorb more green and yellow light and therefore appear red, instead of reflecting more red light (Jain \& Gould, 2015b). Another red plant pigment, called anthocyanin shows similar spectral properties (Neill \& Gould, 1999; Jain $\&$ Gould, 2015b) and there has been abundant evidence that these pigments have a direct role in photoprotection by abating incident quantum fluxes (Gould et al., 2010; Jain \& Gould, 2015b).

Accumulation of betacyanins upon light exposure has been observed in Alternanthera species (Reis et al., 2015), Chenopodium quinoa (Imamura et al., 2018), D. australe, M. crystallinum (Vogt et al., 1999), and Portulaca callus (Kishima et al., 1991) suggesting that betacyanins have a role in response to light stress. Plants of the Caryophyllales family, to which all of the before mentioned plants belong, often occur in arid and semi-arid regions and/or on saline soils, where both light and salinity are a main stressors (Soltis et al., 2005). Betacyanins might protect these plants from photoinhibition in those challenging environments.

Both light and salt stress can induce the formation of reactive oxygen species (ROS), such as singlet oxygen and $\mathrm{H}_{2} \mathrm{O}_{2}$, which can cause oxidative damage to cell membranes, proteins, and DNA (Gill \& Tuteja, 2010). Betacyanin production in S. salsa (Wang et al., 2007) and B. vulgaris (Sepúlveda-Jiménez et al., 2004) could be induced by $\mathrm{H}_{2} \mathrm{O}_{2}$, when applied to roots and leaves, respectively. Moreover, purified betacyanin from $S$. japonica could prevent $\mathrm{H}_{2} \mathrm{O}_{2-}$ induced protein oxidation (Hayakawa \& Agarie, 2010), strongly suggesting an antioxidant activity for betacyanins. A similar function has been found for anthocyanin. In an in vivo study anthocyanins were identified as one of the major low molecular weight antioxidants in leaves, and they enhanced $\mathrm{H}_{2} \mathrm{O}_{2}$ scavenging significantly (Gould et al., 2002). In N. tabacum and Arabidopsis thaliana plants that overexpressed anthocyanins, the total ROS scavenging activity was significantly higher than in control plants (Li et al., 2017a; Naing et al., 2017, 2018). Another ROS induced by photooxidative stress, is singlet oxygen; interestingly, it has been suggested that carotenoids are the first line of defence against singlet oxygen (Ramel et al., 2012). Carotenoids are not only directly involved in the photosynthetic system; they are also 
potent ROS scavengers. There are two $\beta$-carotene molecules in the reaction centre of PSII, which can quench singlet oxygens (Ramel et al., 2012). Lutein and zeaxanthin are thylakoid antioxidants and also involved in quenching singlet oxygens (Burke et al., 2000; Foyer, 2018) BtOE leaf discs maintained a much higher carotenoid content under both salt and light stress then WT and EV leaf discs. Photoprotection by betacyanins might reduce carotenoid degradation and thus enhance singlet oxygen scavenging.

However, a photoprotective effect is the more likely explanation for the positive effects the presence of betacyanins had on $N$. tabacum during salt and light stress than ROS scavenging. First, betacyanins are stored in the vacuoles of cells and thus are located in a different cell compartment than ROS, which are mostly generated in the chloroplast. Secondly, ROS are important secondary messenger in response to biotic and abiotic stress (Farooq et al., 2019). Both biotic and abiotic stresses can change the redox homeostasis in plants by increasing ROS generation (Noctor et al., 2018; Farooq et al., 2019). ROS signals are working both up- and downstream from other secondary messengers, such as $\mathrm{Ca}^{2+}$, abscisic acid, jasmonic acid, salicylic acid, and mitogen-activated protein kinases and are an essential component in plant stress signalling (Farooq et al., 2019). Moreover, covering leaf discs with a red filter had a similar effect in Fv/Fm and chlorophyll degradation than the presence of betacyanins, strongly suggesting that the beneficial effects on salt tolerance in betacyanic leaves are not caused by ROS scavenging, but by reduced excitation pressure of PSII due to the photoprotective effect of betacyanin.

In conclusion, this study could transfer the advantages of betacyanin production on salt tolerance, as observed in D. australe to $N$. tabacum. The salt tolerance of betacyanic N. tabacum plants was most likely increased by a photoprotective effect of betacyanin. Transferring betacyanin production into crop species could increase salt tolerance in a similar manner as we described in this study for $N$. tabacum. This could be an entire new way to increase the salt tolerance of common crops and maintain food production on salinizing soils. 


\section{Chapter 5 General Discussion}

In this thesis, I presented a series of experiments that further our understanding of the role betacyanins play in plant salt tolerance, as well as electrophysiological experiments highlighting a new and entirely unique ion flux response to salinity in Disphyma australe and Disphyma crassifolium. Furthermore, one of these studies showed that the photoprotective effect of betacyanins during salt stress can be transferred to non-betacyanic plants by introducing betacyanin production, resulting in increased salt tolerance

Leaf mesophyll in D. australe is evidently better protected against the effects of salt stress when betacyanin pigments are present in the epidermis. $\mathrm{Na}^{+}$accumulated predominantly in the betacyanic epidermal cells, while the green leaves showed a more uniform distribution of $\mathrm{Na}^{+}$. By drawing $\mathrm{Na}^{+}$away from the photosynthetically active tissue and into the epidermis cells, betacyanic leaves were able to maintain a higher cytosolic $\mathrm{K}^{+} / \mathrm{Na}^{+}$ratio in the mesophyll and increase mesophyll viability during salt stress. How $\mathrm{Na}^{+}$is drawn to the betacyanic epidermis still remains unclear. Both excess $\mathrm{Na}^{+}$and betacyanins are stored in the vacuole. The compartmentalisation of $\mathrm{Na}^{+}$into the vacuole is facilitated by $\mathrm{Na}^{+} / \mathrm{H}^{+}$-antiporters (NHXs). The electrochemical gradient that is needed for this process is provided by V-ATPases and V-PPases (Jiang et al., 2010; Bassil \& Blumwald, 2014; Almeida et al., 2017). Previous studies have found that the V-ATPase activity was greater in betacyanic $S$. salsa seedlings than green seedlings (Wang et al., 2001, 2008b). Thus, the authors suggested that the increased ATPase activity in the presence of betacyanins might also energise the active transport of $\mathrm{Na}^{+}$into the vacuole via NHXs (Wang et al., 2008b). A similar mechanism might explain the altered $\mathrm{Na}^{+}$ distribution in D. australe. More $\mathrm{Na}^{+}$might be transported into the vacuole of betacyanic epidermis cells in contrast to mesophyll cells due to an increased NHX activity caused by a higher V-ATPase or V-PPase activity. Further studies are needed to test whether the V-ATPase and/or V-PPase activity in the epidermis cells of betacyanic $D$. australe leaves is higher than in green leaves. Comparting the NHX activity in epidermis cells from red and green morphs could help further the understanding how preferential $\mathrm{Na}^{+}$compartmentalisation in betacyanic vacuoles is mediated. However, it is still unclear how $\mathrm{Na}^{+}$moves through the leaves towards the epidermis. $\mathrm{Na}^{+}$could reach the epidermis and salt glands via symplastic transport through plasmodesmata (Shabala \& Mackay, 2011) or via apoplastic transport (Almeida et al., 2017). This would involve that $\mathrm{Na}^{+}$is extruded from cells, such as mesophyll cells or bundle sheath cells, and/or preferentially taken up by epidermis cells and salt glands. Further studies that 
compare $\mathrm{Na}^{+}$ion fluxes into epidermis and mesophyll cells of red and green $D$. australe leaves during salt stress are needed to determine how $\mathrm{Na}^{+}$is directed towards the epidermis of betacyanic leaves.

RNA sequencing experiments (Appendix 1) in leaves from the red and green morph of $D$. australe before and after hight light and salt stress could identify ion channels and transporters that might play an important role in $\mathrm{Na}^{+}$homeostasis in betacyanic leaves. Interestingly, SOS1, a $\mathrm{Na}^{+} / \mathrm{H}^{+}$antiporter located at the plasma membrane was only upregulated $24 \mathrm{~h}$ after salt treatment in betacyanic leaves but not in green leaves. At the roots SOS1 facilitates $\mathrm{Na}^{+}$ extrusion (Tester \& Davenport, 2003; Munns, 2005; Almeida et al., 2017), in the mesophyll cells of betacyanic $D$. australe leaves SOS1 could mediate $\mathrm{Na}^{+}$transport out of mesophyll cells into the apoplast. $\mathrm{Na}^{+}$might then be preferentially taken up by epidermis cells. Thus, SOS1 might have an important role in drawing $\mathrm{Na}^{+}$away from the mesophyll and towards betacyanic epidermis cells. Moreover, a tonoplast $\mathrm{Na}^{+} / \mathrm{H}^{+}$antiporter, $\mathrm{NHX} 2$, was also only upregulated in betacyanic leaves. NHXs facilitate $\mathrm{Na}^{+}$compartmentalisation into the vacuole and an upregulation in betacyanic leaves might explain why $\mathrm{Na}^{+}$is preferentially accumulated in betacyanic cells. However, the RNA-sequencing analysis was performed on whole leaves. With single cells RNA-sequencing NHX expression patterns upon salt stress could be compared between betacyanic epidermis cells and mesophyll cells of the red morph to determine whether NHX upregulation is specific for betacyanic cells.

It is notable that in the presence of betacyanin the salt secretion rate increased 2-fold. Both morphs of $D$. australe secreted salt if exposed to high salinity, and both morphs had salt glands on the three ridges of the triangular leaves. In the Aizoaceae, the family to which D. australe belongs, salt glands are usually of the salt bladder type (Figure 5.1). These salt glands consist of a large vacuolated cell with or without a stalk cell (Dassanayake \& Larkin, 2017). Epidermal bladder cells were studied in Mesembryanthemum crystallinum, a species closely related to $D$. australe. Mutants that lacked epidermal bladder cells were more susceptible to salt stress and showed lower growth rates and lower reproductive capacity compared to wild type plants that could secret excess $\mathrm{Na}^{+}$(Agarie et al., 2007). The preferential accumulation of $\mathrm{Na}^{+}$in the betacyanic epidermal cells results in higher $\mathrm{Na}^{+}$concentrations in the tissue surrounding the salt glands which might result in more efficient $\mathrm{Na}^{+}$secretion. This might be a mechanism to maintain low $\mathrm{Na}^{+}$concentrations in the mesophyll during salt stress and thus protecting the photosynthetically active tissue from the cytotoxic effects of $\mathrm{Na}^{+}$. 

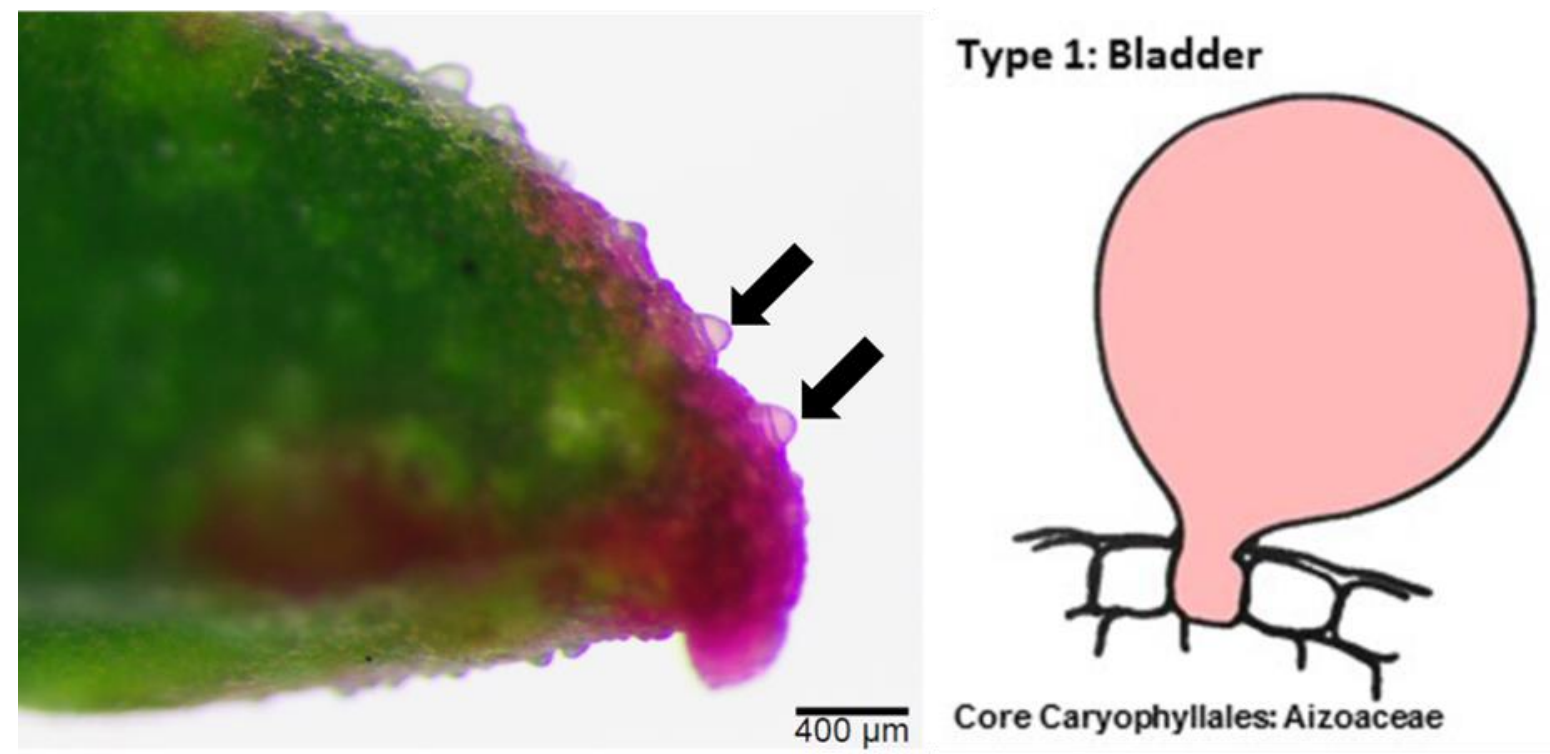

Figure 4.5.1 Photomicrograph of a betacyanic leaf of $D$. australe showing salt glands (arrows), and (right) drawing of a typical bladder type salt gland common in the Aizoaceae based on consensus representations of species salt gland structures. Adapted from (Dassanayake \& Larkin (2017).

While betacyanin might play an important role in salt tolerance, a betacyanin-independent salt tolerance mechanism was discovered in D. crassifolium and D. australe in Chapter 3. Exposure to high apoplastic $\mathrm{NaCl}$ concentrations induced the uptake of $\mathrm{K}^{+}$into mesophyll cells in both betacyanic and green leaves. Moreover, the presence of $\mathrm{Cl}^{-}$was needed for $\mathrm{K}^{+}$uptake under salt stress. This unique response to salinity has, to the best of my knowledge, never been reported before and might be an entirely novel mechanism to maintain a high cytosolic $\mathrm{K}^{+} / \mathrm{Na}^{+}$ratio in mesophyll cells and simultaneously avoid membrane depolarisation due to the increased cation uptake. RNA sequencing experiments (Appendix 1) in leaves from the red and green morph of D. australe before and after hight light and salt stress could identify ion channels and transporters that might play an important role in salt tolerance. Upon salt stress the gene expression of a high affinity $\mathrm{K}^{+}$transporter (AKT1) was upregulated in D. australe leaves. While in green leaves AKT1 was only upregulated after 6 d., in betacyanic leaves AKT1 was already upregulated after $24 \mathrm{~h}$. In Arabidopsis thaliana AKT1 is mediating high affinity $\mathrm{K}^{+}$ uptake into roots (Pyo et al., 2010). In D. australe leaves AKT1 might facilitate $\mathrm{K}^{+}$uptake into mesophyll cells upon salt stress.

$\mathrm{Cl}^{-}$is an essential nutrient for higher plants and also plays an important role in osmoregulation, cell elongation, photosynthetic $\mathrm{O}_{2}$ evolution, stabilisation of the membrane potential, regulation 
of enzyme activity and intracellular pH (Marschner, 1995; White \& Broadley, 2001; Colmenero-Flores et al., 2007). However, accumulating $\mathrm{Cl}^{-}$in high concentrations can be toxic (White \& Broadley, 2001; Colmenero-Flores et al., 2007; Geilfus, 2018). $\mathrm{Cl}^{-}$accumulation in roots can impair $\mathrm{NO}_{3}{ }^{-}$uptake, as both are monovalent anions with a similar ionic radius (Li et al., 2017b; Geilfus, 2018). Furthermore, excessive $\mathrm{Cl}^{-}$accumulation in the chloroplasts can lead to chlorophyll degradation and impair photosynthesis, by inhibiting enzyme activity and affecting thylakoid swelling (Geilfus, 2018).

Similar to $\mathrm{Na}^{+}, \mathrm{Cl}^{-}$can be extruded back into the soil solution and loading $\mathrm{Cl}^{-}$into the xylem is restricted under salt stress (Lorenzen et al., 2004; Sun et al., 2009a; Geilfus, 2018). Xylem loading might be highly regulated by transporters, such as nitrate excretion transporters (NAXT) or S-type anion channels (SLAH), or chloride cation co-transporters (CCCs) (Colmenero-Flores et al., 2007; Cubero-Font et al., 2016; Geilfus, 2018). In leaves $\mathrm{Cl}^{-}$is compartmentalised into vacuoles to maintain low cytosolic $\mathrm{Cl}^{-}$concentration. In mesophyll cells of A. thaliana a anion/ $\mathrm{H}^{+}$antiporter (AtCLCa) and a $\mathrm{Cl}^{-}$channel like protein (AtCLCg) have been identified, which might facilitate $\mathrm{Cl}^{-}$transport into the vacuole (De Angeli et al., 2006; Wege et al., 2010; Geilfus, 2018). $\mathrm{Cl}^{-}$might accumulate in epidermis cells to avoid high $\mathrm{Cl}^{-}$concentration in the mesophyll (James et al., 2006b; Geilfus, 2018). In D. australe, in contrast, $\mathrm{Cl}^{-}$is most likely not excluded at the roots, as high amounts were taken up into the mesophyll during salt stress. How $\mathrm{Cl}^{-}$is transported to the mesophyll in D. australe is still unclear. Apoplastic transport from the bundle sheath cells to the mesophyll seems to be most likely, as high apoplastic $\mathrm{Cl}^{-}$concentrations were needed for the salt induced $\mathrm{K}^{+}$uptake. It remains unclear how $\mathrm{K}^{+}$and $\mathrm{Cl}^{-}$are taken up into the mesophyll cells; CCCs might be a good candidate as this type of cotransporters could couple $\mathrm{K}^{+}$and $\mathrm{Cl}^{-}$uptake in a highly energy efficient manner. CCCs expression was not upregulated in D. australe upon salt treatment (Appendix 1), but CCCs could be still activated during salt stress. However, other $\mathrm{Cl}^{-}$channels could also be involved in $\mathrm{NaCl}$-induced $\mathrm{K}^{+}$and $\mathrm{Cl}^{-}$influx. More studies are needed to investigate which transporters and channels are involved in this unique salt response. Applying a CCC blocker to mesophyll cells of $D$. australe and monitoring $\mathrm{K}^{+}$and $\mathrm{Cl}^{-}$fluxes could answer whether $\mathrm{CCCs}$ are involved in the unique salt stress response. Additional $\mathrm{K}^{+}$and $\mathrm{Cl}^{-}$fluxes in response to salt stress on other closely related halophytes, such as Carpobrotus, Mesembryanthemum, Suaeda, Salicornia, or Sarcocornia, are needed to determine whether the salt induced $\mathrm{K}^{+}$uptake is a mechanism specific to Disphyma, or a more common salt tolerance mechanism in halophytes. 
Based on the studies on D. crassifolium and D. australe, I propose the following model for salt tolerance (Figure 5.2) and the crucial role betacyanin plays for these halophytes (Figure 5.3). If the $\mathrm{Na}^{+}$concentration in the soil is high $\mathrm{Na}^{+}$enters the root cells via passive transport, which is mostly facilitated by non-selective cation channels (NSCCs) (Maathuis et al., 2014). In M. crystallinum, an ice plant species closely related to $D$. australe, a high- affinity $\mathrm{K}^{+}$transporter (McHKT1) was expressed in root epidermis and cells of the vascular cylinder. McHKT1 has a similar affinity for both $\mathrm{Na}^{+}$and $\mathrm{K}^{+}$. McHKT1 expression was upregulated during salt stress (Su et al., 2003) and thus, McHKT1 might be involved in $\mathrm{Na}^{+}$and $\mathrm{K}^{+}$uptake from the soil and in loading both cations into the xylem during salt stress. Therefore, HKT1 might also be involved in $\mathrm{Na}^{+}$and $\mathrm{K}^{+}$uptake from the soil in D. australe. $\mathrm{Na}^{+}$and $\mathrm{K}^{+}$reach the leaves via long distance transport in the xylem. In A. thaliana CCCs are preferentially expressed in the xylem/symplast boundary and are most likely involved in loading $\mathrm{Cl}^{-}$along with cations, such as $\mathrm{Na}^{+}$and $\mathrm{K}^{+}$into the xylem (Colmenero-Flores et al., 2007; Zhu et al., 2017). While glycophytes primarily exclude $\mathrm{Na}^{+}$from the roots and limit $\mathrm{Na}^{+}$uptake, halophytes, such as $M$. crystallinum and D. australe, accumulate $\mathrm{Na}^{+}$in leaves and shoots, where it is compartmentalised into vacuoles and functions as an osmoticum to maintain cell turgor (Adams et al., 1998; Su et al., 2003).

McHKT1 was strongly expressed in leaf tissues, and its expression was upregulated by salt. Interestingly McHKT1 was more abundant in tissues surrounding the vascular bundle (Su et al., 2003). Thus, HKT1 might facilitate the unloading of $\mathrm{Na}^{+}$and $\mathrm{K}^{+}$from the xylem, as well as transporting these ions to the mesophyll and epidermal tissues. Salt treatment also increased the levels of SOS1-type $\mathrm{Na}^{+} / \mathrm{H}^{+}$antiporter (McSOS1) transcripts in M. crystallinum leaves (Cosentino et al., 2010). SOS1 transports $\mathrm{Na}^{+}$out of the cells and McSOS1 might be involved in maintaining low cytosolic $\mathrm{Na}^{+}$concentrations in photosynthetically active tissues by directing $\mathrm{Na}^{+}$away from mesophyll and towards salt glands (Cosentino et al., 2010). Another $\mathrm{Na}^{+} / \mathrm{H}^{+}$antiporter (McNHX) was upregulated in M. crystallinum leaves after salt treatment. McNHX is a vacuolar transporter that facilitates $\mathrm{Na}^{+}$compartmentalisation into the vacuole, thus maintaining low cytosolic $\mathrm{Na}^{+}$concentrations (Su et al., 2003; Cosentino et al., 2010). These transporters could be involved in $\mathrm{Na}^{+}$and $\mathrm{K}^{+}$transport in D. australe leaves as well. A HKT1 might unload $\mathrm{Na}^{+}$and $\mathrm{K}^{+}$from the xylem and then SOS1 and HKT1 might facilitate lateral $\mathrm{Na}^{+}$and $\mathrm{K}^{+}$transport. However, in D. australe leaves HKT1 expression was down regulated upon salt stress, thus it is much more likely that AKT1 facilitated the $\mathrm{K}^{+}$uptake into mesophyll upon salt stress (Chapter 3). SOS1 could be involved in maintaining low cytosolic 
$\mathrm{Na}^{+}$concentrations in mesophyll cells, by transporting excess $\mathrm{Na}^{+}$into the apoplast and directing $\mathrm{Na}^{+}$towards the epidermis and salt glands, while NHX achieves the same by compartmentalising $\mathrm{Na}^{+}$into the vacuole. $\mathrm{CCC}$ might be involved in the salt induced $\mathrm{K}^{+}$uptake into the mesophyll and explain the essential role $\mathrm{Cl}^{-}$has in D. australe's ability to maintain normal $\mathrm{K}^{+}$homeostasis during salt stress. $\mathrm{CCC}$ might directly couple $\mathrm{K}^{+}$uptake to $\mathrm{Cl}^{-}$uptake and thus avoid membrane depolarisation and the resulting $\mathrm{K}^{+}$leak, thus playing a crucial role in maintaining a high cytosolic $\mathrm{K}^{+} / \mathrm{Na}^{+}$ratio.

Both McHKT1 and McNHX expression were upregulated by salt stress in the epidermal bladder cells of $M$. crystallinum and most likely play an essential role in salt secretion . (Barkla et al., 2002; Su et al., 2003; Oh et al., 2015b). Similarly, in D. australe HKT1 might facilitate $\mathrm{Na}^{+}$ uptake into the salt glands and NHX2 might be involved in accumulating excess $\mathrm{Na}^{+}$in the vacuoles of salt glands. 


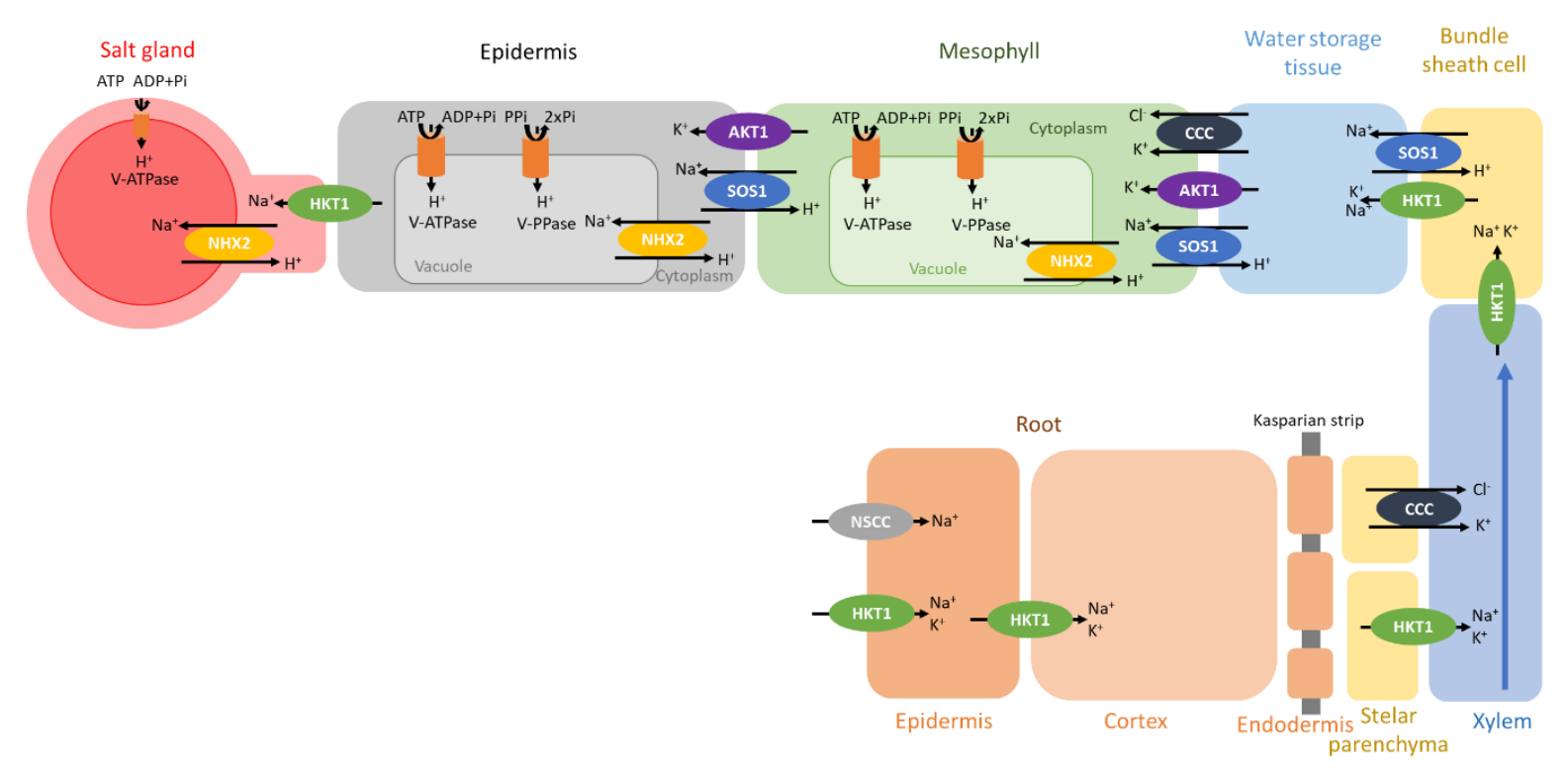

Figure 4.5.2 Proposed salt tolerance mechanism in D. australe, showing key plasma and tonoplast membrane transporters, channels, and pumps mediating $\mathrm{Na}^{+}, \mathrm{K}^{+}$, and $\mathrm{Cl}^{-}$ homeostasis in plants under salt stress. $\mathrm{Na}^{+}$could enter the root epidermis cells via nonselective cation channels (NSCC) high affinity $\mathrm{K}^{+}$transporters (HKT1) might mediate $\mathrm{Na}^{+}$ and $\mathrm{K}^{+}$uptake into the roots and transport into the xylem. In the leaves HKT1could facilitate xylem unloading of $\mathrm{Na}^{+}$and $\mathrm{K}^{+}$, as well as, transport away from the vascular bundle to the mesophyll, epidermal tissue, and into salt glands. Cation $\mathrm{Cl}^{-}$cotransporters (CCC) load $\mathrm{K}^{+}$ and $\mathrm{Cl}^{-}$into the xylem and might be responsible for taking up both $\mathrm{K}^{+}$and $\mathrm{Cl}^{-}$into mesophyll cells upon salt stress. The high affinity $\mathrm{K}^{+}$transporter (AKT1) might be responsible for $\mathrm{K}^{+}$ uptake upon salt stress. The $\mathrm{Na}^{+} / \mathrm{H}^{+}$antiporter SOS1 is suggested to mediate xylem unloading of $\mathrm{Na}^{+}$and transport away from the vascular bundle towards the epidermal tissue. Tonoplast $\mathrm{H}^{+}$-ATPase (V-ATPase) and tonoplast $\mathrm{H}^{+}$-PPase (V-PPase) generate electrochemical potential gradient for secondary active transport into vacuoles. The $\mathrm{Na}^{+} / \mathrm{H}^{+}$antiporter $(\mathrm{NHX})$ is localized at the tonoplast and might facilitate $\mathrm{Na}^{+}$uptake into vacuoles of mesophyll, but most importantly into vacuoles of epidermis cells and salt glands.

Betacyanins play a crucial role in salt tolerance in D. australe (Figure 5.3). While both red and green leaves take up $\mathrm{K}^{+}$from the apoplast into mesophyll cells upon salt stress, only betacyanic leaves accumulate $\mathrm{Na}^{+}$in the epidermis. The salt induced $\mathrm{K}^{+}$uptake into mesophyll might be facilitated by HKT1 and CCC in D. australe and plays a central role in maintaining a high cytosolic $\mathrm{K}^{+} / \mathrm{Na}^{+}$ratio in photosynthetically active tissue. Furthermore, to maintain a high cytosolic $\mathrm{K}^{+} / \mathrm{Na}^{+}$ratio, $\mathrm{Na}^{+}$might be compartmentalised into the vacuole of mesophyll cells. Over-all lateral $\mathrm{Na}^{+}$transport towards salt glands could be facilitated by HKT1 and SOS1 in 
both red and green morphs. To avoid membrane depolarisation and activation of voltage gated channels, that can cause a $\mathrm{K}^{+}$leak, $\mathrm{Cl}^{-}$and $\mathrm{K}^{+}$uptake are coupled via CCCs. However, in betacyanic leaves, betacyanin is stored in the vacuole and vacuolar betacyanin accumulation is most likely an active transport mechanism. While vacuolar transport of betacyanins is not a well-studied field of research, there has been plenty of research on anthocyanin, another plant pigment that is stored in the vacuole. The main driving force of anthocyanin transport into the vacuole is the proton gradient across the tonoplast. A secondary active transporter family of multidrug and toxin extrusion (MATE) transporters has been identified as potential anthocyanin $/ \mathrm{H}^{+}$exchangers (Gomez et al., 2009). Secondary active transport mechanisms use the electrochemical gradient across the tonoplast generated by the V-ATPases and/or V-PPases. Wang and colleagues (2008b) have found that ATPase activity is higher in betacyanic plants and proposed that betacyanin increased V-ATPase activity as a greater electrochemical gradient is needed to fuel betacyanin uptake into the vacuole and at the same time an increased VATPase activity could also result in a more efficient $\mathrm{Na}^{+}$sequestration into betacyanic vacuoles. The same mechanism might cause the epidermal $\mathrm{Na}^{+}$accumulation in red morphs of $D$. australe. NHX2 a tonoplast $\mathrm{Na}^{+} / \mathrm{H}^{+}$antiporter is dependent on the proton gradient generated by V-ATPase and V-PPase. NHX2 was upregulated in betacyanic leaves and might play important role in $\mathrm{Na}^{+}$accumulation in betacyanic vacuoles. SOS1 expression was upregulated in betacyanic leaves after salt stress, thus SOS1 might be important in drawing $\mathrm{Na}^{+}$away from the mesophyll and towards the betacyanic epidermis. Moreover, excess $\mathrm{Na}^{+}$is stored in salt glands and HKT1 most likely facilitates $\mathrm{Na}^{+}$uptake into the salt glands. This process might be more efficient in red morphs compared to green morphs, as the surrounding betacyanic epidermis cells already contain a higher $\mathrm{Na}^{+}$concentration. $\mathrm{Na}^{+}$is then transported into the large vacuoles of the salt glands via NHX2 and stored until it is secreted onto the leaf surface. 


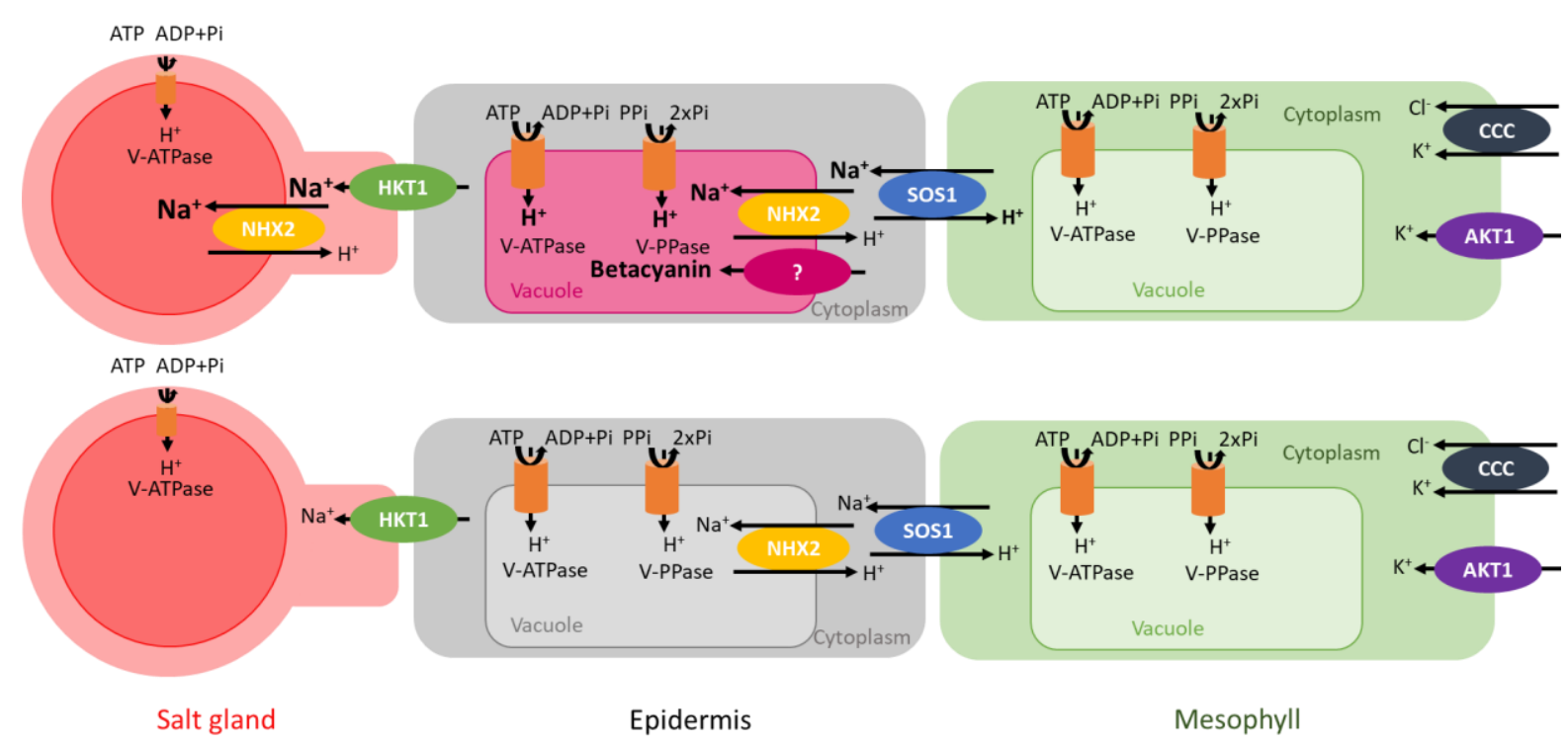

Figure 4.5.3 Proposed role of betacyanin in salt tolerance of D. australe. Differences in transporter activity between the red (top) and green (bottom) morph are indicated by bold letters. $\mathrm{Na}^{+}$uptake into mesophyll and epidermis cells might be mediated by a $\mathrm{Na}^{+} / \mathrm{H}^{+}$ antiporter (SOS1) and high affinity $\mathrm{K}^{+}$transporters AKT1 could facilitate both $\mathrm{K}^{+}$uptake into mesophyll cells upon salt stress. HKT1 could mediate $\mathrm{Na}^{+}$uptake into salt glands. In both betacyanic (top) and green (bottom) leaves. Cation $\mathrm{Cl}^{-}$Cotransporters (CCC) might mediate the salt induced $\mathrm{K}^{+}$and $\mathrm{Cl}^{-}$uptake. Tonoplast $\mathrm{H}^{+}$-ATPase (V-ATPase) and tonoplast $\mathrm{H}^{+}$PPase (V-PPase) generate electrochemical potential gradient for secondary active transport into vacuoles. The $\mathrm{Na}^{+} / \mathrm{H}^{+}$antiporter $\mathrm{NHX} 2$ might facilitate $\mathrm{Na}^{+}$uptake into vacuoles of mesophyll, epidermis cells and salt glands.

Chapter 4 showed that the beneficial effects of betacyanin production could be transferred to a plant, which normally does not produce betacyanins. Betacyanin production could be transferred to Nicotiana tabacum by overexpressing three betacyanin synthesis genes, namely CYP76AD1, cDOPA5GT and DODA. The betacyanin overexpressing N. tabacum mutant, BtOE, produced two betacyanins, betanin and isobetanin. These are two of the five betacyanins that have been identified in D. australe (Jain \& Gould, 2015b). Betacyanins were found in roots, shoots, leaves, flowers, and seeds of BtOE. BtOE seedling survival under severe salt stress was significantly higher compared to wild type (WT) and empty vector (EV) control seedlings. In contrast to WT and EV seedlings, BtOE seedlings were able to recover from salt stress. Seedling establishment is a critical stage during the life cycle of a plant, especially in challenging environments (Adolf et al., 2013) and this study could show that betacyanin production could be advantageous in seedling establishment on saline medium, even in normally non-betacyanic 
plants. After exposure to saturating light, betacyanic leaves of $N$. tabacum showed less photoinhibition and recovered quicker form photoinhibition than green leaves. Thus, the beneficial effect of betacyanin on salt tolerance that could be transferred to $N$. tabacum is most likely due to a photoprotective effect by abating incident quantum fluxes.

Introducing betacyanin production into normally non-betacyanic plants could increase plant viability under environmental stress, such as drought, flooding and salinity stress. (Wang \& Liu, 2007; Nakashima et al., 2011; Jain \& Gould, 2015b). The occurrence and intensity of extreme temperatures, soil salinity, and drought are increasing due to human-made global changes and threaten crop production. Therefore, there is an urgent need to develop more stresstolerant crops to meet the growing world population's need for food, fibre, and fuel (Shrivastava \& Kumar, 2015; Smith et al., 2016). It is not surprising therefore that there has been a considerable effort worldwide to produce genetically modified salt tolerant crops. Most studies have focused on a few key salt-tolerance mechanisms, including exclusion and compartmentalisation, and mostly target overexpressing ion transporters or introducing additional ion transporters into crop plants (Colmer et al., 2006; James et al., 2006b; Munns et al., 2006, 2016; Mian et al., 2011). However, salt tolerance is a multigenic trait and plants have developed a variety of different salt tolerance mechanisms (Flowers, 2004; Munns et al., 2006). The many attempts at overexpressing salt tolerance genes have not resulted in commercially available salt tolerant crops, yet. In this study we increased the salt tolerance of a glycophyte by introducing only three genes to produce betacyanins. Betacyanin production could increase the salt tolerance of a glycophyte considerably due to the photoprotective effect of these pigments and might function in a similar way, if introduced to crops. Future experiments should test whether betacyanin production can be transferred to crop plants, by introducing CYP76AD1, cDOPA5GT and DODA. Additionally, further experiments characterising the salt tolerance mechanism in the betacyanin overexpressing $N$. tabacum mutant are needed.

In conclusion, this thesis has contributed to our understanding of the role of betacyanins in salt tolerance through the photoprotection of salt-compromised chloroplasts, by diverting $\mathrm{Na}^{+}$into leaf epidermal cells, and through the uptake of $\mathrm{K}^{+}$and $\mathrm{Cl}^{-}$into mesophyll cells. It has, moreover, provided compelling evidence that the beneficial effects of betacyanin can be transferred to non-betacyanic plants through the introduction of three betacyanin synthesis genes. This work establishes a solid foundation for future studies on the protective properties of this fascinating group of pigments. 


\section{References}

Abideen Z, Ansari R, Khan MA. 2011. Halophytes: Potential source of ligno-cellulosic biomass for ethanol production. Biomass and Bioenergy 35: 1818-1822.

Abrol IP, Yadak JS, Massoud FI. 1988. Salt-affected soils and their management. FAO Soils Bulletin 39: 1-131.

Adams P, Nelson DE, Yamada S, Chmara W, Jensen RG, Bohnert HJ, Griffiths H. 1998. Growth and development of Mesembryanthemum crystallinum (Aizoaceae). New Phytologist 138: $171-190$.

Adolf VI, Jacobsen SE, Shabala S. 2013. Salt tolerance mechanisms in quinoa (Chenopodium quinoa Willd.). Environmental and Experimental Botany 92: 43-54.

Agarie S, Shimoda T, Shimizu Y, Baumann K, Sunagawa H, Kondo A, Ueno O, Nakahara T, Nose A, Cushman JC. 2007. Salt tolerance, salt accumulation, and ionic homeostasis in an epidermal bladder-cell-less mutant of the common ice plant Mesembryanthemum crystallinum. Journal of Experimental Botany 58: 1957-1967.

Ahmad I, Larher F, Stewart GR. 1979. Sorbitol, a compatible osmotic solute in Plantago maritima. New Phytologist 82: 671-678.

Aiton W. 1789. Hortus kewensis: or, a catalogue of the plants cultivated in the Royal Botanic Garden Kew. London: Printed for G. Nicol.

Akbarimoghaddam H, Galavi M, Ghanbari A, Panjehkeh N. 2011. Salinity effects on seed germination and seedling growth of bread wheat cultivars. Trakia Journal of Sciences 9: 4350 .

Almeida P, Katschnig D, de Boer AH. 2013. HKT transporters-state of the art. International Journal of Molecular Sciences 14: 20359-20385.

Almeida DM, Oliveira MM, Saibo NJM. 2017. Regulation of $\mathrm{Na}^{+}$and $\mathrm{K}^{+}$homeostasis in plants: towards improved salt stress tolerance in crop plants. Genetics and Molecular Biology 40: $326-345$.

De Angeli A, Monachello D, Ephritikhine G, Frachisse JM, Thomine S, Gambale F, Barbier-Brygoo H. 2006. The nitrate/proton antiporter AtCLCa mediates nitrate accumulation in plant vacuoles. Nature 442: 939-942. 
Apse MP, Blumwald E. 2007. $\mathrm{Na}^{+}$transport in plants. FEBS Letters 581: 2247-2254.

Ashraf M. 2004. Some important physiological selection criteria for salt tolerance in plants. Flora 199: 361-376.

Ball M, Chow W, Anderson J. 1987. Salinity-induced potassium deficiency causes loss of functional photosystem II in leaves of the grey mangrove, Avicennia marina, through depletion of the atrazine-binding polypeptide. Functional Plant Biology 14: 351-361.

Bano A, Fatima M. 2009. Salt tolerance in Zea mays (L). following inoculation with Rhizobium and Pseudomonas. Biology and Fertility of Soils 45: 405-413.

Barassi CA, Ayrault G, Creus CM, Sueldo RJ, Sobrero MT. 2006. Seed inoculation with Azospirillum mitigates $\mathrm{NaCl}$ effects on lettuce. Scientia Horticulturae 109: 8-14.

Barkla BJ, Vera-Estrella R, Camacho-Emiterio J, Pantoja O. 2002. $\mathrm{Na}^{+} / \mathrm{H}^{+}$exchange in the halophyte Mesembryanthemum crystallinum is associated with cellular sites of $\mathrm{Na}^{+}$storage. Functional Plant Biology 29: 1017-1024.

Barragan V, Leidi EO, Andres Z, Rubio L, De Luca A, Fernandez JA, Cubero B, Pardo JM. 2012. Ion exchangers NHX1 and NHX2 mediate active potassium uptake into vacuoles to regulate cell turgor and stomatal function in Arabidopsis. The Plant Cell 24: 1127-1142.

Bassil E, Blumwald E. 2014. The ins and outs of intracellular ion homeostasis: NHX-type cation/ $\mathrm{H}^{+}$transporters. Current Opinion in Plant Biology 22: 1-6.

Bassil E, Coku A, Blumwald E. 2012. Cellular ion homeostasis: emerging roles of intracellular NHX methylation and chromatin patterning $\mathrm{Na}^{+} / \mathrm{H}^{+}$antiporters in plant growth and development. Journal of Experimental Botany 63: 5727-5740.

Bassil E, Ohto M aki, Esumi T, Tajima H, Zhu Z, Cagnac O, Belmonte M, Peleg Z, Yamaguchi T, Blumwald E. 2011. The Arabidopsis intracellular $\mathrm{Na}^{+} / \mathrm{H}^{+}$antiporters $\mathrm{NHX} 5$ and NHX6 are endosome associated and necessary for plant growth and development. Plant Cell 23: 224-239.

Bazihizina N, Colmer TD, Cuin TA, Mancuso S, Shabala S. 2019. Friend or foe? Chloride patterning in halophytes. Trends in Plant Science 24: 142-151.

Berthomieu P, Conéjéro G, Nublat A, Brackenbury WJ, Lambert C, Savio C, Uozumi N, Oiki S, Yamada K, Cellier F, et al. 2003. Functional analysis of AtHKT1 in Arabidopsis 
shows that $\mathrm{Na}^{+}$recirculation by the phloem is crucial for salt tolerance. EMBO Journal 22: 2004-2014.

Beyenbach KW, Wieczorek H. 2006. The V-type $\mathrm{H}^{+}$ATPase: molecular structure and function, physiological roles and regulation. The Journal of Experimental Biology 209: 57789.

Bianco-Colomas J. 1984. Effect of a cytokinin antagonist on cytokinin and light-dependent amaranthin synthesis in Amaranthus tricolor seedlings. Journal of Plant Growth Regulation 2: 281-287.

Binzel ML, Hess FD, Bressan RA, Hasegawa PM. 1988. Intracellular compartmentation of ions in salt adapted tobacco cells Plant Physiology 86: 607-614.

Blumwald E. 2000. Sodium transport and salt tolerance in plants. Current Opinion in Cell Biology 12: 431-434.

Bohnert HJ, Nelson DE, Jensen RG. 1995. Adaptations to environmental stresses. Plant Cell 7: 1099-1111.

Boscari A, Clément M, Volkov V, Golldack D, Hybiak J, Miller AJ, Amtmann A, Fricke W. 2009. Potassium channels in barley: Cloning, functional characterization and expression analyses in relation to leaf growth and development. Plant, Cell and Environment 32: 17611777.

Bose J, Munns R, Shabala S, Gilliham M, Pogson B, Tyerman SD. 2017. Chloroplast function and ion regulation in plants growing on saline soils: Lessons from halophytes. Journal of Experimental Botany 68: 3129-3143.

Bose J, Rodrigo-Moreno A, Shabala S. 2014. ROS homeostasis in halophytes in the context of salinity stress tolerance. Journal of Experimental Botany 65: 1241-1257.

Brini F, Masmoudi K. 2012. Ion transporters and abiotic stress tolerance in plants. ISRN Molecular Biology 2012: 1-13.

Brockington SF, Walker RH, Glover BJ, Soltis PS, Soltis DE. 2011. Complex pigment evolution in the Caryophyllales. New Phytologist 190: 854-864.

Brockington SF, Yang Y, Gandia-Herrero F, Covshoff S, Hibberd JM, Sage RF, Wong GKS, Moore MJ, Smith SA. 2015. Lineage-specific gene radiations underlie the evolution of 
novel betalain pigmentation in Caryophyllales. New Phytologist 207: 1170-1180.

Burke M, Land EJ, McGarvey DJ, Truscott TG. 2000. Carotenoid triplet state lifetimes. Journal of Photochemistry and Photobiology B: Biology 59: 132-138.

Céccoli G, Ramos J, Pilatti V, Dellaferrera I, Tivano JC, Taleisnik E, Vegetti AC. 2015. Salt glands in the Poaceae family and their relationship to salinity tolerance. The Botanical Review. 81: 162-178.

Chaves MM, Flexas J, Pinheiro C. 2009. Photosynthesis under drought and salt stress: regulation mechanisms from whole plant to cell. Annals of Botany 103: 551-560.

Chazen O, Hartung W, Neumann PM. 1995. The different effects of PEG 6000 and $\mathrm{NaCl}$ on leaf development are associated with differential inhibition of root water transport. Plant, Cell and Environment 18: 727-735.

Cheeseman JM. 2013. The integration of activity in saline environments: Problems and perspectives. Functional Plant Biology 40: 759-774.

Cheeseman J. 2016. Food security in the face of salinity, drought, climate change, and population growth. In: Khan MA, Ozturk M, Gul B, Ahmed MZ eds. Halophytes for food security in dry lands. Amsterdam: Elsevier Inc., 111-123.

Chen Z, Newman I, Zhou M, Mendham N, Zhang G, Shabala S. 2005. Screening plants for salt tolerance by measuring $\mathrm{K}^{+}$flux: A case study for barley. Plant, Cell and Environment 28: $1230-1246$.

Chen Z, Pottosin II, Cuin TA, Fuglsang AT, Tester M, Jha D, Zepeda-jazo I, Zhou M, Palmgren MG, Newman IA, et al. 2007. Root plasma membrane transporters controlling $\mathrm{K}^{+}$ $\mathrm{Na}^{+}$homeostasis in salt-stressed barley. Plant Physiology 145: 1714-1725.

Chinnock R. 1971. Studies in Disphyma - A genus related to Mesembryanthemum. A revision of Disphyma australe (Ait.) JM Black. New Zealand Journal of Botany 9: 331-344.

Chinnock R. 1972. Natural hybrids between Disphyma and Carpobrotus (Aizoaceae) in New Zealand. New Zealand Journal of Botany 10: 615-625.

Cho K, Toler H, Lee J, Ownley B, Stutz JC, Moore JL, Augé RM. 2006. Mycorrhizal symbiosis and response of sorghum plants to combined drought and salinity stresses. Journal of Plant Physiology 163: 517-528. 
Chow W, Ball M, Anderson J. 1990. Growth and photosynthetic responses of spinach to salinity: Implications of $\mathrm{K}^{+}$nutrition for salt tolerance. Functional Plant Biology 17: 563-578.

Christinet L, Brudet FX, Zaiko M, Hinz U, Zryd J-P. 2004. Characterization and functional identification of a novel plant 4,5-extradiol dioxygenase involved in betalain pigment biosynthesis in Portulaca grandiflora. Plant Physiology 134: 265-274.

Clement JS, Mabry TJ. 1996. Pigment evolution in the Caryophyllales: a systematic overview. Botanica Acta 109: 360-367.

Colmenero-Flores JM, Martinez G, Gamba G, Vazquez N, Iglesias DJ, Brumos J, Talon M. 2007. Identification and functional characterization of cation - chloride cotransporters in plants. The Plant Journal 50: 278-292.

Colmer TD, Flowers TJ, Munns R. 2006. Use of wild relatives to improve salt tolerance in wheat. Journal of Experimental Botany 57: 1059-1078.

Conde A, Chaves MM, Gerós H. 2011. Membrane transport, sensing and signaling in plant adaptation to environmental stress. Plant and Cell Physiology 52: 1583-1602.

Connor JD, Schwabe K, King D, Knapp K. 2012. Irrigated agriculture and climate change: The influence of water supply variability and salinity on adaptation. Ecological Economics 77: $149-157$.

Cosentino C, Fischer-Schliebs E, Bertl A, Thiel G, Homann U. 2010. $\mathrm{Na}^{+} / \mathrm{H}^{+}$antiporters are differentially regulated in response to $\mathrm{NaCl}$ stress in leaves and roots of Mesembryanthemum crystallinum. New Phytologist 186: 669-680.

Cubero-Font P, Maierhofer T, Jaslan J, Rosales MA, Espartero J, Díaz-Rueda P, Müller HM, Hürter AL, AL-Rasheid KAS, Marten I, Hedrich R, Colmenero-Flores JM, Geiger D. 2016. Silent S-type anion channel subunit SLAH1 gates SLAH3 open for chloride root-toshoot translocation. Current Biology 26: 2213-2220.

Cuenoud P, Savolanien V, Chatrou LW, Powell M, Grayer RJ, Chase MW. 2002. Molecular phylogenetics of Caryophyllales based on nuclear $18 \mathrm{~S}$ rDNA and plastis $R B C L$, ATPB, and MATK DNA. American Journal of Botany 89: 132-144.

Cuin TA, Miller AJ, Laurie SA, Leigh RA. 2003. Potassium activities in cell compartments of salt-grown barley leaves. Journal of Experimental Botany 54: 657-661. 
Cuin TA, Tian Y, Betts SA, Chalmandrier Ŕ, Shabala S. 2009. Ionic relations and osmotic adjustment in durum and bread wheat under saline conditions. Functional Plant Biology 36: $1110-1119$.

Dagar JC, Yadav RK. 2017. Climate resilient approaches for enhancing productivity of saline agriculture. Journal of Soil Salinity and Water Quality 9: 9-29.

Dassanayake M, Larkin JC. 2017. Making plants break a sweat: the structure, function, and evolution of plant salt glands. Frontiers in Plant Science 08: 1-20.

Debez A, Ben Hamed K, Grignon C, Abdelly C. 2004. Salinity effects on germination, growth, and seed production of the halophyte Cakile maritima. Plant and Soil 262: 179-189.

Deinlein U, Stephan AB, Horie T, Luo W, Xu G, Schroeder JI. 2014. Plant salt-tolerance mechanisms. Trends in Plant Science 19: 371-379.

Deloache WC, Russ ZN, Narcross L, Gonzales AM, Martin VJJ, Dueber JE. 2015. An enzyme-coupled biosensor enables (S)-reticuline production in yeast from glucose. Nature Chemical Biology 11: 465-471.

Demidchik V, Cuin TA, Svistunenko D, Smith SJ, Miller AJ, Shabala S, Sokolik A, Yurin V. 2010. Arabidopsis root $\mathrm{K}^{+}$-efflux conductance activated by hydroxyl radicals: single-channel properties, genetic basis and involvement in stress-induced cell death. Journal of Cell Science 123: $1468-1479$.

Dimkpa C, Weinand T, Asch F. 2009. Plant-rhizobacteria interactions alleviate abiotic stress conditions. Plant, Cell and Environment 32: 1682-1694.

Dreyer I, Uozumi N. 2011. Potassium channels in plant cells. FEBS Journal 278: 4293-4303.

Egamberdieva D, Kucharova Z. 2009. Selection for root colonising bacteria stimulating wheat growth in saline soils. Biology and Fertility of Soils 45: 563-571.

English JP, Colmer TD. 2013. Tolerance of extreme salinity in two stem-succulent halophytes (Tecticornia species). Functional Plant Biology 40: 897-912.

Farooq MA, Niazi AK, Akhtar J, Saifullah, Farooq M, Souri Z, Karimi N, Rengel Z. 2019. Acquiring control: The evolution of ROS-Induced oxidative stress and redox signaling pathways in plant stress responses. Plant Physiology and Biochemistry 141: 353-369.

Flowers TJ. 2004. Improving crop salt tolerance. Journal of Experimental Botany 55: 307- 
319.

Flowers TJ, Colmer TD. 2008. Salinity tolerance in halophytes. New Phytologist 179: 945963.

Flowers TJ, Colmer TD. 2015. Plant salt tolerance: Adaptations in halophytes. Annals of Botany 115: 327-331.

Flowers TJ, Dalmond D. 1992. Protein synthesis in halophytes: The influence of potassium, sodium and magnesium in vitro. Plant and Soil 146: 153-161.

Flowers TJ, Galal HK, Bromham L. 2010. Evolution of halophytes: Multiple origins of salt tolerance in land plants. Functional Plant Biology 37: 604-612.

Flowers A, Hajibagheri MA, Yeo AR. 1990. Salt tolerance in the halophytic wild rice, Porteresia coarctata Tateoka. New Phytologist 114: 675-684.

Flowers TJ, Munns R, Colmer TD. 2015. Sodium chloride toxicity and the cellular basis of salt tolerance in halophytes. Annals of Botany 115: 419-431.

Flowers TJ, Troke PF, Yeo AR. 1977. The mechanism of salt tolerance in halophytes. Annual Review of Plant Physiology 28: 89-121.

Flowers TJ, Yeo AR. 1986. Ion relations of plants under drought and salinity. Australian Journal of Plant Physiology 13: 75-91.

Foyer CH. 2018. Reactive oxygen species, oxidative signaling and the regulation of photosynthesis. Environmental and Experimental Botany 154: 134-142.

Fricke W, Leigh RA, Tomos AD. 1994. Epidermal solute concentrations and osmolality in barley leaves. Planta 192: 317-323.

Fricke W, Leigh RA, Tomos AD. 1996. The intercellular distribution of vacuolar solutes in the epidermis and mesophyll of barley leaves changes in response to $\mathrm{NaCl}$. Journal of Experimental Botany 47: 1413-1426.

Fuglsang AT, Paez-Valencia J, Gaxiola RA. 2011. Plant proton pumps: Regulatory circuits involving $\mathrm{H}^{+}$-ATPase and $\mathrm{H}^{+}$-PPase. In: Geisler M, Venema $\mathrm{K}$ eds. Transporters and Pumps in Plant Signaling. Berlin, Heidelberg: Springer, 39-64.

Fukuda A, Nakamura A, Hara N, Toki S, Tanaka Y. 2011. Molecular and functional analyses of rice NHX-type $\mathrm{Na}^{+/} \mathrm{H}^{+}$antiporter genes. Planta 233: 175-188. 
Gambino G, Perrone I, Gribaudo I. 2008. A rapid and effective method for RNA extraction from different tissues of grapevine and other woody plants. Phytochemical Analysis 19: 520525.

Gaxiola RA, Palmgren MG, Schumacher K. 2007. Plant proton pumps. FEBS Letters 581: 2204-2214.

Gaymard F, Pilot G, Bouchez D, Bruneau D, Boucherez J, Michaux-ferrie N, Thibaud J, Sentenac H. 1998. Identification and disruption of a plant shaker-like outward channel involved in $\mathrm{K}^{+}$release into the xylem sap. Cell 94: 647-655.

Geilfus CM. 2018. Chloride: From nutrient to toxicant. Plant and Cell Physiology 59: 877886.

Gill SS, Tuteja N. 2010. Reactive oxygen species and antioxidant machinery in abiotic stress tolerance in crop plants. Plant Physiology and Biochemistry 48: 909-930.

Glenn EP, Brown JJ, Blumwald E. 1999. Salt tolerance and crop potential of halophytes. Critical Reviews in Plant Sciences 18: 227-255

González-Núñez LM, Tóth T, García D. 2004. Integrated management for the sustainable use of salt-affected soils in Cuba. Ecosistemas y Recursos Agropecuarios 20: 85-102.

Gorji T, Sertel E, Tanik A. 2017. Monitoring soil salinity via remote sensing technology under data scarce conditions: A case study from Turkey. Ecological Indicators 74: 384-391.

Gould KS, Dudle DA, Neufeld HS. 2010. Why some stems are red: Cauline anthocyanins shield photosystem II against high light stress. Journal of Experimental Botany 61: 2707-2717.

Gould KS, Kuhn DN, Lee DW, Oberbauer SF. 1995. Why leaves are sometimes red. Nature 378: $241-242$.

Gould KS, McKelvie J, Markham KR. 2002. Do anthocyanins function as antioxidants in leaves? Imaging of $\mathrm{H}_{2} \mathrm{O}_{2}$ in red and green leaves after mechanical injury. Plant, Cell and Environment 25: 1261-1269.

Grattan SR, Grieve CM. 1999. Salinity-mineral nutrient relations in horticultural crops. Scientia Horticulturae 78: 127-157.

Greenway H, Munns R. 1980. Mechanisms of salt tolerance in nonhalophytes. Annual Review of Plant Physiology 31: 49-90. 
Grotewold E. 2006. The genetics and biochemistry of floral pigments. Annual Review of Plant Biology 57: 761-780.

Hamaji K, Nagira M, Yoshida K, Ohnishi M, Oda Y, Uemura T, Goh T, Sato MH, Morita MT, Tasaka M, et al. 2009. Dynamic aspects of ion accumulation by vesicle traffic under salt stress in Arabidopsis. Plant and Cell Physiology 50: 2023-2033.

Hanitzsch M, Schnitzer D, Seidel T, Golldack D, Dietz K. 2009. Transcript level regulation of the vacuolar $\mathrm{H}^{+}$-ATPase subunit isoforms VHA-a , VHA-E and VHA-G in Arabidopsis thaliana. Molecular Membrane Biology 24: 507-518.

Haro R, Banuelos MA, Senn ME, Barrero-Gil J, Rodrihuez-Navarro A. 2005. HKT1 mediates sodium uniport in roots. Pitfalls in the expression of HKT1 in yeast. Plant Physiology 139: $1495-1506$.

Harris NN, Javellana J, Davies KM, Lewis DH, Jameson PE, Deroles SC, Calcott KE, Gould KS, Schwinn KE. 2012. Betalain production is possible in anthocyanin-producing plant species given the presence of DOPA-dioxygenase and L-DOPA. BMC Plant Biology 12: 1234.

El Harti A, Lhissou R, Chokmani K, Ouzemou J, Hassouna M, Bachaoui EM, El Ghmari A. 2016. Spatiotemporal monitoring of soil salinization in irrigated Tadla Plain (Morocco) using satellite spectral indices. International Journal of Applied Earth Observation and Geoinformation 50: 64-73.

Hasegawa PM. 2013. Sodium $\left(\mathrm{Na}^{+}\right)$homeostasis and salt tolerance of plants. Environmental and Experimental Botany 92: 19-31.

Hatlestad GJ, Akhavan N a, Sunnadeniya RM, Elam L, Cargile S, Hembd A, Gonzalez A, McGrath JM, Lloyd AM. 2015. The beet Y locus encodes an anthocyanin MYB-like protein that activates the betalain red pigment pathway. Nature Genetics 47: 92-96.

Hayakawa K, Agarie S. 2010. Physiological roles of betacyanin in a halophyte, Suaeda japonica Makino. Plant Production Science 13: 351-359.

Hayat R, Ali S, Amara U, Khalid R, Ahmed I. 2010. Soil beneficial bacteria and their role in plant growth promotion: A review. Annals of Microbiology 60: 579-598.

Hernández JA, Olmos E, Corpas FJ, Sevilla F, del Río LA. 1995. Salt-induced oxidative stress in chloroplasts of pea plants. Plant Science 105: 151-167. 
Herrmann KM. 1995. The shikimate pathway: Early steps in the biosynthesis of aromatic compounds. The Plant Cell 7: 907-919.

Himabindu Y, Chakradhar T, Reddy MC, Kanygin A, Redding KE, Chandrasekhar T. 2016. Salt-tolerant genes from halophytes are potential key players of salt tolerance in glycophytes. Environmental and Experimental Botany 124: 39-63.

Hirano H, Sakuta M, Komamine A. 1996. Inhibition of betacyanin accumulation by abscisic acid in suspension cultures of Phytolacca americana. Zeitschrift fur Naturforschung Section C - Journal of Biosciences 51: 818-822.

Hooke RL, Martín-Duque JF, Pedraza J. 2012. Land transformation by humans: A review Roger. GSA Today 22: 4-10.

Horsch RB, Fry JE, Hoffmann NL, Eichholtz D, Rogers SG, Fraley RT. 1985. A simple and general method for hybridization revealed the expected. Science 227: 1229-1231.

Hosy E, Vavasseur A, Mouline K, Dreyer I, Gaymard F, Porée F, Boucherez J, Lebaudy A, Bouchez D, Véry A-A, et al. 2003. The Arabidopsis outward $\mathrm{K}^{+}$channel GORK is involved in regulation of stomatal movements and plant transpiration. Proceedings of the National Academy of Sciences 100: 5549 LP - 5554.

Ibdah M, Krins A, Seidlitz HK, Heller W, Strack D, Vogt T. 2002. Spectral dependence of flavonol and betacyanin accumulation in Mesembryanthemum crystallinum under enhanced ultraviolet radiation. Plant, Cell and Environment 25: 1145-1154.

Imamura T, Takagi H, Miyazato A, Ohki S, Mizukoshi H, Mori M. 2018. Isolation and characterization of the betalain biosynthesis gene involved in hypocotyl pigmentation of the allotetraploid Chenopodium quinoa. Biochemical and Biophysical Research Communications 496: $280-286$.

Isayenkov S V., Maathuis FJM. 2019. Plant salinity stress; many unanswered questions remain. Frontiers in Plant Science $\mathbf{1 0 .}$

Jacobs A, Ford K, Kretschmer J, Tester M. 2011. Rice plants expressing the moss sodium pumping ATPase PpENA1 maintain greater biomass production under salt stress. Plant Biotechnology Journal 9: 838-847.

Jain G. 2016. Functional role of betalains in Disphyma australe under salinity stress. PhD thesis, Victoria University of Wellington 
Jain G, Gould KS. 2015a. Are betalain pigments the functional homologues of anthocyanins in plants? Environmental and Experimental Botany 119: 48-53.

Jain G, Gould KS. 2015b. Functional significance of betalain biosynthesis in leaves of Disphyma australe under salinity stress. Environmental and Experimental Botany 109: 131140 .

Jain G, Schwinn KE, Gould KS. 2015. Betalain induction by L-DOPA application confers photoprotection to saline-exposed leaves of Disphyma australe. New Phytologist 207: 10751083.

James RA, Davenport RJ, Munns R. 2006a. Physiological characterization of two genes for $\mathrm{Na}^{+}$exclusion in durum wheat, Nax1 and Nax2. Plant Physiology 142: 1537-1547.

James RA, Munns R, Von Caemmerer S, Trejo C, Miller C, Condon T. 2006b. Photosynthetic capacity is related to the cellular and subcellular partitioning of $\mathrm{Na}^{+}, \mathrm{K}^{+}$and $\mathrm{Cl}^{-}$ in salt-affected barley and durum wheat. Plant, Cell and Environment 29: 2185-2197.

Jamil A, Riaz S, Ashraf M, Foolad MR. 2011. Gene expression profiling of plants under salt stress. Critical Reviews in Plant Sciences 30: 435-458.

Janmaat J. 2004. Calculating the cost of irrigation induced soil salinization in the tungabhadra project. Agricultural Economics 31: 81-96.

Jesus J, Castro F, Niemelä A, Borges M-T, Danko AS. 2015. Evaluation of the impact of different soil salinization processes on organic and mineral soils. Water, Air, and Soil Pollution 226: 102 .

Ji H, Pardo JM, Batelli G, Van Oosten MJ, Bressan RA, Li X. 2013. The salt overly sensitive ( SOS ) pathway : Established and emerging roles. Molecular Plant 6: 275-286.

Jiang X, Leidi EO, Pardo JM. 2010. How do vacuolar NHX exchangers function in plant salt tolerance? Plant Signaling and Behavior 5: 792-795.

Khan MI, Giridhar P. 2015. Plant betalains: Chemistry and biochemistry. Phytochemistry 117: $267-295$.

Khodaverdiloo H, Hamzenejad Taghlidabad R. 2014. Phytoavailability and potential transfer of $\mathrm{Pb}$ from a salt-affected soil to Atriplex verucifera, Salicornia europaea and Chenopodium album. Chemistry and Ecology 30: 216-226. 
Kinsman LT, Pinfield NJ, Stobart AK. 1975. The hormonal control of amaranthin synthesis in Amaranthus caudatus seedlings. Planta 127: 207-212.

Kishima Y, Nozaki K, Akashi R, Adachi T. 1991. Light-inducible pigmentation in Portulaca callus; selection of a high betalain producing cell line. Plant Cell Reports 10: 304-307.

Kishima Y, Shimaya A, Adachi T. 1995. Evidence that blue light induces betalain pigmentation in Portulaca callus. Plant Cell, Tissue and Organ Culture 43: 67-70.

Klobus G, Ward MR, Huffaker RC. 1988. Characteristics of injury and recovery of $\mathrm{Net}^{\mathrm{NO}_{3-}}$ transport of barley seedlings from treatments of NaCl. Plant Physiology 87: 878-882.

Kohler J, Caravaca F, Carrasco L, Roldán A. 2006. Contribution of Pseudomonas mendocina and Glomus intraradices to aggregate stabilization and promotion of biological fertility in rhizosphere soil of lettuce plants under field conditions. Soil Use and Management 22: 298-304.

Köhler B, Hills A, Blatt MR. 2003. Control of guard cell ion channels by hydrogen peroxide and abscisic acid indicates their action through alternate signaling pathways. Plant Physiology 131: $385-388$.

Kronzucker HJ, Britto DT. 2011. Sodium transport in plants: a critical review. New Phytologist 189: 54-81.

Kuznetsova A, Brockhoff PB, Christensen RHB. 2017. \{lmerTest $\}$ Package: Tests in Linear Mixed Effects Models. Journal of Statistical Software 82: 1-26.

Lauchli A, Epstein E. 1970. Transport of potassium and rubidium in plant roots. Plant Physiology 45: 639-641.

Läuchli A, Grattan SR. 2011. Plant responses to saline and sodic conditions. In: Wallender WW, Tanji. Agricultural salinity assessment and management. Reston: American Society of Civil Engineers, 169-205

Läuchli A, James RA, Huang CX, McCully M, Munns R. 2008. Cell-specific localization of $\mathrm{Na}^{+}$in roots of durum wheat and possible control points for salt exclusion. Plant, Cell and Environment 31: 1565-1574.

Lebaudy A, Véry AA, Sentenac H. 2007. $\mathrm{K}^{+}$channel activity in plants: Genes, regulations and functions. FEBS Letters 581: 2357-2366. 
Lenth R. 2018. emmeans: Estimated Marginal Means, aka Least-Squares Means.

Letey J, Hoffman GJ, Hopmans JW, Grattan SR, Suarez D, Corwin DL, Oster JD, Wu L, Amrhein C. 2011. Evaluation of soil salinity leaching requirement guidelines. Agricultural Water Management 98: 502-506.

Lhissou R, El Harti A, Chokmani K. 2014. Mapping soil salinity in irrigated land using optical remote sensing data. Eurasian Journal of Soil Science 3: 82-88.

Li C, Lei J, Zhao Y, Xu X, Li S. 2015. Effect of saline water irrigation on soil development and plant growth in the Taklimakan Desert Highway shelterbelt. Soil and Tillage Research 146: 99-107.

Li P, Li YJ, Zhang FJ, Zhang GZ, Jiang XY, Yu HM, Hou BK. 2017a. The Arabidopsis UDP-glycosyltransferases UGT79B2 and UGT79B3, contribute to cold, salt and drought stress tolerance via modulating anthocyanin accumulation. The Plant Journal 89: 85-103.

Li P, Qian H, Wu J. 2018. Conjunctive use of groundwater and surface water to reduce soil salinization in the Yinchuan Plain, North-West China. International Journal of Water Resources Development 34: 337-353.

Li B, Tester M, Gilliham M. 2017b. Chloride on the move. Trends in Plant Science 22: 236248.

Liang W, Ma X, Wan P, Liu L. 2018. Plant salt-tolerance mechanism: A review. Biochemical and Biophysical Research Communications 495: 286-291.

Lichtenthaler HK, Buschmann C. 2001. Chlorophylls and carotenoids: Measurement and characterization by UV-VIS spectroscopy. Current Protocols in Food Analytical Chemistry 1: F4.3.1-F4.3.8.

Liu J, Zhu J-K. 1997. An Arabidopsis mutant that requires increased calcium for potassium nutrition and salt tolerance. Proceeding of the Natlional Academy of Science USA 94: 1496014964.

Lorenzen I, Aberle T, Plieth C. 2004. Salt stress-induced chloride flux: A study using transgenic Arabidopsis expressing a fluorescent anion probe. Plant Journal 38: 539-544.

Lu C, Qiu N, Lu Q, Wang B, Kuang T. 2002. Does salt stress lead to increased susceptibility of photosystem II to photoinhibition and changes in photosynthetic pigment composition in 
halophyte Suaeda salsa grown outdoors? Plant Science 163: 1063-1068.

Lugtenberg B, Kamilova F. 2009. Plant-growth-promoting Rhizobacteria. Annu. Rev. Microbiol. 63: 541-556.

Ma XL, Cui WN, Zhao Q, Zhao J, Hou XN, Li DY, Chen ZL, Shen YZ, Huang ZJ. 2016. Functional study of a salt-inducible TaSR gene in Triticum aestivum. Physiologia Plantarum 156: $40-53$.

Maathuis FJM, Ahmad I, Patishtan J. 2014. Regulation of $\mathrm{Na}^{+}$fluxes in plants. Frontiers in Plant Science 5: 1-9.

Maathuis FJM, Amtmann A. 1999. $\mathrm{K}^{+}$nutrition and $\mathrm{Na}^{+}$toxicity: The basis of cellular $\mathrm{K}^{+} / \mathrm{Na}^{+}$ ratios. Annals of Botany 84: 123-133.

Maathuis FJ, Ichidaa M, Sanders D, Schroeder JI. 1997. Roles of higher plant $\mathrm{K}^{+}$channels. Plant Physiology 114: 1141-1149.

Machado RMA, Serralheiro RP. 2017. Soil salinity: Effect on vegetable crop growth. management practices to prevent and mitigate soil salinization. Horticulturae 3: 30.

Madawala S, Hartley S, Gould K. 2014. Comparative growth and photosynthetic responses of native and adventive iceplant taxa to salinity stress. New Zealand Journal of Botany 52: $352-$ 364.

Mahmood S, Daur I, Al-Solaimani SG, Ahmad S, Madkour MH, Yasir M, Hirt H, Ali S, Ali Z. 2016. Plant growth promoting rhizobacteria and silicon synergistically enhance salinity tolerance of mung bean. Frontiers in Plant Science 7: 876.

Malash NM, Flowers TJ, Ragab R. 2008. Effect of irrigation methods, management and salinity of irrigation water on tomato yield, soil moisture and salinity distribution. Irrigation Science 26: 313-323.

Malcolm C V., Lindley VA, O’Leary JW, Runciman H V., Barrett-Lennard EG. 2003. Halophyte and glycophyte salt tolerance at germination and the establishment of halophyte shrubs in saline environments. Plant and Soil 253: 171-185.

Marschner H. 1995. Mineral Nutrition of Higher Plants. London: Academic Press.

Marschner P. 2012. Marschner's Mineral Nutrition of Higher Plants Third Edition. Elsevier Ltd. 
Mäser P, Hosoo Y, Goshima S, Horie T, Eckelman B, Yamada K, Yoshida K, Bakker EP, Shinmyo A, Oiki S, et al. 2002. Glycine residues in potassium channel-like selectivity filters determine potassium selectivity in four-loop-per-subunit HKT transporters from plants. Proceedings of the National Academy of Sciences 99: 6428-6433.

Matsumoto H, Chung GC. 1988. Increase in proton-transport activity of tonoplast vesicles as an adaptive response of barley roots to $\mathrm{NaCl}$ stress. Plant and Cell Physiology 29: 1133-1140.

Mian A, Oomen RJFJ, Isayenkov S, Sentenac H, Maathuis FJM, Véry AA. 2011. Overexpression of an $\mathrm{Na}^{+}$- and $\mathrm{K}^{+}$-permeable HKT transporter in barley improves salt tolerance. Plant Journal 68: 468-479.

Miguel M. 2019. Betalains. eLS: 1-62.

Mishra A, Tanna B. 2017. Halophytes: Potential resources for salt stress tolerance genes and promoters. Frontiers in Plant Science 8: 1-10.

Mitsuya S, Kawasaki M, Taniguchi M, Miyake H. 2003. Light dependency of salinityinduced chloroplast degradation. Plant Production Science 6: 219-223.

Mosco A. 2012. Tissue localization of betacyanins in cactus stems. Revista Mexicana de Biodiversidad 83: 413-420.

Munns R. 2002. Comparative physiology of salt and water stress. Plant, Cell and Environment 25: $239-250$.

Munns R. 2005. Genes and salt tolerance: Bringing them together. New Phytologist 167: 645663.

Munns R, Gilliham M. 2015. Tansley insight salinity tolerance of crops - what is the cost? New Phytologist 208: 668-673.

Munns R, Husain S, Rivelli AR, James RA, Condon AGT, Lindsay MP, Lagudah ES, Schachtman DP, Hare RA. 2002. Avenues for increasing salt tolerance of crops, and the role of physiologically based selection traits. Plant and Soil 247: 93-105.

Munns R, James RA, Gilliham M, Flowers TJ, Colmer TD. 2016. Tissue tolerance: an essential but elusive trait for salt-tolerant crops. Functional Plant Biology 43: 1103-1113.

Munns R, James RA, Lauchli A. 2006a. Approaching to increasing the salt tolerance of wheat and other cereals. Journal of Experimental Botany 57: 1025-1043. 


\section{Munns R, James R a, Xu B, Athman A, Conn SJ, Jordans C, Byrt CS, Hare R a, Tyerman}

SD, Tester M, et al. 2012. Wheat grain yield on saline soils is improved by an ancestral $\mathrm{Na}^{+}$ transporter gene. Nature Biotechnology 30: 360-364.

Munns R, Schachtman DP, Condon AG. 1995. The significance of a two-phase growth response to salinity in wheat and barley. Australian Journal of Plant Physiology 22: 561-569.

Munns R, Sharp RE. 1993. Involvement of abscisic acid in controlling plant growth in soils of low water potential. Australian Journal of Plant Physiology 20: 425-437.

Munns R, Tester M. 2008. Mechanisms of salinity tolerance. Annual Review of Plant Biology 59: $651-681$.

Naing AH, Ai TN, Lim KB, Lee IJ, Kim CK. 2018. Overexpression of rosea1 from snapdragon enhances anthocyanin accumulation and abiotic stress tolerance in transgenic tobacco. Frontiers in Plant Science 9: 1-14.

Naing AH, Park K Il, Ai TN, Chung MY, Han JS, Kang YW, Lim KB, Kim CK. 2017. Overexpression of snapdragon Delila (Del) gene in tobacco enhances anthocyanin accumulation and abiotic stress tolerance. BMC Plant Biology 17: 65-79.

Nakashima T, Araki T, Ueno O. 2011. Photoprotective function of betacyanin in leaves of Amaranthus cruentus L. under water stress. Photosynthetica 49: 497-506.

Neales TF, Sharkey PJ. 1981. Effect of salinity on growth and on mineral and organic constituents of the halophyte Disphyma australe (Soland.) J. M. Black. Australian Journal of Plant Physiology 8: 165-179.

Neill S, Gould KS. 1999. Optical properties of leaves in relation to anthocyanin concentration and distribution. Canadian Journal of Botany 77: 1777-1782.

Netondo GW, Onyango JC, Beck E. 2004. Sorghum and salinity : I. response of growth , water relations, and ion accumulation to $\mathrm{NaCl}$ salinity. Crop Science 44: 797-805.

Newman IA. 2001. Ion transport in roots: Measurement of fluxes using ion-selective microelectrodes to characterize transporter function. Plant, Cell and Environment 24: 1-14.

Noctor G, Reichheld JP, Foyer CH. 2018. ROS-related redox regulation and signaling in plants. Seminars in Cell and Developmental Biology 80: 3-12.

Noctor G, Veljovic-Jovanovic S, Driscoll S, Novitskaya L, Foyer CH. 2002. Drought and 
oxidative load in the leaves of C3 plants: A predominant role for photorespiration? Annals of Botany 89: 841-850.

Oguchi R, Terashima I, Kou J, Chow WS. 2011. Operation of dual mechanisms that both lead to photoinactivation of photosystem II in leaves by visible light. Physiologia Plantarum 142: 47-55.

Oh DH, Barkla BJ, Vera-Estrella R, Pantoja O, Lee SY, Bohnert HJ, Dassanayake M. 2015a. Cell type-specific responses to salinity - the epidermal bladder cell transcriptome of Mesembryanthemum crystallinum. New Phytologist 207: 627-644.

Paranychianakis N V., Chartzoulakis KS. 2005. Irrigation of Mediterranean crops with saline water: From physiology to management practices. Agriculture, Ecosystems and Environment 106: $171-187$.

Pardo JM. 2010. Biotechnology of water and salinity stress tolerance. Current Opinion in Biotechnology 21: 185-196.

Percey WJ, Shabala L, Breadmore MC, Guijt RM, Bose J, Shabala S. 2014. Ion transport in broad bean leaf mesophyll under saline conditions. Planta 240: 729-743.

Pérez-Sirvent C, Martínez-Sánchez MJ, Vidal J, Sánchez A. 2003. The role of low-quality irrigation water in the desertification of semi-arid zones in Murcia, SE Spain. Geoderma 113: $109-125$.

Peterson RG, Joslyn MA. 1958. Nature of betanin, the pigment of red beet. Nature 182: 4546.

Platten JD, Cotsaftis O, Berthomieu P, Bohnert H, Davenport RJ, Fairbairn DJ, Horie T, Leigh RA, Lin H-X, Luan S, et al. 2006. Nomenclature for HKT transporters, key determinants of plant salinity tolerance. Trends in Plant Science 11: 372-374.

Plett DC, Møller IS. 2010. $\mathrm{Na}^{+}$transport in glycophytic plants: What we know and would like to know. Plant, Cell and Environment 33: 612-626.

Polturak G, Aharoni A. 2018. "“ La Vie en Rose "” biosynthesis, sources, and applications of betalain pigments. Molecular Plant 11: 7-22.

Polturak G, Aharoni A. 2019. Advances and future directions in betalain metabolic engineering. New Phytologist 224: 1472-1478. 
Polturak G, Breitel D, Grossman N, Sarrion-perdigones A, Weithorn E, Pliner M, Orzaez D, Granell A, Rogachev I, Aharoni A. 2016. Elucidation of the first committed step in betalain biosynthesis enables the heterologous engineering of betalain pigments in plants. New Phytologist 210: 269-283.

Polturak G, Grossman N, Vela-Corcia D, Dong Y, Nudel A, Pliner M, Levy M, Rogachev I, Aharoni A. 2017. Engineered gray mold resistance, antioxidant capacity, and pigmentation in betalain-producing crops and ornamentals. Proceedings of the National Academy of Sciences 114: 9062-9067.

Qiu Q-S, Guo Y, Quintero FJ, Pardo JM, Schumaker KS, Zhu J-K. 2004. Regulation of vacuolar $\mathrm{Na}^{+} / \mathrm{H}^{+}$exchange in Arabidopsis thaliana by the salt-overly-sensitive (SOS) pathway. The Journal of Biological Chemistry 279: 207-215.

Qureshi AS, McCornick PG, Qadir M, Aslam Z. 2008. Review: Managing salinity and waterlogging in the Indus Basin of Pakistan. Agricultural Water Management 95: 1-10.

R Core Team. 2018. R: A Language and Environment for Statistical Computing.

Rajendran K, Tester M, Roy SJ. 2009. Quantifying the three main components of salinity tolerance in cereals. Plant, Cell and Environment 32: 237-249.

Ramadoss D, Lakkineni VK, Bose P, Ali S, Annapurna K. 2013. Mitigation of salt stress in wheat seedlings by halotolerant bacteria isolated from saline habitats. SpringerPlus 2(1), 6 . doi:10.1186/2193-1801-2-6

Ramel F, Birtic S, Cuiné S, Triantaphylidès C, Ravanat JL, Havaux M. 2012. Chemical quenching of singlet oxygen by carotenoids in plants. Plant Physiology 158: 1267-1278.

Ratajczak R. 2000. Structure, function and regulation of the plant vacuolar $\mathrm{H}^{+}$-translocating ATPase. Biochimica et Biophysica Acta 1465: 17-36.

Raven JA. 1985. Regulation of $\mathrm{pH}$ and generation of osmolarity in vascular plants : A costbenefit analysis in relation to efficiency of use of energy, nitrogen and water. New Phytologist 101: $25-77$.

Reis A, Kleinowski AM, Klein FRS, Telles RT, Do Amarante L, Braga EJB. 2015. Light quality on the in vitro growth and production of pigments in the genus Alternanthera. Journal of Crop Science and Biotechnology 18: 349-357. 
Ren Z-H, Gao J-P, Li L, Cai X, Huang W, Chao D-Y, Zhu M, Wang Z-Y, Luan S, Lin H. 2005. A rice quantitative trait locus for salt tolerance encodes a sodium transporter. Nature Genetics 37: 1141-1146.

Rengasamy P. 2002. Transient salinity and subsoil constraints to dryland farming in Australian sodic soils: An overview. Australian Journal of Experimental Agriculture 42: 351-361.

Rengasamy P. 2006. World salinization with emphasis on Australia. Journal of Experimental Botany 57: 1017-1023.

Rodríguez-Rosales MP, Gálvez FJ, Huertas R, Aranda MN, Baghour M, Cagnac O, Venema K. 2009. Plant NHX cation/proton antiporters. Plant Signaling and Behavior 4: 265276.

Roy SJ, Negrão S, Tester M. 2014. Salt resistant crop plants. Current Opinion in Biotechnology 26: 115-124.

Rozema J, Flowers T. 2008. Crops for a salinized world. Science 322: 1478-1480.

Rus A, Lee B, Munoz-Mayor A, Sharkhuu A, Miura K, Zhu J, Bressan RA, Hasegawa PM. 2010. AtHKT1 facilitates $\mathrm{Na}^{+}$homeostasis and $\mathrm{K}^{+}$nutrition. Plant Physiology 136: 2500 2511.

Sandhya V, Z. AS, Grover M, Reddy G, Venkateswarlu B. 2009. Alleviation of drought stress effects in sunflower seedlings by the exopolysaccharides producing Pseudomonas putida strain GAP-p45. Biology and Fertility of Soils 46: 17-26.

Sasaki N, Adachi T, Koda T, Ozeki Y. 2004. Detection of UDP-glucose:cyclo-DOPA 5-Oglucosyltransferase activity in four o'clocks (Mirabilis jalapa L.). FEBS Letters 568: 159-162.

Sasaki N, Wada K, Koda T, Kasahara K, Adachi T, Ozeki Y. 2005. Isolation and characterization of cDNAs encoding an enzyme with glucosyltransferase activity for cycloDOPA from four O'clocks and feather cockscombs. Plant and Cell Physiology 46: 666-670.

Schachtman DP. 2000. Molecular insights into the structure and function of plant $\mathrm{K}^{+}$transport mechanisms. Biochimica et Biophysica Acta (BBA) - Biomembranes 1465: 127-139.

Sepúlveda-Jiménez G, Rueda-Benítez P, Porta H, Rocha-Sosa M. 2004. Betacyanin synthesis in red beet (Beta vulgaris) leaves induced by wounding and bacterial infiltration is preceded by an oxidative burst. Physiological and Molecular Plant Pathology 64: 125-133. 
Sepúlveda-Jiménez G, Rueda-Benítez P, Porta H, Rocha-Sosa M. 2005. A red beet (Beta vulgaris) UDP-glucosyltransferase gene induced by wounding, bacterial infiltration and oxidative stress. Journal of Experimental Botany 56: 605-611.

Shabala S. 2000. Ionic and osmotic components of salt stress specifically modulate net ion fluxes from bean leaf mesophyll. Plant, Cell and Environment 23: 825-837.

Shabala S. 2009. Salinity and programmed cell death: Unravelling mechanisms for ion specific signalling. Journal of Experimental Botany 60: 709-712.

Shabala S. 2013. Learning from halophytes: Physiological basis and strategies to improve abiotic stress tolerance in crops. Annals of Botany 112: 1209-1221.

Shabala S. 2017. Signalling by potassium : another second messenger to add to the list? Journal of Experimental Botany 68: 4003-4007.

Shabala S, Bose J, Fuglsang AT, Pottosin I. 2016. On a quest for stress tolerance genes: Membrane transporters in sensing and adapting to hostile soils. Journal of Experimental Botany 67: 1015-1031.

Shabala S, Bose J, Hedrich R. 2014. Salt bladders: Do they matter? Trends in Plant Science 19: 687-691.

Shabala S, Cuin TA. 2008. Potassium transport and plant salt tolerance. Physiologia Plantarum 133: 651-669.

Shabala L, Cuin TA, Newman IA, Shabala S. 2005. Salinity-induced ion flux patterns from the excised roots of Arabidopsis sos mutants. Planta 222: 1041-1050.

Shabala S, Demidchik V, Shabala L, Cuin TA, Smith SJ, Miller AJ, Davies JM, Newman IA. 2006a. Extracellular $\mathrm{Ca}^{2+}$ ameliorates $\mathrm{NaCl}$-induced $\mathrm{K}^{+}$loss from Arabidopsis root and leaf cells by controlling plasma membrane $\mathrm{K}^{+}$-permeable channels. Plant Physiology 141: 165365 .

Shabala S, Mackay A. 2011. Chapter 5 - Ion Transport in Halophytes. In: Turkan I, ed. Advances in Botanical Research. Plant Responses to Drought and Salinity Stress. Cambridge, Massachusetts: Academic Press, 151-199.

Shabala S, Newman I. 1999. Light-induced changes in hydrogen, calcium, potassium, and chloride ion fluxes and concentrations from the mesophyll and epidermal tissues of bean leaves. 
Understanding the ionic basis of light-induced bioelectrogenesis. Plant Physiology 119: 11151124.

Shabala L, Ross T, McMeekin T, Shabala S. 2006b. Non-invasive microelectrode ion flux measurements to study adaptive responses of microorganisms to the environment. FEMS Microbiology Reviews 30: 472-486.

Shabala S, Shabala L. 2011. Ion transport and osmotic adjustment in plants and bacteria. Biomolecular Concepts 2: 407-419.

Shabala S, Shabala S, Cuin TA, Pang J, Percey W, Chen Z, Conn S, Eing C, Wegner LH. 2010. Xylem ionic relations and salinity tolerance in barley. Plant Journal 61: 839-853.

El Shaer HM. 2010. Halophytes and salt-tolerant plants as potential forage for ruminants in the Near East region. Small Ruminant Research 91: 3-12.

Shah N, Anwar S, Xu J, Hou Z, Salah A, Khan S, Gong J, Shang Z, Qian L, Zhang C. 2018. The response of transgenic Brassica species to salt stress: a review. Biotechnology Letters 40: $1159-1165$.

Shannon MC, Grieve CM. 1998. Tolerance of vegetable crops to salinity. Scientia Horticulturae 78: 5-38.

Sharma T, Dreyer I, Riedelsberger J. 2013. The role of $\mathrm{K}^{+}$channels in uptake and redistribution of potassium in the model plant Arabidopsis thaliana. Frontiers in Plant Science 4: $1-16$

Shi H, Zhu J-K. 2002. Regulation of expression of the vacuolar $\mathrm{Na}^{+} / \mathrm{H}^{+}$antiporter gene AtNHX1 by salt stress and abscisic acid. Plant molecular biology 50: 543-550.

Shrivastava P, Kumar R. 2015. Soil salinity: A serious environmental issue and plant growth promoting bacteria as one of the tools for its alleviation. Saudi Journal of Biological Sciences 22: $123-131$.

Silva P, Gerós H, Silva P, Gerós H. 2009. Pyrophosphatase activities and $\mathrm{Na}^{+} / \mathrm{H}^{+}$exchange Regulation by salt of vacuolar $\mathrm{H}^{+}$-ATPase and $\mathrm{H}^{+}$-pyrophosphatase activities and $\mathrm{Na}^{+} / \mathrm{H}^{+}$ exchange. Plant Signaling \& Behavior 4: 718-726.

Singh A. 2015. Soil salinization and waterlogging: A threat to environment and agricultural sustainability. Ecological Indicators 57: 128-130. 
Sirault XRR, James RA, Furbank RT. 2009. A new screening method for osmotic component of salinity tolerance in cereals using infrared thermography. Functional Plant Biology 36: 970-977.

Slimen IB, Najar T, Abderrabba M. 2017. Chemical and antioxidant properties of betalains. Journal of Agricultural and Food Chemistry 65: 675-689.

Smith P, House JI, Bustamante M, Sobocká J, Harper R, Pan G, West PC, Clark JM, Adhya T, Rumpel C, et al. 2016. Global change pressures on soils from land use and management. Global Change Biology 22: 1008-1028.

Soltis DE, Soltis PS, Endress PK, Chase MW. 2005. Phylogeny and evolution of angiosperms. Sunderland, Massachusetts: Sunderland Inc.

Steglich W, Strack D. 1990. Chapter 1 Betalains. In : Brossi A ed. The Alkaloids: Chemistry and Pharmacology. Cambridge, Massachusetts: Academic Press 39: 1-62.

Stintzing FC, Carle R. 2004. Functional properties of anthocyanins and betalains in plants, food, and in human nutrition. Trends in Food Science and Technology 15: 19-38.

Stintzing FC, Herbach KM, Mosshammer MR, Carle R, Yi W, Sellappan S, Akoh CC, Bunch R, Felker P. 2005. Color, betalain pattern, and antioxidant properties of cactus pear (Opuntia spp.) clones. Journal of Agricultural and Food Chemistry 53: 442-451.

Storey R, Jones RGW. 1979. Responses of Atriplex spongiosa and Suaeda monoica to salinity. Plant Physiology 63: 156-162.

Strack D, Vogt T, Schliemann W. 2003. Recent advances in betalain research. Phytochemistry 62: $247-269$.

Stracke R, Holtgräwe D, Schneider J, Pucker B, Sörensen TR, Weisshaar B. 2014. Genome-wide identification and characterisation of R2R3-MYB genes in sugar beet (Beta vulgaris). BMC Plant Biology 14: 1-17.

Su H, Balderas E, Vera-Estrella R, Golldack D, Quigley F, Zhao C, Pantoja O, Bohnert HJ. 2003. Expression of the cation transporter McHKT1 in a halophyte. Plant Molecular Biology 52: 967-980.

Sun J, Chen S, Dai S, Wang R, Li N, Shen X, Zhou X, Lu C, Zheng X, Hu Z, et al. 2009a. $\mathrm{NaCl}$-induced alternations of cellular and tissue ion fluxes in roots of salt-resistant and salt- 
sensitive poplar species. Plant Physiology 149: 1141-1153.

Sun J, Dai S, Wang R, Chen S, Li N, Zhou X, Lu C, Shen X, Zheng X, Hu Z, et al. 2009b. Calcium mediates root $\mathrm{K}^{+} / \mathrm{Na}^{+}$homeostasis in poplar species differing in salt tolerance. Tree Physiology 29: 1175-1186.

Sunnadeniya R, Bean A, Brown M, Akhavan N, Hatlestad G, Gonzalez A, Symonds VV, Lloyd A. 2016. Tyrosine hydroxylation in betalain pigment biosynthesis is performed by cytochrome P450 enzymes in beets (Beta vulgaris). Plos One 11: e0149417.

Swarajyalakshmi G, Gurumurthy P, Subbaiah G V. 2003. Soil salinity in South India: Problems and solutions. Journal of Crop Production 7: 247-275.

Taira J, Tsuchida E, Katoh MC, Uehara M, Ogi T. 2015. Antioxidant capacity of betacyanins as radical scavengers for peroxyl radical and nitric oxide. Food Chemistry 166: $531-536$.

Takahashi S, Badger MR. 2011. Photoprotection in plants: A new light on photosystem II damage. Trends in Plant Science 16: 53-60.

Takahashi K, Takamura E, Sakuta M. 2009. Isolation and expression analysis of two DOPA dioxygenases in Phytolacca americana. Zeitschrift fur Naturforschung - Section C Journal of Biosciences 64: 564-573.

Tester M, Davenport R. 2003. $\mathrm{Na}^{+}$tolerance and $\mathrm{Na}^{+}$transport in higher plants. Annals of Botany 91: 503-527.

Tester M, Langridge P. 2010. Breeding technologies to increase crop production in a changing world. Science 327: 818-822.

Tripathy BC, Oelmüller R. 2012. Reactive oxygen species generation and signaling in plants. Plant Signaling \& Behavior 7: 1559-2324.

Tzin V, Galili G. 2011. The biosynthetic pathways for shikimate and aromatic amino acids in Arabidopsis thaliana. In: Somerville C, Meyerowitz E eds. The Arabidopsis Book Rockville: The American Society of Plant Biologists. e0132. doi:10.1199/tab.0132

Ventura Y, Sagi M. 2013. Halophyte crop cultivation: The case for Salicornia and Sarcocornia. Environmental and Experimental Botany 92: 144-153.

Ventura Y, Wuddineh WA, Myrzabayeva M, Alikulov Z, Khozin-Goldberg I, Shpigel M, 
Samocha TM, Sagi M. 2011. Effect of seawater concentration on the productivity and nutritional value of annual Salicornia and perennial Sarcocornia halophytes as leafy vegetable crops. Scientia Horticulturae 128: 189-196.

Véry A, Nieves-cordones M, Daly M, Khan I, Fizames C, Sentenac H. 2014. Molecular biology of $\mathrm{K}^{+}$transport across the plant cell membrane : What do we learn from comparison between plant species? Journal of Plant Physiology 171: 748-769.

Vogt T, Ibdah M, Schmidt J, Wray V, Nimtz M, Strack D. 1999. Light-induced betacyanin and flavonol accumulation in bladder cells of Mesembryanthemum crystallinum. Phytochemistry 52: 583-592.

Wang CQ, Chen M, Wang BS. 2007. Betacyanin accumulation in the leaves of C3 halophyte Suaeda salsa $\mathrm{L}$. is induced by watering roots with $\mathrm{H}_{2} \mathrm{O}_{2}$. Plant Science 172: 1-7.

Wang CQ, Liu T. 2007. Involvement of betacyanin in chilling-induced photoinhibition in leaves of Suaeda salsa. Photosynthetica 45: 182-188.

Wang B, Lüttge U, Ratajczak R. 2001. Effects of salt treatment and osmotic stress on VATPase and V-PPase in leaves of the halophyte Suaeda salsa. Journal of Experimental Botany 52: $2355-2365$.

Wang CQ, Wang BS. 2007. $\mathrm{Ca}^{2+}-$ Calmodulin is involved in betacyanin accumulation induced by dark in C3 halophyte Suaeda salsa. Journal of Integrative Plant Biology 49: 1378-1385.

Wang Y, Xiao D, Li Y, Li X. 2008a. Soil salinity evolution and its relationship with dynamics of groundwater in the oasis of inland river basins: Case study from the Fubei Region of Xinjiang Province, China. Environmental Monitoring and Assessment 140: 291-302.

Wang CQ, Xu C, Wei JG, Wang HB, Wang SH. 2008b. Enhanced tonoplast $\mathrm{H}^{+}$-ATPase activity and superoxide dismutase activity in the halophyte Suaeda salsa containing high level of betacyanin. Journal of Plant Growth Regulation 27: 58-67.

Wang C-Q, Zhao J-Q, Chen M, Wang B-S. 2006. Identification of betacyanin and effects of environmental factors on its accumulation in halophyte Suaeda salsa. Journal of Plant Physiology and Molecular Biology 32: 195-201.

Wege S, Jossier M, Filleur S, Thomine S, Barbier-Brygoo H, Gambale F, De Angeli A. 2010. The proline 160 in the selectivity filter of the Arabidopsis $\mathrm{NO}^{3-} / \mathrm{H}^{+}$exchanger AtCLCa is essential for nitrate accumulation in planta. The Plant JournalPlant Journal 63: 861-869. 
Wei W, Bilsborrow PE, Hooley P, Fincham DA, Lombi E, Forster BP. 2003. Salinity induced differences in growth, ion distribution and partitioning in barley between the cultivar Maythorpe and its derived mutant Golden Promise. Plant and Soil 250: 183-191.

Welle PD, Mauter MS. 2017. High-resolution model for estimating the economic and policy implications of agricultural soil salinization in California. Environmental Research Letters 12.

White PJ, Broadley MR. 2001. Chloride in soils and its uptake and movement within the plant: A review. Annals of Botany 88: 967-988.

Wintermans JFGM, Mots A De. 1965. Spectrophotometric characteristics of chlorophylls a and $\mathrm{b}$ and their phenophytins in ethanol. Biochimica et Biophysica Acta (BBA) - Biophysics including Photosynthesis 109: 448-453.

Wu S-J, Ding L, Zhu J-K. 1996. SOS1, a genetic locus essential for salt tolerance and potassium acquisition. The Plant Cell 8: 617-627.

Wu H, Zhu M, Shabala L, Zhou M, Shabala S. 2015. $\mathrm{K}^{+}$retention in leaf mesophyll, an overlooked component of salinity tolerance mechanism: A case study for barley. Journal of Integrative Plant Biology 57: 171-185.

Wyler H, Dreiding AS. 1957. Kristallisiertes Betanin. Vorläufige Mitteilung. Helvetica Chimica Acta 40: 191-192.

Wyn Jones R, Storey R. 1978. Salt stress and comparative physiology in the Gramineae. IV. comparison of salt stress in spartina $\times$ townsendii and three barley cultivars. Australian Journal of Plant Physiol 5: 839-850.

Yamaguchi T, Apse MP, Shi H, Blumwald E. 2003. Topological analysis of a plant vacuolar $\mathrm{Na}^{+} / \mathrm{H}^{+}$antiporter reveals a luminal $\mathrm{C}$ terminus that regulates antiporter cation selectivity. Proceedings of the National Academy of Sciences 100: 12510-12515.

Yamasaki H, Sakihama Y, Ikehara N. 1997. Flavonoid-peroxidase reaction as a detoxification mechanism of plant cells against $\mathrm{H}_{2} \mathrm{O}_{2}$. Plant Physiology 115: 1405-1412.

Yang X, Yu Y. 2017. Estimating soil salinity under various moisture conditions: An experimental study. IEEE Transactions on Geoscience and Remote Sensing 55: 2525-2533.

Yokoi S, Quintero FJ, Cubero B, Ruiz MT, Bressan RA, Hasegawa PM, Pardo JM. 2002.

Differential expression and function of Arabidopsis thaliana $\mathrm{NHX} \mathrm{Na} / \mathrm{H}^{+}$antiporters in the 
salt stress response. The Plant Journal 30: 529-539.

Zepeda-Jazo I, Shabala S, Chen Z, Pottosin II. 2008. $\mathrm{Na}^{+}-\mathrm{K}^{+}$transport in roots under salt stress. Plant Signaling \& Behavior 3: 401-403.

Zewdu S, Suryabhagavan K V., Balakrishnan M. 2016. Land-use/land-cover dynamics in Sego Irrigation Farm, southern Ethiopia: A comparison of temporal soil salinization using geospatial tools. Journal of the Saudi Society of Agricultural Sciences 15: 91-97.

Zhang JL, Flowers TJ, Wang SM. 2010. Mechanisms of sodium uptake by roots of higher plants. Plant and Soil 326: 45-60.

Zhou M, Butterbach-Bahl K, Vereecken H, Brüggemann N. 2017. A meta-analysis of soil salinization effects on nitrogen pools, cycles and fluxes in coastal ecosystems. Global Change Biology 23: 1338-1352.

Zhu J-K. 2002. Salt and drought stress signal transduction in plants. Annual Review of Plant Biology 53: 247-273.

Zhu J-K. 2003. Regulation of ion homeostasis under salt stress. Current Opinion in Plant Biology 6: 441-445.

Zhu M, Zhou M, Shabala L, Shabala S. 2017. Physiological and molecular mechanisms mediating xylem $\mathrm{Na}^{+}$loading in barley in the context of salinity stress tolerance. Plant, Cell and Environment 40: 1009-1020. 


\section{Appendix 1}

Table 1.1 RNA-seq data from leaves of the green morph of D. australe. Samples were taken 24 h or $6 \mathrm{~d}$ after salt stress was applied. Log 2 -fold changes $\geq 1$ or $\leq-1$ and p-values (padj) $\leq$ 0.001 indicate significant differences in gene expression

\begin{tabular}{|c|c|c|c|c|}
\hline \multirow[t]{2}{*}{ Gene } & \multicolumn{2}{|c|}{$24 \mathrm{~h}$} & \multicolumn{2}{|c|}{$6 \mathrm{~d}$} \\
\hline & log2FoldChange & padj & log2FoldChange & padj \\
\hline CLC-d & -0.139639359 & 0.398505907 & 0.037625591 & 0.836274272 \\
\hline CLC-c & 0.136617489 & 0.757543093 & 0.24401684 & 0.411454408 \\
\hline CLC-g & 0.069537318 & 0.786984563 & -0.362783635 & 0.007072403 \\
\hline CLC-b & -0.116539674 & 0.905153637 & 0.614574697 & 0.230361581 \\
\hline CLC-e & 1.15197869 & 0.00012779 & 2.15245967 & $3.94 \mathrm{E}-17$ \\
\hline CLC-f & -0.037431924 & 0.904086616 & -1.136864934 & $2.8 \mathrm{E}-21$ \\
\hline CCC1 & 0.079245152 & 0.786353601 & 0.017660982 & 0.948538809 \\
\hline SLAH3 & 1.906394369 & 0.00555677 & 2.526178608 & 0.0000215 \\
\hline GORK & 1.16314258 & 0.001522466 & 1.150596069 & 0.000639222 \\
\hline CHX1 & 3.648785116 & 0.056016687 & 6.751029952 & 0.00000611 \\
\hline HKT1 & -0.943137864 & 0.011540723 & -0.698037086 & 0.054282347 \\
\hline SKOR & 1.16314258 & 0.001522466 & 1.150596069 & 0.000639222 \\
\hline AKT2/3 & -0.251137869 & 0.572603736 & -3.238188405 & $1.56 \mathrm{E}-43$ \\
\hline AKT1 & 1.449127095 & 0.072817098 & 2.115746677 & 0.001204511 \\
\hline NHX3/4 & -0.500438792 & 0.4816392 & 2.18695788 & $1.09 \mathrm{E}-09$ \\
\hline NHX2 & 0.777743485 & 0.03851264 & 1.453964023 & 0.00000104 \\
\hline SOS1 & 0.592426258 & 0.115642158 & 0.11839495 & 0.80767591 \\
\hline V-ATPase A & 0.240276131 & 0.376067611 & -0.407699574 & 0.03835699 \\
\hline V-ATPase B & 0.143323524 & 0.60342981 & -0.460691138 & 0.004851811 \\
\hline V-ATPase C & 0.168237573 & 0.535050737 & -0.395576951 & 0.02475182 \\
\hline V-ATPase E & 0.184820871 & 0.449568668 & 0.005274585 & 0.992507865 \\
\hline V-ATPase E & -0.971799783 & 1 & -1.430040811 & 0.107666113 \\
\hline V-ATPase G1 & 0.277010101 & 0.391182459 & 0.150425277 & 0.629580372 \\
\hline V-ATPase H & -0.038685299 & 0.914098209 & -0.383357325 & 0.017112173 \\
\hline V-PPase & 0.091996669 & 0.838306211 & -0.32399086 & 0.201645362 \\
\hline
\end{tabular}


Table 1.2 RNA-seq data from leaves of the red morph of D. australe. Samples were taken 24 h or $6 \mathrm{~d}$ after salt stress was applied. Log 2 -fold changes $\geq 1$ or $\leq-1$ and p-values (padj) $\leq 0.001$ indicate significant differences in gene expression

\begin{tabular}{|c|c|c|c|c|}
\hline \multirow[t]{2}{*}{ Gene } & \multicolumn{2}{|c|}{$24 \mathrm{~h}$} & \multicolumn{2}{|c|}{$6 \mathrm{~d}$} \\
\hline & log2FoldChange & padj & log2FoldChange & padj \\
\hline CLC-d & -0.070886414 & 0.672888203 & -0.055293979 & 0.75842341 \\
\hline CLC-c & 0.095436133 & 0.803523136 & 0.141067712 & 0.69169528 \\
\hline CLC-g & -0.694229494 & $3.73 \mathrm{E}-08$ & -0.257953692 & 0.090692348 \\
\hline CLC-b & -0.447092284 & 0.433253296 & -0.222534452 & 0.746036573 \\
\hline CLC-e & 1.497666294 & $1.24 \mathrm{E}-08$ & 0.64636292 & 0.045667378 \\
\hline CLC-f & -0.839381687 & $9.94 \mathrm{E}-12$ & -0.258951928 & 0.101466202 \\
\hline $\mathrm{CCC} 1$ & 0.156835768 & 0.430171699 & 0.039011116 & 0.883109672 \\
\hline SLAH3 & 2.482291534 & 0.0000374 & 2.330493493 & 0.000218715 \\
\hline GORK & 1.606060571 & 0.000000642 & 1.501872297 & 0.000009 \\
\hline CHX1 & 7.71838859 & 0.000000848 & 5.095181368 & 0.003581624 \\
\hline HKT1 & -1.477368601 & 0.00000245 & -2.019288234 & $1.12 \mathrm{E}-10$ \\
\hline SKOR & 1.606060571 & 0.000000642 & 1.501872297 & 0.000009 \\
\hline AKT2/3 & -3.356634091 & $4.2 \mathrm{E}-46$ & -0.806064445 & 0.003841644 \\
\hline AKT1 & 2.383926914 & 0.000257707 & 2.386370762 & 0.000406823 \\
\hline NHX3/4 & 2.598010877 & $2.4 \mathrm{E}-10$ & -0.49943615 & 0.508474389 \\
\hline NHX2 & 1.309552326 & 0.0000185 & 1.137055294 & 0.000456913 \\
\hline SOS1 & 0.272170223 & 0.511070323 & 1.093757048 & 0.00027944 \\
\hline V-ATPase A & -0.176586462 & 0.480474796 & 0.221062577 & 0.357446562 \\
\hline V-ATPase B & -0.285389928 & 0.128007059 & 0.062402225 & 0.81846856 \\
\hline V-ATPase C & -0.315634036 & 0.095829793 & -0.007418803 & 0.981765338 \\
\hline V-ATPase E & 0.079891294 & 0.753079835 & 0.255399308 & 0.183531828 \\
\hline V-ATPase E & -3.148312443 & 0.009432954 & -1.46404092 & 0.116225678 \\
\hline V-ATPase G1 & 0.269386093 & 0.330524375 & 0.495280072 & 0.039781923 \\
\hline V-ATPase H & -0.201458243 & 0.298722117 & 0.008801219 & 0.976450548 \\
\hline V-PPase & -0.233207295 & 0.410535699 & 0.037480762 & 0.926366024 \\
\hline
\end{tabular}

